\title{
LAS INSCRIPCIONES LATINAS DE SANTA LUCÍA DEL TRAMPAL (ALCUÉSCAR, CÁCERES) Y EL CULTO DE ATAECINA EN HISPANIA
}

POR

\author{
JUAN MANUEL ABASCAL PALAZÓN \\ Universidad de Alicante
}

\section{RESUMEN}

Los trabajos de excavación y restauración del templo de Santa Lucia del Trampal (Alcuéscar. (áceres) proporcionaron 31 inscripeiones romanas. de las que 15 son altares dedicados a la diosa indigena Ataecina. Este conjunto, unido al gran número de monumentos anepigrafos, constituye la evidencia del mayor santuario de esta divinidad conocido hasta la fecha, sólo comparable al del dios lusitano Endouellicus. La revisión de todos los testimonios de Ataecina hallados en Hispania permite ver que su culto se extendió por las regiones orientales de la provincia de Lusitania y que, ocasionalmente, entró en contacto con el culto de Proserpina. Turihriga/Turobriga, el enclave principal del culto, pudo estar dentro del territorium de Emerita Augusta, no lejos del templo de Santa Lucia y cerca del paraje de «Las Torrecillas».

\section{SUMMARY}

The excavation and restauration works carried out at the temple of Santa Lucia del Trampal in Alcuéscar (Cáceres) have provided us with 31 Roman inscriptions, 15 of which are altars dedicated to the native goddess Ataecina. This series, together with the high number of anepigraphical monuments, is a proof of the up-to-now greatest sanctuary devoted to this goddess, the only one that can be compared with that of Endouellicus, the Lusitanian god. After checking all the inscriptions of Ataecina found in Hispania, we have been able to discover that its worship spred throughout the eastern regions of Lusitania, and that it sometimes was mixed with that of Proserpina. Turibriga/Turobriga, the main worshipping place, may have been located in the territorium of Emerita Augusta, not far away from the temple of Santa Lucia, and near the spot called "Las Torrecillas".

\section{INTRODUCCIÓN}

Entre los años 1983 y 1990 un equipo de excavación dirigido por $\mathrm{L}$. Caballero intervino sobre los restos de un pequeño templo conocido bajo la advo- cación de Santa Lucia, en el paraje de El Trampal, en término de Alcuéscar (Cáceres)' '. La construcción habia sufrido numerosas reformas que incluian una obra gótica y algunas actuaciones posteriores, aunque lo conservado permitia ver una triple

\footnotetext{
' Agradecemos a D. Luis Caballero Zoreda su generosidad al poner a nuestra disposición el rico conjunto de epigrafes aparecido durante sus trabajos, asi como la documentación fotográfica y los dibujos obtenidos durante la excavación y restauración. Nuestra gratitud también para D. Manuel Garrido Santiago, Director del Museo Provincial de Cáceres, y para D. Ignacio Gutiérre\%, por las facilidades que nos dieron para documentar los monumentos de Alcuéscar custodiados en esa institución. La autopsia de los epigrafes conservados en Santa Lucia se realizó el 19 de agosto de 1994 en compañia de Luis Caballero; la de los trasladados al Museo de Cáceres, el 23 de marzo de 1995. con autorización de la Dirección General de Patrimonio Cultural de la Junta de Extremadura. Estamos en deuda también con Helena Gimeno y José Luis Gamallo, del equipo de redacción de Hispania Epigraphica, que nos resolvieron cuantas dudas bibliográficas se nos presentaron sobre los epigrafes ya publicados, y con José Luis Ramírez Sádaba, que puso a nuestra disposición el testimonio inédito de Salvatierra de los Barros. M." Paz Garcia-Bellido, Javier de Hoz. M. Almagro Gorbea y Armin U. Stylow nos aportaron también amables y muy valiosas sugerencias durante la redacción del manuscrito, entendiéndose que los errores u omisiones que puedan observarse son de la exclusiva responsabilidad del autor. Aunque según la relación publicada en Extremadira Arqueológica 1. 1988, pp. 231-249, un grupo de inscripciones deberian encontrarse en el Museo de Cáceres. en nuestra visita al centro sólo pudimos localizar algunas de ellas; pese a ello, en la descripción de los monumentos de la citada relación hemos mantenido su ubicación en el Museo cacereño. Los dibujos han sido realizados a partir de calcos directos del equipo de excavación, de los efectuados por nosotros en el Museo de Cáceres y de autopsias directas. Las fotografias son obra de L. Caballero (núms. 2, 4, 5, 7, 8, 10-13, 15, 17, 19, 21, $23,25-33,35-37,39-40)$ y del propio autor $(3,6,9,14,16,18$, $20,22,24,34,38,53$ )
} 
nave con crucero $y$ tres pequeños ábsides, que sus excavadores consideran construida en época visigoda ${ }^{2}$.

Durante los trabajos de excavación y en la posterior restauración apareció un conjunto de monumentos romanos con inscripciones, que habian sido reempleados en las sucesivas fases edilicias, alguno de los cuales presentaba un extraordinario grado de conservación (fig. 1). En estos mismos trabajos se exhumaron algunas otras piezas que permanecian semiocultas por la vegetación, $y$ aún en los alrededores se documentaron más monumentos epigráficos desconocidos hasta la fecha.

Si una parte de los ejemplares ha podido ser retirada de las construcción, otros - incluso algunos con texto - han debido permanecer empotrados, por lo que su documentación fotográfica presenta mayores dificultades.

Junto a los monumentos con inscripción, en la intervención arqueológica aparecieron elementos anepigrafos o fragmentos que pertenecieron en su dia a aras y estelas fracturadas de antiguo. En el

\footnotetext{
: Las referencias bibliográficas sobre el templo y sus alrededores son numerosas: L. Téllez et alii. «Descubierta en Alcuéscar una basilica visigoda". Boletin informativo del grupo cultural de Valdeobispo 5, 1981: eid., "Basilica hispanovisigoda de Alcuéscar, Cáceres", en Boletín informativo del grupo cultural de Vuldeobispo 8, 1982; A. Blanco, "Iglesia hispano-visigoda de Santa Lucia, en Alcuéscar (Cáceres). Declaración de monumento histórico-artistico", en $B R A H 179,1982$, p. $397 ;$ id., «Ermita de Santa Lucia (Alcuéscar, Cáceres). Declaración de monumento histórico-artísticon, $B R A H 180,1983$, pp. $587-588 ; \mathrm{L}$. Caballero, "Hacia una propuesta tipológica de los elementos de la arquitectura de culto cristiano de época visigoda (Nuevas iglesias de EI Gatillo y EI Trampal)", en $/ 1$ Congr. Arqueologia Medieval Española, Madrid 1987, pp. 61-98; L. Caballero y J. Rosco, «lglesia visigoda de Santa Lucía del Trampal, Alcuéscar (prov. Cáceres). Primera campaña de trabajos arqueológicos 198384n, Exiremadura Arqueológica 1, 1988, pp. 231-249; L. CabaIlero, "Santa Lucia del Trampal, Alcuéscar (Cáceres). Una nueva iglesia visigoda", Información Cultural. Ministerio de Cultura 75,1989 , pp. 12 ss.; L. Caballero, A. Almagro, A. Madroñero y A. Granda, "La iglesia de época visigoda de Santa Lucia del Trampal. Alcuéscar (Cáceres)", Extremadura arqueológica 2 , 1991, pp. 497-523; L. Caballero y J. C. Sánchez, "Reutilizaciones de material romano en edificios de culto cristiano", en Cristianismo y aculturación en tiempos del Imperio Romano. Antigüedad y Cristianismo 7, 1990, pp. 444 ss.; N. Veas y J.C. Sánchez, "El elemento acuático en las iglesias visigodas», en ibidem, pp. 492-493; V. Rodrigo y S. Haba, Espacio, Tiempo y Forma. Ser. 2. Historia antigua 5, 1992, pp. 376-377; S. Andrés Ordax, «La basilica hispano-visigoda de Alcuéscar (Cáceres)", Norba 2, 1981, pp. 7-22; L. Caballero e I. Velázquez, «Un grafito en el cimborrio central de la iglesia visigoda de Santa Lucia del Trampal, Alcuéscar (Cáceres)", AEA 62, 1989, pp. 262-271; E. Cerrillo, «Arqueologia de los centros de culto en las iglesias de épocas paleocristiana y visigoda de la Peninsula Ibérica: ábsides y santuarios", Cuadernos de arqueologia de la Universidad de $\mathrm{Na}$ varra 2,1994 , pp. 270 y 280 , figuras 7 y 8 .
}

estudio que figura a continuación se han individualizado estos últimos elementos, pese a la evidencia de que algunos de ellos son fragmentos de monumentos epigráficos.

Santa Lucia del Trampal se ubica en la ladera oriental de la sierra del Monesterio, al pie del pico del Centinela, en el extremo oriental de la sierra de San Pedro. La zona posee diversos acuiferos, algunos muy próximos al propio templo y ante ella se extiende una fértil llanura limitada en su extremo occidental por el cerro que sirve de asiento hoy a la localidad de Montánchez ${ }^{3}$. Con una riqueza natural que incluye la mineria de hierro, el lugar dispone además de buenas comunicaciones, ya que al otro lado de la sierra del Monesterio discurre la Via de la Plata, el gran eje que de norte a sur atravesaba Lusitania por el interior.

El término de Alcuéscar, antes del descubrimiento de este nuevo conjunto epigráfico, ya habia proporcionado otras tres inscripciones. Una de ellas es el epigrafe funerario de Pacula, procedente del paraje de "Las Torrecillas» ${ }^{4}$, la segunda es un texto funerario, de lectura no confirmada aún, encontrado en las proximidades de la población ${ }^{5}$, y la tercera es una dedicación a Mercurio de la que hablaremos en el apartado 5. Aunque el topónimo "Trampal», indicativo de áreas de pastos con o sin vegetación, es frecuente en la región, hay que señalar la hipotética procedencia de los alrededores de Santa Lucía, y por lo tanto en relación con el conjunto que vamos a describir, de tres epigrafes funerarios que Roso de Luna encontró en Arroyomolinos de Montánchez ${ }^{6}$, en el valle situado a los pies de Santa Lucía; el editor se limita a indicar que proceden de «Los Trampales», lo que podría aludir a los alrededores de la ermita de Santa Lucía; sin embargo, por necesaria prudencia omitimos su inclusión en el conjunto.

\footnotetext{
${ }^{3}$ Sobre los recursos naturales de la región y la ventajosa posición geográfica del templo, cfr. L. Caballero et alii, Extremadura arqueológica 2, op. cit. en nota 2, p. 498.

4 A. González Cordero et alii, «Nuevas aportaciones a la epigrafia de Extremadura», Studia Zamorensia 6, 1985, núm. 7. pp. 293-295, lám. $6(=$ HEp I, 152); V. Soria Sánchez, XVI Coloquios Históricos de Extremadura, Trujillo 1987, p. 26, núm. 2; id., Aguas Vivas 8, 1988, III, núm. 2.

5 J. Vidal, Extremadura, 23 de febrero de 1987, p. 25 y V. Soria, XVI Coloquios Históricos de Extremadura, Trujillo 1987. p. 26, nủm. 1; id., Aguas Vivas 8,1988 , III, nủm. 1 (= HEp 2 , 202). Según los primeros editores el texto dice Macili/a C(ai) f(ilia)/Anus/an(norum) $L X V / h$ (ic) s(ita) e(st)/s(it) t(ibi) t(erra) l(euis); seria ésta la primera huella en Hispania de este gentilicio latino.

${ }^{6}$ CPIL Cáceres 52, 53 y 54
} 


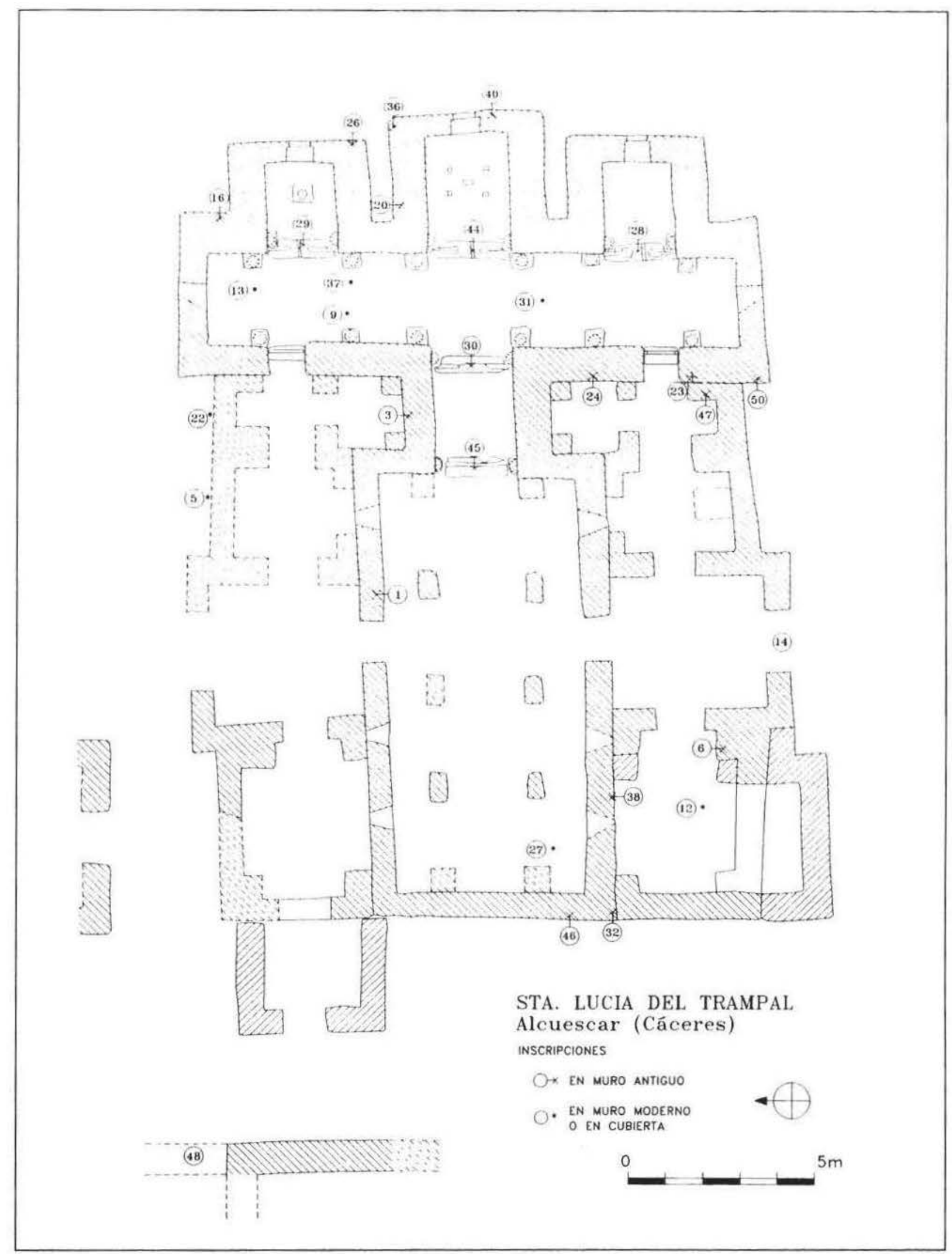

Figura 1.-Mapa de localización de hallazgos epigráficos en el templo de Santa Lucia (sobre plano e información de L. Caballero). 


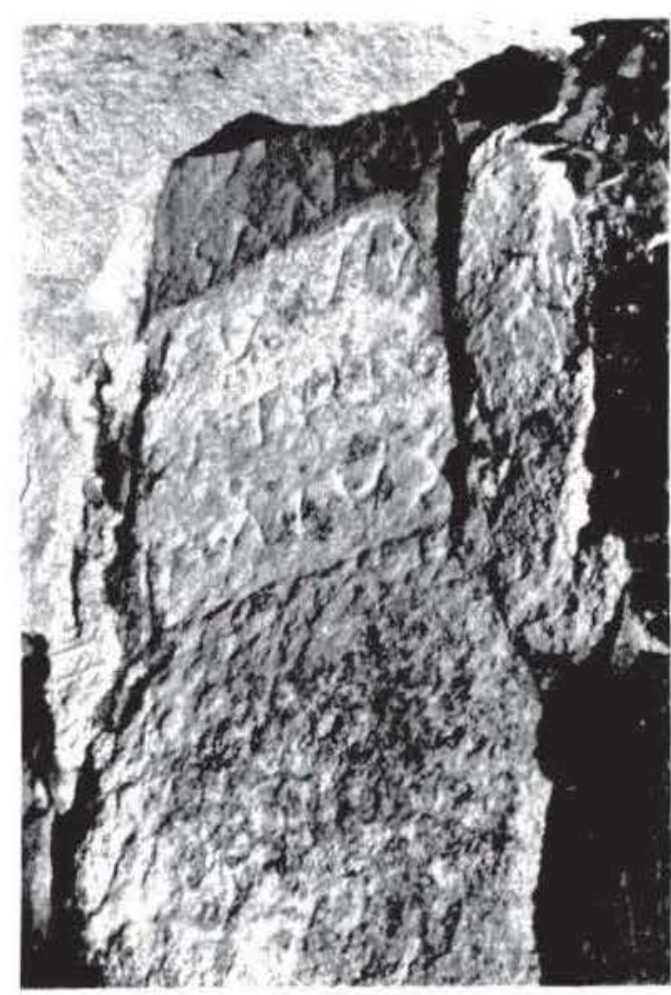

Figura 2. Inscripctón num 1.

\section{CORPUS MONUMINTAI}

\subsection{INSCRIPCIONES}

1. Fig. 2 y 46 , num. 1.

L. Caballero y J Rosco: Extremadura Arqueologica 1. 1988, pág. 248, núm. B.3 (sin texto).

Ara de granito empotrada en el interior del aula del templo de Santa Lucia, junto a la jamba oriental de la puerta norte, actualmente cubierta de yeso. Aunque la cabecera queda dentro del muro, parece

Las abreviaturas bibliográficas se cinen, siempre que es posible, at las de $L$ Annece Philulogrque. En las referencias bibliograficas, ademas de las corrientes de 1 :Annèe Epigraphique y del Corpus Inscriptimum Latinarum, se citan abreviadamento las siguientes obras o series: Abascal. Nombres - J. M. Abascal. Los nombres persunates en las inscripciones latinas de llispania, Madrid-Murcia 1994. Albertos, Tarracenense $=$ M. I. Albertos. La onomastica personal primitiva de Hispania. Tarra. conense y Betica, Salamanca 1966. Blazquez. Religiones 1962 = M. Blárques. Religiones primitivas de llispania. Finentes epigraficas, Roma 1962 Caballero y Rosco, Evtremadura dr queoliggica L. 1988 - L. Caballero y J Rosco, "Iglesia visigoda de Santa Lucia del Trampal. Alcuescar (prov. Caceres). Primera campaña de irabajos arqueologicos 1983-84", Evrremadura Arqueologica 1. 1988. pp. 231-249. Caballero y Roseo. Inedite 1986 - L. Caballero y J. Rosco, clglesia visigoda de Santa Lucia del Trampal. Alcuescar (prov. (aceres). Informe preliminar Segunda camparia de excavaciones arqueológicas (Informe inedito de 1986 remitido a la Junta de Extremadura). CPILCace- conservarse cast completa y sin restos de molduras El pie, exageradamente alto dentro del conjunto de Santa Lucia. ha stdo retallado para ajustarlo a las medidas del aparcjo. aunque esta modificacion no afecta al texto. Durante los trabajos de restauracion se pudo documentar una altura del monumento stperior a los $93 \mathrm{~cm}$ entonees visibles. Su anchura es de $31 \mathrm{~cm}$ en el cuerpo central y parece tener un fondo en torno a $10035 \mathrm{~cm}$.

El campo epigrafico mide $40.27 \mathrm{~cm}$ y la altura de las letras, aunque irregulares, estat en torno a los $5 \mathrm{~cm}$. con interlincas muy amplias que oscilan entre los 4 y $\operatorname{los} 4.5 \mathrm{~cm}$. Las letras son muy irregulares y apenas se pueden observar afinidades entre los tipos repetidos. La $A$ carece de travesano. la $\mathrm{V}$ siempre es muy abierta y la S es estilizada con cierto aire de cursiva. Las únicas interpunciones visibles, en la úlima linea, son circulares. EI monumento se conserva empotrado en el mismo lugar en que se hallo. El texto dice

$$
\begin{aligned}
& \text { Adecin } / a \mid \\
& \text { eanct- } \\
& \text { ac linia } \\
& \text { Patric- } \\
& 5 \text { ia arnimo) /(ibens) u(otum) s(o/wit) }
\end{aligned}
$$

Las dos primeras lineas de texto quedan dentro del muro, pero pudieron leerse en los trabajos de restauración, asi como fotografiarse. En ambas esta clara la monoptongación de $-a e$ en $-e$ y la existencia de cortes asilabicos que aparecen también en la linea 4. En I.3 la última letra es claramente una cursiva. Puede descartarse la presencia de una invocación del tipo dreae) d(ominae) s(anctae) debido a que el apelativo sancta figura tras el nombre de Atatecina.

La onomástica de la dedicante es muy representativa del ámbito regional proximo al templo de Santa Lucia. En la cercana Mérida la gens Vihia está representada por ocho testimonios, tanto masculinos como femeninos, de los que cuatro llevan cognomen de origen griego ${ }^{\circ}$. Aunque no se menciona ex-

res $=$ R. Hurtado, (ormus provinctal de inscripeienes latimas Ciceres, Caceres 1977. 111:p - Hespama Epigraphica. Madrid IRCP - J. D'Encarnaçao. Inscricoes rumanas do consentus Pa censis, Coimbra 1984 Leite, Refigives = I I eite de Vasconcelhos. Relighóes de Linsitania, vol. 2. Lisboa 1905. Solin \& Salomies. Repertorium = H. Solin y O. Salomes, Repertorium nommum gentilium ef cognominum Latinorum. Hildesheim 1988

- Solin \& Salomics. Repertorium. p. 207: Abascal. Nombres. p. 247

"Vibra Asctepiace (sic) y Vibus Asctepiades: Gi. Gamer, For men rö̀mischer Altäre auf der Hispamischen Ilalbinsel. Madrider Berträge 12. Mainz 1989, p. 194, BA-31. Taf. 77 d: Vithia 
presamente. un buen número de los ejemplos deben ser libertos de este grupo familiar. La gens libia estat sobradamente representada en otros lugares de la provincia de Badajo, "1". y son mas escasos los hallazgos en el area cacereña". La forma sin distinción consonántica tal como aparece en la inscripcion de Santa Lucia. solo es conocida en Hispania sobre dos textos beticos ${ }^{13}$. El cognomen latino de la dedicante. Patricialt es tambien corriente en la ciadad de Merida . que concentra tres de los quance testimonios hispanos que conocemos

II nombre de la divinidad presenta una mas de las grafias inusuales propias del conjunto, con sonorizacion de la dental. monoptongación de la desinencia y reduccion de la cantidad silabica al escribir - $e$ para el par - $a-c$, perteneciente a dos silabas distintas. Sobre los epitetos de la divinidad. rial infra el apartado 5

2. Fig. 3 y 48 , num. 2. Inédita.

Cabecera de un ara en granito que formaba parte de la cerca oriental de Santa Lucia, que presenta dos perforaciones superiores en lugar de foculus. destinadas a insertar algún tipo de objeto. Aunque a primera vista podria pensarse que el soporte incluye parte del cuerpo central del ara, un examen detenido demuestra que se trata de una caracteristica cabecera cubica cuya parte inferior ha sido tallada para reaprovecharla en la construcción del templo. En el proceso de talla sobrevivieron, aunque no en toda su altura, las tres letras que constituian el comienzo del texto inscritas en la cabecera y que

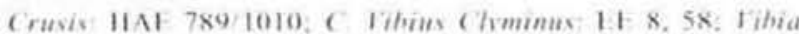
Admata: CII II 567. ( I thous Alhan/u/s: CII II 600, I. Thhus Geme/llus/: (II. II 567. I IIbius) Norhantus) HAI: $501+$ I W Haley. Forcigners in Roman imporial spain investigation. of geosraphical mohility in the Spanish prosinese of the Re, man tmpire 311 B(-AI) 284. Columbia. Ph. Diss. 1986, p. 187. num. 81

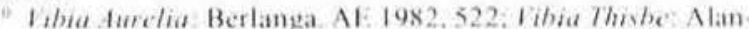
ge. IIAl: 693:G. Vihus Probus 1. Brocri I. Jeres de los Caballe ros CIL II $6277 \mathrm{c:} /$ Vibius Secumitus: Jeres de los Caballeros

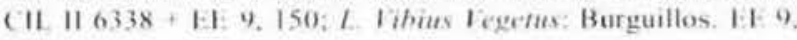
143

Iitha Felicitas: Mirabel. CII II 797, C Libius Proculus Madrigalejo. IE 8, 69a, I, Tibiux Quiri Reburrus: Talavera Ia Vicja (II II 938 5343: Vibms Tercullus: Trujillo. C'II II 638 Solin \& Salomies. Reperturium, p. 212. Ahascal. Nembres. p. 249

Vium/s/ Faustu/s/: Cádb E1: 9,237 b: L. Vinius M.f, /. 17/aumus (sic): Sevilla. CII II 1190.

14 Solin \& Salomies, Repertorium, p. 376

Patricia: CIL II 5270/5458; /P/atricta: HAL 692: /P/atricia IIAE 697

in Abascal. Nombres, p. 451

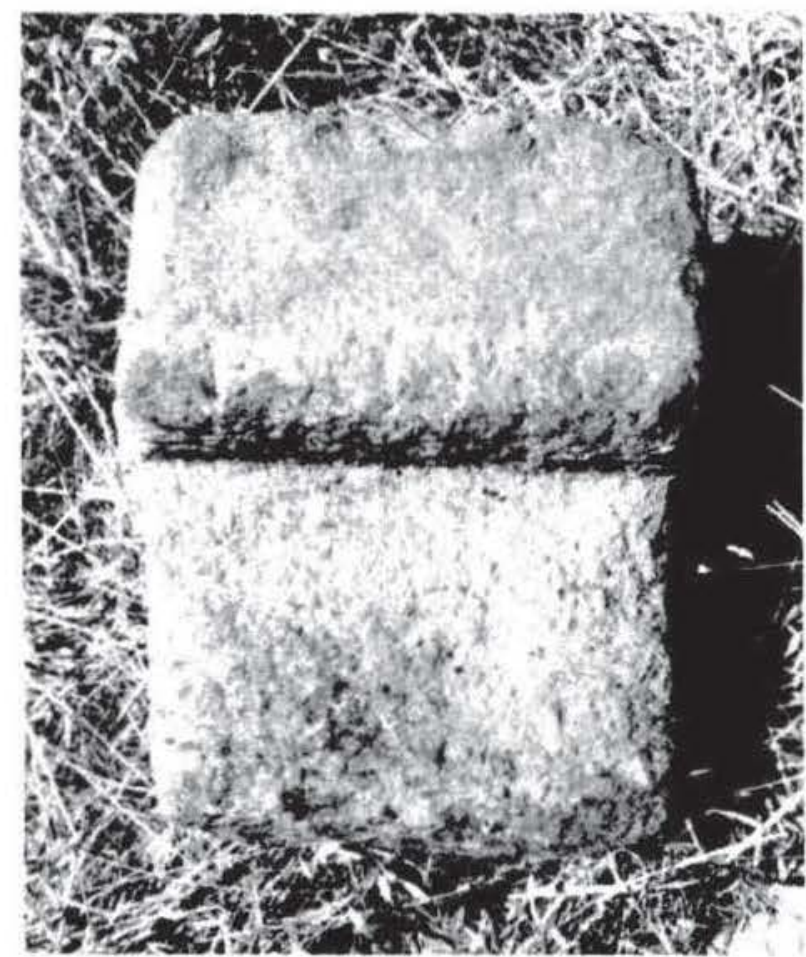

Figura 3 Inscripcion num. 2

incluian parte de la dedicación ". Las dimensiones maximas del soporte son hoy $[46] \times 38 \times 36 \mathrm{~cm}$; la altura de las letras debe estar en torno a $\operatorname{los} 8 \mathrm{~cm}$. y el menguado campo epigrafico alcanza $\operatorname{los} 29 \mathrm{~cm}$ de anchura. Se conserva en el exterior del templo de Santa Lucia. El texto dice:

\section{D(eae) d(ominae) stanctae) $1-1$}

El orden de desarrollo de las abreviaturas $D(\ldots)$ $D(--)$ responde a lo visto en la inscripción num. 7 de este mismo conjunto (vid. infra) Sobre los epitetos de la divinidad, vid. infira el apartado 5.

\section{Fig. 4 y 46 , num. 3 .}

Inédita.

Ara de granito hallada en la cata 2 de la excavación del templo, en la cara externa del muro norte del tramo de paso entre el crucero y el aula del templo de Santa Lucia. Apareció formando parte de una hilada del muro por debajo de un suelo de guijarros. Pese a las dificultades que ofrece su ubicación for-

17 Antes de nuestra inspeccion directa de la pieza, el 25 de agosto de 1994, alguien resalio con tira los rasgos conservados 


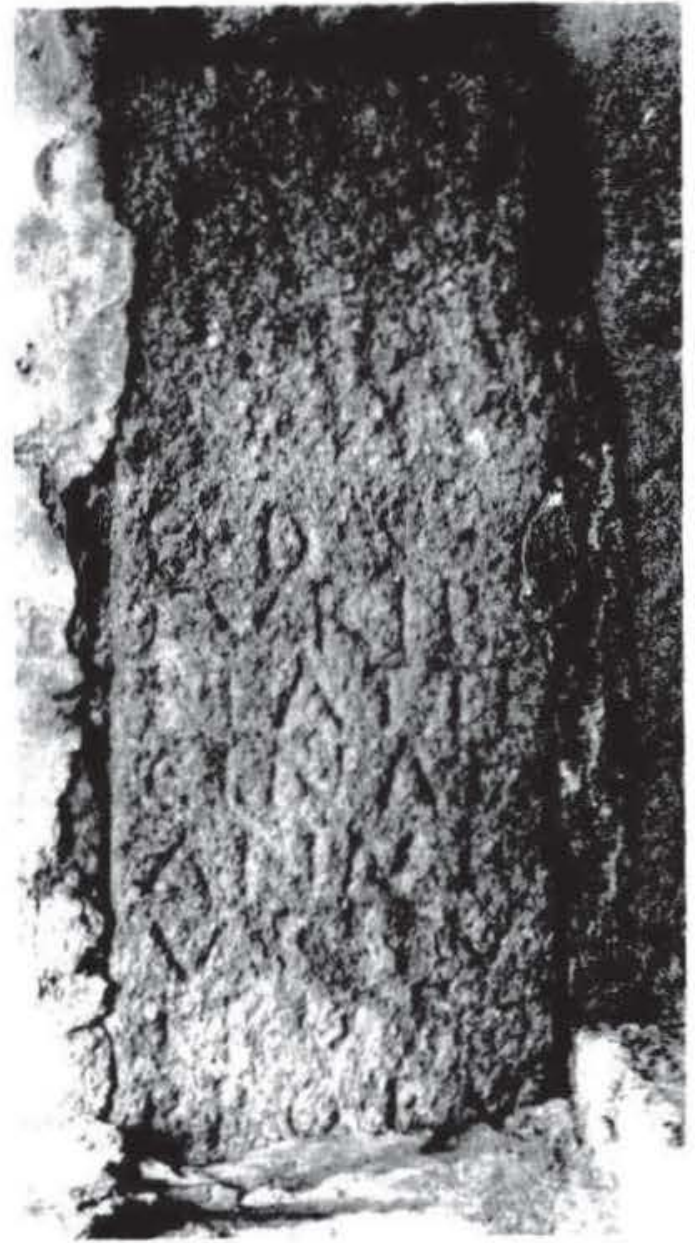

Figurat Inseripcion num. 3

mando parte de un lienzo y en posición horizontal. parecen observarse en su cara superior dos orificios similares a los de otros monumentos del lugar. Para poder ser reutilizada, se rebajó en su día el relieve del coronamiente, de proporciones comunes a las de otras piezas del enclave; de tal manipulación quedan huellas evidentes que permiten diferenciar el cuerpo central del ara. que hoy ofrece el aspecto propio de una estela.

El texto no está completo, pues a la altura de la octava línea el monumento queda oculto por los elementos del lienzo contiguo. En su estado actual, las dimensiones del ara son $74 \times 35 \times(\cdots) \mathrm{cm}$. El campo epigráfico visible mide [49] $\times 27 \mathrm{~cm}$, y la altura de las letras oscila entre los 4 y $\operatorname{los} 5 \mathrm{~cm}$, con interlineas de $1-1.5 \mathrm{~cm}$. En la primera linea aparecen interpunciones circulares muy poco marcadas. El texto está alineado a la izquierda y las letras son bastante regulares dentro de la falta de uniformidad caracteristica de todo el conjunto local; la A carece de travesaño horizontal, la $\vee$ es muy abierta y la $\mathrm{N}$ es más ancha que el resto de los tipos. En las lineas 3,6 y 8 existen cortes asilábicos y hay una simplificación sonora al final de 1.3 en el nombre de la divinidad. Probablemente a la inseripcion solo le falta una linea final si atendemos al sentido del texto

En las dos ultimas tineas. que conticnen el motivo de la dedicacion, solo las interpunciones permiten hacer una propuesta de lectura. Al final de 1.7 parece visible una $0 . y$ al comienzo de 1.8 es clara la B. al final de esta misma linea no hay posibilidad de entender ex / $/$ otos/ debido a que el cruce de los des trazos oblicuos es muy bajo y fuer/a la lectura de una $\mathrm{V}$ : de ahi nuestra propuesta tal como apareec aqui.

Se conserva empotrada en el mismo lugar en que fue descubierta. El texto dice:

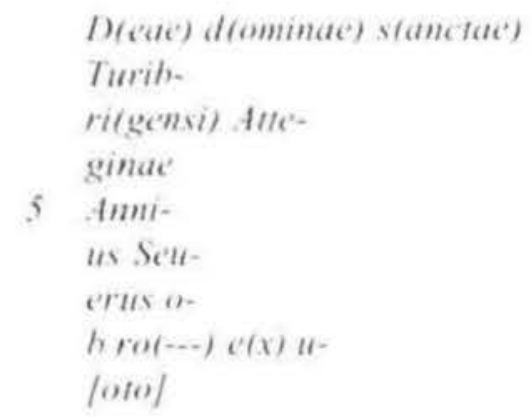

El nombre de la divinidad ofrece una grafia inusual, con geminación de la dental: al final de 1.3 se observa una reducción silábica al unir los sonidos a-e de dos silabas en un solo fonema: la sonorización de la dental es evidente, pues no hay dificultades para identificar la G, y no C. de 1.4. Sobre los epitetos de la divinidad, vid, infra el apartado 5.

El sentido de la dedicación se nos escapa, toda vez que son varias las posibilidades de desarrollo de la abreviatura de la linea 8 . El nombre del de dicante ofrece, en si mismo, pocas particularidades. Los Annii t" son raros en la antroponimia extremeña, en donde no llegan a la decena los testimonios ${ }^{14}$. El importante volumen de inscripciones emeritenses ofrece, lógicamente, el mayor número de ejemplos ${ }^{21}$, sin que se pueda extraer de ello ninguna conclusión útil a nuestro propósito. Seuera/-us ${ }^{21}$ es el cognomen más frecuente en Hispania, con 258 testimonios ": muestra una especial incidencia en el ámbito extremeño, de donde procede la quinta parte de los ejemplos y, especialmente, en la ciudad de Mérida, que agrupa 15 personajes con ese cognomen.

\footnotetext{
17. Solin \& Salomies, Repertorium, D. 16

14 Abascal. Nombres, pp. 76 ss.

"3nnia l.f. Sabina y I. Annius Rufux: EE 8, 33:1. Annius

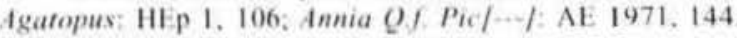

21. Solin \& Salomies, Repertorium, p. 402.

2) Abascal, Nombres, pp. 506 ss.
} 
4. 1 ig. 5 y 46, num 4

$V$ Soria Sanchez: «Edad del brence en Extremadura». 117 Congr: Vas . frq. Cartagena-1/arcia / $9 \mathrm{~S}_{2}$, 7aragoza, 1983, pág. 353:1.. Caballero y J. Rosco. Ertremadura Arqueologica 1. 1988, pag. 249. num. B.10, fig. $3.1=$ HEP 2, 200; J. L. Melena: eNotas de epigrafia romana de Extremadura 1. Sobre un pretendido teonimo nuevo de Lusitanian. Ieleia 7. 1990, pag. 152. nota 26 - HEP 4. 211 .

Ara de granito partida en dos fragmentos entro la quinta y la sexta linea de texto, con dos pequenos orificios contiguos en su parte superior. que apareció formando una tumba en la ladera del Cerro de San Jorge, situado al norte de la "Charea de Santiagow. Fl monumento tienc cabecera y plinto casi cúbicos sin ningún tipo de decoracion y el texto sc halla repartido entre la cabecera y el cuerpo central. Sus dimensiones máximas son $90 \times 32 \times 30.5 \mathrm{~cm}$. de los que $52 \mathrm{~cm}$ de altura se reparten a partes iguales entre los extremos superior e inferior; el campo epigrafico mide $47 \times 25 \mathrm{~cm}$. las letras, de ejecucion algo tosea, estan profundamente grabadas y miden entre 5.5 y $6 \mathrm{~cm}$, con interlineas de $1-1.5 \mathrm{~cm}$. Las interpunciones. todas ellas circulares y bien grabadas, pueden confundirse con algunos pequeños golpes del soporte. Se conserva en un pequeño habitaculo al pie del cerro en que se hallo. El texto dice:

D(eae) dfominae) stanctae)

Turihr-

i(gensi) tdaec-

inae

5 G(aius) C(accilius? Seu-

erus

a(nimo) l(ibens) u(otum) s(oluit)

\section{L.6: IRVS, Soria.}

El nombre de la divinidad sólo ha sufrido una sonorización de la dental en 1.3, y presenta una grafia formalmente mas correcta que otros testimonios del enclave de Santa Lucia. Los epitetos de Alaeci$n a$, escritos sobre la cabecera del ara tal y como ocurre en los nums. 2 y 11 , están abreviados en las tres consonantes habituales en el conjunto (vid. infira apartado 5), pero se añade el adjetivo Turibrigensis, señalando la vinculación del culto a Turibriga (vid. infira apartado 8).

En cuanto al dedicante, en la quinta linea la letra $\mathrm{G}$ es clara por la presencia de un apéndice semi-

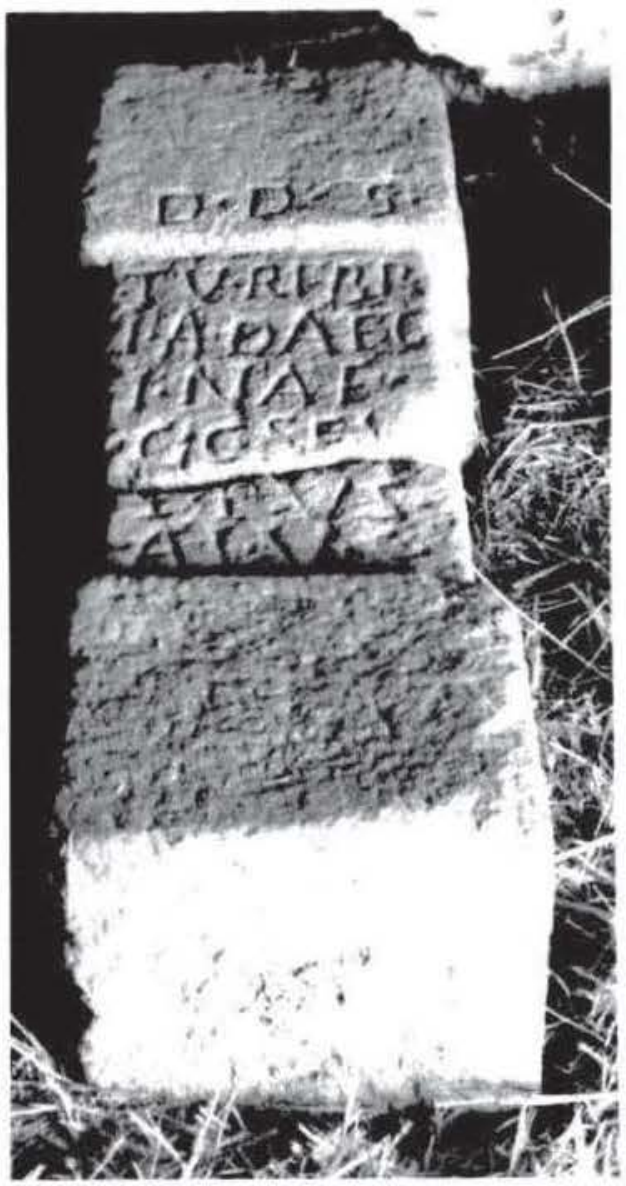

Figura 5. Inscripcion num. 4

oblicuo que evita una lectura ( (aiks): aunque no es posible restituir con seguridad el nomen abreviado. es probable, por su frecuencia, que pueda tratarse de un Caecilius: sobre el cognomen Senerus, vid. Io dicho para el texto anterior.

5. Fig. 6 y 47 , num. 5 .

L. Caballero y J. Rosco: Extremadura Arqueologica I. 1988, pág. 246, núm. A.5, fig. $3.2=$ HEp 2. 196.

Ara de granito hallada en la casa adosada en la segunda mitad del siglo xix en el lado norte de Santa Lucia. Aunque el pie del monumento se ha perdido, es muy probable que, como el coronamiento, presentara una sencilla decoración de incisiones paralelas horizontales insinuando molduras; en el lugar del foculus tradicional, que no existe en sentido estricto, aparece un pequeño hueco casi ovalado cuyos ejes miden $8 \times 4,5 \mathrm{~cm}$, que podría estar destinado a insertar algún tipo de elemento decorativo o exvoto como ocurre en otros monumentos del lugar. Sus 


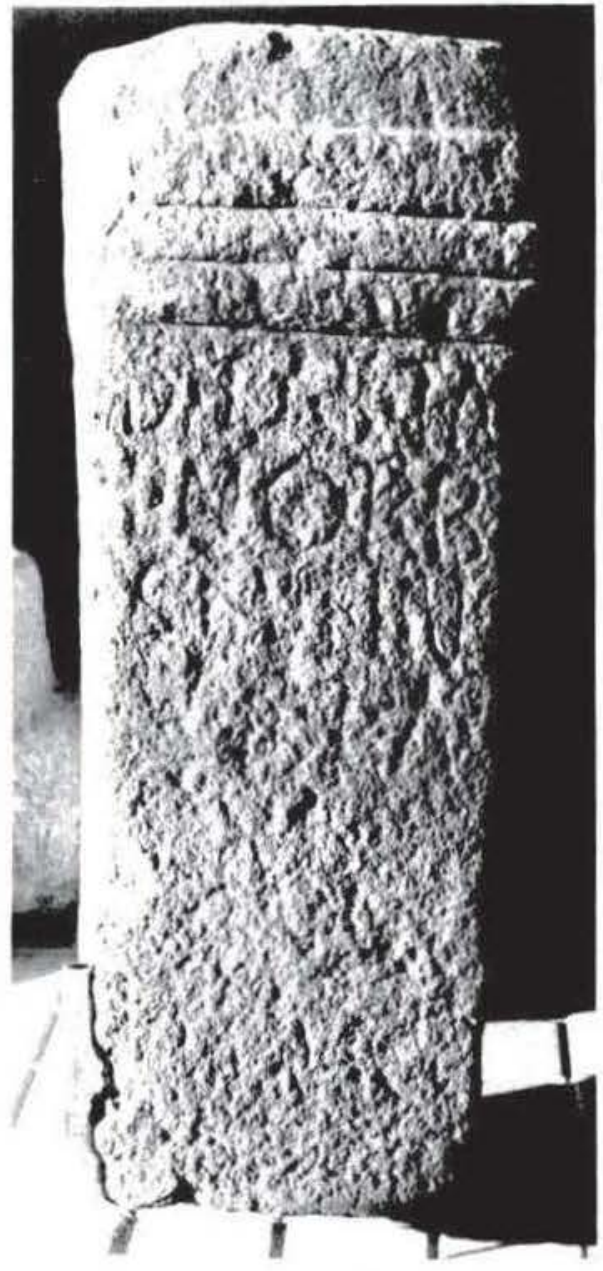

Figura 6.-Inscripcion num 5

dimensiones son $71 \times 29 \times 22 \mathrm{~cm}$, y conserva cuatro lineas de texto. todas en el cuerpo central, con interpunciones circulares; el campo epigrafico mide $25 \times 22 \mathrm{~cm}$; la altura de las letras en las cuatro lineas es de $5.5 \mathrm{~cm}$, con una interlinea reducida de apenas $1-1,5 \mathrm{~cm}$. Todo el texto está apoyado $\mathrm{en} \mathrm{el}$ margen izquierdo del soporte.

El aspecto formal de las letras es algo diferente al de otros textos de Santa Lucia. La $O$ de la segunda linea es circular, con restos de un punto central a partir del cual se ha trazado; las consonantes finales de esta segunda linea tienen una altura ligeramente superior a la de las demás letras; la $V$ en 1.3 y 1.4 no experimenta el mismo grado de apertura, debido a que en 1.3 escaseó el espacio por la inexistencia de paginación previa y fue necesario estilizar las dos letras finales, lo que en el caso de la $S$ Ilega al extremo. Se conserva en el Museo Arqueológico Provincial de Cáceres.
El terto dice

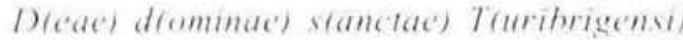 \\ d(taecinae) \\ L.rucius) Norbranus) \\ Seтети \\ ar(olum) s(olut) l(ibens) a(nimo)
}

\section{L.3: S(LI)BFRVS. Caballero y Roseo.}

Aunque el encaberamiento del texto es similar al de las inscripeiones nums. 3 y 4 del grupo de Santa Lucia. solo en este caso se abrevia la dedicacion con cinco consonantes separadas por interpunciones. La restitución no ofrece dudas a partir de los otros testimonios, pero nos prisa de conocer la forma grafica del nombre de la divinidad.

La restitución de las lineas 2 y 3 concuerda basicamente con la propuesta de HEp 2 a partir de la primera edición del texto. Fl dedicante presenta un nombre con elementos corrientes en el ámbito regional. Norbanus es un nombre propio del área cacereña. sobre todo del area suroriental de la actual provincia de Caceres, que terminaria ocupando posiciones de gentilicio en las formulas nominales y funcionando como tal: es especialmente frecuente en el conjunto epigráfico de lbahernando, que agrupa casi una quincena de testimonios, y no falta en Montánchez, Santa Ana, Salvatierra de Santiago, etc. incluso en la vecina Mérida ${ }^{27}$, sólo en el conjunto de Santa Lucia portan este nomen 3 individuos. Sobre el cognomen Setuerus, restituido ahora a su grafia habitual tras la primera lectura en la forma Seherus. vid. lo dicho para el num. 3.

La decoración del monumento se repite en otros ejemplares de Santa Lucia. Si el coronamiento de este ejemplar mide $28 \mathrm{~cm}$ de altura, el del ara núm. 12 llega a alcanzar $\operatorname{los} 31 \mathrm{~cm}$ con seis molduras. Los mismos elementos se repiten en las aras núm. 21 y 43. una de ellas anepigrafa.

6. Fig. 7 y 46 , núm. 6 . Inédita.

Cuerpo central de un ara de granito que aparecio en 1990 empotrado en el muro situado entre el portico sur y la habitacion trasera meridional del templo de Santa Lucia. La falta del pie y el coronamiento se debe a su reutilización como material de construcción en las diferentes fases edilicias, que ha llevado incluso a retallar el costado derecho, aunque sin afectar al texto. En su estado actual, la pieza 191. 


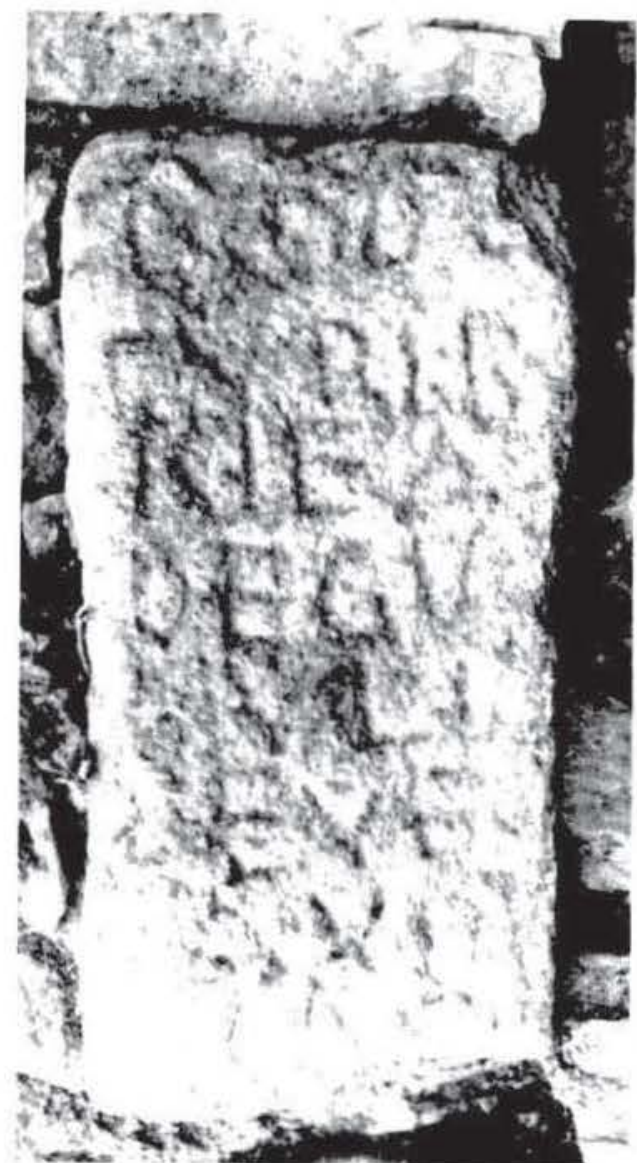

Figura 7. Inscripcion num. 6.

mide $[62] \times[30.5] \times[19] \mathrm{cm}$. por lo que tipológicamente presenta grandes similitudes con el ara dedicada por Annius Setuerus (num. 3). Las letras estan profundamente grabadas y se conservan bien en el centro y parte superior de la superficie escrita, que mide $52 \times 27 \mathrm{~cm}$. La altura de las letras, muy irregular incluso dentro de una misma línea, oscila entre los 6 y los $7 \mathrm{~cm}$, excepto en las dos últimas, cuyas letras miden entre 5 y $6 \mathrm{~cm}$. Sólo en la penúltima linea se observa una interpunción.

El nombre y los epitetos de la divinidad aparecen en las cuatro primeras lineas, aunque al comienzo de la quinta aún se observan trazos de una vocal que debe pertenecer a la desinencia en dativo del nombre de Ataecina. En la primera linea, entre las dos consonantes iniciales aparece en el epigrafe un trazo circular bastante claro, para el que el escultor reservó un cierto espacio, y que sólo puede ser una $\mathrm{O}$. Esta lectura introduce una inversión en el orden de los epítetos con respecto al texto núm. 7 de este repertorio y con respecto a una dedicación a Salus de la vecina Montánchez (vid. infra), por lo que hemos optado por mantener estas últimas evidencias como referencia de desarrollo para las abreviaturas.
El nomen de la dedicante parece claro en la quinta linea pese al deterioro del lateral derecho de la superficie escrita, en donde se ha perdido un traso oblicuo de la A. Del cognomen sólo quedan las tres letras centrales, aunque las opciones de restitucion invitan al desarrollo que sugerimos; aunque al comienzo del renglón se podria cncajar la consonante. al final del mismo solo parece que haya espacio para una letra, por lo que la desinencia del femenino deberia haherse omitido.

Mas dificultades ofrecen las dos altimas lineas: en la septima hay un espacio inicial perdido en el que cabe una letra ancha, como la $E$. pero no hay espacio libre tras la $T$ para una $O$. que tampoco aparece al comienzo de la octava linea. En ésta. la parte inferior de las letras se ha perdido por la rotura del soporte, pero quedan restos suficientes para sugerir esta restitución.

Se conserva en el Museo Arqueologico Provincial de Caceres. Fl texto dice:

\author{
Do(minae) dreat) s (anctae) \\ Turib- \\ rifg)e(nsi) (sic) A- \\ degin- \\ 5 (a)e lulia \\ [S/ener(a) \\ [e/ $x$ uot (o) \\ !(ihens) a(nimo) stoluit)
}

Los epitetos de Ataecina que figuran en el texto son los corrientes dentro del conjunto, con la salvedad del referido a Turibriga, que no da lugar a un adjetivo Turibrigensis o Turobrigensis, como es habitual, sino a una forma Turibrie que, seguramente, es un error del grabador al sustituir la $G$ intervocáli. ca, que debia figurar en la minuta a escribir, por una vocal (vid. infra apartado 3 ). En el nombre de la divinidad se observa la sonorización de las consonantes que ya es corriente en el conjunto, asi como la reducción de la desinencia.

La onomástica de la dedicante es completamente corriente. Iulia/-us y Seuera/-us son, respectivamente, el nomen y el cognomen más frecuentes en la epigrafia hispánica ${ }^{24}$. Sin embargo, no es habitual la abreviatura en la forma en que aparece en el texto, que sólo conocemos en dos inscripciones de Sevilla y del balneario cacereño de Baños de Montemayor ${ }^{25}$.

\footnotetext{
24 Abascal. Nombres, pp. 151 y 506

24 Sevilla, CII. II 1226: Fabr(icius) Setuer(us): Baños de Montemayor. CIL II 883: Trebia Sewerfal
} 
7. Fig. 8 y 47 . num. 7 Incdita.

Parte superior de un ara en granito que en 1986 aun formaba parte de la cerea oriental de Santa Lucia. Conserva en su parte superior dos perforaciones rectangulares paralelas en el lugar que debia ocupar el toemlus. La cabecera es lisa salvo en su union con el areat escrita. en donde presenta una doble moldura. En el cuerpo central del monumento solo se conservan. y no completas. dos lineas de texto In su estado actual, el soporte mide [35] $\times 31.5 \times 29$ $\mathrm{cm}$. Las dimensiones del campo epigráfico conservado son $9 \times 20.5 \mathrm{~cm}$; la altura de las letras es de 4 em en la primera linea y de 5 en la segunda. Conserva una interpunción circular tras la primera abre. viatura del nombre de la divinidad.

Fn la segunda linea el primer rasgo visible es el extremo de un trazo que debe pertenecer a una $N$. pues a continuacion figura ya un angulo que indudablemente pertenece a la parte superior de una $A$. Al final de la linea queda la parte izquierda de la $R$. pero no podemos saber si termina aqui la abreviatura del toponimo o si. por el contrario. continua en la linea siguiente que se ha perdido.

Se conserva en la parte exterior del templo de Santa Lucia. El texto dice:

\section{Derue) dom- \\ li)nate Tur(ihrigensi) \\ (-.)}

La importancia de este pequeno fragmento de texto estriba en que establece el orden de los apelativos de Alaecina en la forma Dea Domina. siguiendo asi

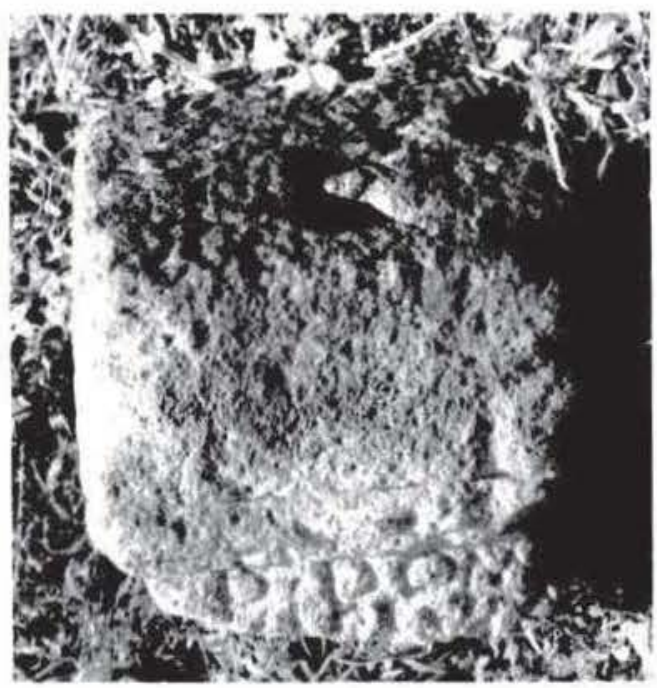

Figura 8.-Inscripción núm. 7. un patron que ya conociamos en una inseripcion dedicada a Salus en Montanchez (rid. infra apartado 5). lo que permite desarrollar las abreviaturas del resto de las inscripciones. Solo la inscripcion num. 6 muestra un orden diverso en los epitetos. como hemos visto con anterioridad.

Como es corriente en el conjunto, los cortes asilabices no son obstáculo para el grabador que, en este caso, parece apoyarse en el lado derecho de la superficic a excribir.

8. No ilustrada.

1. Caballero y J. Rosco Extremadura Arqueologica 1. 1988. pag. 249, num. B.8 HEp 2. 198: J. L. Melena: "Notas de epigrafia romana de Extremadura I. Sobre un pretendido teonimo nuevo de Lusitanian, leleia 7, 1990, pág. 152, nota $26=$ HEp 4. 210: seguramente a ella se refice V. Soria Sanchez: "Catalogacion de inscripciones recientes de Extremaduram, en Actas del XVII Congr Nace Ary ligo 1993. Vigo. 1995. vol. 2. pág. 383.

Ara de granito con cabecera moldurada y dos huecos rectangulares paralelos en su parte superior, hallada en los alrededores del templo de Santa L.ucia. Fuc vista por L. Caballero en un domicilio particular de Alcuéscar, y desconocemos sus medidas y particularidades. El texto, con las salvedades sugeridas por J. L. Melena y nosotros mismos debe decir:

\author{
Domina/el \\ Turibr(igensi) \\ Allaec $[i]$ - \\ nate \\ 5 L(ucius) Pontiu/s] \\ Senc[rus] \\ [P]robati \\ f(ilius) M(-..?) not(um) \\ $|\cdots|$
}

\section{I: Ligadura NA.}

L.6-7: SEVE[RV/S] ROBATI, Melena.

L.6-7: SEV(RISI V)/ .) ROBATI, Caballero y Rosco. L.8: EMVOT, Caballero y Rosco.

La inscripción es una de las cuatro de Santa Lucia que prescinden del calificativo de Dea para Ataecina, a la que se refieren con la expresión Domina Turibrigensis Ataecina con diversas grafias (vid. infra apartado 5). En el nombre de la divinidad de observa una geminación de la dental como única anomalia gráfica, lo que emparenta el texto con nuestra 


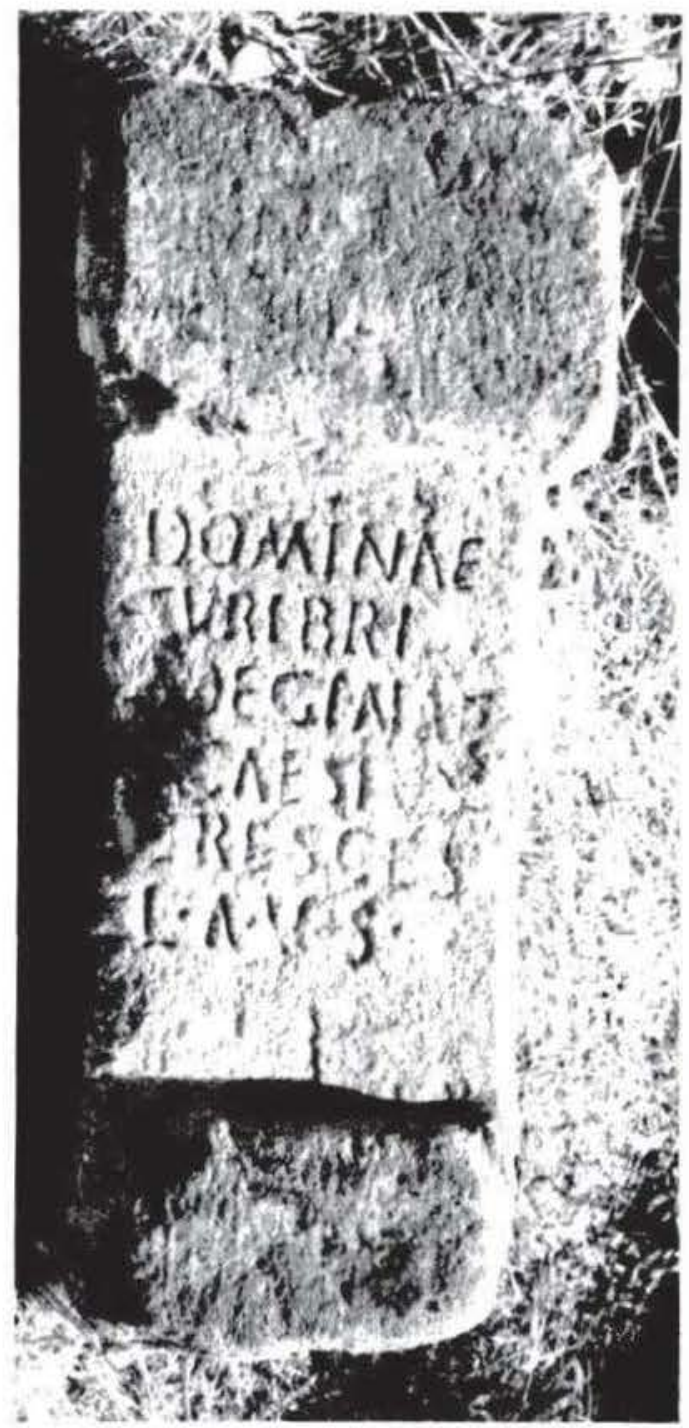

Figura 9 Inscripcion num 9

inscripción num. 3 y con un epigrafe dedicado a Ataecina en La Bienvenida (Badajoz) ${ }^{26}$.

Las mayores dificultades las plantea la octava linea del texto, en donde tras la indicación de la filiación aparece una $M$ de dificil restitución si no es como m(onumentum), cuya mención no tiene mucho objeto seguida de uot(um).

En el nombre del dedicante aparece una vez más el cognomen Seuerus, tan frecuente en este conjunto de Santa Lucia, y el nomen Pontius ${ }^{27}$, solamente

26. J. Esteban, "Epigrafe sobre la diosa Ataccinan. Actas de las Sexundas Jornadas de Metodologia y Didactica de la llistoria (llistoria Antigua), (áceres 1984, pp. 21-25, R. I opez Melero, "Nueva evidencia sobre el culto de Ategina: el epigrafe de Bienvenidan. Primeras jornalas sobre manifestaciones religiosas en la Lusitania. Caceres 1984. Cáceres 1986, pp. 93 ss.

Solin \& Salomies, Repertorium, p. 147. atestiguade en diecisiete ocasiones en Hispania " y del que solo dos testimonios se pucden aducir como proximos a Aletescar ". El nombre del padre del dedeante es raro en Hispania. con sólo seis testimonios fuera del ambito regional que nos ocupa ${ }^{* 1}$.
9. Fig. 9 y 48 , num. 9
1. Caballeroy I. Rosco: Exzremadura Arqueologica 1. 1988. paig. 248. num. 13.1. fig. 7.5 H1p 2. 197.

Ara de granito de seccion horizontal cuadrada que aparecio empotrada sobre el arco sur del cimborrio norte en el templo de Santa lucia. No presenta clementos decorativos ni en cabecera ni en plinto, y en su parte superior conserva una pequeña hendidura rectangular que no debe ser un tosco /oculus. sino el orificio destinado a insertar una figura de bronce. La cara frontal solo presenta una pequena rotura en su costado izquierdo, que afecta parcialmente a las lineas 3-5, Las dimensiones del soporte son $84 \times 37 \times 36 \mathrm{~cm}$ : el campo epigrafico mide $28.5 \times 23 \mathrm{~cm}$; la altura de las letras es de $3.5-4 \mathrm{~cm}$ con una interlinea que oscila entre I y $1.5 \mathrm{~cm}$. La mayor parte de las letras conserva aun restos de pintura roja.

El texto está alineado a la izquierda y su cjecucion es mas cuidada que en la mayor parte de los epigrafes del conjunto de Santa Lucia. Las letras, unas capitales algo estilizadas, tienen en algunos casos muy buena factura. Aunque con dificultad, se lee integramente el final de la cuarta linea, y noexiste ninguna duda sobre la $G$ (y no $\left(C^{\prime}\right)$ de la tercera. Se conserva en el exterior del templo de Santa Lucia. El texto dice:

\section{Dominae \\ Turibri(gensi) \\ (A) deginae \\ 1-1 Caesius \\ 5 Cresces \\ l(ibens) a(nimo) u(otum) s(oluil)}

Pese a que quedaba espacio suficiente a la derecha, el autor del texto rehusó emplear en la segunda linea una expresión más acorde como el dativo Turibrig(ensi), optando por la supresión de la consonante y haciendo una abreviación «silábica", acorde

2* Abascal, Nombres, pp. 201-202; debe añadirse ahora A. Caballos, "Varia funeraria ttalicense", Hahis 25, 1994, p. 235. num. 2. con un nuevo testimonio.

24 Paulla Pontia: Caceres. J. Salas y J Roseo, Norha 10, 1989. 90, p. 81: Pentius (?): Conquista de la Sierra, Cáceres, (11 II 657.

in Abascal, Nembres, p. 469 
con los rasgos de impericia latina que contiene el texto. La sonorización de las consonantes en el nombre de la divinidad pone este epigrafe en relación con el texto núm. 6 del conjunto y con una inscripción de Medellin (Badajoz) ${ }^{31}$. Curiosamente, mientras la grafia -ae en la desinencia del nombre de Ataecina se ha mantenido con valor gráfico, el grabador ha optado por la forma Adegina frente a Adaegina.

En el nombre del dedicante falta, por la rotura del soporte, el praenomen. Su nomen Caesius ${ }^{32}$ es bien conocido en ámbitos hispanos como Carthago Nova, donde se conservan varios testimonios de un mismo grupo familiar ${ }^{33}$, y tiene amplias resonancias en el mundo bético del medio y bajo Guadalquivir ${ }^{34}$. En los ámbitos extremeños relativamente próximos a Alcuéscar conocemos algunas evidencias ${ }^{35}$, y también es cacereña la curiosa forma Cesia de una inscripción de Madrigalejo ${ }^{36}$.

Cresces es una forma anómala de Crescens ${ }^{37}$, cuya frecuencia en Hispania evita cualquier comentario. En esta grafia inusual sólo conocemos otros dos ejemplos además de éste de Alcuéscar ${ }^{38}$ : uno procedente de Trujillo (Cáceres) ${ }^{39}$ y otro de Villagarcia de la Torre (Badajoz) ${ }^{40}$.

Las proporciones del soporte son superiores a la media de Santa Lucía no tanto en su altura (no debió alcanzar los $100 \mathrm{~cm}$ a juzgar por la rotura) como

\footnotetext{
" CIL II 605; M. de Monsalud, «Nuevas inscripciones visigóticas y romanas", $B R A H 30,1897$, p. $490=\mathrm{EE} 9$, p. $42 . C \mathrm{fr}$. infra $\mathrm{n} .254$ con el resto de la bibliografia.

12 Solin \& Salomies, Repertorium, p. 40

3 CIL II 3456 y AE 1977. 456.

4 Peñaflor, Sevilla (HAE 1864); Utrera, Sevilla (CIL II 1283 + HEp 1, 580); Osuna, Sevilla (CIL II 1410); Alcolea del Rio, Sevilla (J. González, Corpus de Inscripciones latinas de Andalucia, vol. II: Sevilla, tomos I y II, Sevilla 1991, núm. 250); Villafranca de Córdoba, Córdoba (CIL II 2184); S. Sebastián de los Ballesteros, Córdoba (AE 1986, 372); Montemayor, Córdoba (AE 1961, 343); Estepa, Sevilla (CIL II 1444); Ecija, Sevilla (AE 1988, 724); S. Juan de Aznalfarache, Sevilla (CIL II 1256); Cádiz (J. González, Inscripciones romanas de la provincia de Cádiz, Cádiz 1982, núm. 407); ltalica (J. González, Corpus...Sevilla, op. cit., núm. 352).

${ }^{35}$ Caesia Felicisuma, en Mérida (Badajoz): J. Álvarez Sáenz de Buruaga, «Museo arqueológico de Mérida», MMAP 4, 1943. pp. 44-52, lám. IX, 2; Caesia Corneli(a)e liberta, en Escurial (Cáceres): CIL II 659 + F. Fita, «Nueva lápida romana del Escurial (Trujillo)", BRAH 60, 1912, p. 159; Caesia Osi f. Sequnda, en Villamesias (Cáceres): M. Roso de Luna, «Nuevas inscripciones romanas de la región norbensem, $B R A H 47,1905$, p. 62 ; L. Caesius C.f., en Alcántara (Cáceres): AE 1984, 495.

${ }^{36} \mathrm{AE} 1965,72$.

37 Solin \& Salomies, Repertorium, p. 319.

38 Abascal, Nombres, p. 338.

39 HAE 1389.

40 CIL II 1035.
}

por su anchura. Sus $37 \mathrm{~cm}$ frontales máximos obligan a ponerlo en relación con los restos de la cabecera núm. 2, de dimensiones similares.

Los restos de pintura roja en el interior de las letras constituyen una auténtica rareza en la epigrafia hispana sobre granito, habida cuenta de que lo corriente es que ésta aparezca sobre inscripciones en mármoles y calizas. Al decir de Plinio ${ }^{41}$, uno de los usos corrientes del minio era su empleo en la decoración de inscripciones; en Hispania existen multitud de epigrafes que presentan aún restos de pintura roja mejor o peor conservada; aunque la mayor parte de ellos proceden de la Bética y del ámbito emeritense $^{42}$, no faltan los ejemplos fuera de estos territorios. A partir de los testimonios conocidos hay que descartar toda posibilidad de emplear esta característica como indicador cronológico, ya que conocemos testimonios inéditos fechables hacia el cambio de Era en el sureste peninsular y las inscripciones italicenses con pintura roja pueden alcanzar los momentos finales del siglo II o comienzos del siglo III d.C. ${ }^{43}$.

10. No ilustrada.

L. Caballero y J. Rosco: Extremadura Arqueológica 1, 1988, pág. 249, núm. B.9 = HEp 2, 199.

Ara de granito hallada en fecha desconocida en Santa Lucía y trasladada a un domicilio particular de Alcuéscar, en donde pudo verla L. Caballero al comienzo de sus trabajos. Desconocemos las características del soporte y sus medidas. El texto debe decir:

$$
\begin{aligned}
& \text { Domin- } \\
& \text { ae Turi- } \\
& \text { bri(gensi) Add- } \\
& \text { aecin(ae) } \\
& \text { [---] }
\end{aligned}
$$

Es ésta la tercera de las dedicaciones a Ataecina en la forma Domina Turibrigensis Ataecina, que en esta inscripción abrevia el epíteto referido al topónimo y presenta una curiosa geminación de la dental después de sonorizarla.

\footnotetext{
41 N.h. 33, 40, 122.

${ }^{42}$ Es muy probable, sin embargo, que algunas inscripciones fueran retocadas en el Renacimiento, por lo que no todos los testimonios hoy visibles se pueden aducir como antiguos.

${ }^{43} \mathrm{Cfr}$. al respecto los comentarios de A. Caballos, "Varia funeraria italicense", Habis 25,1994 , p. 232 , núm. 1 y pp. 235 ss.. núm. 2.
} 


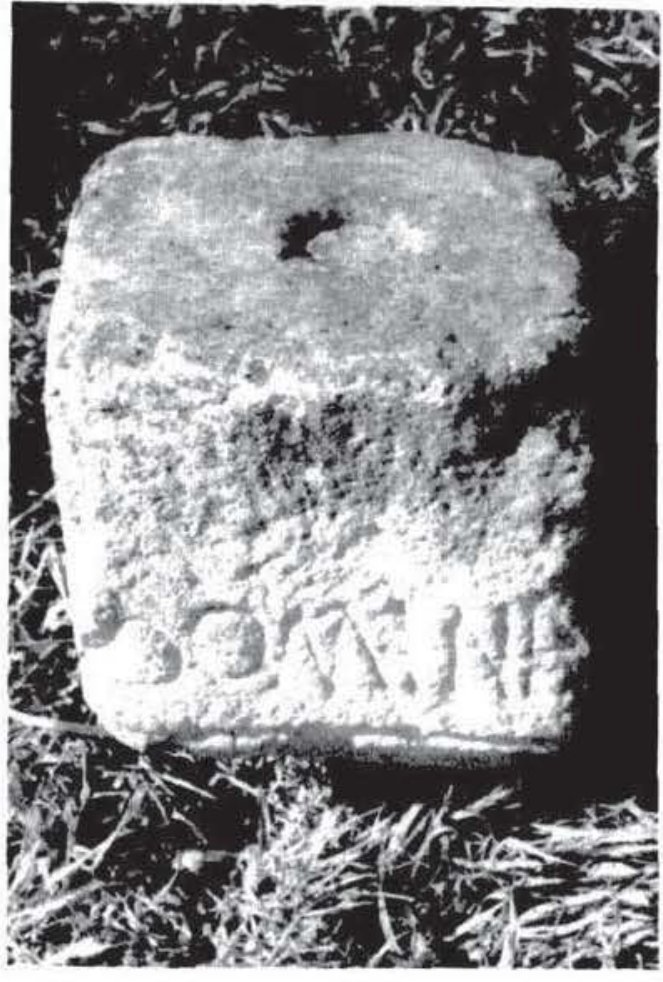

Figura 10. Inscripcion num. 11

11. Fig. 10 y 47 , núm. 11. Inédita.

Cabecera de un ara de granito hallada en la cerca occidental de Santa Lucia, con una pequeña perforación circular superior que no nos atreveriamos a calificar de foculus y restos de una moldura antes de la fractura. Las dimensiones del fragmento son $32 \times 30 \times 30 \mathrm{~cm}$; el área escrita mide $7 \times 26 \mathrm{~cm}$ y la altura de las letras en la única línea conservada es de $7 \mathrm{~cm}$. Los tipos de estas letras son poco uniformes y, mientras las dos primeras tienen un aire próximo a la cuadrada, las cuatro últimas son muy estilizadas. Se conserva en el exterior del templo de Santa Lucia. El texto dice:

\section{Domina- \\ [e ---]$$
\text { [--] }
$$

Al final de la primera línea no se observan restos de ningún trazo horizontal que haga pensar en un nexo para la dedicación en dativo, por lo que, por chocante que sea, necesariamente la $E$ debia figurar al comienzo de la segunda, ya en el cuerpo central del ara; la estructura que esto supone invita a imaginar la presencia del epiteto Turibrigensis antes del nombre de Alaecina. El uso de la cabecera del monumento para iniciar la escritura relaciona este epígrafe con los núms. 2 y 3 .

La grafía del texto conservado evidencia una ausencia absoluta de paginacion, y la progresiva falta de espacio a medida que se grababan las letras fue llevando a una estilización que produjo incluso un aumento de altura de los tipos.

Frente a lo que suele ser corriente en el conjunto que comentamos, en esta inscripción no se ha abreviadoel nombre común referente a la divinidad, hecho que se repite en los textos nums. 8.9 y 10 , además de en tres inseripciones de Salvatierra de Santiago iC aceres). La Bienrenida (Badajoz) y Medellin (Badajos) (rid infra).

\section{Fig. 11 y 48. num. 12 Inedita.}

Ara de granito en buen estado de conservación hallada en un murete moderno superpuesto a los cimientos arruinados del edificio primitivo, en el testigo $4 / 8$ durante la campaña de 1990 en Santa Lucía. Presenta un pequeño golpe al comienzo de la tereera linea y ha perdido casi completamente la sexta. sin que ello cause graves inconvenientes a la lectura. En su parte superior, que no presenta foculus ni otro tipo de oquedades como en las aras de Ataeci$n a$, la decoración está constituida por una doble moldura que rodea toda la pieza; en el pie es una única moldura la que separa el campo epigráfico de una prolongación irregular preparada para clavar en cl suelo y sostener en pie el monumento. Sus dimensiones son $117 \times 31 \times 34 \mathrm{~cm}$; el campo epigráfico mide $60 \times 30 \mathrm{~cm}$; la altura de las letras en la primera linea es de $6,5 \mathrm{~cm}$, que se reducen a $6 \mathrm{~cm}$ entre las lineas 2 y 6 ; en la séptima linea sólo miden 4,5 $\mathrm{cm}$. La interlínea oscila entre $\operatorname{los} 3$ y $\operatorname{los} 3,5 \mathrm{~cm}$, salvo entre las líneas 4 y 5 , en donde sólo mide $1 \mathrm{~cm}$. Presenta interpunciones circulares en todo el texto.

Las letras son capitales de surco profundo y buena factura, con una cierta uniformidad. La $O$ es completamente circular en las líneas primera y tercera. Salvo en la invocación del comienzo, los caracteres tienen una cierta estilización en relación con su anchura. Aunque a primera vista la linea inicial contiene una invocación del tipo I(oui) o(ptimo) $m$ (aximo), el examen del epigrafe demuestra que la letra inicial es una $D$, cuyo arco se ha trazado con un surco menos profundo. Se conserva en el exterior del templo de Santa Lucia. El texto dice:

Dom(inae)
C(aius) Val(erius) Te-
lespho-
rus ex ui-
su et mo-
nu!m(entum)] po-
suit

http://aespa.revistas.csic.es/index.php/aespa 


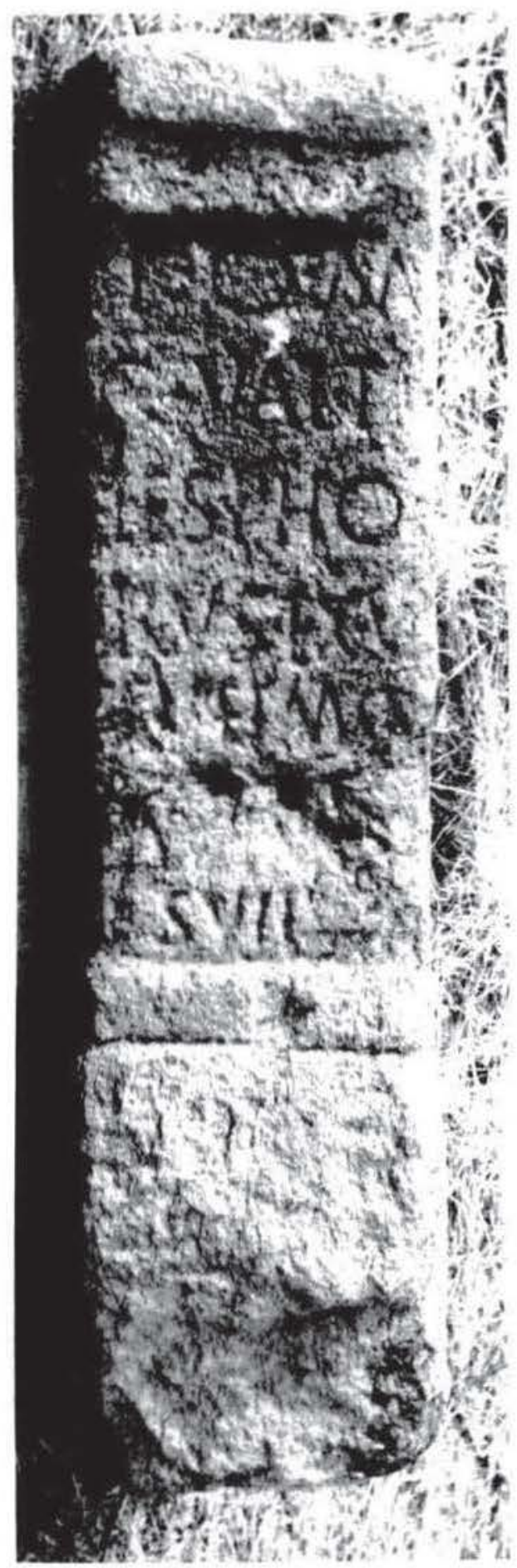

Figura 11. Inscripción num. 12

El cognomen Telesphorus ${ }^{4+}$ hasta la fecha solo habia sido atestiguado en Hispania sobre dos inscripciones de Barcelona y Tarragona ${ }^{45}$.

4 II. Solin. Die griechisehen Personennamen in Rom Ein Namentuch, Berlin 1982, p. 363.

1) CII. II 4567: CII II 4082 + RIT 37
Los testumomos de dedicaciones ox thise the abundan en Hispania. aunque no faltan ejemplos Ya fernande, fuster en 1950 habia catalogado ocho textos , a los que añadiria un nuevo testimonio lacense M. Varque/ Seijas en $1951^{\text {th }}$, y aun otro más A. Balil en 1953 al revisar los textos de Bracara Augasta cditados en Ephemeris Epigraphica $\mathrm{x}^{\text {th }}$ : de I ugo procede un ejemplo mas reciente "de una formulat que se tasa preferentemente en el noroeste penimsular

\section{1 ig. 12 y 47 , num. 13.} Incitia.

Cabecera y parte del cuerpo central de un ara de granito hallada en ef relleno del suelo moderno del extremo norte del crucero de Santa Lucia. Su parte posterior ha sido picada labrando un canal de seccion rectangular que recorre la pieza de arriba a abajo. sin duda para reemplearla como umbral o apoyo de eancel. La decoración de la cabecera la constituyen cuatro incisiones casi paralelas algo inclinadas hacia abajo por la derecha, que dibujan muy toscamente una serie de molduras. El grado de desgaste del soporte, especialmente en su cara izquierda se podria considerar una consecuencia del retallado. aunque la perdida por ese lado del campo epigrafico es insignificante.

I as dimensiones actuales del soporte son [60] * [31] $\times 26 \mathrm{~cm}$ : cl campo epigrafico mide $16 \times 23 \mathrm{~cm}$. las interlineas son de $4 \mathrm{~cm}$ y la altura de las letras es de $6 \mathrm{~cm}$. La incision es profunda y los tipos ofrecen la falta de uniformidad caracteristica en el conjunto: la 4 carece de tratesaño horizontal; el ligero re-

\footnotetext{
4. Oeasionalmente puede verse en low textos fa anomalia of

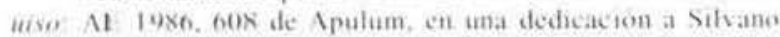
lanto en este cass come en otras expresiones como ex muntio (Al 1977 . $526 \mathrm{~b}$, de Miflothan. I seocia), se hace referencea dedieaciones que resuban de inferpretaciones de suenos o séccucion de premoniciones

1. Fermande/ l uxter, ol a formula ex vise en la epprafia

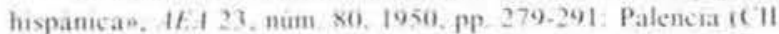
116338 V). Asterga (I con (II 115076.5602 ). Luga (CII II 2576). Orense (C'II II 2527). (haves fid. Vila Real AI 1933, 23 ). Ierena ( Alandroat. Ivera. (II II 140/5201). Moraleja del Peral (Caceres (II II 799) y Garlitos (Batajos Af 1913, 7), que inexplicablemente figura en esta relacion pues ef texto solo diee es uic...)

" M Vazque Senas, of in ara mas con fa formula 'ex visu's. en AE 24, 1951. pp 236 ss Al 1953, 18.1 Arias I Rous y A. Tranoy, Inscriptions rmmanes de la province de Luge. Pars 1979, p 41, num 1.5, con el resto de la hibliografia

44 I: 8,116 . Anadida a la lista de fernande, Fuster por A

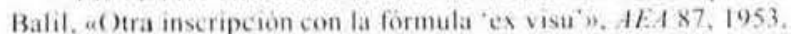
Pp. $|x|$ ss:

(1) 1 Arias Vilas et alit, Inscriptioms romaines de l.ugo, Paris 1979, num. 12
} 


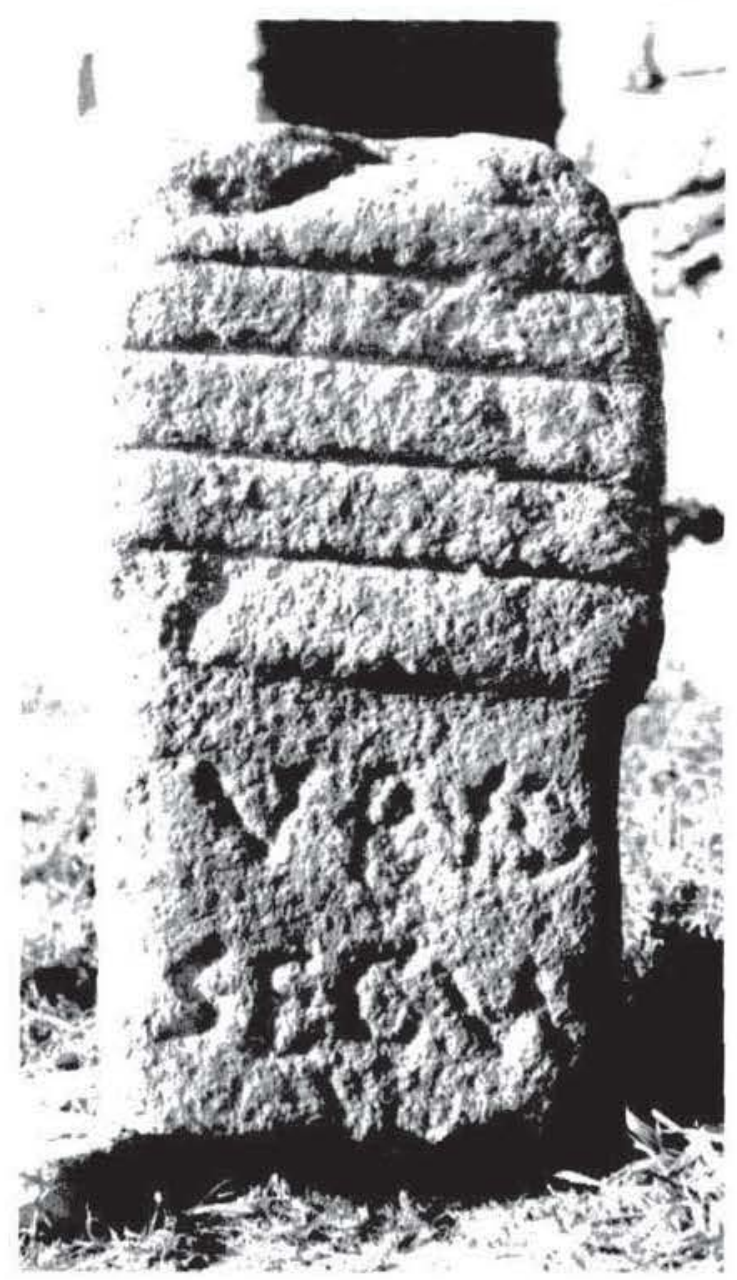

Figura 12. Inscripción num. 13

tallado por la parte derecha del soporte ha hecho desaparecer la $D$ que debia figurar al final de la segunda linea, posiblemente ligada a la $N$, pues la primera letra de 1.3 es claramente una $V$ correspondiente al nombre del dedicante; tras esta letra se conservan una seric de trazos que no pertenecen a ninguna letra sino que son golpes y arañazos del soporte. En la primera linea se observa una pequeña interpunción circular. Se conserva en el exterior de la iglesia de Santa Lucia. El texto dice:

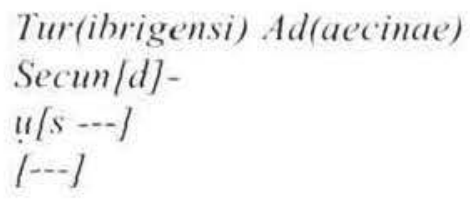

\section{I: Nexo AD.}

L. 2: Nexo VN.

Es éste el único epigrafe conservado en Santa Lucia que emplea tan lacónica dedicatoria abreviando de forma peculiar tanto el nombre de la divinidad como su epiteto (vid. infra apartado 5). El nombre del dedicante, Secundus, es muy frecuente en His-

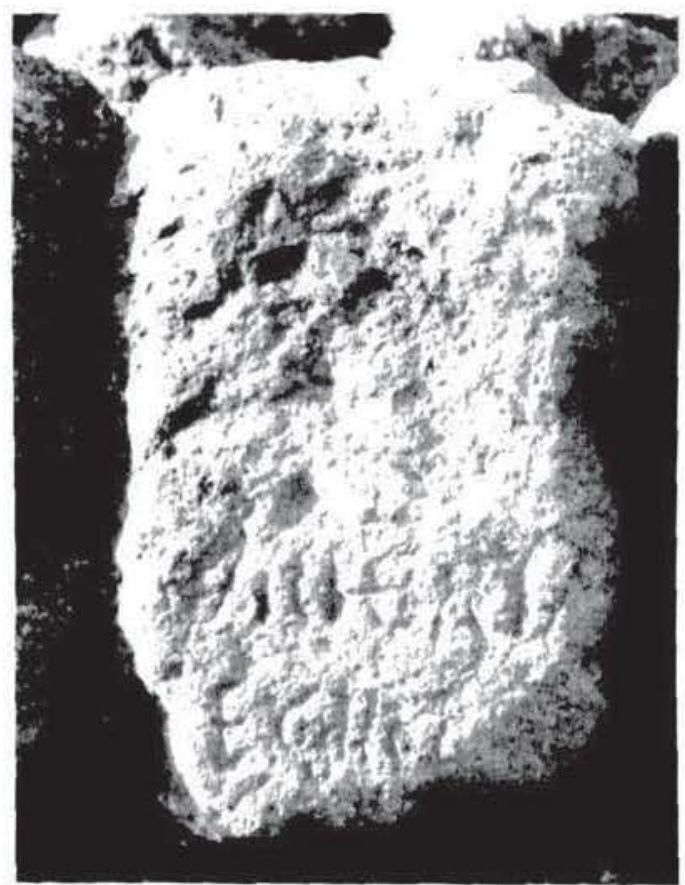

Figura 13. Inseripeion num. 14

pania y ocupa la décima posición en un rango numerico de hallazgos".

La forma del monumento recuerda vagamente el altar dedicado por $L$. Norb(amus) Setrerus (núm. 5), con el que coincide en las dimensiones horizontales del soporte, aunque en aquél el coronamiento es más simple y las molduras son más elaboradas, lejos de la simple insinuación visible en este caso.

14. Fig. 13 y 46 , núm. 14. Inedita.

Parte superior de un ara de granito, con el coronamiento retallado y muy erosionado, que apareció formando parte del escalón superior de la puerta central del portico sur de Santa Lucia. Aparentemente el monumento pertenece al grupo de arae de coronamiento no moldurado, pero el fuerte retallado que ha sufrido impide confirmar o desmentir esta sospecha. En su estado actual, el soporte mide $[48] \times 30,5 \times[24] \mathrm{cm}, y$ el campo epigráfico se reduce a un área de $28 \times 14 \mathrm{~cm}$; la altura de las letras oscila entre los 5 y los $6 \mathrm{~cm}$ y no hay restos de interpunciones.

El texto presenta dificultades de lectura debido al acusado deterioro de los rasgos, especialmente en la primera linea. Al final de ésta es bien visible un asta oblicua, sin duda perteneciente a una $A$, pero

\footnotetext{
51 Abascal. Nombres, pp. 499-501
} 
delante de ella se enctentra ya un traso renteal que parece pertenecer al epiteto de la divinidad La letra I. no llega a cerrarse en su parte central. hecho que es manifiestamente visible en los dos ejemplos de esta linear, delante del primero de ellos aparece un tra/o oblicue de una 1 y no hay restos de la letra que debia precederle. Al comien/o de la segunda linea hay un pequeno golpe en la superficie del ara que induce a suponetlo parte de una letra, pero no parece que sea ast. y la primera letra se puede dar por perdida, por lo que tendremos que suponer la presencia alli de una dental, aunque sin poder precisar si la grafia empleada es la de la sorda o la sonora.

El monumento se conserva en el lugar de su hallazgo y el texto dice:

\section{[T]urihri(gensi) A- $[t / d]$ ecin/ate -]$$
|\cdots|
$$

Al no existir una linea superior, la förmula empleada para la dedieacion es similar a la del texto num. 12, aunque sin la exagerada abreviatura de aquél.

La peeuliaridad de este texto viene dada por la presencia de una $B$ retrograda en la linea inicial. y que solo se puede entender en el marco de una officina lapidaria rural poco experimentada. No es, sin embargo, la única presencia de tipos retrógrados en el conjunto de Alcuéscar (cfr. num. 23), ni tampoco es la primera ver que esto ocurre en la epigrafia cacereña si se acepta la presencia de una $D$ retrograda en un texto de Alcantara"?

\section{Fig. 14}

Inedita.

Parte superior de un árula de granito sin diferenciación de cabecera que procede del molino situado al suroeste de Santa Lucia ( Molineta del Trampal»); en la cima de la cabecera presenta una perforación rectangular de $6,5 \times 4 \mathrm{~cm}$ en la posición del foculus. Sus dimensiones actuales son $[24] \times 20 \times 17 \mathrm{~cm}$ y conserva tres lineas de texto con restos de una cuarta. La altura de ésta es de 3,5, 4 y $4 \mathrm{~cm}$ respectivamente, con $1 \mathrm{~cm}$ de interlinea. EI campo epigráfico mide $[17] \times[14] \mathrm{cm}$.

La primera letra en el ángulo superior izquierdo es una $S$ muy estilizada con un trazo vertical, y pa-

1" AE 1977. 478. Aunque no es frecuente, se pueden aducir algunos casos claros de letras grabadas en posición invertida sobre algunos monumentos; un caso evidente es el de E:E 8,125 a-b, de Casa do Avelar, en Bracara Augusta, en el que una 'D' aparece escrita del reves con absoluta claridad: $c f r$. AE 1983. 570. con la autopsia de Santos, Tranoy y le Roux. recen segurle dos $D$ a juzgar por la rectitud de sus trazos 1/quierdos, el monumento ha perdido por la derecha el espacio equis alente a una letra en la pri. mera linea. a jusgar por la posicion de la perforacion rectangular de su cima. lo que invita a imaginar que nos encontramos ante una nueva sariante de las invocaciones a flaceina ya que, por lo conservado en las lineas 2 y 3 . esta letra solo puede ser unat 7 A final de la tereera linea aparece un traso iertical undo a otro oblicuo. que no encajan con la lectura de la dedicacion. por lo que seguramente estamos ante el comien/o del nombre del dedicante. bien un praenomen como Harews, o bien uno de los muchos nombres personales con este comien/o: en la resolucion del problema no ayudan los trazos de la cuarta linea: el primero es un asta vertical con un travesaño, probablemente una $T$, y el segundo un trazo oblicuo facilmente perteneciente a una $l$. Intre los fragmentos conservados en Santa L ucia y sus alrededores no hay ninguno que pudiera corresponder a la parte inferior de este monumento, ya que de la Molineta del Trampal solo proceden otras dos piczas, el ara dedicada por licinius Rusticus (num. 21) y otra ara anepigrafa (num. 33 ).

Se conserva en el Museo Arqueológico Provincial de Caceres. El texto dice:

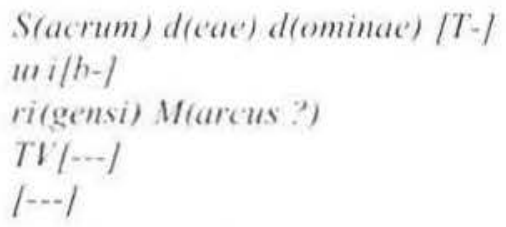

Caballero y Roseo: IOR(?)/VRI(?)/RII(?)/(.)A(?)

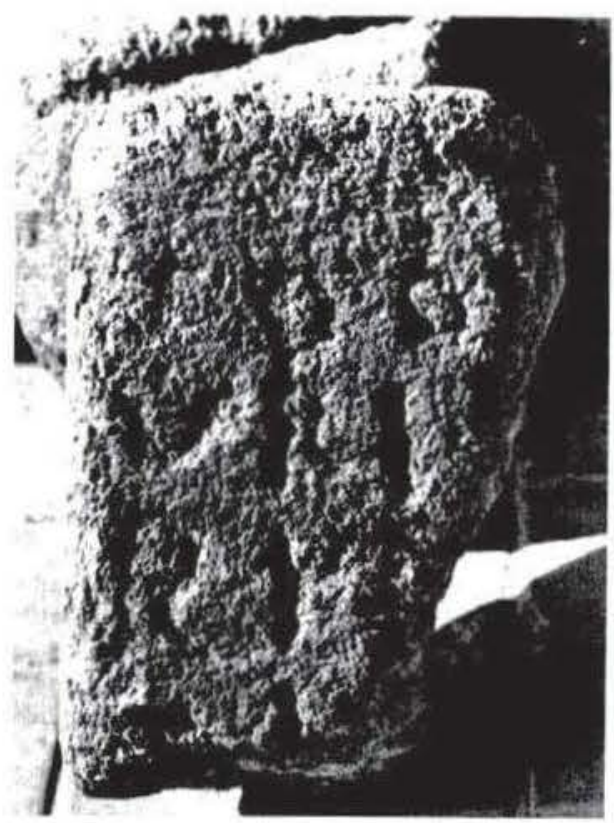

Figura 14.- Inscripciỏn nủm. 15 
La particularidad de este breve texto estriba en la presencia delante de los epitetos de la divinidad. no identificada por su nombre. de la expresión sacrum. Curiosamente, el altar también es diferente al resto de los ejemplares de El Trampal, pues carece de diferenciación de cabecera que, aunque sencilla y sin decoracion. es corriente en el resto de los ejemplares. Sin embargo, presenta en su parte superior la caracteristica perforacion rectangular en el lugar del foculus lo que, unido a su condición de monumento dedicado a Ataecina, permite encardinar la piča en el grupo de Santa Lucia. La laconica mencion del dedicante impide cualquier tipo de consideración onomástica.

16. Fig. 15.

Incidita.

Ara de granito, aparentemente completa, cuya cabecera se encuentra empotrada en la cara exterior del muro oriental del tramo norte del crucero en el templo de Santa Lucia. Formalmente guarda mucha relación con otros monumentos del enclave, aunque ignoramos si poseia foculus o perforaciones rectangulares en su parte superior. El pie carece de molduras y es un paralelepipedo bastante rozado en sus aristas. La cara frontal ha sufrido un tremendo deterioro excepto en la parte más cercana al muro. en donde éste ha preservado el texto de las dos primeras lineas. Los rasgos paleográficos parecen más cuidados que en otros epigrafes del lugar aunque no nos atrevemos a ver en ello ningún indicador cronológico. Sus dimensiones son $[75] \times 38 \times(-) \mathrm{cm}, \mathrm{y}$ la altura de las letras conservadas es de $8 \mathrm{~cm}$. El texto dice:

\section{Laribus uial[ibus] $[--]$}

Las dedicaciones a los Lares Viales son especialmente abundantes en el noroeste peninsular, en donde sobran los ejemplos. A los textos conocidos hay que añadir en los últimos años dos aparecidos en el Principado de Asturias, procedentes de Lugo de la Llanera ${ }^{53}$ y Tuna (conc. Tineo) ${ }^{54}$ y otros dos coruñeses hallados en Castrofeito (El Pino, Coru-

" C. Fernández Ochoa et alii, Asentamiento romano y necró. polis medieval en Lugo de la Llanera, Llanera 1991. pp. 43-44 $=$ HEp 4, 67 .

4 HEp 1.78
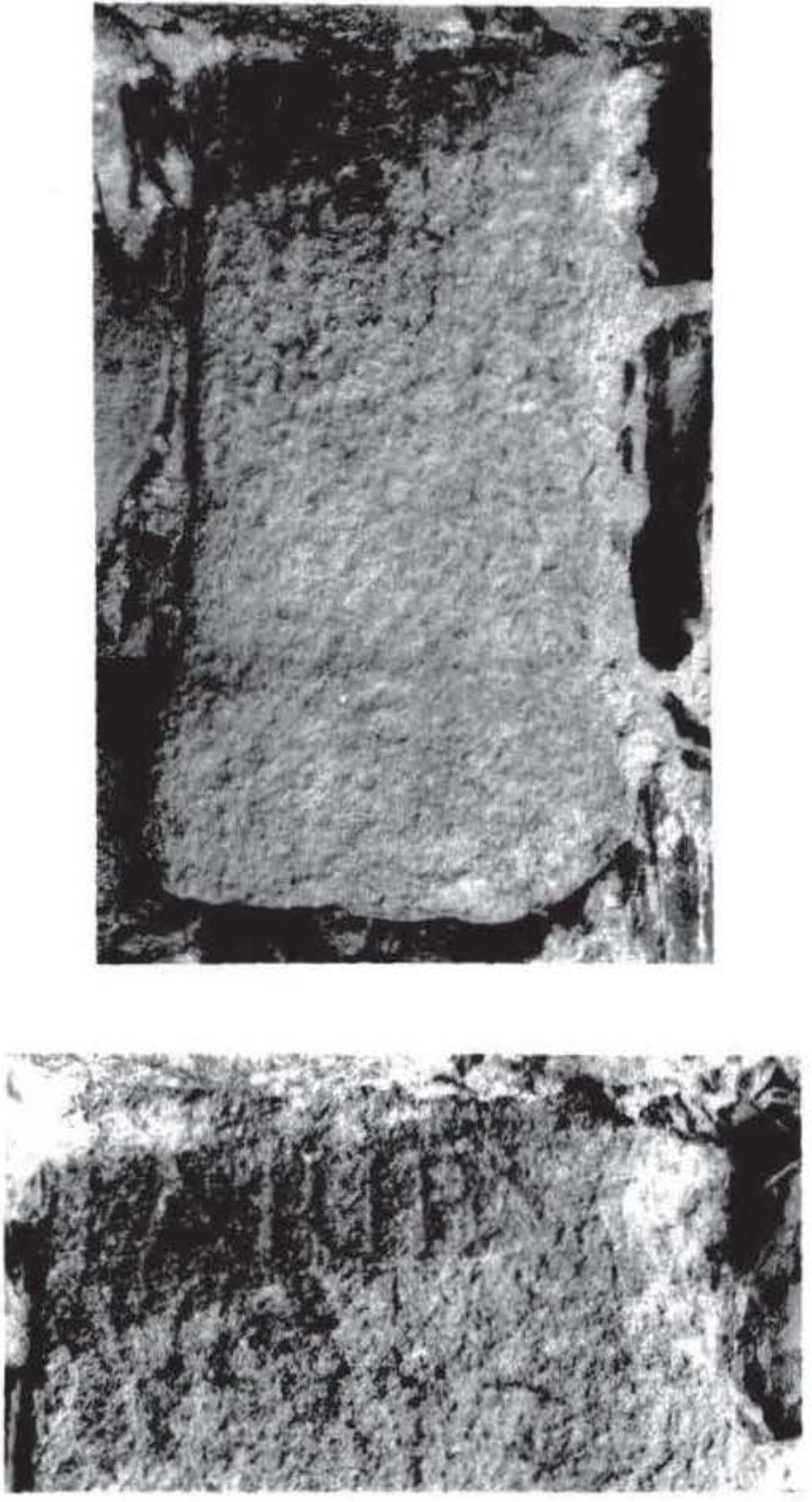

Figura 15.-Inscripción núm. 16 y detalle del área escrita

ña) ${ }^{55}$. El hallazgo más meridional podria ser el de Monforte (dist. Protalegre), en la zona de Elvas ${ }^{56}, y$ el más oriental una dedicación ex somnio hallada al norte de la provincia de Alicante hace pocos años. en territorium de Dianium ${ }^{57}$. A corta distancia de

"G. Pereira, Corpus de inscripcions romanas de Galicia I. Provincia de A Coruña. Santiago 1991, núm. 57 y $58(=$ HLp 4. 341-342).

4 J. D'Encarnaçao, «Inscriçoes romanas do conventus Pacensis. Aditamentos, Trabalhos de Arqueologia do Sul I. 1986. pp. 105. 106 (- HEp 3, 487).

5) Corell, (L'epigrafia romana al Pais Valencià (1982-1986)», en M. Mayer e 1. Rodá, "Epigrafia», Fonaments 7, 1988, pp. $197 \mathrm{ss} .$, sobre informes de prensa $(=\mathrm{AE} 1987,701$ b y HEp 2, 216): J. M. Abascal y J. A. Gisbert, "Epigrafia romana de la villa de La Almadrava (Setla-Mirarosa-Miraflor). Apéndice: Nuevas aportaciones a la epigrafia de Dianium», en $I I I$ Congres d'Estudis Comarcals, Institut a'Estudis Comarcals Marina Alta. Denia. 


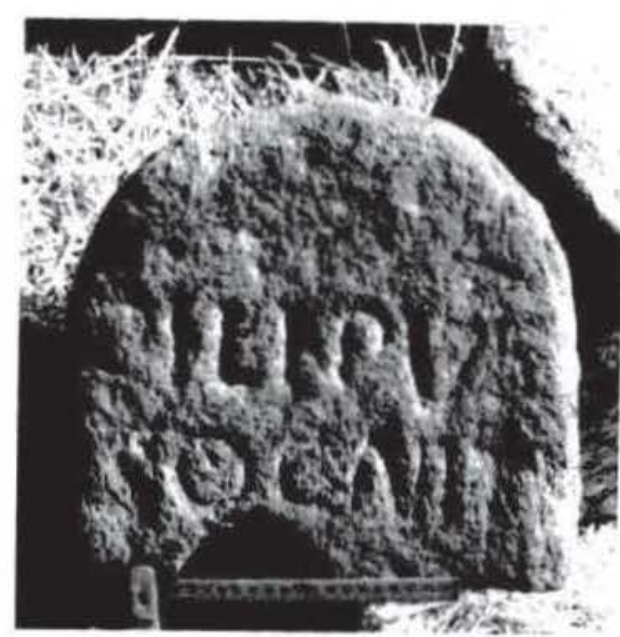

Figura 16. Inscripcion num. 17.

Alcuéscar se conoce otra dedicación a los Lares Viales en Valdefuentes (Cäceres) ${ }^{2 *}$.

17. Fig. 16 y 50 , num. 17 . Inédita.

Parte superior de una estela de cabecera semicircular en granito, sin ningún tipo de decoración, haIlada en la cerca norte de la "Charca de Santiagom. EI soporte esta tallado en su parte posterior $y$, bajo la segunda linea del texto, presenta restos de una perforación circular que bien puede ser la evidencia del uso de la pieza como umbral. Conserva únicamente dos lineas de texto de factura regular y algunos Irazos informes de una tercera. Hay que destacar la presencia de una $P$ sin cerrar en 1 . I y el carácter casi circular de la $O$ en 1.2 . El soporte mide en su estado actual [31] $\times 32 \times 22 \mathrm{~cm}$; las dimensiones del campo epigráfico conservado son $18,5 \times 27 \mathrm{~cm}$; la altura de las letras es de $5 \mathrm{~cm}$ en 1.1 y de $4 \mathrm{~cm}$ en 1.2; las interlineas miden 2 y $3,5 \mathrm{~cm}$, respectivamente. Se conserva en el exterior del templo de Santa Lucia. El texto dice:

\section{Pilipus \\ cognit \\ $[-1$}

noviembre 1990. Alicante 1992, pp. 69 ss, num. I.1; L. Abad y J. M. Abascal, Textos para la historia de Alicante. Historia Antigua. Alicante 1992, p. 156, núm. 114.

in Caballero y Rosco, Extremadura Arqueológica I, 1988. p. 240, con las adiciones y correcciones de HEp 2, 223, que descarta su relación con Ataecina.
El nombre de origen griego Philippus "solo aparece en otras cinco ocasiones en llispania ${ }^{\text {. }}$, sin que los hallazgos sugieran una distribucion especial que no sea la relación con grandes centros urbanos en donde abundan los contingentes de libertos y esclavos ${ }^{61}$.

La segunda linea plantea serios problemas de interpretacion. Cognir/..-/ puede ser tante el elemento inicial de una forma de cognoseo. fäcilmente un participio y de cuyo uso epigrafico existen evidencias incluso en textos funerarios ", como parte de un sustantivo cognitio o cognitor, que introduce un sin fin de posibilidades de desarrollo"n.

\section{Fig. 17.}

L. Caballero y J. Rosco: Extremadura Arqueologica 1. 1988, pảg. 248, núm. A.36- HIp 2, 201.

Ara de granito con dos pequenas acróteras frontales en su parte superior y foculus, completamente diferente a todos los monumentos votivos de Santa Lucia del Trampal. Procede de la Ilamada "Charea de Santiagom, a escasa distancia del templo. En la parte inferior presenta dos suaves y delgadas molduras para diferenciar el fuste del plinto. Sus dimensiones actuales son $50 \times 21 \times 21 \mathrm{~cm}$.

La superficie escrita se encuentra bastante erosionada y sobre ella aparecen una serie de letras de dificil identificación que hacen pensar en un reaprovechamiento del soporte para inscribir encima un segundo texto. En efecto, frente a letras de pequeño tamaño y buena factura como las que aun quedan en los extremos superior e inferior, otros trazos son descuidados, sin guardar la horizontalidad y claramente diferentes. Así en el ángulo superior izquierdo queda una $L$ muy clara, similar a la que aparece al inicio de la última linea: otro tanto se puede decir de la $S$ del ángulo superior izquierdo. En contrapartida, en la parte central del epigrafe aparecen letras como $V, R$ o $S$ que nada tienen que ver con esta grafia.

\footnotetext{
"H. Solin, op. cit. en n. 44, p. 223.

in Abascal, Nombres, p. 456.

* Los testimonios proceden de Cádiz: CII. II 1876; Caldes de Montbuy (Bareelona): CIL. II 4492; Mérida (Badajoz): CIL II 497: Tarragona: G. Alföldy, Die römischen Inschriften von Ta. rraco, Berlin 1975, nùm. 378; Sagunto (Valencia): F. Beltrain, Epigrafia latina de Saguntum y su territorium, Valencia 1980. núm. 103.

62 CLE 64 (Roma, funerario): qui bene cognorunt. cognifam bene existumant; CLE 1327 (Africa proc, funerario): cognitum est locus amoenissimus...: CLE 1518 (Roma, funerario):...cognita si tibi fuisset.

4) ThLL., col. 1483 ss.
} 


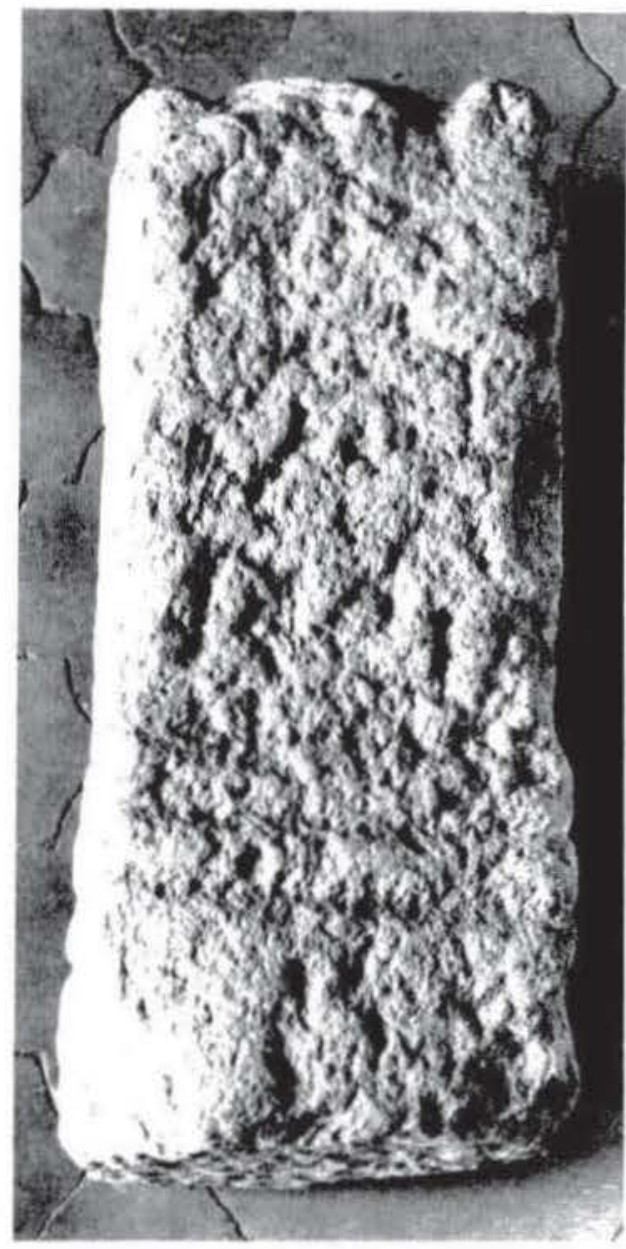

Figura 17. Inscripcion maม. I8.

incxactia, transcribimos a continuacion los elementos visibles, sin que sean en absoluto una propuesta: renunciamos a interpretar estos signos y remitimos al lector a la fotografia de la fig. 17.

Texto 1. Letras de pequeño tamaño $(4-5 \mathrm{~cm}$ de altura). regulares y dispuestas en lineas horizontales:

$$
\begin{aligned}
& \mathrm{L}+[-] \mathrm{L} \\
& \text { [- }[-] \mathrm{T}[\mathrm{]} \\
& {[\cdots]}
\end{aligned}
$$

Texto 2. Letras de mayor tamano, irregulares en altura $(5-7 \mathrm{~cm})$, en lineas oblicuas y profundamente grabadas:

$$
\begin{aligned}
& \text { MA } \\
& \text { RS(?)IA }
\end{aligned}
$$

El distanciamiento formal de los epigrafes de flweina sugiere que en el texto 1, el de mayor antigüedad, estamos ante un epigrafe consagrado a otra divinidad, sin que podamos valorar el contenido de la segunda inseripcion.

\section{Fig. Ix.}

I. Caballeroy J. Rosco: Extremadura Arqueologica I. 1988 , pag. 246 , num. A.2 HE. 2.193

Parte inferior de un ara en granito, que conserva ain parte del cuerpo central con el texto. un pie de mayor anchura muy crosionado y una moldura de media caña que los separar. Procede del pozo de la finca al sureste de Santa Lucia. Sus dimensiones actuales son $[37] \times 25 \cdot 19 \mathrm{~cm}$. de los que el área eserita solo ocupa un area de 17 × $16 \mathrm{~cm}$. Son visibles aun tres lineas de texto en desigual estado de conservacion. y solo es posible establecer la altura de las letras en las dos ultimas, que miden $3 \mathrm{~cm}$ con una interlinea similar. Las proporciones de las letras son muy uniformes y conserva una interpuncion circular en la tercera linea. Se conserva en el Musco Arqueológico Provincial de Cáceres, en donde tuvimos oportunidad de efectuar el correspondiente calco. EI texto dice:

\section{$|-\cdots|$ \\ taui \\ frilius) un(tum) \\ s(oluit) l(ithe'ns) a(nimo)}

En la primera publicación del monumento se

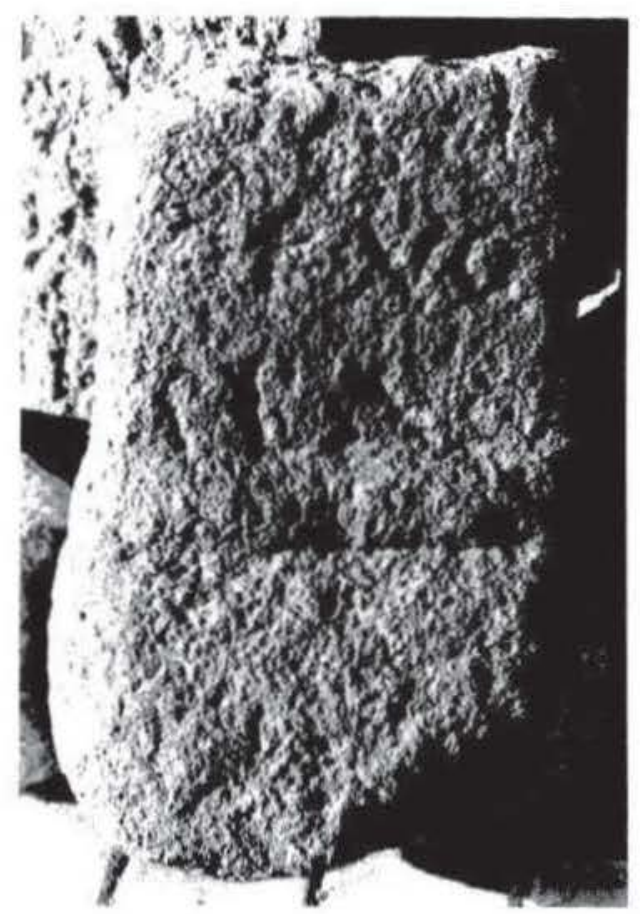

Figura 18. Inscripcion num. 19. 
supuse que lo consersado correspondia at la parte supertor del soporte y no a la inferior. de ahi la lectura propuesta en su dia ${ }^{\text {ia }}$. Hoy no hay duda de que estamos ante parte de un ara dedicada a una dis intdad que bien pudo ser flacema a ju/gar por el luga del hallargo, atunque tal extremo no se pueda establecer

20. fig. 48. nim. 20.

Inediti

Parle inferior de un ara de granito del mismo estalo que la precedente. que se conserva aun empotrada en la segunda hilada del muro sur de la esquina interior del espacio interabsidal norte en el templo de Santa Lucia. Conserva parte del pie y de la moldura que separaba éste del cucrpo central, aunque parece que tambien en el extremo inferior se ha producido una rotura para adaptarla al muro en que ibat a ser empotrada. Sus dimensiones frontales son $[22.5] \cdot 27.5 \cdot(2) \mathrm{cm}$. Del tevo solo subsiste la linea inferior, cuyas dimensioncs son $4.23 \mathrm{~cm}$. y restos de dos letras no identificables de la penulrima. Fi texto dice

$$
\begin{aligned}
& \text { |-.. | + } \\
& \text { soluit (vie) }
\end{aligned}
$$

Por el contenido de la linea de texto conservada no hay duda de la pertenencia del fragmente a un texto votivo, bien dedicado a Alaecina, bien a cuatquier otra divinidad.

\section{Fig. 19 y 47 , nùm. 21.}

1. Caballero y J. Rosco: Extremadura Arqueologica I. 1988, pág. 246, núm. A.I HEp 2, 192.

Ara de granito que ha perdido el pie y casi todo el coronamiento, pero que conserva intacta el area escrita. Se encontro empotrada en el muro sur del molino situado al suroeste de Santa Lucia ( Molineta del Trampals). En la parte superior presenta tres molduras planas, apenas dibujadas por sencillas incisiones paralelas, que recuerdan formalmente la cabecera del monumento dedicado por L. Norbanus Sewerus (num. 5 de este catálogo): por desgracia, tampoco a partir de aquél podemos reconstruir el pie perdido. Sus dimensiones actuales son $[41] \times 18 \times 15,5 \mathrm{~cm}$; el campo epigráfico mide $19 \times 15 \mathrm{~cm}$ y la altura de las letras es de $4,5-5 \mathrm{~cm}$ en

- L. Caballero y 3. Rosco, Extremadura Arqueolsgica 1, 1988. p. 246. num. 2: IOVIS/OA(.)O/I(...)

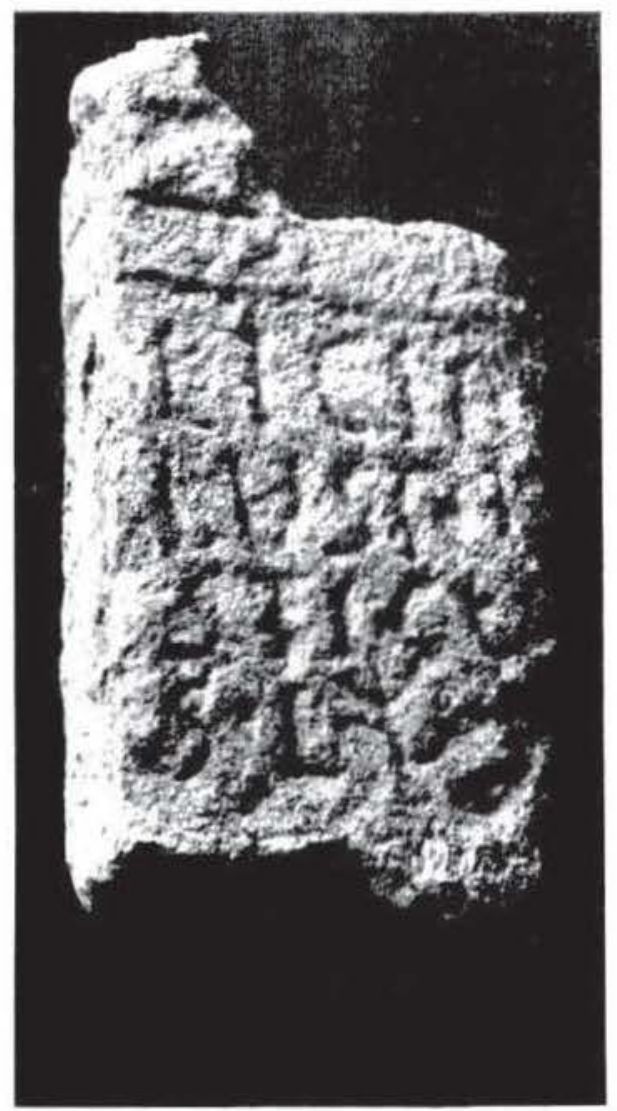

Figura 19 Inscripcion num. 21

las dos primeras lineas y de $4-4,5 \mathrm{~cm}$ en las dos últimas. Presenta interpunciones circulares en las lineas segunda y cuarta, aun muy nitidas. Se conserva en el Museo Arqueologico Provincial de Caceres. El texto dice.

$$
\begin{aligned}
& \text { licin- } \\
& \text { ius Ru- } \\
& \text { sticu- } \\
& \text { s (tibens) u(otum) s(oluit) }
\end{aligned}
$$

El texto conservado omite el nombre de la divinidad. Aunque se podria pensar que este, como ocurre en otros monumentos de Alcuéscar, figurara sobre el coronamiento, parece poco probable por no decir imposible, ya que sobre las molduras no queda ningún tipo de rasgo que pudiera inducir esta idea. En el conjunto de Santa Lucia, la cabecera del monumento se convierte en área de escritura sólo en ausencia de decoracion, tal y como puede verse en los textos nums. 2, 4 y 11.

La ausencia del teónimo en algunos textos hispanos, a cuyo grupo perteneceria éste, ya fue objeto de un brillante trabajo hace pocos aǹos ${ }^{65} \mathrm{e}$ invita a 
imaginar que el ara en cuestion fuc colocada en un espacio sobradamente identificado con una divinidad. esto es, un santuario: ello refuerza la hipotesis de que éste y los otros monumentos votivos provengan de un área de culto dedicada a flaceima. a quen tambien habria ofrecido su voto Licinius Rusticus.

El dedicante presenta una onomástica corriente. sin rasgos peculiares: Licinia-us es el sexto gentilicio más frecuente en Hispania. con más de 300 testimonios y un reparto desigual que no prima el área extremeña : los cognomina Rustica-us ocupan el puesto num. 16 de la frecuencia de cognomina en Hispania y tampoco tienen rasgos geograficos peculiares".

\section{Fig. 20 .}

L. Caballero y J. Rosco: Extremadura Arqueologica 1. 1988, pág. 246. núm. A. $4=$ HEp 2.195.

Estela de granito partida en dos fragmentos que apareció empotrada en los muros de la la casa adosada en la segunda mitad del siglo xix en el lado norte de Santa Lucia. La parte conservada parece indicar que estamos ante un monumento de cabecera semicircular, actualmente partida, bajo la cual un par de lineas muy toscas dibujan un fronton triangular que corona el texto. Bajo este fronton aparece un pequeño circulo decorativo que, en determinadas condiciones de luz, puede ser confundido con una $C$.

Ignoramos la altura original del soporte. que se ha perdido por debajo de la cuarta linea del texto: sus dimensiones actuales son [43] $\times 46 \times 27 \mathrm{~cm}$; el area escrita ocupa una superficie de $35 \times 36 \mathrm{~cm}$. y la altura de las letras oscila entre los 5.5 y $\operatorname{los} 6 \mathrm{~cm} \mathrm{cn}$ todas las lineas conservadas, salvo la $B$ de la primera, que monta sobre el margen y que llega a los 7 $\mathrm{cm}$ : la interlinea, muy irregular, oscila entre 1 y 2 $\mathrm{cm}$; sólo se observa una interpunción circular en la última linea. Aparentemente, el texto se conserva integro por los márgenes laterales, exceptuando claro está la rotura central que no plantea excesivos problemas de lectura. En la tercera linea la autopsia y

J. D' Encarnaçao, "Omassao dos teónmos em inseriçoes vo. livasm, en Studia Palacohispanica. Actas del II Coloquie solore tenguas y culturas paleohispanicas. Titoria 1985. Veleta 2-3. $1985-86$ [1987]. pp. 305-310. a proposito de una inseripción de Cascais idist Lisboa) $(1 / 2.24=$ At $1983,470 / 1984.476+J$. Alvar. aUn posible testimonio de culto a Cibeles en Cascais (Portugal)m, AE.A 56. 1983, p. 123-130-111.p 2.810).

in Solin \& Salomics, Repertorium, pág. 104: Abascal. Nom bres. p. $168 \mathrm{ss}$

6) Solin \& Salomies, Repertorium, p. 394: Abascal, Nombres, p. 490 ss.
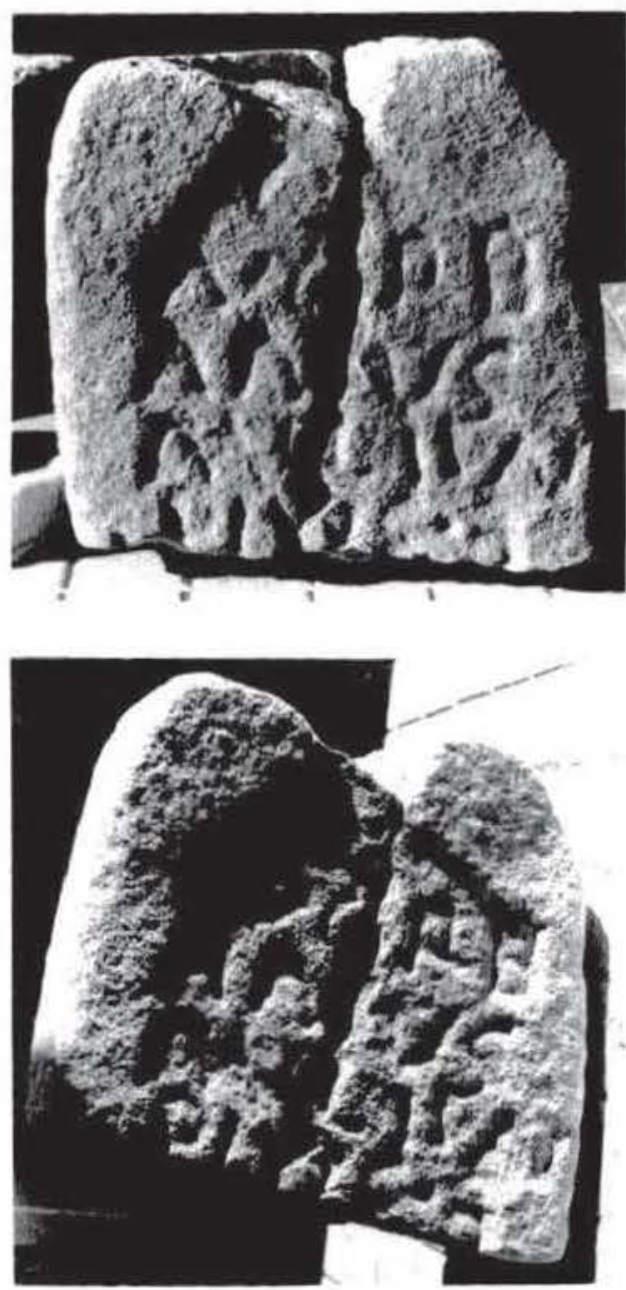

Figura 20. Inscripcion num. 22 con distintas oricntaciones de la lus.

calco del texto prueba la presencia de una $M$ inicial seguida de un trazo vertical antes de la rotura: tras ésta no hay dificultad en ver la $L$, con un ángulo muy marcado y profundo, seguida de dos tra sos oblicuos y de una $N$ que monta sobre el margen. En la cuarta linea se conserva integra la parte superior de la $P$. lo que aclara la lectura de la letra rota del centro, no existiendo dificultad para identificar las dos $S$ finales. No es posible determinar si s(uis) figuraba abreviado o continuaba en la linea siguiente.

Se conserva en el Museo Arqueológico Provincial de Cáceres. El texto dice:

\footnotetext{
Norb-

anus

Milen(us)

pius s-(-uis?)

5 [uis?'---]
} 


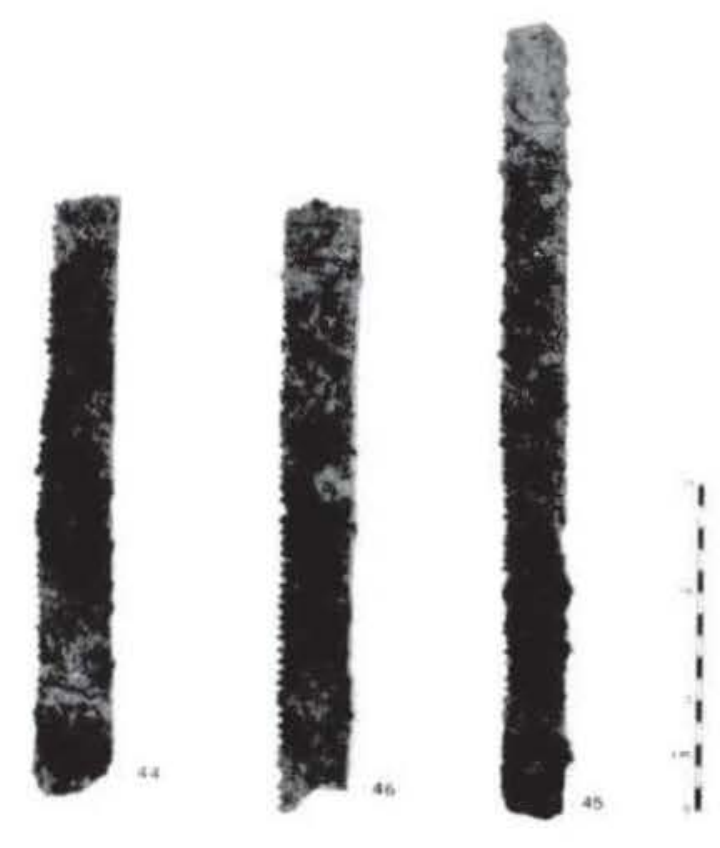

A

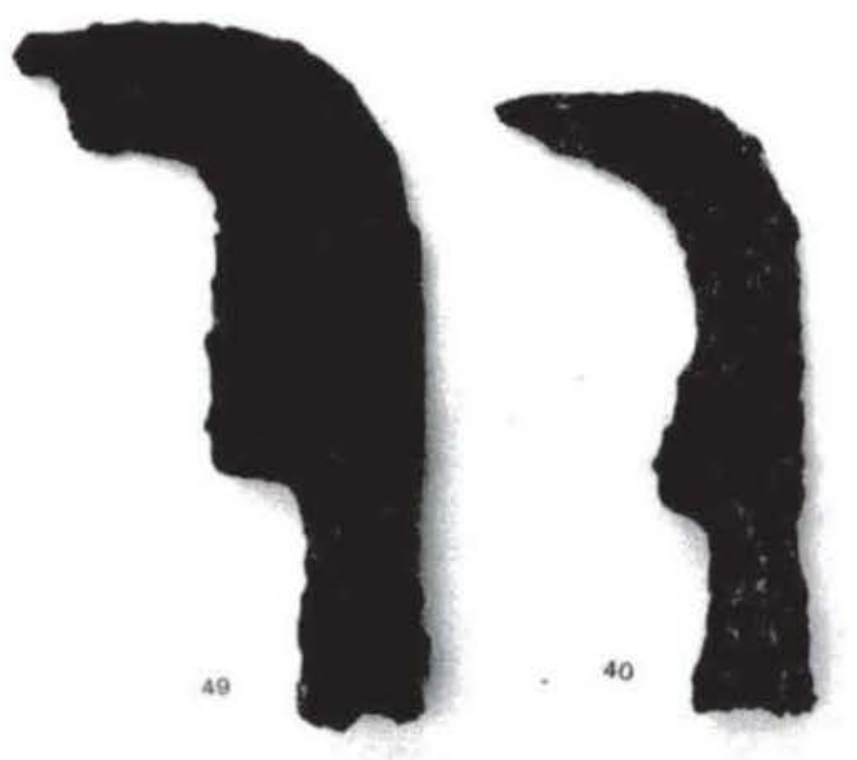

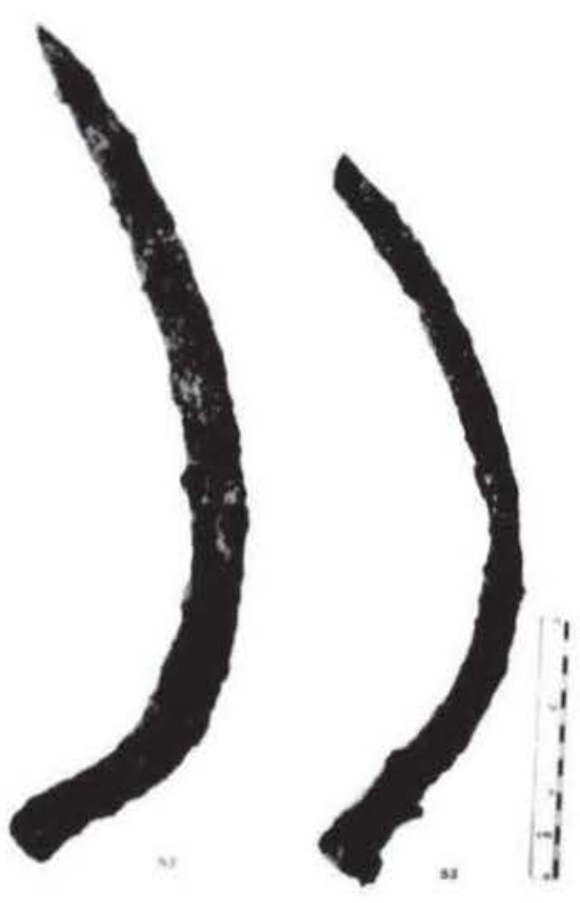

B

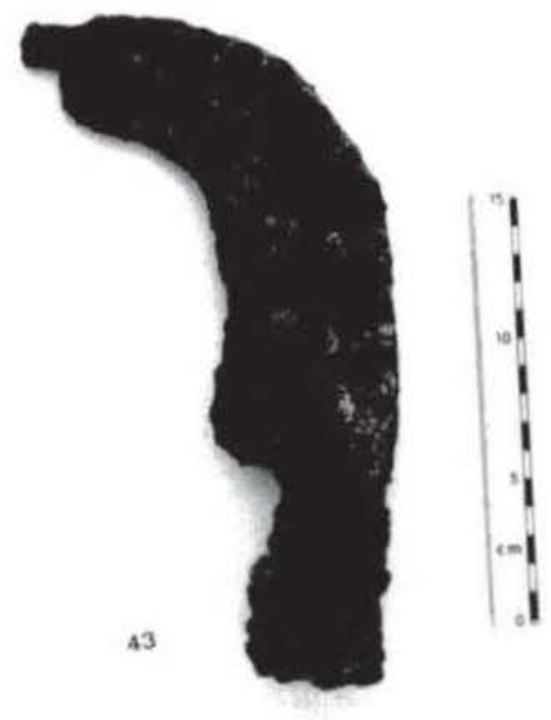

C

Figura 13. Materiales del depósito votivo del silo I01: A, sierras; B, hoces; $C$, podones. 
men Sillo en su forma actual no es conocido hasta el presente en Hispania, aunque parece efecto de la geminación de la $L$ en el más popular Silo" . muy repartido en términos gencrales, pero del que un buen numero de testimonios proceden de ambitos regionales no demasiado alejados de Alcuéscar: asi ocure con los hallazgos de Coria ${ }^{\text {h }}$ o Villar de Plasencia ambos en territorio cacereño, y con los del cercano distrito portugués de Castelo Branco. que agrupa ocho testimonios: en general. el cognomen ahunda más en la mitad occidental de la Peninsula Iberica, sin que su reparto permita extraer otro genero de conclusiones.

Una de las peculiaridades del texto es la förmula funcraria con omision del verbo tras el participio. Sin embargo, se trata de una anomalia ampliamente extendida por el ámbito regional del mediodia cacereño, a la que podrian servir de ejemplos algunas inscripciones de Campolugar. Herguijuela. Ibahernando, Salvaticra de Santiago, Trujillo. etc. "7. La estructura onomástica, el uso del nominativo y la formula final sugieren datar el texto a fines del siglo 1 o comienzos del $\| \mathrm{d}$. C.

\section{Fig, 22.}

Incidita.

Altar? funcrario rematado en su parte superior por dos molduras simples a modo de coronamiento. Se encuentra empotrado a ras del nivel de rotura del murete adosado a la cara exterior del muro occidental del crucero, al norte de la puerta del templo de Santa Lucia. Aunque no se puede confirmar con rotundidad la tipologia, la sencilla ornamentacion superior parece descartar la condición de estela del monumento. Sus dimensiones actuales son $[75] \times[29] \times[-] \mathrm{cm}$ y conserva diez lineas cuya altura es de $5 \mathrm{~cm}$.

Aparentemente no falta texto por los márgenes laterales, aunque el campo epigráfico ocupa toda la superficie visible y algunas letras quedan semiocultas por el propio muro. En la primera linea la letra

\footnotetext{
Albertos. Tarraconense. p. 207, cad, "Nuevos antroponimos hispánicos (continuacion)m, Emeritat 33.1. 1965. 109-143. Solin \& Salomics, Repertorinm, p. 403; Abascal. Nombres, pp $5 \mid 1-512$.

thile: CII II 773 y CII. II 792; Silo Mami of: AE 1967, 219 a. p. 196

S/illo: CII II $822+$ F.W. Haley, op cit en n. 9. 1986

* Campolugar: Al: 1967,210: Herguijuela: CPILCaceres 755. 757 y 760 : Ibahermando: FE 9.102 a. 105 a. 106. 108: Salvatiera de Santiago: HEp 1, 184. Trujillo: CIL. II 628 .
}

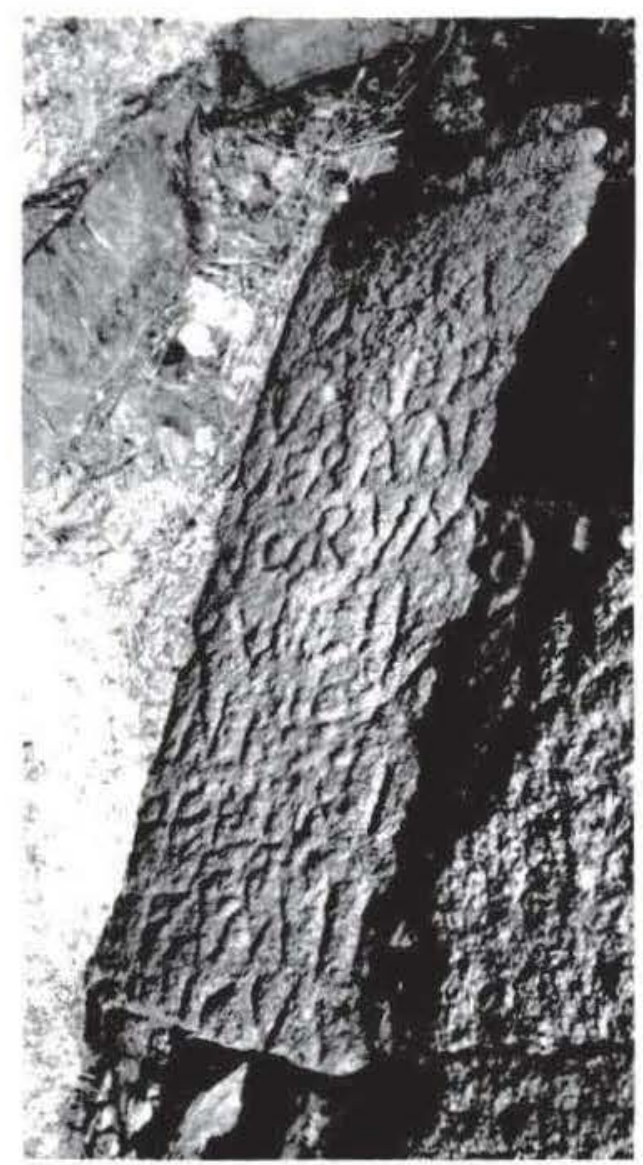

Figura 22. Inseripción num. 24.

antepuesta a la $E$ es una $L$, como demuestra el trazo oblicuo inferior, aunque una erosión superficial pueda hacer pensar en alternativas como $D$ o $Q$. El corte entre las lineas 3 y 4 parece indicar que al menos por la derecha la inscripción no ha sufrido mutilaciones. Tanto en la segunda como en la sexta y séptima lineas la superficic escrita presenta algunos deterioros que afectan a la inscripción y no es descartable la presencia de una décima linea. En la sexta linea se pueden reconocer bien las letras centrales, incluida la $O$ de pequeño tamaño, pero al comienzo se observa un trazo aparentemente vertical que no podemos identificar con seguridad; al final de la línea la rotura impide precisar la letra perdida. En la séptima linea la primera letra parece una $P$. seguida de $F E$ y del grupo - BRI - claramente legible. En la octava la primera letra es una $E$ con toda seguridad. Con estas dudas, renunciamos a una interpretación equivoca de esta zona de la inscripción. Se observa una pequeña interpunción circular en la tercera linea. 
El texto dice:

D(is) M(anibus)
Valer(---)
uer(nae) an-
norum
5 XVIIII

+ NNO $[-]$
PFBRI--

Efamil-

[i]aricus
I0 $[--]$

El nombre del difunto (o difunta) ofrece diversas posibilidades de desarrollo como Valer(io/-ia) o Valer(iano/-iana), siempre dentro de la extrañeza de que esta familia nominal sea empleada para denominar a un individuo de condición servil. En las lineas 6-8 podria figurar un elogio del difunto/a, aunque no es descartable que estemos únicamente ante el nombre de quien dedica la inscripción en su condición de familiaricus.

Familiaricus es un sustantivo con una característica desinencia de influjo griego ${ }^{79}$ que parece ocasional en la literatura antigua ${ }^{\mathrm{x}}$; es más frecuente el adjetivo de la misma forma para el masculino ${ }^{\mathrm{x} 1}$, aunque en todos los casos deriva de un adjetivo, familiaris, que con frecuencia remite el signifi-

${ }^{74}$ M. Leumann, Lateinische Latı- und Formenlehre, München 1977, p. 338, que aduce como ejemplos dominicus, colonicus o familiaricus.

Eio Edict. imp. Diocl. 26, 10 y 26, 31, a propósito de un tejido para vestimentas.

xt ThLL 6, 1, fasc. 2, Leipzig 1974, col. 246; Diff. gramm. (Ed. Keil, Gramm. Lat., vol. VII), pp. 529 ss.: qui ad familiam. i. seruos pertinet; Ulpiano, Dig. 34, 2, 23, 2: familiarica sunt. quae ad familiam vestiendam parata sunt. Nuestra gratitud a la Dra. M." Paz López y al Dr. Juan J. Chao (Univ. Alicante) por sus indicaciones al respecto. La única prueba del uso epigráfico del adjetivo es CIL III 7807, en donde Mommsen entiende que debe interpretarse (sepulcrum) familiaricum.

*2 El sustantivo familia se emplea habitualmente para referirse al conjunto de esclavos y libertos de una gens o de un personaje. Asi aparece en algunos epigrafes colectivos de panteones destinados a albergar los restos del conjunto de sirvientes de un grupo. A nivel ciudadano, familia publica es el conjunto de siervos y libertos publicos que atienden una comunidad, de lo que no faltan evidencias en la epigrafia; $c f r$. G. Fabre, "Les affranchis et la vie municipale dans la Péninsule Ibérique sous le HautEmpire romain: quelques remarques", en Actes du Colloque 1973 sur l'esclavage, Paris 1976, pp. 417 ss. El mismo sentido servil parece aceptado por las fuentes antiguas; $c f r$. Fest. p. 87: famuli origo ab Oscis dependet apud quos seruus famel nominabantur. La literatura sobre el término y sus implicaciones históricas es muy amplia: R. Martin, "Familia rustica. Les esclaves chez les agronomes latinesw, en Actes du Colloque sur l'esclavage. 1972 , Paris 1974, pp. 267-298; E. Sereni, «Recherche sur le vocabulaire des rapports de dépendance dans le monde antique», en Actes du Colloque 1973 sur l'esclavage, Paris 1976, pp. 11 ss; R.C. Weaver, Familia Caesaris. A social study of the Empe- cado al marco de lo servil ${ }^{\mathrm{x} 2}$. Aunque no conocemos el uso epigráfico del sustantivo hasta la fecha ${ }^{x_{3}}$, es probable que deba entenderse también aqui la pertenencia a una familia, entendiendo como tal el conjunto de siervos de un individuo o un colegio funeraticio integrado por esclavos; no es descartable que bajo la forma familiaricus se esconda aqui la pertenencia a una familia publica que, ocasionalmente, aparece como dedicante en algunos textos funerarios. Esta relación con el marco de lo servil vendría apoyada por la condición de uerna del difunto.

Verna, el indicativo de la condición servil del difunto - más que un cognomen - , aparece en Hispania sobre una quincena escasa de testimonios compitiendo con el mucho más popular seruus/serua. La forma abreviada uer(na) se documenta sólo en una pequeña parte de los ejemplos ${ }^{x 4}$. El uso de Dis Manibus sugiere datar el texto a partir del siglo ॥ d.C., mientras que el empleo de este tipo de altares funerarios, una práctica corriente en amplias zonas de la Lusitania norte, aconseja una cronología tardía dentro de ese siglo o las primeras décadas del III d.C.

25. Fig. 23 y 50 , núm. 25. Inédita.

Parte superior de una estela de granito con cabecera semicircular hallada en el depósito de agua situado al oeste de Santa Lucia. En la parte superior presenta un creciente lunar colocado hacia arriba, limitado por una incisión que corre paralela al borde del monumento y que sólo se conserva en la mitad derecha del mismo. Bajo el creciente figuran dos lineas de texto y algunos trazos de una tercera. Sus dimensiones son [42] $\times 34 \times 15 \mathrm{~cm}$. El campo epigráfico mide $25 \times 24 \mathrm{~cm}$; la altura de las letras oscila en torno a los $5,5 \mathrm{~cm}$, con una interlínea similar. En el segundo renglón se observa una interpunción circular. Se conserva en el Museo Arqueológico Provincial de Cáceres. El texto dice:

Secunda
$a[n] n($ orum) $I I I$ ḥ(ic)
sị[t]ạ ẹ(st)
[---]

ror's freedmen and slaves, Cambridge 1972; G. Fabre, Lihertus. Recherches sur les rapports patron-affranchi à la fin de la Republique romaine, Roma 1981. Cfrr. ahora la interpretación de un elocuente epigrafe de S. Sebastiâo do Freixo (dist. Leiria) en J. da Silva Ruivo, «L. Antonio Vrso liberti et familia. Notas sobre uma inscriçao de Collipon, Conimbriga 31, 1992, pp. 119-154.

*3. Agradecemos al amigo Armin U. Stylow la confirmación de esta sospecha.

${ }^{84}$ Torregamones (Zamora. HEp 3, 413); Cartagena (Murcia. CIL II 3501); Lisboa (AE 1950, 256). 


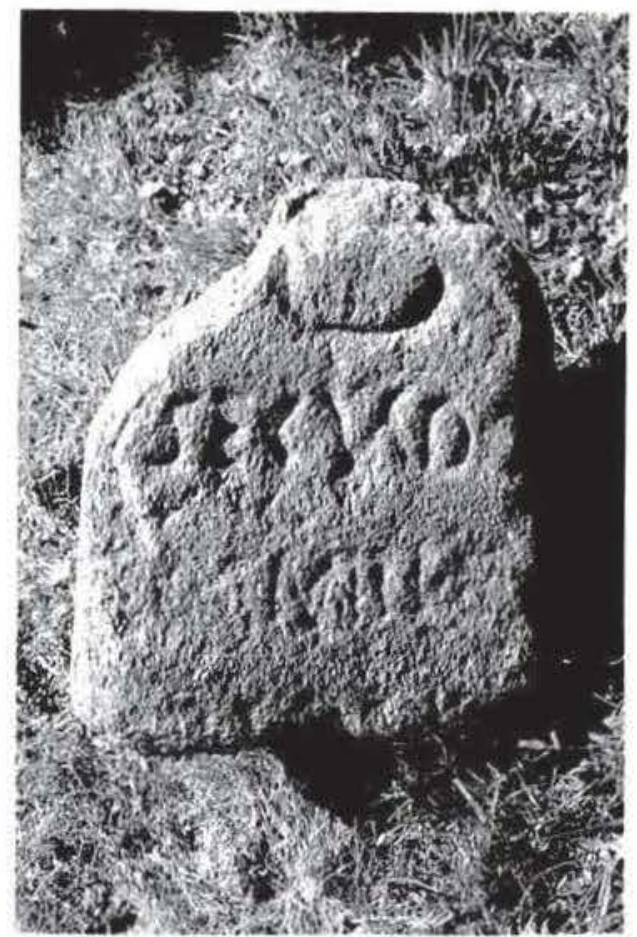

Figura 23. Inscripcion num. 25

\section{1: Nexo VND}

El nombre de la difunta. Secunda, ocupa la décima posicion en el rango numerico de cognommina en Hispania ${ }^{x}$. Sobre la decoración de estelas con crecientes vid infra el apartado 3. En el texto destaca la anomala abreviacion de la formula funeraria. La inscripcion podria ser de tines del siglo 1 o comienzos del II d. C.

\section{Fig. 24 .}

Inédita.

Estela de granito con cabecera semicircular perdida, decorada en su parte superior con un creciente lunar con los extremos hacia arriba. El monumento formaba el dintel del espacio interabsidal norte de Santa Lucia, y fue mutilado en su cima para adaptarlo a la construcción. Pese a las peripecias sufridas, el estado de conservación del soporte y del texto es bastante aceptable, no habiendo que lamentar pérdidas importantes del contenido. Sus dimensiones actuales son $107 \times 43 \times 25 \mathrm{~cm}$; el campo epigrafico mide $50 \times 38 \mathrm{~cm}$; la altura de las letras oscila entre los 5 y $\operatorname{los} 6 \mathrm{~cm}$ con una interlinea constante

* Abascal. Nombres, pp. 499-501 de $2 \mathrm{~cm}$. Todas las interpunciones del texto. bien sisibles en las lineas 3.5.6 y 7. son circulares

El texlo de la primera linea no se dispone horicontalmente. puesto que se ha adaptado a la forma del ereciente superior. Junto a esta importante alteracion fisica. la segunda letra de la primera linea ( la $R$ ) esta ligeramente cabeceada hacia la derecha. mentras la tereera (la $B$ ) se estilisa invadiendo la interlinea superior. A partir de aqui el texto gana progresivamente regularidad. lo que llevaria a pensar que ha habido una ordenacion del espacio a gratbat solo desples de este titubeante inicio. Al final de la septima linea aparece una abreviatura correspondiente a la forma ierbal ffecit) a la que no parece seguir nimgun trako real: en este espacio existen algunas pequenas erosiones que no forman parte de nuguna letra, tampoco pareec que pueda identilicarse como tal el trazo curvo que figura en el espacio inferior por debajo de esta septima linea: su as-

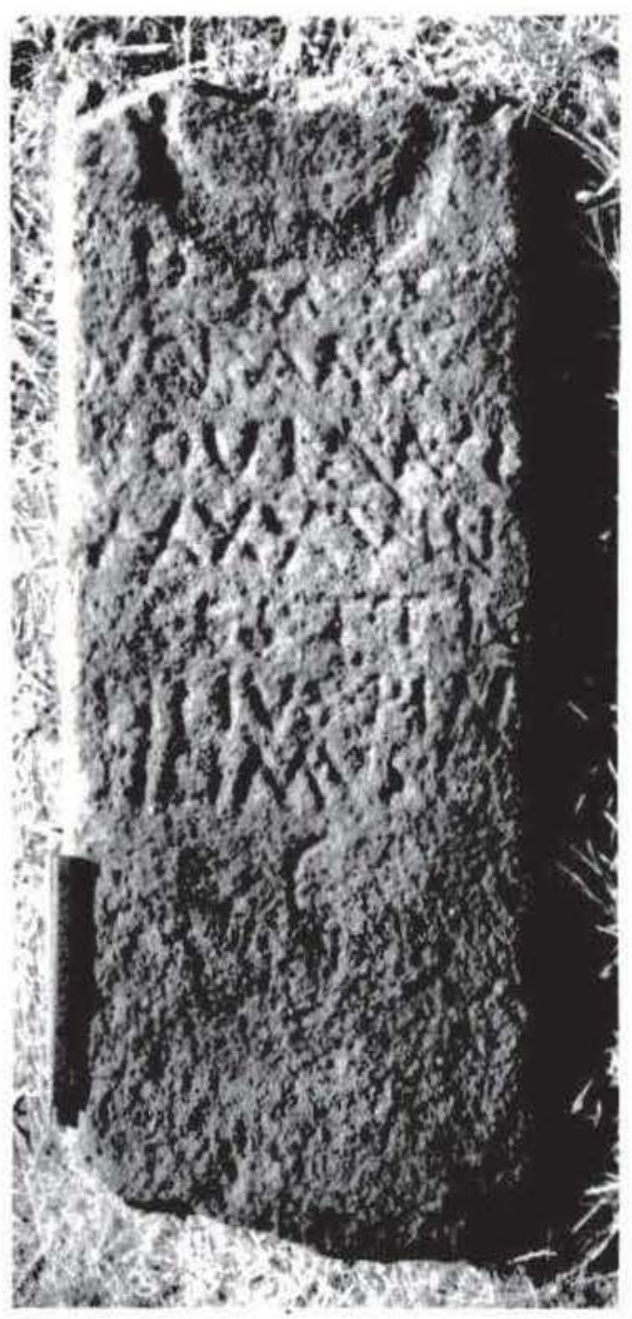

Figura 24. Inscripcion num. 26. 
pecto de consonante queda descartado no solo por sus exageradas proporciones en relacion al resto del texto, sino por la inspección directa.

El monumento se conserva en el exterior del templo de Santa Lucia. El texto dice:

\author{
D(is) W(anihus) s(acrum) \\ lihana \\ Bolaia an(norum) $L$ - \\ XIXIIIII \\ 5 /h(ic)/ s(ita) e(st) s(it) t(ibi) t(erra) lleuis) \\ filius pill- (sic) \\ tisimus frecit) (sic)
}

\section{L.3: Nexo AN}

El nombre de la difunta no ofrece demasiadas particularidades. La inversión de las posiciones de nomen y cognomen en nombres femeninos no es rara en la epigrafia latina. Las inscripciones de Hispania registran un buen puñado de ejemplos sin predilección por una u otra zona del territorio ${ }^{\mathrm{xt}}$; aparte de alguna mención explicita, da la impresión de que muchos de estos testimonios son epigrafes funerarios de libertas.

Botial-ius es, en este caso, un nomen latino ${ }^{x ?}$ del que los pocos ejemplos hispanos proceden de la Lusitania ${ }^{\times x}$. Existe ademas un nombre personal indigena similar ${ }^{89}$ cuyos testimonios, curiosamente, proceden también del mismo ámbito lusitano" . En

6. Paulla Aemilia (Emporiae. CII. II 4623): Rustica Bachia (Sagunto. CIL II 6028). Quinta Caecilia * tscil. Canae) I. Manroola (Merida. IIAE 16.35): /Q)/uinta Caecilia (Santanyi. Mallorca, CII II 3680 + C. Veny. Corpus de inscripciones halearicas hasta la dominacion arabe. Roma 1965, num. 86): (uinta Fahia (S. Romản de San Millan. Alava. CIL. II 2945): Paulla fuluia (Tarragona. (II. II 4363): /S/ccunda Heluia (Logrosán. Caceres. Roso de Luna. "Nuevas inscripciones romanas de la region norbense». BR.All 44, 1904, 127): Paula lulia tnlaci I. (Mérida. AF 1962, 69, con correccion nuestra): Felicia lunia (Valeria, Cuenca. CIL II 3195): Seuera Mania L.f. (Oropesa. Toledo. CIL II 945); Teria Norbana (Albalá del Caudillo, Cáceres. CPILCaceres 820): Paulla Pontia (Cáceres. J. Salas y J. Rosco, Norba 10, 1989-90, 81); Nigrina Sulpicia (Zalamea de la Serena, Badajoz. CIL II 2356); Sicca Veneria (Tarragona. AE 1928, 196); etc

xt Solin \& Salomies, Repertorium. p. 37: Abascal. Nombres. p. 97.

*x Coimbra (CIL II 378): Bouia Materna; Sta. Maria (Torres Vedras, Lisboa. AE 1982, 465): $Q$. Bouius Atimetio Victor $Q$. B(oui) Marciani (f.), Q. B(ouius) Marciamus y Q. B(ouius) Potitus; Oeiras (id., Lisboa. CIL II 5011): L. Bouius /ulianus; Barbacena (Elvas, Portalegre. IRCP 581): M. Bou/--./ Mipa/---1.

*o Albertos, Tarraconense, pág. 60; ead... «Nuevos antropónimos hispánicos», Emeriia 32, 1964, p. 231; Abascal, Nombres, pp. 302-303.

90 Bouia Luci f: Meixedo (conc. y dist. Bragança. F. M. Alves, Guia epigráfico do Museu Regional de Bragança. Memorias arqueológico-históricas do distrito de Bragança 9. Porto

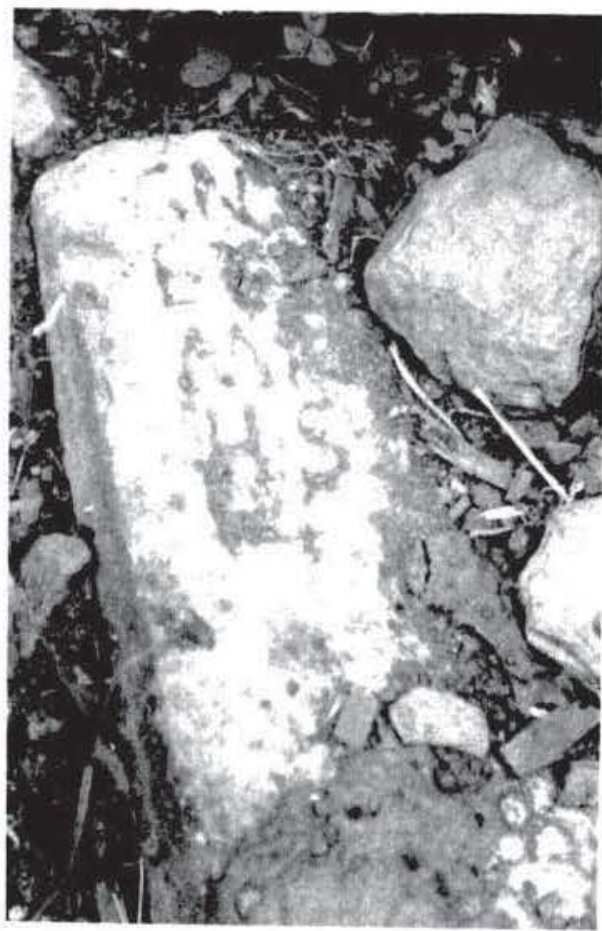

Figura 25. Inscripcion num. 27

cuanto al cognomen de la difunta ", la forma femenina de lrbana-us aparece en Hispania en algo más de una decena de ocasiones ${ }^{92}$ de las que la mayor parte proceden del área occidental. El encabezamiento y la fórmula funeraria sugieren datar el texto a fines del siglo $\|$ o comienzos del III d.C.

\section{Fig. 25.}

L. Caballero y J. Rosco: Extremadura Arqueológica 1, 1988, pág. 246, núm. A.3 = HEp 2, 194.

Fragmento de una gran estela de granito que, al iniciar los trabajos de excavación en Santa Lucía. formaba parte del escalón de la entrada occidental al templo de Santa Lucia. El monumento fue retallado de antiguo para servir de dovela en el propio templo, aunque en algún momento posterior fue retirado para formar parte finalmente de este escalón. Debido a las mutilaciones obligadas por su función

1933. núm. 26 + ILER 5044): Bouia Tangini f: Coria (Cáceres. EF 9, 121); Bouius Taloci $f:$ Baçal (conc. y dist. Bragança. EE 8, $300+$ EE 9, 279). Los otros tres ejemplos son genitivos masculinos en filiaciones y proceden de Freixial do Campo (conc. y dist. Castelo Branco. FE 175). Idanha-a-Velha (Idanha-a-Nova. Castelo Branco. HAE 1146) y Ulme (Chamusca. Santarem. AE 1990, 493).

9) Solin \& Salomies, Repertorium, p. 416.

a2 Abascal. Nombres, p. 550. 
arquitectonica, hoy solo es posible leer el comenth$10 \mathrm{de}$ sus cuatro lincis de texto, suficientes para advertir que estamos ante una inscripcion funcraria. Las dimensiones actuales del soporte son $[69] \cdot \mid 44.5] \cdot[26] \mathrm{cm}$. FI area de texto conservadia mide $24 \times 11 \mathrm{~cm}$. con letras de $5 \mathrm{~cm}$ de altura y una interlinea regular de $1 \mathrm{~cm}$. En las lineas segunda y cuarta se observan interpunciones circulares.

In la primera linea se ven elaramente las dos letras iniciales, que parecen corresponder al praemomen de uno de los difuntos: al comienes de la segunda se lee bien la conjuncion seguida de una interpunción y de un asta vertical; en la tercera la $1 /$ incial es seguida por un trazo oblicuo que necesariamente debe pertenecera una $A$. y en la cuarta figura el comienso de la formula funeraria.

Se conserva en el Museo Arqueológico Prowinctal de Caceres. El texto dice:

$$
\begin{aligned}
& \text { Cinincus) 1-- / } \\
& \text { et }+|-| \\
& \text { IHA/ - - / } \\
& \text { h(ic) s(iti) /s(unt) -..- }
\end{aligned}
$$

No es posible sugerir la restitucion de las letras perdidas habida cuenta de lo fragmentario del soporte. y seria aventurado sugerir una datacion, pese a que la paleografia sugicre una cronologia anterior a comienzos del siglo $\| \mathrm{d}$.C.

\section{Fig. 26 y 49 , num. 28}

L. Caballere y J. C. Sanchez: "Reutilisaciones de material romano en edificios de culto cristianom. en Cristianismo y aculturacion en tiempos del Imperio Romano. Antigïedad y (irstianismo 7. 1990, paig. 459. tig. 6.2 y págs. $473 \mathrm{~s}$. (solo foto).

Estela funcraria en granito con cabecera semicircular. reempleada como umbral del cancel en el abside meridional en el templo de Santa Lucia. Pese a que el monumento cubre todo el vano de entrada al abside. es posible incluso que fuera recortado longitudinalmente en su parte inferior, aunque tal extremo es imposible de precisar. A fin de adaptar la estela a su nueva función en el templo se practicaron sendas aberturas, pretendidamente rectangulares, y los correspondientes surcos para apoyo del cancel: desgraciadamente una de estas perforaciones coincide con el campo escrito, por lo que sólo quedan algunos restos del texto. En sus dimensiones actuales la estela mide $193 \times 38 \mathrm{~cm}$, siendo imposible precisar su grosor por hallarse parcialmente embutida en el suelo. La cartela que contiene el texto mide $38 \times 28 \mathrm{~cm}$. Las escasas letras conservadas miden $6-6.5 \mathrm{~cm}$ en la primera linea y $5 \mathrm{em} \mathrm{en} \mathrm{la}$ cuarta.

Aparentemente la inscripcion constaba de cinco lineas. En la primera. a la i/quierda de la rotura queda un traso inclinado. que bien pudiera pertenceer a una 4 . a cuya i/quierda aun cabria un caracter. y las letras C 7 a la derecha del surco. De las lincas segunda y tercera solo quedan algunos tra/os. toda se/ que en el proceso de tallado del rectangulo para filar el cancel se erosionaron los bordes, De la cuarta linea solo queda una $t$ al tinal. y de la quinta un astat vertical en el angulo inferior derecho de la cartela, que bien pudiera pertenecer a una $/$ y formar parte de la formula funeraria. Bajo la rotura central aparecon unos rasgos lerticales quic no eorresponden a ninguna letra.

La estela se encuentra empotradia en st emplafamiento original. $\mathrm{PI}$ texto dice

$$
\begin{aligned}
& 1+1.1 /-6: 2-1(1) 1 \\
& 1-1+1 \\
& 1-1.1 \\
& 1-1.1 \\
& 1-11
\end{aligned}
$$

In buena lógica la primera linea deberia contener el nombre de la difunta. que bien podria continuar en la segunda. De esa manera, igual que cabria

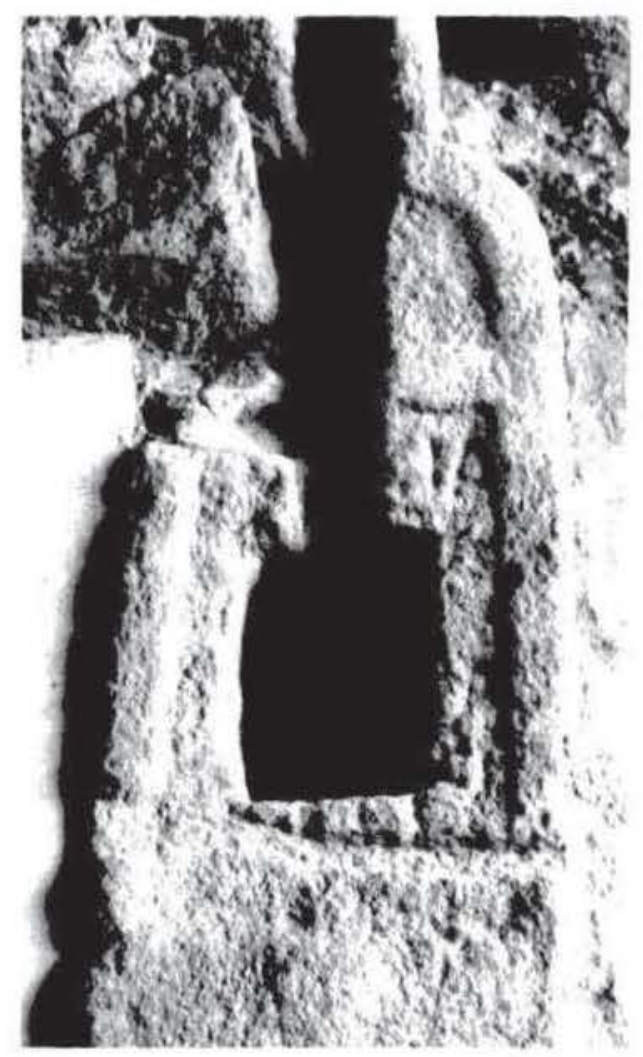

figura 26. Inscripeton num 28 . 
una solucion con un nombre personal indigena como $/ \mathrm{S} / \mathrm{a} / \mathrm{ma} / \mathrm{ciat}$. ya documentado en el area cacereña podra pensarse en un gentilicio latino como Anicta. Allic za o incluso Harcha, seguido de un congnomen en la segunda linca. Aunque el grupo cia podria formar parte de un nemen masculino. esta solucion. por problemas de espacio. parece menos probable. If deterioro del texto sugiere evitar otras solucienes mas arriesgadas para las dos ultimas lineas, aunque probablemente alli figuraria la formula funcraria. Por comparacion con el epigrafe num. 29) podria datarse a finales del siglo i d.C.

\section{Fig. 27 y 49 , num. 29}

L. Caballero y J. C. Sanchez: "Reutilizaciones de material romano en edificies de culto cristianom. en Cristianismo y aculturacion en tiempos del Imperio Romano. Antigïedad y Cristianismo 7. 1990. paig. 459 , fig. 7.3 y pàgs $473 \mathrm{~s}$. (solo foto).

Fstela funeraria de granito con cabecera semicircular utilizada como umbral y soporte de cancel en el abside septentrional de Santa Lucia. Igual que en el caso de la inscripeion anterior. el reempleo del monumento provoco una serie de roturas necesarias para adaptarlo a su nueva función. de forma que la parte central de la inscripcion ha desaparecido completamente. Seguramente durante su colocacion se partio la cabecera, de manera que se puede observar una rotura entre la cuarta y la quinta linea. Las dimensiones actuales del monumento son $202 \times 45 \mathrm{~cm}$. sin que pueda precisarse el grosor, y cabe la posibilidad de que la altura fuera ligeramente superior antes de reemplearse como material arquitectónico. El área escrita mide $80 \times 38 \mathrm{~cm}$ y la altura de las letras oscila entre los 6 y $\operatorname{los} 7 \mathrm{~cm}$, con una interlinea de 2,5-3 $\mathrm{cm}$. Las interpunciones son. en todos los casos, circulares.

Los caracteres están profundamente grabados y quedaron protegidos por la presencia del cancel. El texto presenta ocho lineas bastante regulares en su disposición y longitud. En la superior sólo quedan dos letras a la izquierda de la rotura, una $P$ y una $l$. separadas por una interpunción, que deben pertenecer al praenomen y nomen de uno de los difuntos. En la segunda linea debia aparecer el cognomen. del que sólo quedan las dos letras iniciales, una $/ \mathrm{y}$

* Samacia M Acill $\rightarrow$, Fromfis libterta), de Villar de Plasencia (CIL II 844); Samacia Perceati filia), de Coria (CIL II 764, con sugerencia de M*1. Albertos, "Correcciones a los Irabajes sobre onomástica personal indigena de M. Palomar Lapesa y M. ${ }^{*}$ Lourdes Albertos Firmats, Emerita 45, 1977, p 371 : Cfr. M. Palomar. La inomástica personal primitiva de la antigua lusitania, Salamanca 1957. p. 95: Abascal. Nombres, p. 495

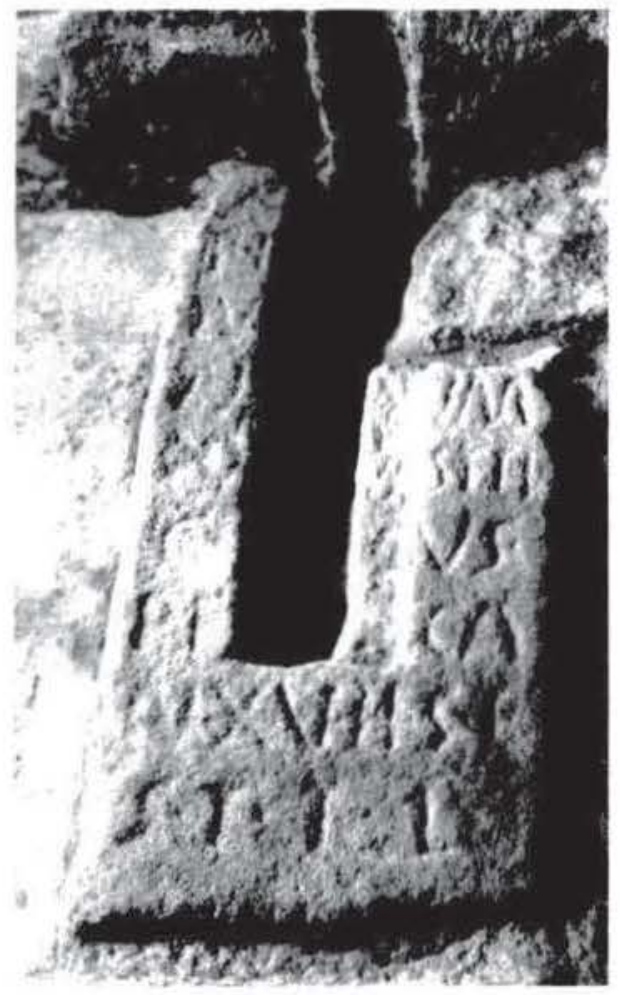

I igura 27 Inscripcion 1 iuse 29

una $l:$ en la tercera puede restituirse sin dificultad la voz annorum pese a la rotura central y. finalmente. en la cuarta aparece el comienzo de una edad de defunción a la izquierda de la rotura y parte de la formula funeraria a la derecha. En esta cuarta linea. y a tenor de lo que se observa en la octava, es preciso suponer la formula h(ic) s(itus) e(st) en el espacio perdido, por lo que no habria modo de ver una edad superior a los 35 años expresados como . XXXT para la edad del difunto.

Las cuatro lineas inferiores contienen el nombre, la edad y la formula funcraria del segundo de los difuntos. De nuevo son visibles el praenomen y la desinencia del genitilicio en la quinta linea; la sexta contiene la filiacion y el final del cognomen. mientras el resto de los elementos citados se reparten entre las lineas séptima y octava.

El gentilicio perdido en la quinta linea debe, en buena lógica, ser idéntico al desaparecido en la primera, toda ve zue la fíliación de la sexta linea parece referida al personaje de aquélla. Si sabemos por la primera linea que el nomen perdido empieza con una $/$. y por la quinta que tiene $3 / 4$ letras antes del grupo conservado de - us, sólo es posible la solución lulius/lunius, que encaja perfectamente en las lagunas existentes; en razón de la frecuencia del primero hemos preferido emplearlo en la restitucion. 
H texto dice

\author{
P(ublius) I/ulius] \\ Iu $[-\cdots)$ \\ an/nor/um \\ XX/XT h(ic) stitus) e(st)] s(it) t(ihi) terrat \\ lenis) \\ 5 (raius) /luli/us \\ P(ubli) trilius) [-.-/ca \\ an(norum) $\mathrm{XT}$ heric) s(itus) c(st) \\ s(ii) tribi) t(erra) I(ewis)
}

\section{3: $\mathrm{NexOAN}$ \\ L. 7: Nexo AN}

La exacta disposición de cada uno de los textos funerarios en cuatro lineas y la presencia de una formula funcraria para cada uno de los individuos sugiere que la defunción de ambos no fue contemporanea, aunque la estela se aprovecho para señalar el lugar de enterramiento del padre y luego el del hijo. Esta diferencia temporal podria explicar la escasa diferencia de edades entre ambos. que serian dificiles de aceptar en otras condiciones.

La onomástica de los difuntos es poco elocuenic. Su gentilicio, lulius, es el más corriente de los aparecidos en Hispania, con más de 800 testimonios que cubren todas las regiones ${ }^{44}$. Sus cognomina, Iu/ - / y / - / / ca, no permiten ninguna observación precisa habida cuenta de las múltiples posibilidades de restitución que ofrecen. El texto podría datarse a finales del siglo I d.C.

30. Fig. 28 y 49 , núm, 30 .

L. Caballero y J. C. Sanches: «Reutilizaciones de material romano en edificios de culto cristiano". en Cristianismo y aculturacion en tiempos del Imperio Romano. Antigüedad y Cristianismo 7. 1990, pág. 459 , fig. 7.2 y pàgs. $473 \mathrm{ss.} \mathrm{(sólo} \mathrm{foto).}$

Estela funeraria de cabecera semicircular reempleada como umbral y soporte del cancel oriental del coro de Santa Lucia. En sus dimensiones actuales, convenientemente mutilada para adaptarla al espacio disponible, mide [201] $\times 50 \mathrm{~cm}$, sin que se pueda precisar su grosor. Pese al tremendo deterioro que ha sufrido la inscripción, parece que tuvo cuatro lineas de texto, de las que sólo se observan algunos trazos sueltos y unos rasgos de la segunda, correspondientes a una letra de $6 \mathrm{~cm}$ de altura. No es des-

"4 Solin \& Salomies, Repertorium, paig. 99; sobre los hallazgos hispanos, cfr. Abascal. Nombres. p. Isi.

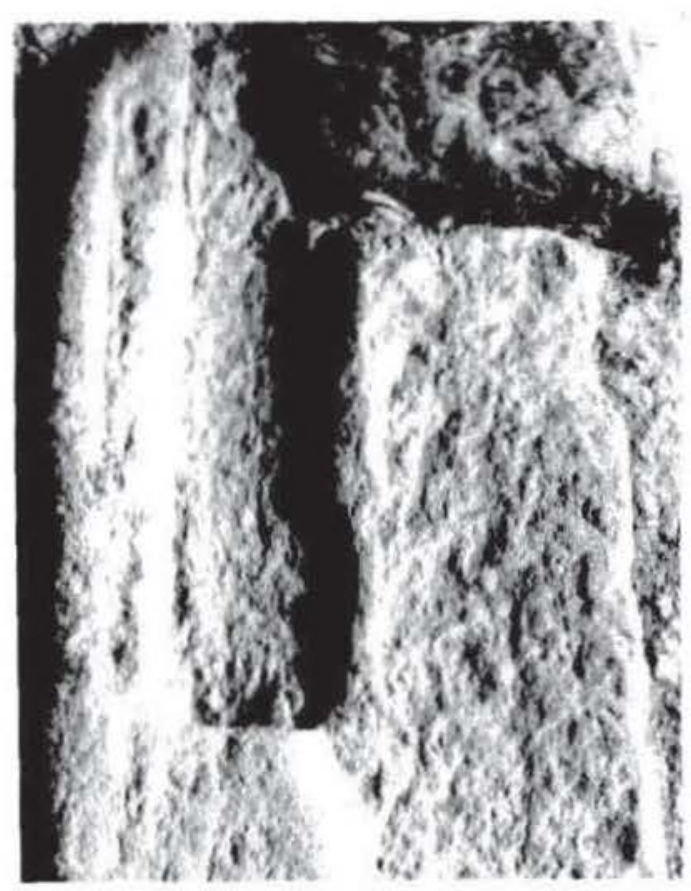

ligura 2X, Inscripcion num. 30.

cartable que bajo estas lineas existiera una segunda cartela de texto, aunque el estado del monumento impide confirmarlo". En el texto sólo puede verse una letra en la siguiente posición:

$$
\begin{gathered}
+[-\cdots] \\
+E(-\cdots) \\
+1-\cdots] \\
+1 \cdots]
\end{gathered}
$$

Por comparación con el resto de las estelas de este tipos y proporciones halladas en el templo, es probable que estemos ante un texto funerario antiguo, de tines del siglo 1 d.C.

\section{Fig. 29.}

L. Caballero e 1. Velázquez: "Un grafito en el cimborrio central de la iglesia visigoda de Santa Lucia del Trampal, Alcuéscar (Cáceres)", AEA 62, 1989 , pàgs. $262-271=\operatorname{HEp} 3,114$.

Grafito sobre la primera capa del enlucido de la cara exterior del muro meridional en el cimborrio central de Santa Lucia. Ocupa un campo epigrálico

49 En la fotografia publicada por S. Andrés Ordax. "La basilica hispano-visigoda de Aleuéscar (Caceres)", Norba 2, 1981, p. 74. anterior a los trabajos de excavación y restauración del templo. se ve que esta estela sirve de escalón para salvar el pequeño desnivel de acceso al coro, lo que podria explicar su mayor deverioro respecto a otros umbrales del mismo tipo. 


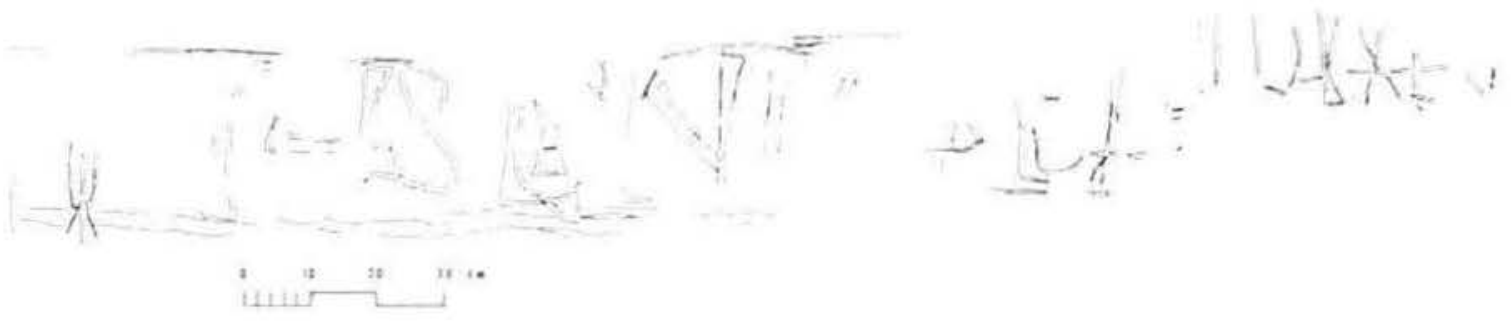

Figura 20 Inscriperon num 31 (scgun Ciballero y lela/qued

de $26 \times 212 \mathrm{~cm}$. con una sola linca cn la que las letras presentan alturas irregulares que oscilan entre los 12 y $\operatorname{los} 23 \mathrm{~cm}$. La posicion que ocupa el texto obliga a suponer que fue grabado cuando aủn no se habian colocado las tejas del espacio que une los cimborrios central y meridional, y antes de cubrirlo con el estucado definitivo. lo que lo pone en relacion con la construcción del edificio. El texto, segun sus primeros editores, dice:

$$
\begin{aligned}
& \text { (signum) / watal?//|-c:2-/ ISC/N/ |---1 ALI } \\
& |-c \therefore||1|)|X| 1 / \cdots \mid
\end{aligned}
$$

Los criterios paleograficos hacen suponer a $L$. Caballero e 1. Velizque' que el texto puede ser datado en el siglosind. C.. fecha que condiciona la de construceion del edificio, quisit ligeramente anterior.

\subsection{MONIMINTOS ANIPIRAIOSOCON} H. TIT() PFRII)

32. Fig. 30

Incitita.

Ara de granito, con cabecera y plinto separados del fuste por sencillas molduras similares a las de otros ejemplares del conjunto. que se encuentra empotrada en la cara exterior de la esquina surocei-

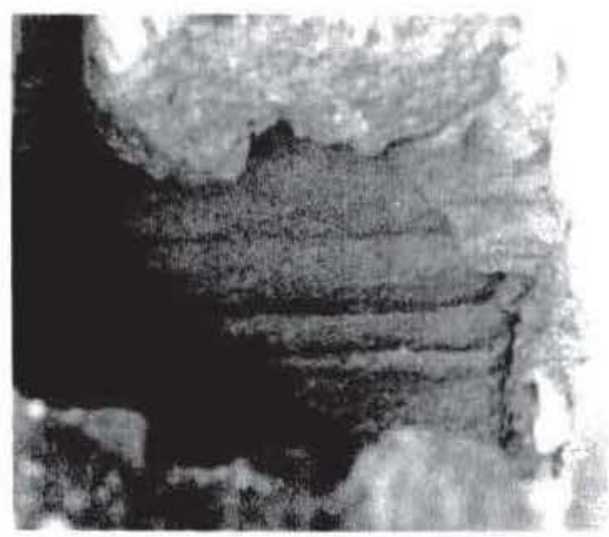

Figura 30-Monumento num. 32. dental del aula de Santa Lucia. La posición del monumento impide confirmar si se conserva en su totalidad. aunque en los trabajos de restauracion se vieron dos pequeños hueces en su parte superior. Las dimensiones documentadas son $[94] \times 23 \times[15]$ cm. Aparentemente carecia de texto.

33. Fig. 47. núm. 33.

I. Caballero y J Roseo: Extremadura Arqueologica 1. 1988. pág. 249, nủm. B.7

Parte superior de un ara que conserva la cabecera. decorada con sencillas incisiones horizontales delimitando molduras, y parte del fuste: Aparecio entre Santa Lucia y la molineta del Trampal y se conserva en el exterior del templo. Sus dimensiones $\operatorname{son}[82] \cdot 35 \times 25 \mathrm{~cm}$

34. Fig. 31 .

Incitita.

Ara de granito de cabecera y plinto lisos diferenciados del fuste por su mayor anchura. Tipologicamente pertenece al mismo grupo que los altares num. 1. 3, 4.6 o 14, aunque se le practico el rebaje parcial del ancho de la cabecera para adaptarla a alguna construcción. Se conserva empotrada en la cerea de Santa Lucia, y sus dimensiones actuales son $88 \times[36] \times[28] \mathrm{cm}$.

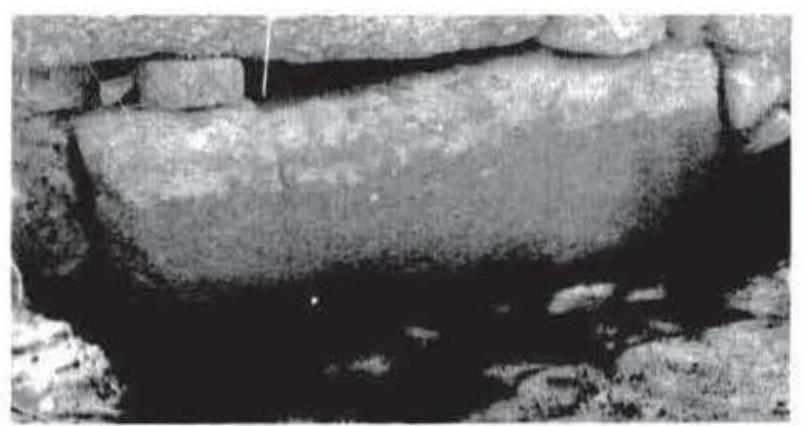

Figura 31. Monamento num. 34. 


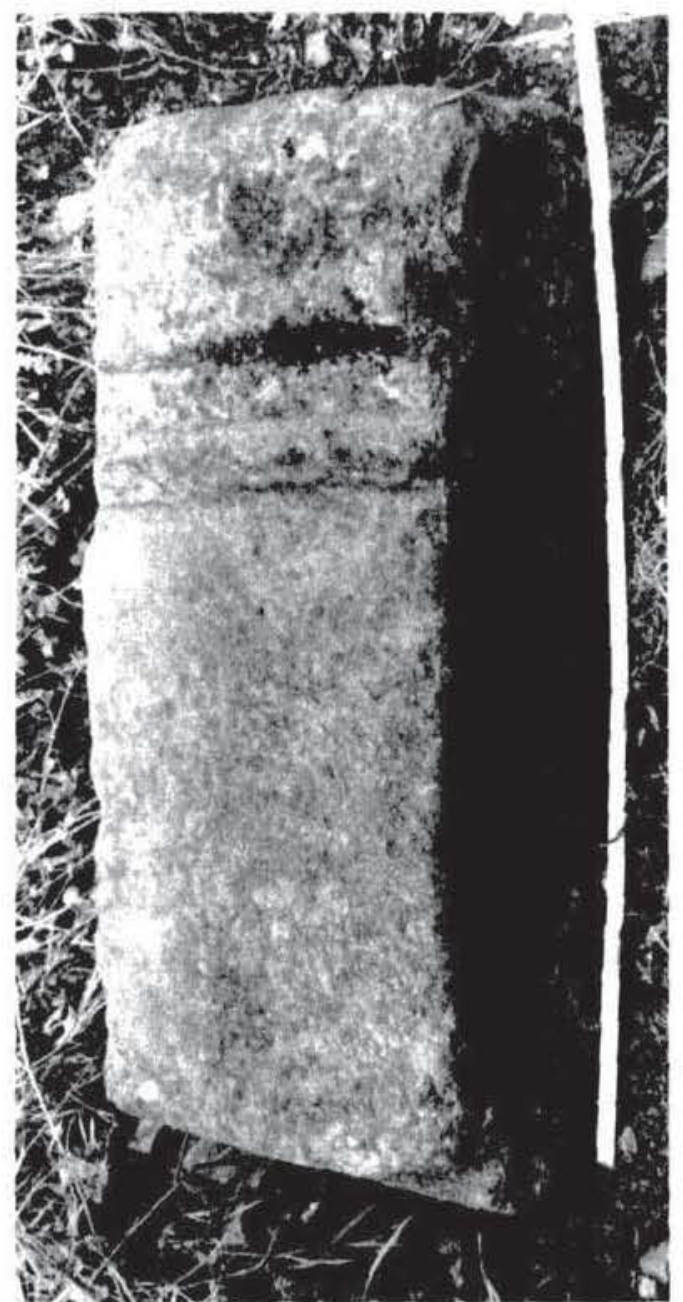

ligura 32. Monumento num. 35

35. Fig. 32 y 47 , num. 35 .

Inédita.

Parte superior de un ara similar a los nums. 33 y 36, decorada con sencillas molduras para separar el fuste de la cabecera. Formaba parte de la cerca occidental de Santa Lucía. La parte inferior fue retallada para acomodarla a su uso arquitectónico, y sus dimensiones actuales son $[93] \times[38,5] \times 30 \mathrm{~cm}$.

36. Fig. 33 y 47 , núm. 36 .

Inédita.

Ara con cabecera y plinto decorados con senciIlas molduras horizontales que se encuentra empotrada en la cara externa del muro norte del ábside central de Santa Lucía, formando esquina. La parte visible del monumento es uno de los laterales y probablemente la parte inferior del plinto, lo que permite conocer su grandes dimensiones, $111 \times 41,5 \times 27$ $\mathrm{cm}$, que la convierten en uno de los soportes más importantes del conjunto. Desgraciadamente el tex-

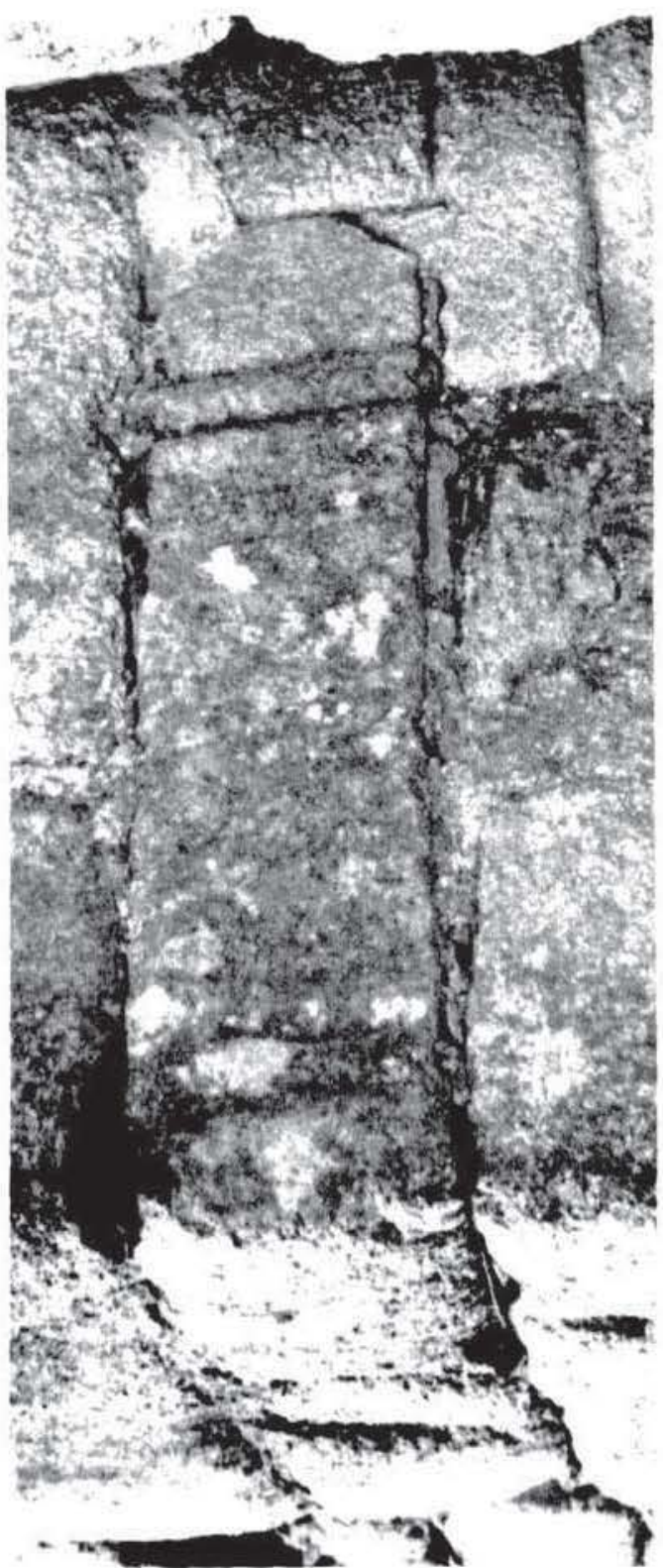

Figura 33.-Monumento num. 36.

to, si llegó a ser grabada, queda oculto en la construcción. Tipológicamente se puede poner en relación con los núm. 33 y 35 .

37. No ilustrada.

L. Caballero y J. Rosco: Extremadura Arqueológica 1, 1988, pág. 248 , núm. B.2

Ara anepigrafa hallada sobre sobre el muro sur del cimborrio norte de Santa Lucia, junto a la inscripción núm. 9.

38. No ilustrada. Inédita. 


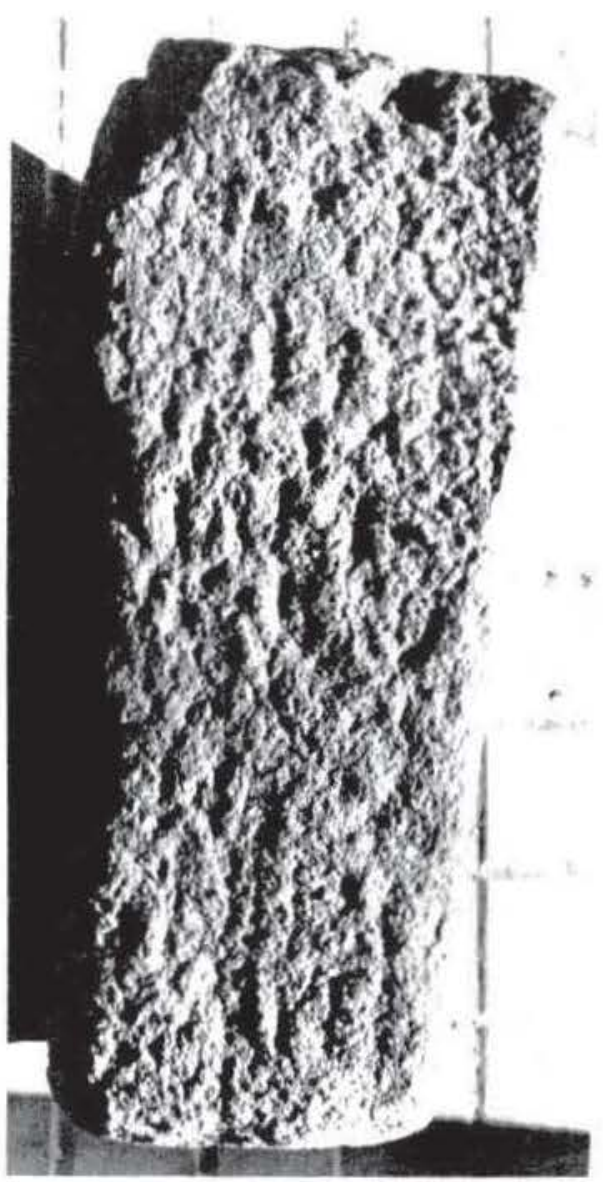

Figura 34. Momomentos nim. 39

Parte superior de un ara cuya cabecera presenta tres molduras delimitadas por suaves incisiones. Se encuentra empotrada en la cara exterior del muro sur del aula de Santa Lucia, y sólo es visible al ex. terior uno de sus laterales por lo que desconocemos sin tiene texto y la anchura de la parte frontal. Sus dimensiones actuales son $[54] \times[-] \times 18 \mathrm{~cm}$.

\section{Fig. 34 .}

L. Caballero y J. Rosco: Extremadura Arqueológica 1. 1988, pág. 246, núm. A.6

Parte superior de un ara hallada en los alrededores de Santa Lucia y retallada para asiento de dovela. Su grado de deterioro es máximo y resulta imposible reconocer sus proporciones originales salvo en la cabecera, en donde parece adivinarse una linea horizontal bajo la que se sitúa el campo epigráfico. En su lateral izquierdo aún se observan tres pequeñas molduras casi planas dibujadas por cuatro incisiones horizontales. En la actualidad mide $[60] \times[26] \times[19] \mathrm{cm}$.
In la superficie frontal se atisban restes de le tras que prucban que el ara fic empleada para grabar un epigrafe cuyo sentide hoy se nos excapa Ngunos rasgos verticales en las primeras lineas. contundides con golpes y crosiones, son lo que quedat del probable texto de una invocacion a flacema. In la parte inferior querria serse una $S$ y una $F$ sin $x$ gurdad. Ni stquera el calco permite confirmar cual yuicra de estas hipotesis. Se conserva en el Mtusen arqueologice de Citeeres

40. 1 ig. $35 y+8$, num. 40 .

Incitita.

Cabecera de un ara empotrada en la cara exterior del muro de testero en el ábside central de Santa Lucia. Presenta una sencilla decoracion de dobles volutas a ambos lados de su cara frontal. y dos huecos pequeños y alargados en su parte superior sustituyendo al foculus. No es posible determinar ta longitud real del soporte dada su ubicacion. Sus dimensiones visibles son $[23,7] \times 33 \cdot 28,5 \mathrm{~cm}$.

\section{Fig. 47, num. 41.}

Inedita.

Cabecera lisa de un ara, unida al fuste por nedo de dos molduras de media caña. En su parte superoor presenta un hueco estrecho y alargado como el de otras arac del conjunto. Sus dimensiones son $|31| \times 31.5 \times 3 \mid \mathrm{cm}$ y se conserva en el exterior del templo de Santa Lucia.

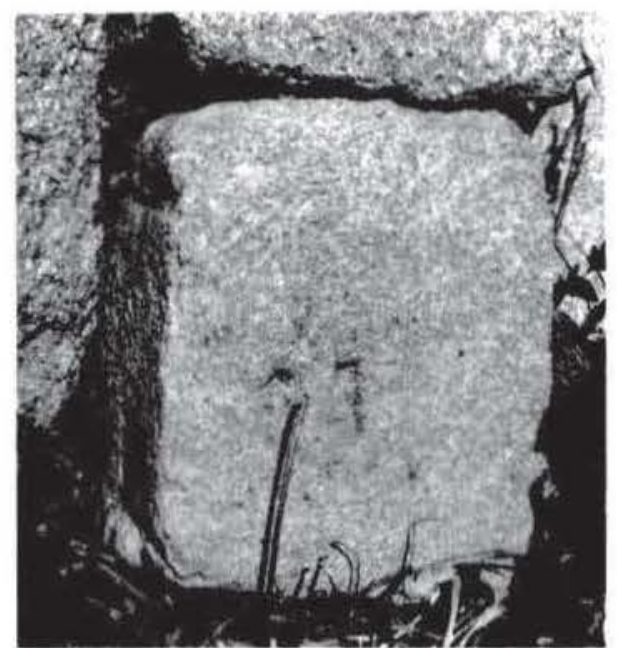

Figura 35.-Monumento nùm. 40. 


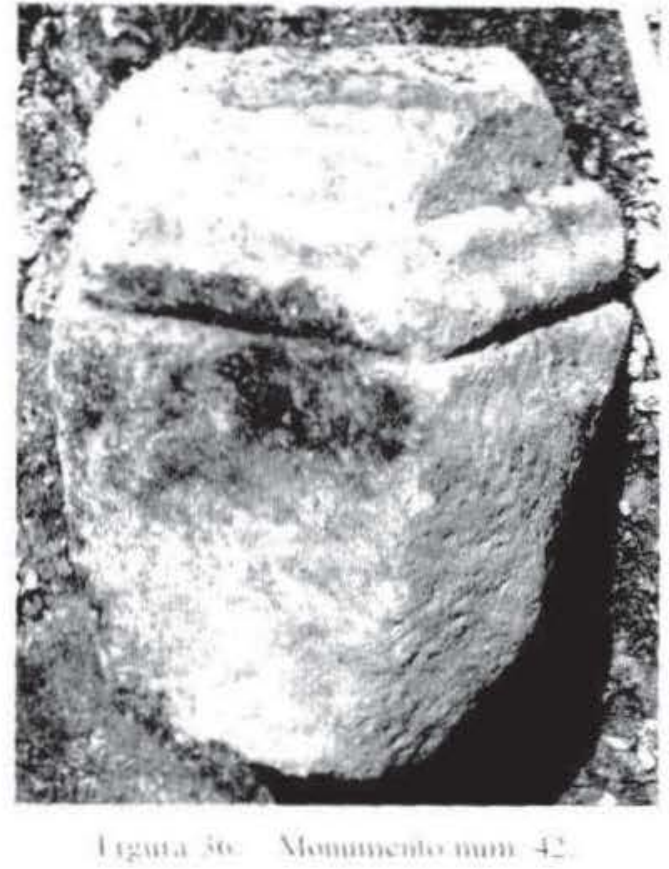

\section{Fig. 36 .}

I. Caballero y J. Rosco: Evremadura Arqueologica I. 1988. pag. 249, num. B.6

Parte superior de un ara hallada a $500 \mathrm{~m}$ al norte de Santa Lucia, que conserva parte del fuste y de la cabecera, separadas por una sola moldura. Se conserva en el exterior del templo de Santa L ucia y sus dimensiones son $[48] \times[38,5] \times[32] \mathrm{cm}$.

\section{Fig, 47, núm. 43}

1. Caballero y I. Roseco: Extremadura Arqueologica 1. 1988, pag. 249, num. B.5.

Cabecera y parte del fuste de un ara que formaba parte de la cerca oriental de la finca de Santa Lucia. En consonancia con otras piczas del grupo, está decorada con sencillas incisiones horizontales y molduras muy suaves no totalmente regulares. Las dimensiones de lo conservado son $[59] \times 43 \times 30,5$. Se conserva en el mismo lugar de su hallazgo.

44. Fig. 37 y 49 , num. 44.

L. Caballero y J. C. Sánchez: "Reutilizaciones de material romano en edificios de culto cristiano", en Cristianismo y aculturación en tiempos del Imperio Romano. Antigüedad y Cristianismo 7 . 1990, pág. 459, fig. 7,1 (sólo foto) y págs. $473 \mathrm{~s}$.

Estela funcraria reutilizada como umbral de cancel en el ábside central de Santa Lucia. El monumento fue recortado para adecuarlo a su posición y fun-

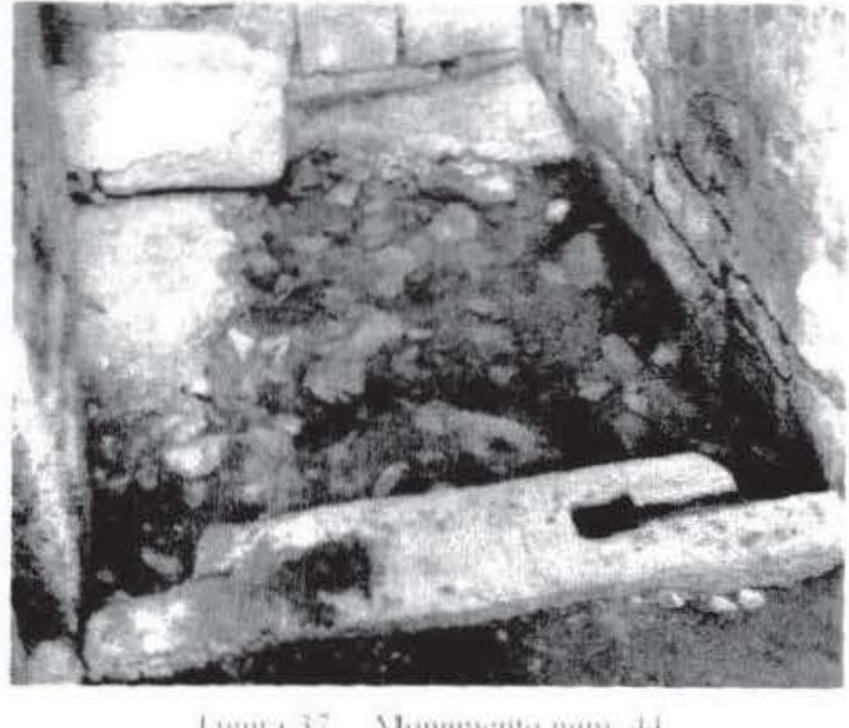

cion en el edificio, para lo cual se tallaron dos grandes sureos laterales en donde se insertarian los canceles. Pese a las previsibles amputaciones sufridas, siguen siendo impresionantes sus medidas $[222] \times[45] \times[\cdots]$. No conserva restos del texto ni huella alguna del lugar que aquél pudo ocupar.

\section{Fig. 38 ,}

S. Andrés Ordax: "L a basilica hispano-visigoda de Alcuéscar (Cáceres)m, Norha 2, 1981, pág. 74 (sólo foto): L. Caballero y J.C. Sánchez: "Reutilizaciones de material romano en edificios de culto cristianom. en Cristianismo I aculturacion en tiempos del Imperio Romano. Antigïedad, (iristianismo 7, 1990, pág. 459, fig. 7.2 (sólo foto) y pagss. 473 ss.

Estela funeraria reutilizada como umbral en el extremo occidental del coro de Santa Lucia. Sus dimensiones actuales son $[177] \times[49] \times(\ldots) \mathrm{cm}$, aun-

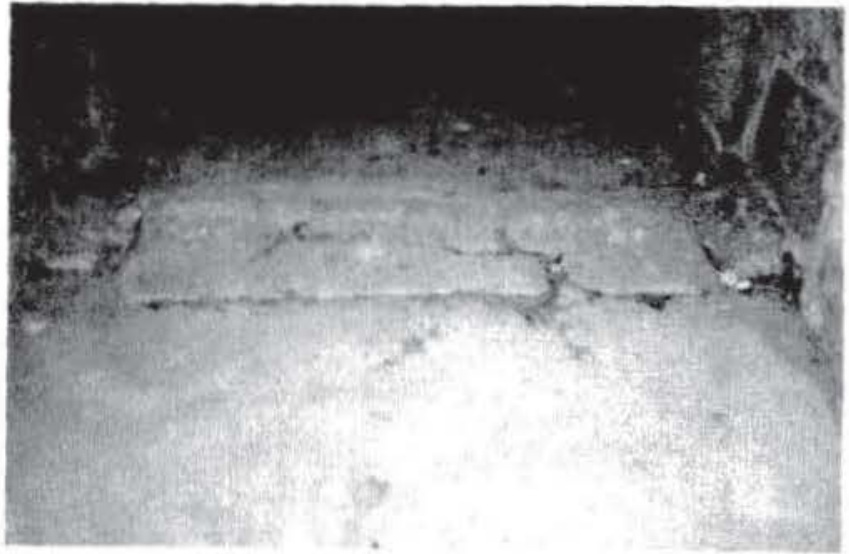

Figura 38,-Monumento num, 45. 
que deblo pertencect al tipo de estelas que aparecen in los demas umbrales y superar facilmente los 200 $\mathrm{cm}$ Su estado de deterioro es tal que no es posible identificar siquera la posicion de la cabera.

46. No ilustrada.

Incetitit

Parte superior i/quierda de una estela de cabecera semecircular decorada con an creciente lunar del que se conserva solo uno de sus extremos. No se observan restos de texto. Aparecuo reutilizado en el hueco de la entrada ocedental del aula de Santa L ueia. Sus dimensiones actuales son $[53] \cdot[24]-[16] \mathrm{cm}$

47. No ilustrada.

Incidita.

Cupa anepigrafa reutilizada en el muro oriental de la habitacion intermedia meridional, junto a la puerta sur del crucero de Santa Lucia, en donde aún se conserva. Sus dimensiones son $50 \cdot[40] \cdot[\cdots] \mathrm{cm}$.

48. No ilustrada

Incdita.

Cupa anepigrafa reutiliada en la cara exterior del muro gótico que atraviesa en dirección nortesur la cata 10 de la campaña de 1990 en Santa Luciat. Sus dimensiones son $[45] \times 45 \times 92 \mathrm{~cm}$.

49. Fig. 39 .

Incida.

Cupa anepigrafa decorada con doble moldura horizontal en su parte inferior y doble circulo concéntrico en sus laterales, que formaba parte de la cerca norte del templo de Santiago. Se conserva en el exterior del templo de Santa Lucia. Sus dimensiones son $42 \times 40 \times 89 \mathrm{~cm}$.

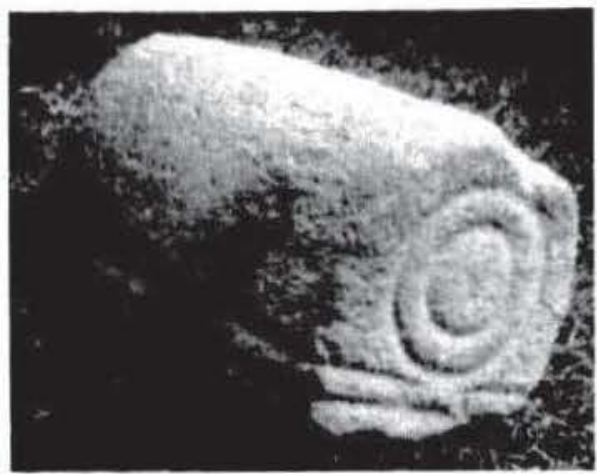

Figura 39. - Monumento num 49

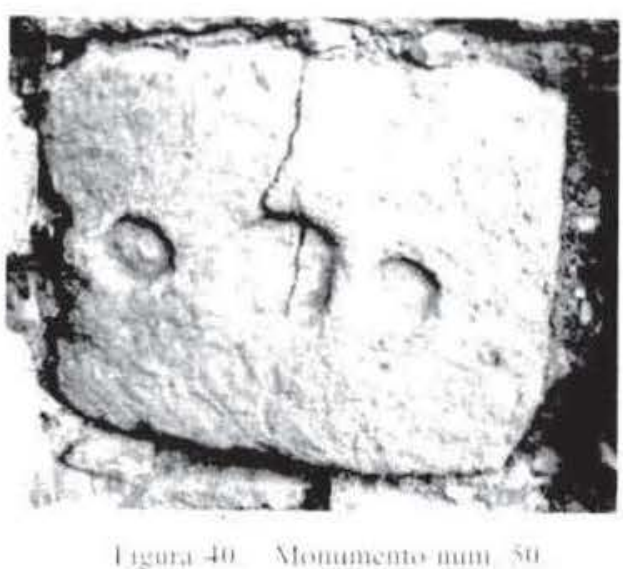

50. Fig. 40 .

Incitito.

Sillar probablemente perteneciente a la cabecera de un ara que se encuentra empotrado en la cara exterior del muro oeste del tramo sur en el crucero de Santa Lucia. Presenta tres huecos alineados en su cara superior. Sus dimensiones son $1-1 \times 35 \times 30 \mathrm{~cm}$

\section{CARACTERESINTIRNOS YFLEMENTOSFORMALES}

\subsection{FORMIULARIOS Y ONOMASIICA}

Si el conjunto epigrafico de EI Trampal contiene 15 dedicaciones a Ataecima, disponemos de otras tantas formas diferentes de invocarla. Bien es cierto que algunas de ellas contienen no sólo los mismos elementos sino un mismo orden de colocacion; sin embargo. las variantes graficas impiden la repeticion de una siquiera de las evidencias, como muestra la lig. 41 .

\begin{tabular}{|l|c|}
\hline \multicolumn{1}{|c|}{ Insocacion } & Num \\
del texto
\end{tabular}

Figura 41. Variantes en las invocaciones a Afaecina en Santa Lucia del Trampal. 
En términos generales se pueden establecer cuatro grupos en la disposición de los elementos:

1. El nombre de la divinidad seguido de epitetos.

2. Dea domina/domina dea con los correspondientes apelativos.

3. Domina seguido o no del topónimo.

4. La forma Turibrigensis Ataecina.

Como veremos al hacer una evaluación de la cronologia (infira 4.1), no existen elementos individuales suficientes para asegurar la datación de ninguno de los epigrafes, por lo que a priori carecemos de criterio para ordenar las invocaciones en una sucesión temporal.

También como era de imaginar, tampoco las fórmulas de consagración de los textos arrojan luz sobre este particular (fig. 42). Los devotos de Ataecina en El Trampal entregaron en sus minutas al artesano tanto fórmulas canónicas como expresiones justificativas del carácter especial de su invocación, tales como la conocida ex uisu o la enigmática $o b$ ro(--). La comparación de estos elementos con la grafia del texto, el tipo del soporte o sus rasgos paleográficos ha sido inútil por la pobreza de los resultados.

El espectro onomástico de los fieles de Ataecina en El Trampal es breve por el acusado deterioro de los textos, y al mismo tiempo muy heterogéneo (fig. 43). Una gran parte de las inscripciones sólo conserva la zona superior con el nombre de la divinidad, habiéndose perdido las lineas que contenian el nombre del dedicante; incluso los nombres conservados presentan lagunas y elementos dudosos. Por ello, el magro repertorio del que disponemos no se puede considerar representativo del conjunto. Sólo seis individuos testimonian la plena ciudadania con el uso de tria nomina; los gentilicios, salvo aquellos que se explican en el ámbito emeritense y turgaliense (Caesius, Vivia, Norbanus), son los corrientes estadisticamente hablando (Caecilius, Iulia, Licinius, etc.). Hasta donde nos permiten observar los testimonios podemos decir que, si en este

\begin{tabular}{|c|c|}
\hline Fórmula & Núm. del texto \\
\hline a(nimo) l(ihens) u(otum) s(oluit) & I y 4 \\
\hline ex uisu et monu/m(entum)] posuit & 12 \\
\hline le/x uol(o) l(ihens) a (nimo) s(oluit) & 6 \\
\hline l(ibens) a(nimo) u(otum) s(oluit) & 9 \\
\hline l(ihens) u(otum) s(oluit) & 21 \\
\hline ob ro(-.-) e $(x) u / o t o]$ & 3 \\
\hline u(otum) s(oluit) l(ibens) a(nimo) & 5 \\
\hline uo(tum) s(oluit) l(ihens) a(nimo) & 19 \\
\hline uot(um) $\mid--1$ & 8 \\
\hline$|\cdots|++$ soluiit & 20 \\
\hline
\end{tabular}

Figura 42.-Fórmulas de consagración.

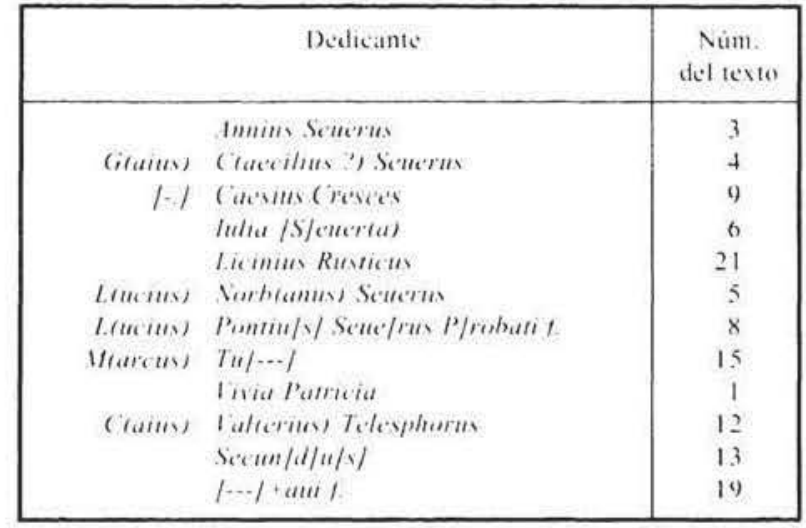

Figura 43, Los fieles de flaceina en El Trampal.

registro existe población indigena, tal condición queda oculta por un altísimo grado de latinización onomástica.

Tal circunstancia tiene dos lecturas. De una parte estamos, con toda probabilidad, en el territorium de Emerita, lo que explicaria la predominancia de formas onomásticas más propias de los medios urbanos de esta época que de los enclaves rurales de la región. Si el santuario de Ataecina fue un centro religioso con tanta tradición como evidencian los múltiples testimonios que conocemos no sólo en el Trampal, su relativa cercanía a la colonia augustea debe ser motivo suficiente para asegurar alli la presencia de fieles de extracción urbana, hecho que se pudo ver favorecido por los procesos de interpretatio a los que más tarde aludiremos (infira apartado 8).

La segunda lectura puede hacerse en términos de latinización onomástica. En efecto, en este reducido repertorio 5 individuos portan el cognomen Selierus/-a (núms. 3, 4, 5, 6 y 8) (fig. 44). En tres casos, los altares sobre los que figuran como dedicantes son piezas idénticas entre si, con plinto y coronamiento casi cúbicos, sin molduras y aparentemente obra de una misma officina. Por añadidura, cuatro de estos cinco ejemplares son los únicos que en el conjunto de el Trampal contienen todos los elementos posibles en la invocación a Ataecina, es decir, dea domina sancta Turibrigensis Ataecina, y en tres de ellos en el mismo orden. Aparentemente estamos ante cinco altares de los que al menos cuatro bien pudieron ser contemporáneos.

En Hispania Seuerus/-a es el más popular de los cognomina latinos por delante del Rufus/-a que tanto éxito tuvo en la latinización onomástica de los territorios situados entre el Miño y el Duero. También en el territorio de Emerita Seuera/-us es un cognomen frecuente; allí conocemos hasta el presente quince testimonios, casi todos ellos en ins- 


\begin{tabular}{|c|c|c|}
\hline Dedicante & Fórmula empleada & Número \\
\hline Annius Seuerus & D(ea) d(omina) s(ancta) Turibri(gensis) Attegina & 3 \\
\hline G(aius) (caecilius ?) Senerus & $D(e a)$ domina) s(ancta) Turibri(gensis) Adaecina & 4 \\
\hline L(ucius) Norb(anus) Setuerus & $D(e a) d$ (omina) s(ancta) T(uribrigensis) A(taecina) & 5 \\
\hline Iulia /S/euer(a) & Do(mina) d(ea) s(ancta) Turibri(g)e(nsis) Adegina & 6 \\
\hline L(ucius) Pontiu/s] Seue/rus P/robati f. & Domina Turibr(igensis) Attaec/i]na & 8 \\
\hline
\end{tabular}

Figura 44.-Dedicantes con cognomen Selueris/- $a$ en el Trampal.

cripciones funerarias ${ }^{96}$. En buena lógica era previsible, por tanto, encontrar este cognomen en varios epigrafes del conjunto de Santa Lucia; sin embargo, salvo el discutible ejemplo del texto núm. 8 , cuatro testimonios parecen pertenecer a un mismo momento de la vida del santuario del que proceden los monumentos. Tales coincidencias desbordan las explicaciones estadísticas y obligan a plantear la posibilidad de que exista otro tipo de razones para este fenómeno.

Mientras existe un cierto consenso sobre la extensión de un nomen como Flauius a consecuencia del impacto juridico del edicto de Latinidad de Vespasiano de los años 73-74 d.C., carecemos de evidencias sobre las modificaciones onomásticas producidas en Hispania por otro tipo de cambios jurídicos. Sabemos que el año 212 d.C. Caracalla generalizó la posesión de la ciudadania, aunque cabe sospechar de la escasa utilidad de esa medida en áreas cuya integración venía produciéndose con fuerza en los últimos 140 años, y en las que este privilegio sería un bien casi común. Sin embargo, a la vista de los testimonios epigráficos a los que estamos haciendo referencia, con la concentración de los cognomina Seuerus/-a en un mismo momento histórico, debemos plantear la hipótesis de que estemos ante el eco onomástico de esa medida en estas regiones del sur cacereño.

Bien es cierto que Seuerus/-a es un cognomen muy bien documentado desde el siglo I d.C.; también lo es que se encuentra tanto en áreas rurales como urbanas. Sin embargo, hay que señalar su mayor difusión en áreas con menor intensidad del fenómeno urbano o con mayor resistencia a la latinización onomástica como es el interior de Lusitania. Sólo en la provincia de Cáceres se concentran más del 10 por 100 de los testimonios conocidos en His-

96 Debemos estos datos a la amabilidad de J. L. Ramírez Sádaba (Univ. Cantabria). pania. Si tenemos en cuenta la aparente datación tardia de los epígrafes votivos de El Trampal, podríamos estar ante la evidencia onomástica de la aplicación de cambios jurídicos personales a comienzos del siglo III d.C.

Por añadidura, Annius, Caecilius, lulius o Norbanus no son gentilicios ocasionales que permitan establecer relaciones familiares con grupos de la periferia; estamos ante nomina populares, corrientes en quien abandona su onomástica indigena para sustituirla por nombres de resonancias latinas.

Llama la atención en el registro onomástico la ausencia de nombres indigenas puros, que son corrientes en la región. En efecto, faltan los Tongius, Viriatus, Boutius, Lubaecus o Tanginus, por citar sólo algunos ejemplos al azar. Si Ataecina es una divinidad indigena, los nombres personales de sus fieles no parecen evidenciarlo. Sin embargo, hay que tener en cuenta que en un centro de culto tan popular, cuya existencia se dilata durante más de dos siglos, el temenos o el espacio destinado a albergar las dedicaciones monumentales de los devotos no mantendría de forma permanente cuantos exvotos y altares alli fueran depositados. En la tradición de este tipo de centros, incluso hoy dia, se produce una renovación periódica de las ofrendas para dejar lugar a nuevas dedicaciones. En el santuario de Ataecina también es probable que los viejos altares fueran apartados progresivamente del área sagrada para reemplearlos en construcciones o destruirlos, dejando asi espacio para las nuevas ofrendas.

Eso explicaría que el conjunto epigráfico del que disponemos sea relativamente reciente, como veremos al hablar de la cronología, y explicaría también la ausencia de un horizonte onomástico antiguo. Sin embargo, entre los fieles registrados en estos epigrafes siguen existiendo individuos de extracción rural, indígenas que lo son por su ascendencia familiar, hijos o nietos de quienes evidenciaron tal condición con su onomástica unas generaciones antes, pero ahora con nombres latinos. 


\begin{tabular}{|c|c|c|c|}
\hline $\begin{array}{l}\text { Fncabe- } \\
\text { zamiento }\end{array}$ & & Nombre & $\begin{array}{c}\text { Núm } \\
\text { del texto }\end{array}$ \\
\hline \multirow[t]{6}{*}{ D. M. $S$. } & & Vrbana Botia & 26 \\
\hline & P(ublius) & 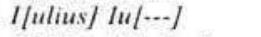 & 29 \\
\hline & (taius) & |luliJus P.f. | - /ca & 29 \\
\hline & & Norhanus Milen(us) & 22 \\
\hline & L(ucius) & Norhanus Sillo & 23 \\
\hline & & Secunda & 25 \\
\hline \multirow[t]{4}{*}{ D. $M$. } & & V'aler $(\ldots)$ & 24 \\
\hline & & $1+|A|-c \cdot 2-|C| A|\cdots|$ & 28 \\
\hline & Cn(eus) & $|\cdots|$ & 27 \\
\hline & & {$[\cdots|M A| \cdots]$} & 27 \\
\hline
\end{tabular}

Figura 45.-Nombres personales en epigrafes funerarios de El Trampal.

Las mismas consideraciones serían válidas para los difuntos señalados en las estelas funerarias reempleadas en la construcción del templo de Santa Lucía (fig. 45). En ellas, y no sólo por su aspecto formal, rezuman también ecos de indigenismo bajo nombres como Bouia o Norbanus. Sin embargo, la mayor antigüedad de algunos de estos epigrafes respecto a los altares, ofrece un panorama más acorde con lo que cabria imaginar en el ámbito regional.

\subsection{LAS ARAE Y EL CONTEXTO REGIONAL}

Los altares de Santa Lucia del Trampal se apartan tipológicamente de los monumentos con inscripciones votivas que conocemos en su ámbito regional. Frente a ejemplares que presentan elementos formales estereotipados como puluini, acróteras o frontones triangulares con foculus bien definido, los ejemplares de Alcuéscar son poco más que un fuste rematado en ambos extremos por cubos o ejemplares con molduras insinuadas por sencillas incisiones. Alrededor de estos esquemas gravita todo el conjunto con muy pocas excepciones. Las diferencias entre unos y otros ejemplares permiten, no obstante, establecer las siguientes categorias:

\section{Arae con fuste diferenciado (fig. 46)}

Pertenecen a esta categoría al menos seis monumentos del grupo que estudiamos (núms. 1, 3, 4, $6,14,34)$, uno de ellos anepigrafo. Este tipo de altares tienen claramente diferenciado el fuste de la cabecera y el plinto gracias a una reducción de su anchura. Una caracteristica común es la total ausencia de decoración en todos los elementos, el superior y el inferior casi cúbicos, con una sobriedad que ga-

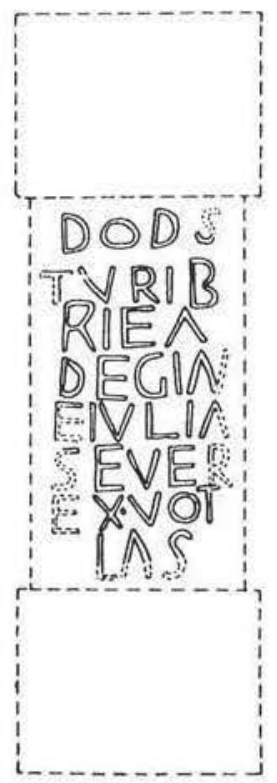

6

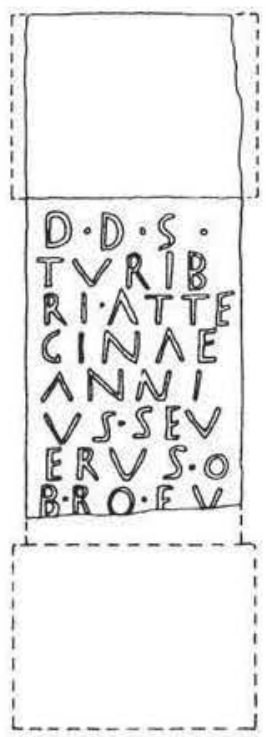

3
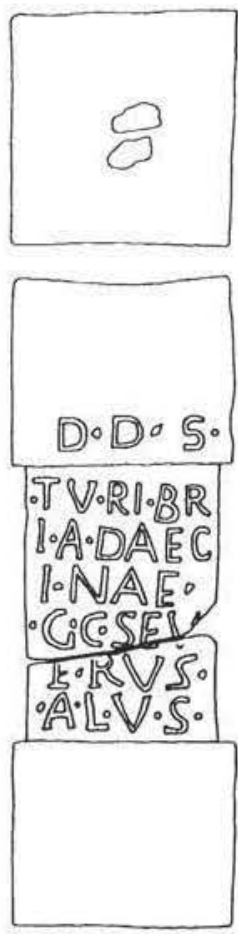
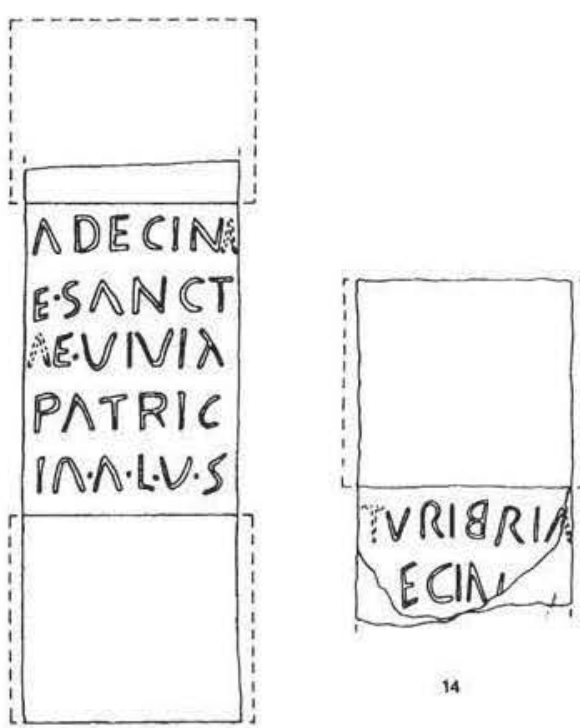

14

Figura 46.-Arae con elementos diferenciados en Santa Lucia del Trampal. 
rantiza la percepción visual de la inscripción. Sólo en un caso la cabecera ha sido empleada para introducir parte de la invocación (núm. 4). Es difícil referirse a paralelos formales exactos para este tipo de monumentos; con las salvedades que impone la lejania, deben anotarse las similitudes que presentan con un altar dedicado a Navia en Castro del Picato (Guntín, Lugo) ${ }^{47}$, y el eco que tienen de dos ejemplares más cercanos, las dedicaciones a Arentia y Arentius halladas en Coria ${ }^{\text {"x }}$, de los que les separan algunas diferencias sensibles.

\section{Arae con delimitación de cabeceras mediante molduras (fig. 47)}

Bajo esta característica podemos agrupar algunos altares del conjunto (núms. 7, 11, 33, 35, 36, 41 ), que guardan ciertas similitudes con los del grupo anterior, pero que como elemento diferenciador de elementos sólo introducen molduras muy sencillas de medio bocel.

Dentro del grupo aún cabria distinguir dos tipos; el primero estaria integrado por las cabeceras núms. 7 y 11 en las que el fuste experimenta una reducción de anchura, y un segundo (núms. 33, 35, $36,41)$ en donde no se puede establecer esta diferencia y cuya ejecución es mucho más simple. En este último caso, aunque pueden considerarse altares por pertenecer al conjunto y disponer en un ejemplar (núm. 41) de perforación superior seguramente para exvoto, más podriamos hablar de cipos o monolitos debido a la lejanía formal con los altares clásicos.

\section{Arae de cabecera decorada con molduras simples (fig. 47)}

No conservamos ningún ejemplar completo de este tipo de monumento, cuya cabecera está decorada en su totalidad con incisiones horizontales que dibujan molduras planas muy sencillas. Los ejemplares más completos son los núms. 13 y 43 , el segundo de ellos anepigrafo. Probablemente pertenece a esta misma categoria el pequeño altar dedicado por Licinius Rusticus (núm. 21) a una divinidad que no aparece en el texto y que también debe ser Ataecina.

El estilo de la pieza núm. 5 está más próximo a los patrones clásicos y parece individualizar un ele-

\footnotetext{
${ }^{97}$ F. Arias et alii, op. cit. en nota 48, núm. 71, PI. 25. G. Gamer, op. cit. en n. 9, núm. LU-31,Taf. 55 i.

98 J. Rodríguez, «Dos nuevas aras en Coria a dos divinidades gemelas», Zephyrus 17, 1966, pp. 121-130 (= AE 1967, 219 ab); CPIL Cáceres 771 y 772; G. Gamer, op. cit. en n. 9. Taf. 67 e-f.
}

mento superior, aunque faltan los puluini y el foculus que cabria esperar.

No es fácil encontrar paralelos a este tipo de monumentos y menos aún en la provincia de Cáceres, aunque se puede traer a colación el altar funerario de M[a]rtia en la Vega Baja de Toledo ${ }^{99}$, que aprovecha estas molduras planas para colocar el texto. Podria también pertenecer a este tipo la parte inferior de un ara hallada en Aldeia de Santa Margarida (conc. Idanha-a-Nova, dist. Castelo Branco) ${ }^{100}$. El tipo recuerda vagamente la forma de un altar de Braga que conserva el Museo Pío XII de la localidad ${ }^{101}$ y aún más la de otro ejemplar de Minhotaes (conc. Barcelos, dist. Braga), conservado en la misma institución ${ }^{102}$, que Tranoy data con reservas en la segunda mitad del siglo $\|$ o a comienzos del siglo III d. C.

\section{Altar con foculus $y$ puluini}

Sólo un monumento del grupo de Santa Lucía del Trampal encaja en esta categoria próxima a los esquemas canónicos del altar romano, aunque desgraciadamente es un texto casi ilegible probablemente no dedicado a Ataecina (núm. 18). Los paralelos formales de este monumento son corrientes, pero por su relativa proximidad al área cacereña citaremos únicamente un ejemplar de Orgaz ${ }^{103}$.

\section{Arae de tipologias diversas (fig. 48)}

Una serie de altares bien por su deterioro, bien por su aspecto general, son dificilmente adscribibles a alguna de las categorías precedentes. Es el caso del núm. 9 , la pieza más llamativa del conjunto por su ordenada grafia y por conservar restos de pintura roja en las letras. Aparentemente se podría adscribir a la primera categoria que hemos enunciado, pero la separa de ella sus proporciones. Es el caso también de la núm. 15 , que carece de cabecera diferenciada y presenta una pequeña oquedad superior; o la núm. 12, perfectamente conservada y que parece un monolito dispuesto a ser hundido en el suelo.

* G. Alföldy, "Epigraphica Hispanica 10. Inschriften von Unfreien aus Toledo und Umgebung", ZPE 67, 1987, pp. 252 ss., núm. 4, Taf. XII.4 (= AE 1987, 674, HEp 2, 696); G. Gamer, op. cit, en nota 9, Taf. $66 \mathrm{~d}$.

${ }^{100}$ F. Patricio Curado, «Fragmento de ara de Aldeia de Santa Margarida), $F E$ 17, 1986, núm. 78 (= AE 1986, 303; HEp 1, 674).

101 L. A. Dos Santos, A. Tranoy y P. Le Roux, «Inscriçoes romanas do Museu Pio XII en Braga», Bracara Augusta 37, 1983. p. 198, lám. X, fig. 34 (= AE 1983, 571).

102 Ibidem, p. 189, lám. III, fig. 8 (= AE 1983, 558).

${ }^{103}$ CIL II 6309; G. Gamer, op. cit. en nota 9, p. 283, Taf. $50 \mathrm{c}$. 

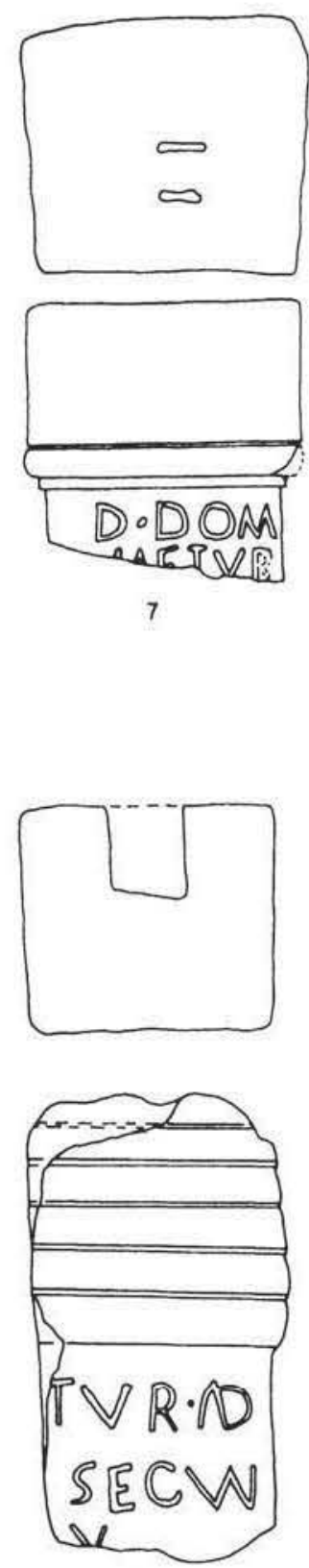

13

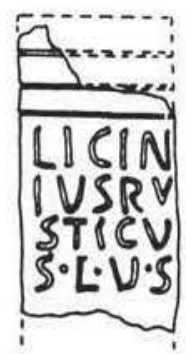

21
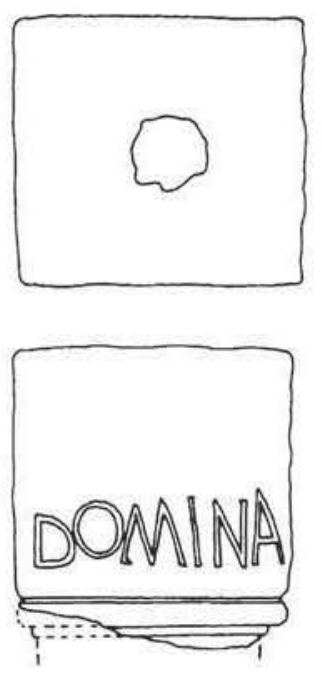

11
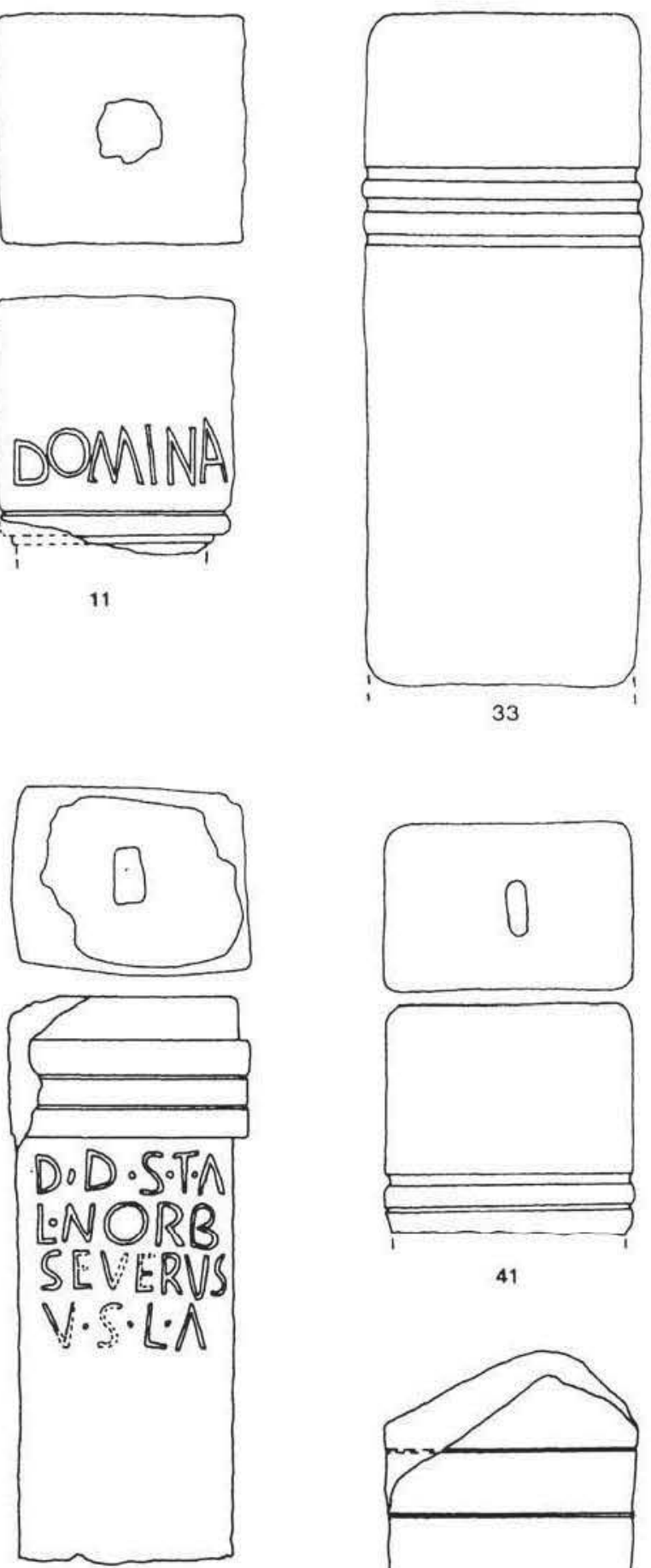

5
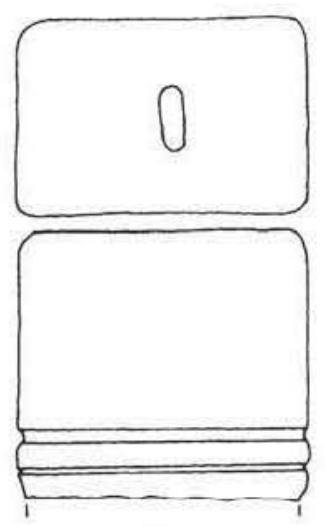

41

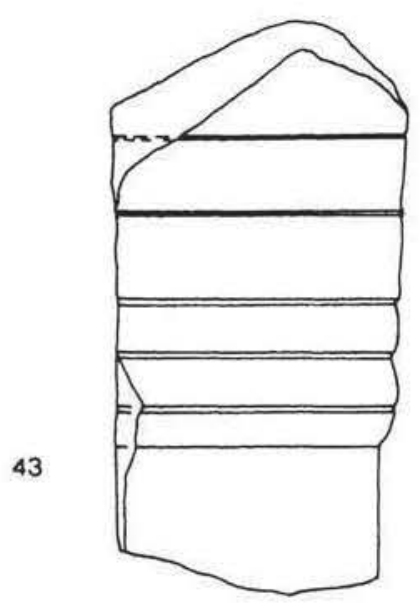

36
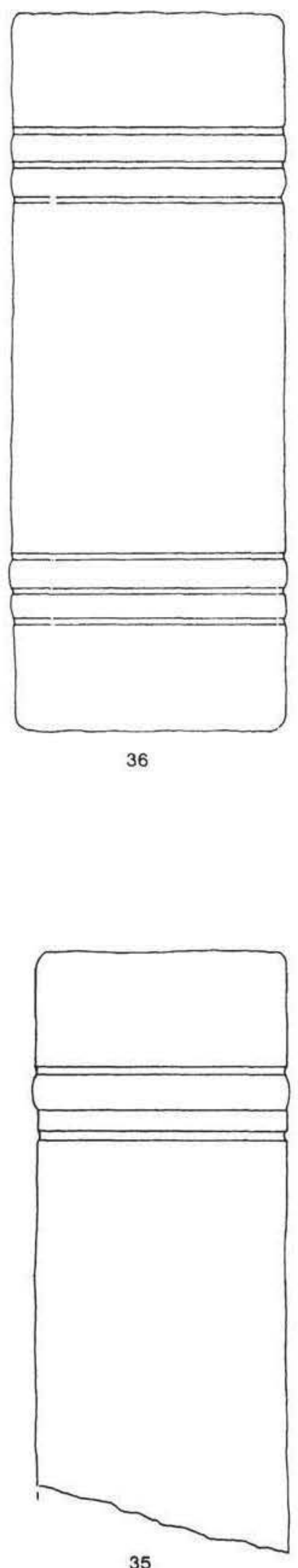

35

Figura 47.-Arue con delimitación de cabeceras mediante molduras o con empleo de éstas para decoración. 

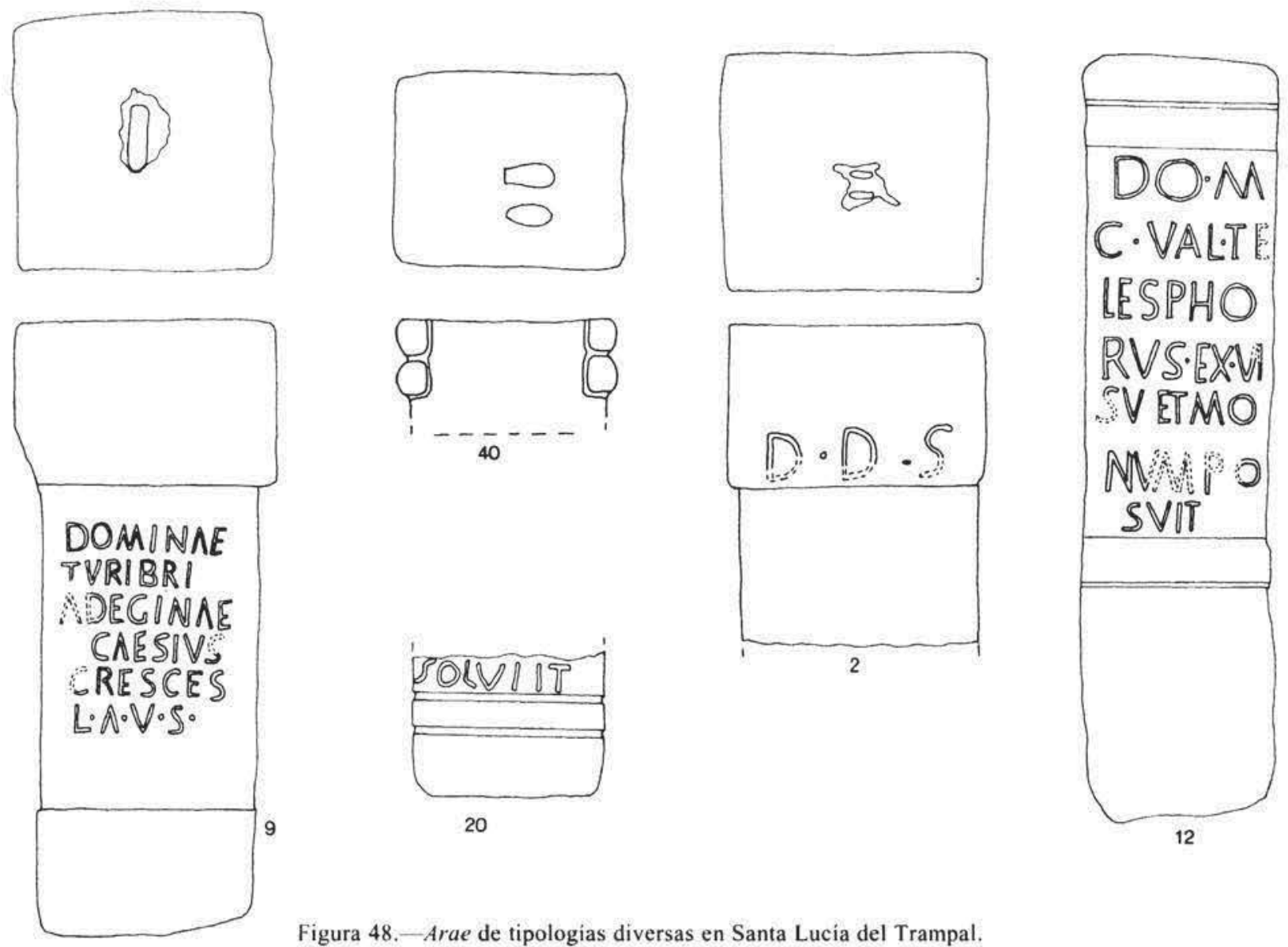

20

Figura 48.-Arae de tipologias diversas en Santa Lucia del Trampal.

El panorama de los altares y monumentos de carácter votivo en el área regional, entendiendo como tal unos límites que desbordan las tierras cacereñas por el sur y el oeste, muestra en términos generales una tremenda falta de homogeneidad. La muestra ilustrada por Gamer para las dos Beiras o Extremadura, aunque escasa, sirve para poner de manifiesto la coexistencia de pequeños altares realizados por officinae sin experiencia ni referentes clásicos con ejemplares elaborados y de mejor calidad formal. En casi todos los casos, sin embargo, el elemento común es el granito empleado como material, algo corriente no sólo para los altares, sino para toda la producción epigráfica en amplias regiones del conuentus Emeritensis y en el ángulo nororiental del Pacensis.

En un área que, grosso modo, integra gran parte de la Beira Baixa, en el distrito portugués de Castelo Branco, y un ancho pasillo del centro-sur cacereño, incluyendo obviamente la zona de Alcuéscar y sus alrededores, se observan, incluso en fechas avanzadas del Principado, una serie de afinidades muy importantes en los rasgos onomásticos, en las creencias y en las modalidades formales del hábito epigráfico. Uno de los centros más importantes para realizar tal evaluación continúa siendo Idanha-aVelha, cuyo registro epigráfico muestra peculiaridades que se mantienen más allá de la actual frontera entre España y Portugal.

Este área contiene una apreciable cantidad de textos votivos a divinidades indígenas, sólo comparable a las evidencias de las regiones de Minho, Trasos-Montes y Beira Alta. En este espacio, hasta bien entrado el siglo III d.C. al menos, la religión indígena se manifiesta con mucha fuerza, poniéndose de manifiesto por la multiplicación de los teónimos y por un hecho sobre el que ha llamado la atención $\mathrm{A}$. Tranoy para zonas más septentrionales, la elaboración de un sistema de abreviaturas comprensibles para los fieles de cada culto ${ }^{104}$.

104 A. Tranoy, "Enigmes épigraphiques et nouveaux cuites indigènes dans le conuentus de Braga», Rev.Guimarães 94, 1984. p. 449 . 


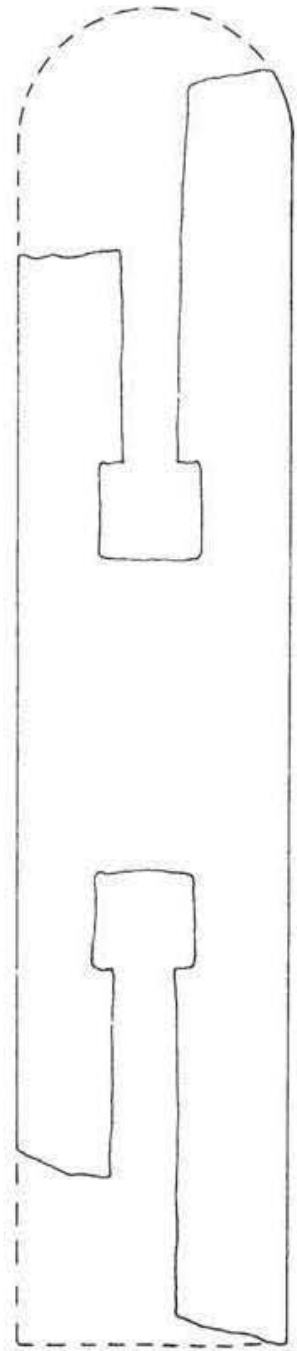

44

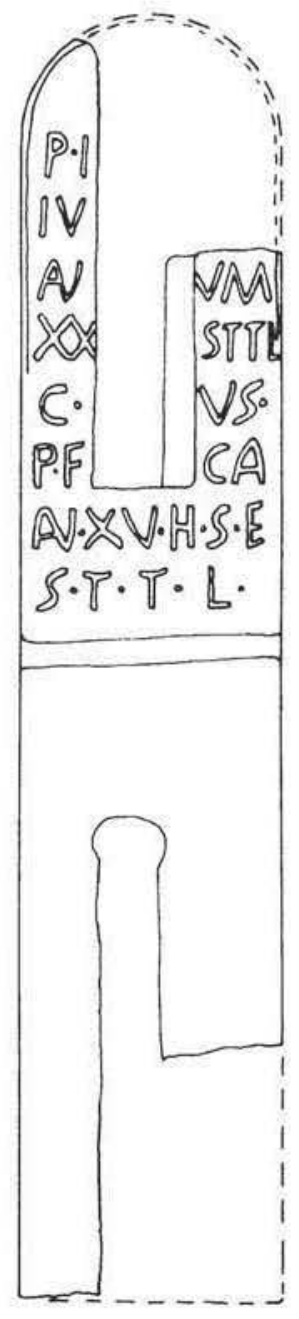

29

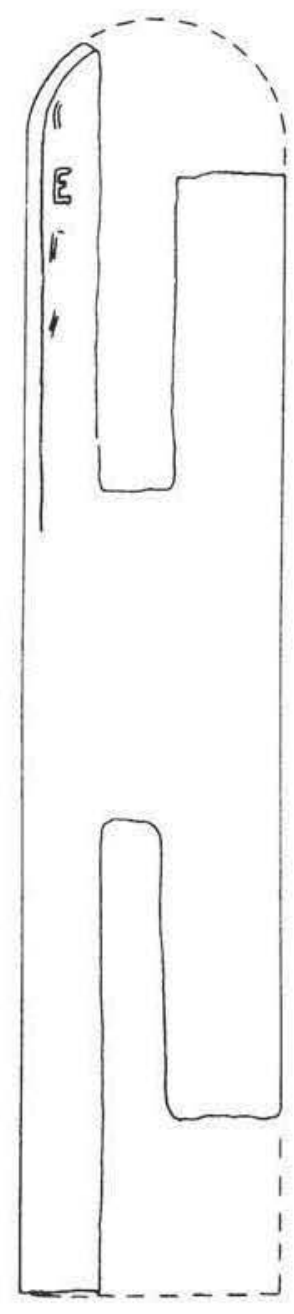

30

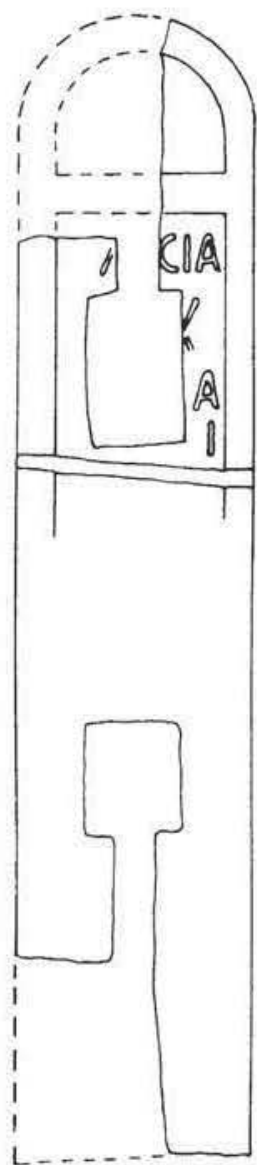

28

Figura 49.--Estelas de cabecera semicircular sirviendo de umbrales en el templo de Santa Lucía del Trampal.

En los diferentes enclaves de esta región, muchos de ellos lejos de la categoría de ciudades o municipios con que podemos referirnos a otras zonas peninsulares, los hallazgos epigráficos $\mathrm{y}$, más aún, la microtoponimia de esos hallazgos, evidencia un sin fin de concentraciones muy alejadas, salvo excepciones, del esquema de grandes necrópolis o centros de culto que podemos aplicar en otras áreas. Dentro de cada uno de estos grupos es posible establecer afinidades formales o de contenido entre un monumento y otro, pero no es tan fácil hacerlo con la concentración vecina. Dicho en otras palabras, en la región que nos ocupa no parece fácil identificar officinae lapidarias que hayan trabajado para áreas extensas; por el contrario, parece que estamos ante canteros que se ocupan de atender las necesidades de un entorno muy reducido. Pese a este carácter individual de la producción no faltan las referencias a prototipos ya establecidos o a los cánones clási$\cos$. De hecho estamos ante poblaciones que poseen una fuerte impronta latina, pero que mantienen hábitos y formas de organización autóctonos.

Esta dispersión de los trabajos epigráficos lleva a la identificación múltiple de estilos locales, de afinidades comarcales, contemporáneas de las vecinas, pero diferentes en la ejecución. Por circunscribirnos a las dedicaciones de Ataecina y no prolongar este excursus, basta aducir el ejemplo de los altares de Herguijuela (Cáceres), semejantes entre sí pero distintos a otros del contorno; o la homogeneidad formal de las dedicaciones de Malpartida de Cáceres, empleando el exvoto en forma de cabra para soldar a sus pies una placa con la inscripción. En otros cultos aún podríamos aducir las dos arae ge- 
melas de Coria dedicadas a Arentia y Arentius y la semejanza formal de muchas de las dedicaciones a Endouellicus del santuario de Terena.

En esas condiciones se entiende fácilmente que el santuario o lugar de culto del que proceden las dedicaciones a Ataecina de Santa Lucia del Trampal manifieste rasgos propios en el quehacer epigráfico: lo más probable es que una misma officina o varias generaciones de canteros locales atendieran las necesidades de un centro cuya vitalidad alcanza, al parecer el siglo ॥i d.C. Otro tema será ubicarlo y de ello hablaremos más adelante.

\subsection{LAS ESTELAS Y LOS TALLERES REGIONALES}

El reempleo de estelas funerarias y de otros tipos de inscripciones romanas en monumentos posteriores es habitual en casi todo el mundo romano, máxime en aquellas zonas cuya riqueza epigráfica ha ofrecido una extraordinaria cantera de la que extraer piezas ya trabajadas (figs. 49 y 50 ).

En el ámbito regional de Alcuéscar esta práctica es corriente durante la antigüedad tardía. Las estelas funerarias, por su especial formato, sirven en más de una ocasión como umbrales para apoyo de canceles en templos tardios; al respecto hay que referirise a la basilica de Ibahernando ${ }^{105}$, fechada por un texto en el año 635 d.C. ${ }^{106}$, en donde una estela funeraria romana sirve de umbral en el acceso al ábside con los correspondientes recortes para la inserción del cancel, exactamente igual que en el templo de Santa Lucía de Alcuéscar ${ }^{107}$; el mismo fenómeno se reproduce en la iglesia de El Gatillo de Arriba (término municipal de Cáceres), en donde la estela alcanza los $185 \mathrm{~cm}$ de longitud conservada (fig. 51) ${ }^{10 x}$; otros ejemplos del reempleo de este tipo

${ }^{109} \mathrm{C}$. Callejo, «Templo visigodo dedicado a la virgen en Ibahernando", REstExtr. 1963, pp. 535-548; E. Cerrillo, «Excavaciones en la basilica de Magasquilla de los Donaires en Ibahernando (Cáceres)", XIII Congr.Nac.Arq. Huelva 1973, Zaragoza 1975, pp. 979 ss.; M. Beltrán Lloris, Museo de Cáceres. Sección de Arqueologia, Cáceres 1982, p. 60: E. Cerrillo, La basi lica de época visigoda de Ibahernando. Cáceres 1983; id., La vida rural romana en Extremadura, Cáceres 1984, pp. 121-2: L Caballero et alii, Extremadura arqueológica 2, op. cit. en nota 2. p. 513.

${ }^{106} \mathrm{C}$. Callejo, "Cuatro inscripciones visigodas de Extremaduraw, Ampurias 24, 1962, pp. 244 ss. (= HAE 2214); ICERV 549; E. Cerrillo, op. cit. en nota 105, p. 980, lám. 1: M. Beltrán Lloris, op. cit. en nota 105, p. 93: CPIL Cáceres 721.

${ }^{107}$ E. Cerrillo, op. cí en nota 105, p. 981, lám. 11, 2.

rox L. Caballero y J. Rosco, elglesia de El Gatillo de Arriba, finca de la Matallana (municipio y provincia de Cáceres). Informe preliminar de la primera campaña de excavaciones arqueológicas. Octubre-noviembre 1985", Extremadura arqueológica 1. 1988, p. 255; L. Caballero, V. Galera y M.D. Garralda, «La

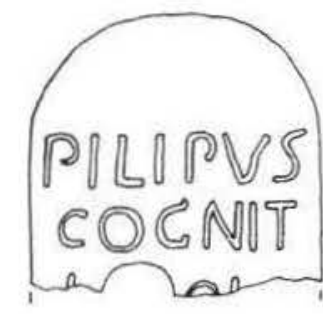

17

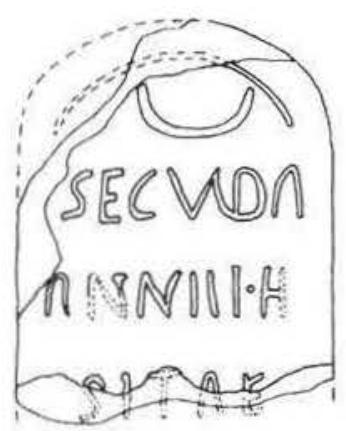

25
Figura 50.-Cabeceras semicirculares de estelas en Santa Lucia del Trampal.

de materiales se pueden encontrar en La Puerta de Coria en la muralla de Trujillo, Alconétar, Santa OlaIla, Portera en Cáceres, S. Pedro de Mérida, etc. ${ }^{109}$.

Las estelas reempleadas en Santa Lucia del Trampal pertenecen a un tipo de monumento de grandes proporciones y remate en cabecera semicircular. En lineas generales el prototipo es habitual en muchos ámbitos de occidente, aunque las tradiciones locales y el peso del indigenismo determinan un $\sin$ fin de variantes.

Aunque no faltan en amplias zonas de la Tarraconense, en donde hay grupos bien definidos en el valle del Ebro ${ }^{110}$, Lara de los Infantes (Burgos) ${ }^{11}$, Ubeda y Santo Tomé (Jaén) ${ }^{112}$, otro muy interesante en el área valenciana de La Safor ${ }^{113}$, etc., la mayor parte de las estelas de cabecera semicircular producidas por talleres hispanos lo fueron en las dos márgenes del bajo Duero, cerca de la desembocadura del Tajo y en áreas muy especificas del sur de Galicia y centro de Extremadura. En cada una de

iglesia de época paleocristiana y visigoda de EI Gatillo de Arriba (Cáceres)m, Extremadura arqueológica 2, 1991, p. 478 (= HEp 4, 221).

${ }^{104}$ E. Cerrillo, op, cit, en nota 105, p. 122. En general, cfr. L. Caballero y J. C. Sánchez, op. cit, en nota 2.

110 G. Gamer, "Römische Altarformen im Bereich der Stelengruppen Burgos und Navarra", MDAI(M) 15, 1974, p. 215; U.

Espinosa, Epigrafia romana de la Rioja, Logroño 1986, p. 138 $y$ fig. 4 .

ii J. A. Abásolo, Epigrafia romana de la región de Lara de los Infantes, Burgos 1974; id.. "Las estelas decoradas de la región de Lara de los Infantes. Estudio iconográficon, BSEAA 43. 1977, pp. 61-97: M. ${ }^{2}$ L. Albertos, $\omega \mathrm{El}$ conjunto epigráfico del Museo de Burgos y los antropónimos hispánicos de Lara de los Infantes y de sus proximidadesn, Hom. Antonio Tovar, Madrid 1972, pp. 47-58.

112 C. González Román y J. Mangas, Corpus de inscripciones latinas de Andalucia. Vol. III: Jaén. Tomo I, Sevilla 1991. pp. 399 ss.

iis J. Corell, Las inscripciones romanas de La Safor. Madrid 1992, passim. 


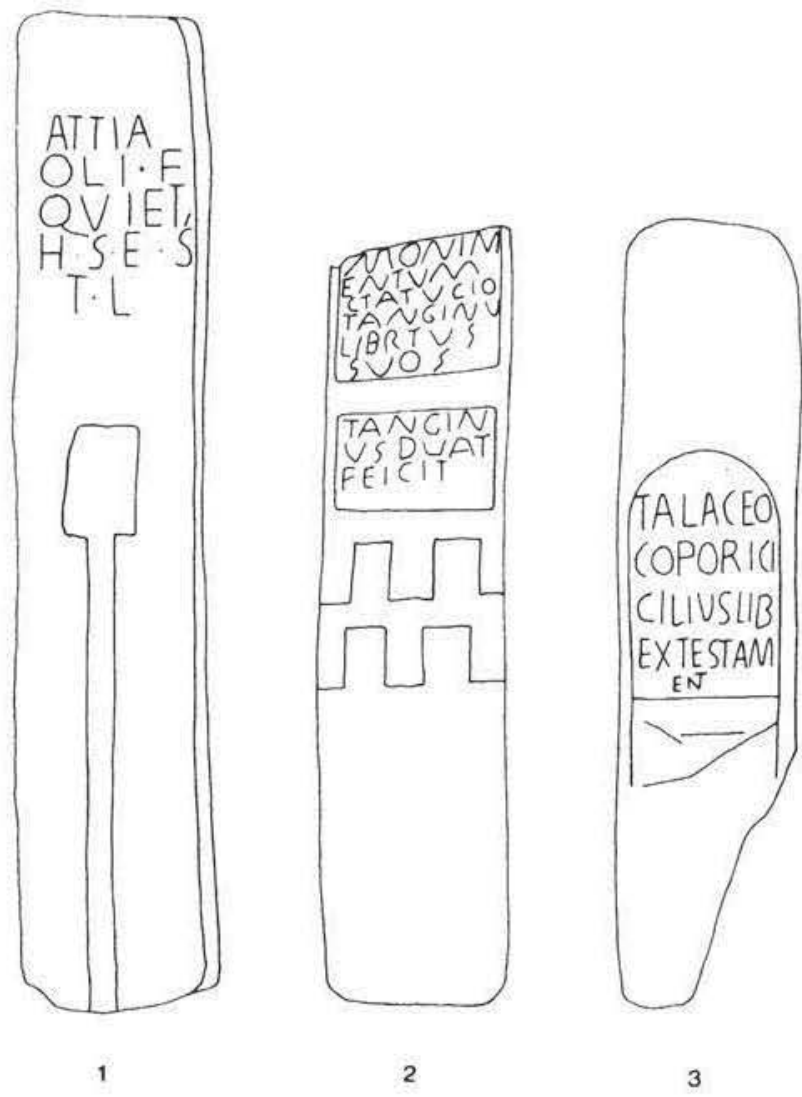

Figura 51.-Grandes estelas extremeñas y portuguesas: I. El Gatillo (Cáceres. A partir de fotografia de L. Caballero, Antigüedad y Cristianismo 7, 1990, p. 451, fig. 5.2); 2 y 3. Vila Boa (Sabugal, Guarda. A partir de fotografias de F. Patricio Curado).

estas zonas se manifiesta la actividad de una o varias officinae que generalmente trabajan para ámbitos locales muy restringidos, lo que nos permite identificar su trabajo por el nombre de un enclave próximo al área en que se concentran las estelas.

Algunos de estos talleres tienen una larga tradición en los estudios historiográficos; es el caso del grupo de Vigo (Pontevedra) ${ }^{114}$, que destaca por el tamaño de sus ejemplares y peculiaridades decorativas como el empleo de figuras humanas, o de los grupos de Braga ${ }^{115}$ y de Picote (conc. Miranda do

114 D. Juliá, Etude épigraphique et iconographique des stèles funéraires de Vigo, Heidelberg 1971; cfr. también J. M." Alvarez Blázquez y $\mathrm{F}$. Bouza Brey, "Inscripciones romanas de Vigo», CEG 16, 1961, pp. 5-42; S. Rodriguez Lage, Las estelas funerarias de Galicia en la época romana, Orense 1974; G. Baños Rodriguez, Corpus de inscripciones romanas de Galicia ( $G$. Pereira, Dir.), II. Provincia de Pontevedra, Santiago 1994, pp. 107 ss.

115 A. Tranoy y P. Le Roux, "Les necrópoles de Bracara Augusta: B. Les inscriptions funéraires", Cadernos de Arqueologia 6-7, 1989-90, pp. 183-230.
Douro, dist. Bragança) ${ }^{116}$, en el distrito de Bragança; este último guarda una gran relación con otros conjuntos muy numerosos y uniformes de las vecinas provincias de Zamora y Salamanca (Muelas del Pan, Villalcampo, Hinojosa del Duero ${ }^{117}$, Yecla de Yeltes $^{11 x}$ ). Otros talleres o grupo de ellos que confeccionan estelas con cabecera semicircular, como el del concelho de Torres Vedras (distrito de Lisboa) ${ }^{119}$, se han conocido en fecha más reciente.

En el ámbito extremeño tampoco faltan las officinae que fabrican este tipo de estelas, en ocasiones con cartelas para el texto, como las que aparecen en Alcuéscar. Sin embargo, el tamaño de estas piezas suele ser más reducido que el de las estelas que sirven de umbrales en Santa Lucia del Trampal. El núcleo más importante de monumentos de este tipo es el de la necrópolis de "Mezquita» en Ibahernando ${ }^{120}$, que constituye el punto clave para entender el hábito epigráfico en el mediodia cacereño.

ith Consideraciones sobre el grupo en M. Gómez Moreno, $\mathrm{Ca}$ tálogo monumental de España: provincia de Zamora (19031905). Madrid 1927, p. 22: A. Tranoy, La Galice romaine. Paris 1979 , p. 353 , nota 295 . Una muestra representativa del conjunto la constituyen los siguientes ejemplares: EE 9, 291, 292, 292 a-c; F. M. Alves, Guia epigráfico do Museu Regional de Bragança. Memórias arqueológico-históricas do distrito de Braganşa 9. Porto 1933, núm. 29, 35 y 36; P. Le Roux y A. Tranoy, "L'épigraphie du nord du Portugal: bilan et perspectives", Conimbriga 23, 1984, p. 35, nota 47: AE 1987. 566; AE 1987, 567; AE 1987, 568; AE 1987, 570; AE 1987, 572; AE 1987, 600: AE 1987, 602.

117 J. Maluquer, Carta arqueológica de España. Salamanca, Salamanca 1956, núm. 38 ss.; C. Morán, "Curiosidades epigráficas de la provincia de Salamanca", $B R A H 77,1920$, pp. 400409; id. Epigrafia romana de Salamanca y su provincia, Salamanca 1922; Joaquin M." de Navascués, "Onomástica salmantina de época romana», $B R A H$ 158, 1966, pp. 181-203; T. Mañanes et alii, «Un conjunto epigráfico inédito en Medina del Campo (Valladolid)", HAnt 16, 1992, pp. 273-308; A. Jiménez de Furundarena et alii, "Contribución a la epigrafia del oeste de la provincia de Salamanca. El conjunto de Medina del Campo (Valladolid)", en Espacio. Tiempo y Forma, serie II. $H^{a}$ Antigua, vol. 6. 1993, pp. 133-160; L. Hernández Guerra et alii, «Nuevas aportaciones a la epigrafia de Salamanca: Hinojosa de Dueron, HAnt 18, 1994, pp. 317-379.

118 R. Martin Valls, "Notas sobre la epigrafia romana de Yecla de Yeltes (Salamanca)", Durius I, 1973, pp. 37-43, con especial interés en p. 38 , nota 4 , en donde remite a los trabajos previos de Morán, Maluquer, Gómez Moreno, Navascués, etc.: id., «Novedades epigráficas del castro de Yecla de Yeltes (Salamanca)", en Estudios dedicados a Carlos Callejo Serrano, Cáceres 1979, pp. 501 ss; id., "La necrópolis del castro de Yecla de Yeltes. Datos arqueológicos y epigráficos para su estudion, Zephyrus 34-35, 1982, pp. 181-201.

119 Vasco Gil Mantas, "Inscriçoes romanas do Museu Municipal de Torres Vedras", Conimbriga 21, 1982, pp. 5-99; id., "Tres inscriçoes romanas do concelho de Torres Vedras", Conimbriga 24, 1985, pp. 125-49.

120 Sobre la necrópolis de Mezquita, $c f r$. Marqués de Monsalud, "Nuevas inscripciones romanas de Extremadura», $B R A H 36$, 1900. pp. 5-13; E. Hübner, "Inscripciones romanas sepulcrales de Ibahernandon, Revista de Extremadura 2, 1900, pp. 145 ss.; M. de Monsalud, «Nuevas inscripciones romanas de Extrema- 
La costumbre de señalar una cartela para el texto es una práctica escultórica común en muchas oficinas lapidarias del mundo romano. En el ámbito cacereño no escasean los ejemplos; sin embargo, es más dificil esgrimir testimonios de estelas de cabecera circular con cartela en este ámbito regional: las pocas estelas de este tipo proceden, curiosamente, del área más próxima a Alcuéscar, y se localizan en Torre de Santa Maria ${ }^{121}$, Salvatierra de Santiago ${ }^{122}$ y Cáceres ${ }^{123}$, aunque en todos los casos citados sus dimensiones son menores que en los ejemplos de Santa Lucia.

La búsqueda de monumentos de dimensiones similares a los del Trampal en Extremadura y en áreas próximas nos permite esgrimir un buen número de ejemplos, aunque sin una correspondencia formal precisa con los epigrafes de Alcuéscar. Generalmente son piezas apenas trabajadas, sin cartelas para contener el texto, que llegan a alcanzar los 220 $\mathrm{cm}$ de altura en el caso del ejemplar de Alconétar (Garrovillas, Cáceres). La dispersión geográfica de estos grandes monumentos señala una mayor concentración en el cuadrante suroriental de la provincia de Cáceres, en un área relativamente próxima a Alcuéscar; algo más al suroeste, ya en provincia de Badajoz, la excepción a todos los cánones modulares es la tosca estela de pizarra de Siruela (Badajoz), que alcanza los $290 \mathrm{~cm}$ de altura ${ }^{124}$. Al menos nueve estelas cacereñas alcanzan o superan los 175 $\mathrm{cm}$ de altura ${ }^{125}$, excepción hecha de las de Santa Lucia del Trampal.

dura", $B R A H 40,1902$, pp. 541-546; id., "Nuevas lápidas romanas de Extremaduran, BRAH 43, 1903, pp. 528-535; M. Roso de Luna, "Nuevas inscripciones de Ibahernando, Cumbre y Santa Ana", en $B R A H 42,1903$, pp. 232-235; J. Sanguino y Michel, "Nueva lápida romana de Ibahernando", $B R A H 44,1904$, p. 424; J. Ramón y Fernández Oxea, "De epigrafía cacereña», $B R A H$ 128, 1951, pp. 165-195; id., Nuevos epigrafes romanos en tierras de Cáceres, $B R A H$ 136, 1955, pp. 252 ss.; $i d$., "Seis inscripciones romanas en tierras cacereñas", $B R A H 150,1962, \mathrm{pp} .123$ ss.; C. Callejo, "Aportaciones a la epigrafia del campo norbense», BRAH 157, 1965, pp. 11-82; E. Cerrillo y J. M." Fernández. «Contribución al estudio del asentamiento romano en Extremadura. Análisis espacial aplicado al sur de Trujillo», Norba I. 1980, pp. 157-175.

121 AE 1968, 220.

122 Tres testimonios: HAE 942; HAE 338/943; HEp I, 185.

123 AE 1971, 155 .

124 M. Beltrán Lloris, "Aportaciones a la epigrafia y arqueología romana de Cáceres», Caesaraugusta 39-40, 1975-76, p. 71 , núm. 50 y fig. $41=\mathrm{AE} 1977,422$.

125 1. Brozas (AE 1977, 413. $237 \times 35 \times 33 \mathrm{~cm}$ ); 2. Garrovillas (HAE 1804. $220 \times 48 \times 30 \mathrm{~cm}$ ); 3. Brozas (M. Beltrán Lloris, op. cit. en nota 105, p. $92: 220 \times 30 \times 29 \mathrm{~cm}) ; 4$. Granadilla (J. Salas y A. Martínez Cordero, «Nuevas aportaciones a la epigrafia latina de la provincia de Cáceres», Norba-Historia 11 . 12, 1991-92, p. 186, núm. 8, lám. $8.197 \times 45 \times 23 \mathrm{~cm}) ; 5$. Torreorgaz (CIL II 5309. $196 \times 40 \times 19 \mathrm{~cm}$ ); 6. Talavera la Vieja
Si nos adentramos en el centro y norte de Portugal es fácil encontrar algunas estelas que recuerdan formalmente los ejemplares de Santra Lucia del Trampal. Es el caso de dos ejemplares procedentes de Vila Boa (conc. Sabugal, dist. Guarda), muy cerca de tierras cacereñas, que, aún fracturados, superan los $170 \mathrm{~cm}$ de altura, se rematan en cabecera semicircular y poseen cartelas de texto ${ }^{126}$; curiosamente, como los testimonios cacereños, también estas dos estelas fueron reaprovechadas como material de construcción, aunque en esta ocasión como jambas de puertas (fig. 51).

Próximas modularmente, pero ajenas al ámbito estético al que nos referimos, son dos preciosas estelas de granito procedentes de Braga, con cabecera semicircular y cartela para texto, profusamente decoradas $^{127}$, o la estela de granito de Favaios (conc. Alijó, dist. Vila Real), con sus $180 \mathrm{~cm}$ de altura ${ }^{12 x}$. Más al este, ya en distrito de Bragança y en el área en que se encuentran las estelas de tipo Picote, junto a la comarca zamorana de Sayago, se pueden ver también estelas de grandes dimensiones pero tampoco relacionables estilisticamente con el grupo que nos ocupa: es el caso de los ejemplares de Pinhovelo (conc. Macedo de Cavaleiros), Santulhao (conc. Vimioso) y Sanhoane (conc. Mogadouro) ${ }^{129}$.

Al sur y este de Alcuéscar, en el suroreste peninsular, desaparecen las estelas y aras de grandes dimensiones como las que se encuentran en zonas más septentrionales. Baste como ejemplo decir que los dos mayores ejemplares del conuentus Pacensis, una estela de granito de Aldeia da Mata (conc. Crato, dist. Portalegre) ${ }^{130}$ y un cipo de lumachela proce-

(ibid. p. 182, núm. 6, lám. 6, $190 \times 42 \times 24 \mathrm{~cm}$ ); 7. El Gatillo de Arriba (Cáceres. Cfr. nota 108. $185 \mathrm{~cm}$ ): 8. Ibahernando (EE 9. 105. $177 \times 36 \times 12 \mathrm{~cm}$ ); 9. Nuñomoral (AE 1977, 385. $175 \times 35 \times 10 \mathrm{~cm})$.

126 F. P. Curado, "Estelas funerarias de Vila Boa (Sabugal)", FE 27, 1988, núm. 123.1 (= AE 1989, 388; HEp 2, 807) y 123.2 (= AE 1989, 389; HEp 2, 808); M.M. Alves, «Para um repertório das inscriçoes romanas do território português (1988)", Euphrosyne 19, 1991, pp. 469 ss., núm. 132 y 133.

$127 \mathrm{AE} 1973,297(184 \times 47,4 \times 14,5 \mathrm{~cm})$ y $\mathrm{AE} 1973,299$ $(175 \times 57.5 \times 15 \mathrm{~cm})$.

12K AE 1983, 584 .

124 Pinhovelo: F. M. Alves, op. cit. en nota 90, pp. 72 ss., núm. $37(151 \times 30 \times 13 \mathrm{~cm})$. Santulhao: F. M. Alves, op. cit., pp. 82 ss., núm. $45(193 \times 42 \times 12 \mathrm{~cm})$. Sanhoane: AE 1987, 587 $(162 \times 62 \times 40 \mathrm{~cm})$.

${ }_{130} \mathrm{FE} 9=\mathrm{AE} 1982,457 ;$ IRCP 624 . Aunque pertenece a este mismo conuentus, no puede tenerse en cuenta la estela de Pata$\lim$ (Montemor-o-Novo), que alcanza los $194 \mathrm{~cm}$, pero que no está trabajada en sus extremos y que carece, por tanto, de un diseño físico previamente establecido; $c f r$. A. Guerra, "Statua Langari. A propósito de uma inscriçâo latina proveniente de Patalim (Montemor-o-Novo)", Portugalia 13-14, 1992-93, pp. 297-303. 
dente de Mélides (conc. Grándola, dist. Setúbal) ${ }^{13}$. sólo miden 176 y $174 \mathrm{~cm}$ de altura, respectivamente.

Tras este rápido repaso a las semejanzas modulares y compositivas de estelas extremeñas y portuguesas, conviene detenerse en un ejemplar mucho más cercano geográficamente a los del Trampal y que puede aclarar algunas dudas sobre la ubicación de la necrópolis que sirvió de cantera a los constructores de Santa Lucia.

Hace unos años fue dado a conocer un epigrafe que servía de asiento en un molino de aceite en $\mathrm{Al}$ cuéscar y que había sido traido de las cercanas ruinas de "Las Torrecillas». El monumento es una estela de granito con cabecera semicircular ${ }^{132}$, de poco más de un metro de altura, que presenta una doble cartela con dos textos funerarios y un creciente lunar superior. La semejanza formal con las estelas de Alcuéscar es alta, hasta el punto de que el ancho y el grosor de la pieza están en la línea de los ejemplares que sirven de umbrales en Santa Lucía del Trampal. La única diferencia sensible, la altura, no parece ser un obstáculo, ya que en los ejemplares de Santa Lucía el texto ocupa sólo la parte superior del monumento, mientras el resto de la estela se encuentra sin trabajar. En el ejemplar ya aludido de «Las Torrecillas» da la impresión de que la parte inferior se ha perdido a juzgar por la fractura visible, por lo que no es descartable que nos encontremos ante un monumento del mismo tipo.

En algunas de las estelas de Santa Lucia del Trampal se puede ver un creciente lunar en la cabecera. Frecuentemente ésta es la única decoración que presentan muchos ejemplares en este ámbito regional. Un rápido repaso por los monumentos del área cacereña muestra lo corriente de estos crecientes lunares en la parte superior de las estelas, pues se pueden ver en epígrafes del área próxima a Alcuéscar, en la periferia del trifinium de Norba, Turgalium y Emerita (Ibahernando, Salvatierra de Santiago, Santa Cruz de la Sierra, Torre de Santa Maria, Villamesias, Escurial, Valdefuentes, Robledillo de Trujillo) ${ }^{133}$, en el propio enclave de Turgalium $^{134}$, en el área

13 EE 8, 5; IRCP 210, que D'Encarnaçao data en el siglo III d.C.

132 A. González Cordero et alii, op. cit. en nota 4, núm. 7, pp. 293-295, lám. 6 = HEp 1, 152; V. Soria, XVI Coloquios Históricos de Extremadura, Trujillo 1987, p. 26, núm. 2; id., Aguas Vivas 8, 1988, III, núm. 2.

I31 Ibahernando: EE 9, 105, 106 y 110 a; HAE 680. Salvatierra de Santiago: CIL II 681, CPIL Cáceres 427 y 428 . Santa Cruz de la Sierra: CIL II 684 y HAE 198. Torre de Santa Maria: HAE 2678 y AE 1968, 223. Villamesias: CIL II 664, CIL II 668, CPIL Cáceres 620 y 635. Escurial: CIL II 660. Valdefuentes: HEp I, 195 y CPIL Cáceres 582. Robledillo de Trujillo: HAE 207 y 210. 400 . suroriental al norte del Guadiana (Logrosán, Herguijuela) ${ }^{135}$, en los valles septentrionales del Alagón y Arrago (Coria, Casillas de Coria, Villanueva de la Sierra, Oliva de Plasencia) ${ }^{136}$ o en zonas próximas al valle del Tajo (Belvis de Monroy, Villar del Pedroso, Garrovillas) ${ }^{137}$, sin ser exhaustivos en una relación que forzosamente tendria que ser más amplia.

\subsection{LAS CUPAE}

En el conjunto de monumentos de Santa Lucia del Trampal figuran tres cupae ${ }^{13 x}$ anepigrafas, pertenecientes a un tipo corriente en amplias regiones del suroeste peninsular que no falta aisladamente en otras zonas de Hispania. Frente a los ejemplares en forma de medio tonel con señalamiento de aros en relieve, típico del área alentejana, los ejemplos de Alcuéscar pertenecen a un modelo más sencillo disperso por áreas del Algarve, Beira Litoral, regiones de Olisipo y Mérida y áreas próximas ${ }^{13 \%}$. No han faltado las opiniones de quienes han visto en las cupae una significación religiosa y una rela-

\footnotetext{
1' Logrosán: CPIL Cáceres 167; HEp 1, 168. Herguijuela: CPIL Cáceres 266.

136 Coria: CIL II 764, 774, 781 y 785; EE 9, 124; AE 1976 278 a. Casillas de Coria: CIL II 798. Villanueva de la Sierra: CIL II 802 y 803 . Oliva de Plasencia: CIL II 818.

137 Belvis de Monroy: CIL II 5349. Villar del Pedroso: HAE 199. Garrovillas: HAE 1804

13x W. Wolski e I. Berciu. "Un nouveau type de tombe mis au jour à A pulum et le problème des sarcophages à voûte de l'Empire romain", Latomus 29. 1970, pp. 919-965; id., "Contribution au problème des tombes romaines à dispositif pour les libations funèraires", Latomus 32, 1973, pp. 370-379; J. N. Bonneville. "Le support monumental des inscriptions: terminologie et analyse», en Epigraphie Hispanique, Paris 1984, p. 128; L. BacchieIIi, "Monumenti funerari a forma di cupula: origine e diffusione in Italia meridionale», en L Africa romana. Atti del III conveg. no di studio. Sassari 1985. Sassari 1986, pp. 303-319; I. di Stefano Manzella, Mestiere di epigrafista. Guida alla schedatura del materiale epigrafico lapideo, Roma 1987, p. 90. En Hispania: A. García y Bellido, Esculturas romanas de España y Portugal, Madrid 1949, pp. 317 ss.; D. Juliá, "Les monuments funéraires en forme de démi-cylindre dans la province romaine de Tarraconaise», $M C V 1$, 1965, pp. 29-70; M. Bendala, «Las necrópolis de Mérida", en Augusta Emerita. Simposio internacional conmemorativo del bimilenario de Mérida 1975, Madrid 1976, pp. 149-150; M." P. Caldera, "Una sepultura de cupa hallada en Mérida", Habis 9, 1978, pp. 455-463; J. N. Bonneville, "Les cupae de Barcelone: les origines du type monumental», $M C V$ 17, 1981, pp. 5-38; V. Gil Mantas, "Inscriçoes romanas do Museu Municipal de Torres Vedras», Conimbriga 21, 1982, núm. 1, pp. 10-17, con un amplio estudio que sirve necesariamente de referencia a trabajos posteriores; A. CabaIlos, "Varia funeraria italicense», Habis 25, 1984, pp. 227 ss., con un detallado análisis a partir de recientes hallazgos en la ciudad.

139 V. Gil Mantas, op. cit. en nota 138, pp. 13-14.
} 
ción directa con el culto de Endouellicus ${ }^{1+1}$, aunque a la vista de la proliferación del tipo en Italia, oriente y Africa parece más prudente relegar esta sugerencia ${ }^{\mid+1}$

Aunque una de las cupae de Santa Lucia se encuentra empotrada y no es posible saber si posee decoración lateral, da la impresión de que el único ejemplar con la superficie trabajada es el núm. 49. que presenta dos círculos concéntricos en la cara frontal.

En el ámbito cacereño conocemos un buen número de monumentos de este tipo, aunque desgraciadamente casi todos ellos anepigrafos o con el texto borrado u oculto. Cabe recordar los 12 ejemplares ilegibles identificados en la muralla de Coria, los 3 del castillo de Trujillo también ilegibles o el empotrado en la muralla de Cáceres cerca de la torre de Espaderos ${ }^{142}$. La excepción es uno de los ejemplares de la muralla de Coria, aparecido hace unos años al derribar una casa adosada a la muralla, que contiene la dedicación funeraria realizada por Quintius [Proc/ulus y Titia [---] a para su hijo ${ }^{1+3}$.

En Hispania, tradicionalmente este tipo de monumentos se han asociado con los ámbitos fuertemente latinizados de la Bética occidental, centro y sur de Lusitania y costa norte de la Tarraconense - donde destaca la extraordinaria serie de Barcino-; sin embargo, recientes descubrimientos están ampliando su área de dispersión a puntos del noroeste peninsular y norte de Extremadura, como lo prueba ya serie cacereña ya mencionada y los 24 ejemplares empotrados en la muralla de Astorga ${ }^{144}$. En el caso extremeño es muy probable que la extensión de este tipo monumental sea consecuencia de la vitalidad de los talleres emeritenses.

140 W. Deonna, "Quand dieu roule ses tonneaux", Genava 24 1946. pp. 46 ss.; S. Lambrino, "Le dieu lusitanien Endovellicusm, Bulletin des études portugaises 15, 1951, pp, 129 ss.

141 Cfr. las reticencias en este sentido de Blázquez, Religiones 1962, p. 163, recogiendo además las opiniones verbales de A. Garcia y Bellido, que suponía una vinculación de estos monumentos con el culto de Dionisos. Vid. al respecto V. Gil Mantas, op. cit. en nota 138, p. 16.

142 Recuento de A. González Cordero et ulii, «Nuevas aportaciones a la epigrafia de Extremadura», Alcántara 8, 1986. p. 71 .

${ }^{143} \mathrm{AE} 1985,537$ y HEp 4, 229, a partir de la reciente edición de Salas y Rosco, que la consideran inédita.

144 T. Mañanes, "De epigrafia leonesa IIl», Archivos Leoneses 45 , núm. 89.90, 1991, pp. 375-378.

\section{CRONOLOGIA Y VALORACIÓN PRELIMINAR DE LAS INSC RIPCIONES}

\subsection{CRONOLOGIA}

Las estelas funerarias empotradas en el templo de Santa Lucia o halladas en sus alrededores ofrecen un abanico cronológico que va de fines del siglo I d.C. a comienzos del III d.C. Tales extremos encierran también la parte sustancial del hábito epigráfico en Hispania, por lo que no aportan ninguna novedad. Sin embargo, el estilo y contenido de los ejemplares que sirven de umbrales parece uniforme y sería testimonio de la existencia de un área funeraria, cuya ubicación ya hemos discutido, en uso a fines del siglo I o comienzos del II d.C., una fecha en que la producción epigráfica en el sur cacereño es muy importante, probablemente como consecuencia del cercano influjo de la capital provincial de Lusitania.

Otro grupo de estelas, con encabezamientos del tipo $D$ (is) M(anihus) o $D$ (is) M(anihus) s(acrum), datadas ya desde comienzos del siglo " hasta comienzos del III d.C., responden a los tipos habituales en amplias áreas de la Extremadura española y el Alto Alentejo. Son los tipos elaborados en granito y calizas locales, corrientes en casi todas las necrópolis de esta zona, que testimonian altos porcentajes de población indígena en diferentes grados de latinización.

Más dificultades ofrece la datación de los altares dedicados a Ataecina. Aludiremos luego a ello, pero adelantaremos aqui que las evidencias epigráficas de los textos hallados en las provincias de Toledo, Badajoz y Cáceres, antes del descubrimiento de Santa Lucía del Trampal, ofrecen fechas que van del siglo I al III d.C.; en consecuencia, la propia presencia de Ataecina como objeto de las dedicaciones carece de valor cronológico. Más éxito puede proporcionar el análisis de la paleografia comparada con la de textos funerarios del ámbito regional regularmente datados.

El material empleado como soporte de los epígrafes de Santa Lucia, un granito procedente de los muchos afloramientos de la región, es tan incómodo para nuestra interpretación de los textos como para su grabación en la antigüedad. Los artesanos que elaboraron los altares sacaron, por añadidura, poco partido de un tipo de soportes que otros talleres supieron elaborar con más cuidado. En la ejecución de los textos se adivina una mezcla de manos con diferentes grados de experiencia que van desde la meticulosidad de quien inscribió la dedicación hecha por [-.] Caesius Cresces (núm. 9) hasta el 

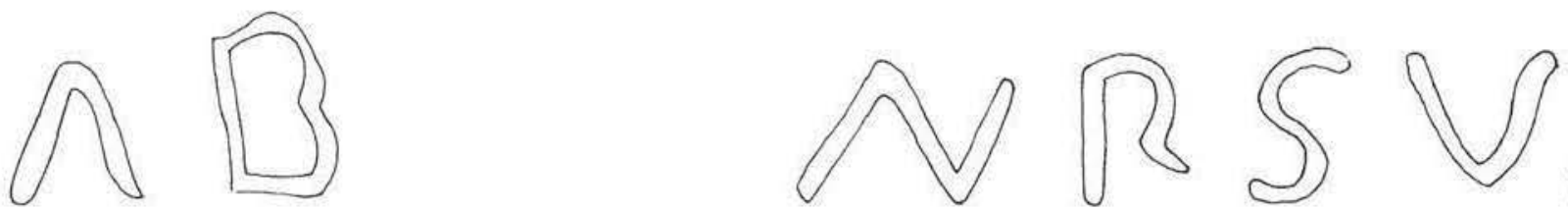

22
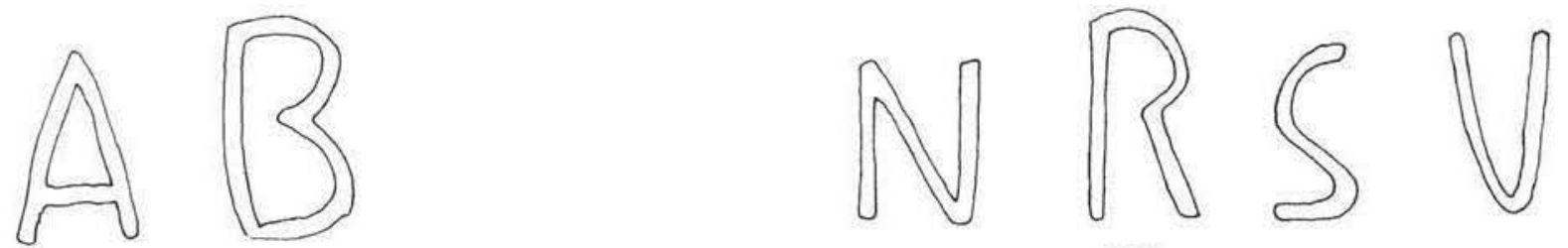

5
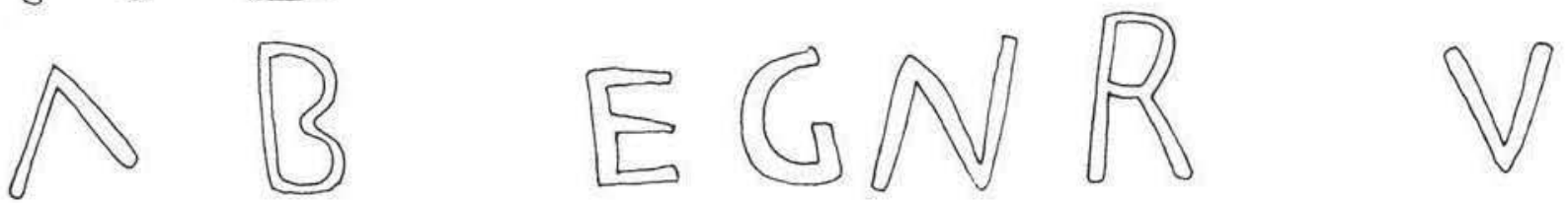

6
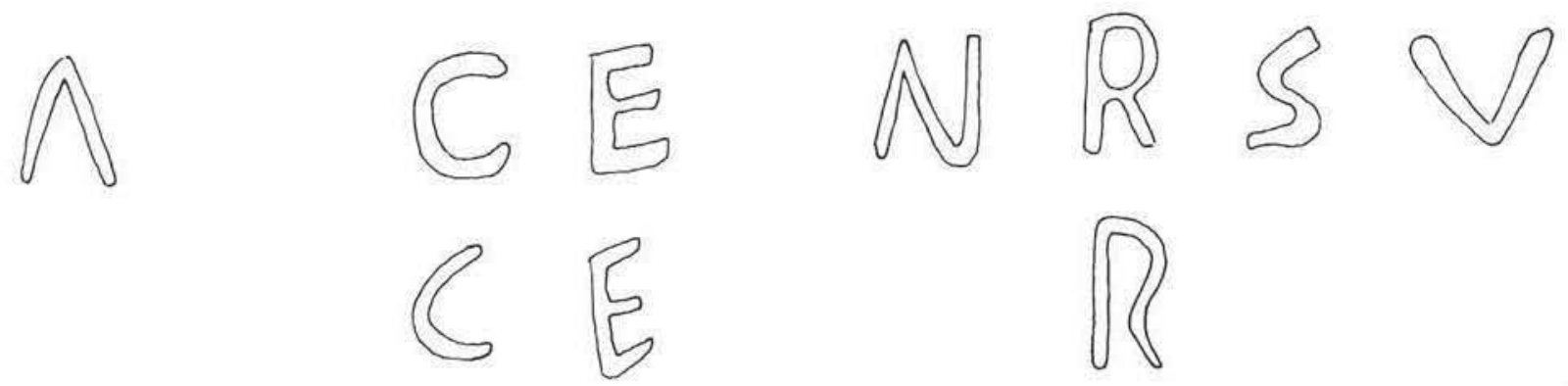

13
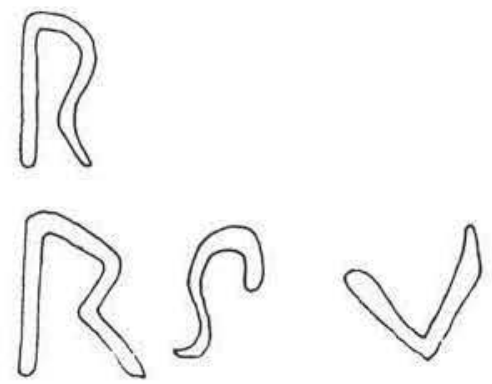

18

Figura 52.-Ejemplos de tipos de letras en las inscripciones de El Trampal.

exagerado descuido de quien ejecutó la inscripción núm. 14.

En medio queda un amplio abanico de resultados que no sirve relacionar con la cronología, pues la tosquedad de los rasgos suele ir pareja con una inexistente paginación e incluso con la omisión del pautado en quien carecia de la habilidad suficiente para mantener una linea horizontal de escritura. En general, estamos ante una officina u officinae que, salvo en contadas ocasiones, dieron salida a sus pedidos con la tranquilidad de disponer de una clientela segura y poco crítica con el resultado. Las grafias que adoptan los diferentes textos son, en general, la obra de manos descuidadas y no tanto un reflejo de más alta o baja cronología.

La falta de uniformidad en los rasgos de unas y otras inscripciones es patente (fig. 52). Sin embargo, algunos tipos mantienen unas constantes forma- les que se pueden asociar fácilmente con otros textos más fácilmente datables. En varios epígrafes la $\mathrm{R}$ no se cierra y sólo un ángulo indica el inicio del segundo apoyo; la misma caracteristica puede verse en estelas de mediados del siglo I d.C. en Salvatierra de Santiago y Herguijuela ${ }^{145}$, en una del siglo II en Abertura ${ }^{146}$, en otra funeraria de Trujillo datable en el siglo II d.C. ${ }^{147}$, o en otra de Torre de Santa María, de comienzos del siglo III d.C. ${ }^{148}$; $\sin$

146 HAE 338 y 943/CPIL Cáceres 437 (Salvatierra) y CPIL Cáceres 756 (Herguijuela).

ith J. L. Gamallo y H. Gimeno, "Inscripciones del norte y sudoeste de la provincia de Cáceres: revisión y nuevas aportaciones", Cuad. Preh. Arq. Univ. Autónoma de Madrid 17, 1990, p. 278, núm. 2.

(4) $\mathrm{AE} 1977,391$

14* HAE 2678; CPIL Cáceres 502. 
cronologia precisa, pero contemporáneo a las dedicaciones de Alaecina de Alcuéscar, debe señalarse aqui el ejemplo del ara dedicada a Mercurio en la vecina Montánche ${ }^{149}$.

La B no llega a cerrarse en algunos textos y, con frecuencia, supera en tamaño al resto de los tipos, excede el margen inferior o cabecea hacia la derecha: los mismos rasgos se ven en una inscripción de Cáceres y en un texto del siglo 11 en Torreor$\operatorname{gaz}^{150} \mathrm{o}$ en la estela de Torre de Santa Maria, de fines del siglo 1 o comienzos del $\|$ d.C. ${ }^{151}$. La A carece en muchas ocasiones de travesaño horizontal. La parte superior de la S es, con frecuencia, desproporcionada con respecto a la inferior. La $\mathrm{N}$ se suele inclinar a la derecha como ocurre en todo el ámbito regional durante los siglos I y $\| \mathrm{d}$.C., sin necesidad de abundar en los ejemplos. La P en algunos casos no llega a cerrarse, como ocurre en el epígrafe trujillano al que ya hemos hecho referencia ${ }^{152}$, etc.

En general, y con las cautelas a que obligan las consideraciones paleográficas en estas áreas rurales de la antigua Lusitania, los textos de las dedicaciones a Ataecina en EI Trampal parecen el eco de las grafias regionales del siglo $\|$ avanzado y de comienzos del ilı d.C. Que el santuario de Ataecina allá donde estuviese existió antes de esta fecha es innegable, aunque no parece que dispongamos en el conjunto de las evidencias epigráficas de su primera etapa.

\subsection{VALORACIÓN DEL CONJUNTO}

En el catálogo de los textos y soportes con el que se inicia este estudio hemos hecho referencia al preciso lugar de hallazgo de cada uno de ellos. Nótese que bajo una misma unidad, Santa Lucia del Trampal, se incluyen aquí epigrafes procedentes de varios lugares, todos ellos próximos entre sí, como son la ladera del Cerro de San Jorge, la "Charca de Santiago», el molino situado al suroeste de Santa Lucía («Molineta del Trampal»), la finca situada al sureste de Santa Lucia y el propio templo en cuestión, al que hemos adscrito dos altares conservados en casas particulares de Alcuéscar, pero también dedicados a Ataecina, que en su dia fueron encontrados aqui.

El conjunto epigráfico romano de Santa Lucía del Trampal está integrado por 49 soportes monu-

\footnotetext{
149 HEp 1, 173 y $3,129$.

150 Cáceres: CIL II 711. Torreorgaz: CIL II 5309; CPIL Cáceres 508.

151 AE 1968, 223: CPIL Cáceres 500.

152 AE 1977, 391.
}

mentales, 30 de ellos con inscripción, y por un grafito grabado sobre el enlucido del cimborrio sur en una de las actuaciones sobre el edificio; en total, 31 inscripciones y 19 elementos anepigrafos o con el tex to empotrado sin que sea posible precisar si existe. En un conjunto de inscripciones romanas como el hallado en la provincia de Cáceres, que debe rondar ya los 900 textos, estas 31 inscripciones de Santa Lucia apenas suponen un 3,5 por 100 , pero cualitativamente tienen una enorme trascendencia, ya que incluyen 15 dedicaciones a Alaecina y varios fragmentos de otros textos votivos. En el cómputo peninsular de las evidencias de este culto estamos, como luego veremos, ante algo más del 40 por 100 de los testimonios, lo que confiere a los caracteres internos de los textos una cierta relevancia a la hora de valorar su desarrollo y obliga a plantearse la razón de ser de tal concentración de evidencias.

Al hablar de las estelas que sirven de umbrales en Santa Lucia del Trampal hemos aludido a una pieza muy semejante traida de las ruinas de «Las Torrecillas». El enclave, conocido desde comienzos de siglo, entró en la bibliografía arqueológica en 1900 a raiz del hallazgo casual de unas termas mientras se realizaban labores agricolas. Lo exhumado, un hypocaustum en perfecto estado de conservación, fue motivo de un amplio informe de J. Sanguino Michel («Memoria sobre los descubrimientos hechos en Alcuéscar, 1900»), a la sazón secretario de la Comisión de Monumentos de Cáceres, fechado el 28 de junio de $1900^{153}$ y leido en la siguiente sesión de la Real Academia de la Historia ${ }^{154}$. Ante la importancia de los restos el propio Sanguino Ilevó a cabo excavaciones en el lugar, lo que le permitió descubrir todo el hypocaustum y comprobar la dilatada cronología del asentamiento, que ofreció denarios republicanos, monedas de los siglos II y III e incluso una fracción de follis de Constantino.

La siguiente noticia que tenemos de este enclave es la recuperación de la estela ya referida, y no hay que olvidar que del mismo lugar puede proceder parte de una escultura representando a Diana, asi como un símpulo y un cuchillo, objetos todos que alberga el Museo de Cáceres ${ }^{155}$.

Habida cuenta de que en ningún otro lugar de las cercanias se han hallado estelas del mismo tipo, es

\footnotetext{
153 Real Academia de la Historia. Sección de Antigüedades, provincia de Cáceres. Legajo 9-7848-22.

${ }_{154} \mathrm{El}$ informe de Sanguino se convertiria en articulo esta vez bajo la firma de S. Santos y Ecay, "Antigüedades romanas de Alcuéscar", BRAH 36, 1900, pp. 409-410.

iss A. Alvarez Rojas y M." C. Garcia-Hoz, Museo de Cáceres. Guia breve de la sección de Arqueologia, Cáceres 1988 p. $48 ;$ M. Beltrán Lloris, op. cit. en nota 105, p. 88.
} 
muy probable que tanto la estela conservada en el pueblo de Alcuéscar como las que sirven de umbrales en Santa Lucia procedan del mismo enclave, el ubicado en "Las Torrecillas", cuya entidad viene probada por los trabajos en parte inéditos de J. Sanguino en 1900.

Si es relativamente fácil establecer las relaciones formales de las estelas, no lo es tanto en el caso de los altares. Parece claro, sin embargo, que los monumentos de este tipo empleados en la construcción del templo de Santa Lucia fueron traidos también de algún paraje cercano. La evidencia de este acarreo estriba en que sirvieron incluso para la construcción del castillo de Montánchez, como demuestra la presencia, a la derecha de su puerta principal, de una cabecera de altar con dos huecos pequeños en su parte superior, similar a las que se encuentran en el Trampal ${ }^{156}$.

De lo expuesto en el apartado 3 y de las consideraciones anteriores es fácil llegar al convencimiento de que todos los altares fueron trasladados desde un mismo lugar, que sirvió de cantera para la actividad edilicia en todo el territorio. Bajo esta perspectiva, dispondriamos de suficientes argumentos para denominar officina al centro o taller que produjo los diferentes altares, ya que se trata de una producción homogénea en lo formal con un mismo destino en el contenido ${ }^{157}$.

Suponemos, por tanto, que las estelas halladas en Santa Lucia del Trampal proceden de una sola necrópolis y que los altares fueron traidos de un solo centro de culto. La cuestión estriba en saber si ambos, necrópolis y centro de culto, pertenecen a una misma unidad demográfica; es decir, si todo el conjunto es evidencia de un solo enclave habitado, sea cual sea su naturaleza.

156 L. Caballero y J. Rosco, Extremadura Arqueológica 1, 1988 , p. 249 , nùm. B. $11: 31 \times 25,5 \times(-) \mathrm{cm}$.

157 Los criterios terminológicos están expuestos en G. Susini. Il lapicida romano, Roma 1968, pp. 29 s.; D. Manacorda, Un officina lapidaria sulla via Appia, Roma 1980, pp. 77 ss. En los últimos cincuenta años son varias las oficinas lapidarias detectadas en el ámbito de la Península Ibérica; junto a ellas y al uso del término officina en la epigrafia hispánica hay que considerar el elevado número de menciones sobre lapidarios y marmorarios, asi como las múltiples afinidades de forma y contenido que se evidencian en un conjunto que se aproxima inexorablemente a los 20.000 monumentos. Muchas de estas officinae han sido puestas ya en evidencia o intuidas en la publicación de los corpora epigráficos, y el trabajo de conjunto sería motivo suficiente de reflexión para un dilatado estudio; a falta de una relación bibliográfica exhaustiva, cfr. por su eficaz análisis de un significativo ejemplo U. Espinosa, «Una officina lapidaria en la comarca de Camero Nuevo (La Rioja)", Estudios sobre la Antigüedad en homenaje al Profesor Santiago Montero Diaz. Anejos de Gerión 2, Madrid 1989, pp. 403 ss. y los testimonios epigráficos en H. Gimeno, Artesanos y técnicos en la epigrufia de Hispania, Bellaterra 1988, pp. 22 ss.
El muestrario formal aqui estudiado ofrece una nutrida representación de los dos tipos de monumentos en que se manifiesta frecuentemente el hábito epigráfico de una comunidad: los altares y las estelas funerarias; el contexto regional del sur cacereño nos ha enseñado que estos dos tipos de soportes constituian la casi única actividad de las officinae lapidarias de la zona; ocasionalmente los talleres podrian haber labrado miliarios o algún que otro pedestal del que no tenemos evidencias, pero al sur de la linea Norba-Turgalium la producción epigráfica apenas tiene variedad.

Entre las estelas funerarias de cabecera semicircular halladas en Santa Lucía se echan de menos las piezas de pequeñas dimensiones, entre 80 y $100 \mathrm{~cm}$ de altura, corrientes en muchas de las necrópolis de los contornos; la explicación debe estar en el acarreo selectivo de aquellos materiales que se ajustaban a las necesidades edilicias. Puesto que el objetivo de los constructores del templo era emplear estas piezas en los umbrales, como se hace en El Gatillo o en Ibahernando, sólo los ejemplares de mayores dimensiones servían a este propósito. Probablemente en la necrópolis quedaron otras muchas piezas, inutilizadas por el paso del tiempo, reempleadas en otras construcciones de la zona o, simplemente, aún por descubrir. Las piezas más pequeñas, de las que tenemos algunas evidencias ocasionales en el conjunto, están rotas en su parte inferior y no es descartable que fueran también grandes estelas, ya que en ellas sólo la parte superior era ocupada por el texto.

En el caso de los altares debemos hacer un planteamiento distinto. Salvo un epígrafe dedicado a los Lares Viales y los escasos textos casi ilegibles o fragmentarios, se trata de inscripciones relacionadas con el culto de Ataecina. Desde un punto de vista cuantitativo sólo la presencia de un santuario sirve para explicar este abultado número de evidencias votivas en una comunidad de los contornos. Y al mismo tiempo se echan en falta los epigrafes a otras divinidades que sabemos que tuvieron culto en la región: Mars, Iupiter, Salus o Bellona. De ellas hay testimonios incluso en lugares tan próximos como Montánchez o el extremo occidental del término de Alcuéscar, muy cerca de Santa Lucia, pero faltan aquí.

La comunidad cuyo santuario sirvió de cantera para este acarreo de material de construcción disponia de un panteón muy restringido; tanto, que prácticamente se circunscribe a una sola divinidad. La presencia de un epigrafe dedicado a los Lares Viales no es un argumento en contra, pues bien pudo pertenecer a una de las vias de entrada o salida de la población. En tales condiciones, es fácil intuir que 
en la comunidad referida la divinidad que ejerció este absoluto protagonismo tenia el carácter de divinidad tutelar. Si es o no Turihriga o Turohriga es algo que sólo tras una evaluación del culto en Hispania podremos establecer (vid. infra apartado 8 ).

\section{TESTIMONIOS DEL CULTO DE ATAECINA EN HISPANIA}

\subsection{LAS INVOCACIONES A DE.A S.ANCTA $Y$ LAS OMISIONES DEL TEÓNIMO}

Entre las inscripciones relacionadas con el culto a Ataecina se suelen considerar algunos textos en los que no aparece expresamente el nombre de la divinidad, aunque la proximidad geográfica al área central del culto y la presencia de los característi$\cos$ epitetos dea sancta induzcan a suponerlo. Sobre este criterio generalista no existe, ni mucho menos, unanimidad; de hecho, un nutrido grupo de las inscripciones tradicionalmente relacionadas con Ataecina pueden ser descartadas hoy por diferentes motivos. Aunque tal adscripción es heredera de las tesis de Leite de Vasconcelos, la polémica bibliográfica tiene sólo un par de décadas y se puso de manifiesto en los coloquios celebrados para conmemorar el bimilenario de Augusta Emerita. Frente a la postura tradicional ${ }^{15 k}$, alli se llegó a plantear la identificación de esta dea sancta, en omisión del teónimo, con el culto de Cibeles ${ }^{159}$.

Los términos deus/dea remiten en principio a dioses de origen indigena o a los correspondientes

${ }^{1 \times}$ L. Gareia Iglesias, "Epigrafia romana de Mérida", en Augusta Emerita. Simposio internacional conmemorativo del bimilenario de Mérida 1975. Madrid 1976, p. 139; IRCP. p. 157. nota 1 ; J. D’Encarnaçao, op, cit. en nota 65 , p. 309 , que aplica este mismo criterio para incluir en el culto de Ataecina la inscripción de Mértola (FE 1. IRCP 95); sin discusión sobre el particular pero aceptando la identificación, J. M. Garcia, Religioes antigas de Portugal. Aditamentos e observascoes as "Religioes da Lusitánia” de J. Leite de Vasconcelos. Fontes epigráficas. Lisboa 1991, pp. 287 y 304 ss.; J. Gonzảlez, "Divinidades prerromanas en Andalucian, en Religio deorum. Actas del coloquio Int. de epigrafia. Culto y sociedad en Occidente. Barcelona 1993. pp. 274.

$190 \mathrm{M}$. Bendala, op. cit. en nota 138, p. 152, seguido entonces por los editores de L'Année Epigraphique: efr. AE 1983, add 486: «il faut, semble-t-il, reconnaitre Cybèle, dont le culte est attesté à Mérida: cf. A. Garcia y Bellido, Les rel. or. dans I'Espagne rom. (EPRO 5) 1967, p. 48.49: L. Garcia Iglesias, op. cit. en nota 158, pp. $68 \mathrm{ss} . m$; estos mismos editores matizarian el comentario en el mismo volumen al recoger la edición de una inscripción en Vila Chá de Esposende (AE 1983, 559): «Dea sancta est connu pour Ataecina dans la province de Cáceres», comentario que se ajusta estrictamente a la realidad. processos de interpretatio ${ }^{\text {trt }}$, pero en ningún caso parecen exclusivos de una sola divinidad. No faltan en Hispania las invocaciones a dioses precedidos del sustantivo deus/dea ${ }^{|t|}$; podrian citarse los ejemplos de Aesculapius, Apollo, Genius, Mars. Mercurius. Neptunus ${ }^{\text {ind }}$, etc., además de un buen número de divinidades indigenas. Igualmente, tampoco los epitetos sanctus/sancta pueden circunscribirse a un solo culto, cuando los ejemplos muestran justamente lo contrario. En esta relación es probablemente descartable, contra la opinión de anteriores editores, un epigrafe de lbahernando que conserva el Museo de Cáceres, grabado sobre un altar muy sencillo que recuerda vagamente los monumentos de Santa Lucía del Trampal, en cuya primera linea se ha creido ver la invocación $\mathrm{Ma}$ (rti) s(ancto) sa(crum) ${ }^{163}$

La combinación de ambos epitetos es frecuente en diversas provincias romanas de occidente. Los diferentes indices epigráficos y el catálogo confeccionado por Raepsaet-Charlier, sólo para inscripciones datadas, ofrecen testimonios suficientemente elocuentes con todo tipo de divinidades: dea sancta Fortuna Conseruatrix; deus sanctus Apollo Pacifer: deus san(ctus) [A]pollo; deus sanctus Cocidius; sanctissima dea Diana; dea Fortuna sancta; deus sanctus Saturnus; deus sanctus Serapis; deus sanctus Siluanus; daeus santus (sic) Siluanus; deus sanctus

ini M.-Th. Raepsaet-Charlier, "La datation des inscriptions latines dans les provinces occidentales de l'Empire romain avec les formules in h(onorem) d(omus) d(ivinae) et d(eo). d(cue)m. ANRW II.3, 1975. p. 234: P. Le Roux, 4 Deus Aernus: CIL II $2607=5651$ reconstituém, Conimbriga 31, 1992, p. 179.

(6) Cfr. CIL II supp. p. 1127.

162 Clunia: CIL II 2777 = ILFR 298; P. de Palol Salellas y J. Vilella, Clunia II. La epigrafía de Clunia, Excav. Arq. Esp. 150, Madrid 1987 [1989], num. $19=$ HEp 2, 88.

iti J. Ramón y Fernández-Oxea, 1962, op. cit. en nota 120. pp. $123 \mathrm{ss},=$ HAE $1884 ; \mathrm{C}$. Callejo, op, cit. en nota $120, \mathrm{pp} .49$. 51. núm. 29 (foto) $=$ AE 1967, 203, que sugiere la invocación a unos Lares Ostiarii; CPIL Cáceres 297; M. Beltrán Lloris, op. cit. en nota 105, p. 112; J. Mangas, «Römische Religionen in Hispanien", $A N R W$ II.18.1, 1986, p. $329=$ HEp 1, 166. La relec. tura del epigrafe confirma ediciones anteriores con el siguiente texto:

MA. S, SA.

LAREBV

OSTIANIS

POSIT A. L.

La disposición de los diferentes elementos parece sugerir que en la primera linea figura un tria nomina abreviado del dedicante, que invoca a los Lares reseñados en las lineas segunda y tercera. Según eso, en 1.1 convendria leer Ma(rcus) S(-.) Sa(-.-), siguiendo una tradición de abreviar el nombre del dedicante que no escasea en las áreas occidentales de Hispania. 
Sol ${ }^{\text {ind }}$, que constituye el testimonio más reciente de estos epitetos, a comienzos del siglo iv d.C. int.

En Hispania son pocas las divinidades cuyo favor se invoca anteponiendo al teónimo las expresiones dea sancta o deus sanctus. Sin embargo, los escasos testimonios disponibles son suficientemente elocuentes e interesa traerlos a colación para mostrar que los epitetos de Ataecina no son, en absoluto, exclusivos de su culto.

De Elvas (dist. de Portalegre), no lejos del área en que se manifiesta el culto de Ataecina, procede una inscripción dedicada a la dea sancta Burru-lobr[ig]ensis ${ }^{16 t}$. Leite de Vasconcelos incluyó este testimonio en el repertorio de Ataecina a partir de los epitetos que porta esta divinidad de nombre desconocido, aunque referida a un topónimo en la probable forma Burrulobriga ${ }^{167}$. La identificación entre ambas divinidades, aún mantenida en fecha reciente ${ }^{16 x}$, parece inviable como ya sugirió $\mathrm{Al}$ bertos ${ }^{169}$.

De S. Miguel de Mota (Terena, conc. Alandroal, dist. Evora) procede el impresionante grupo de epigrafes dedicados a Endouellicus, cuyo número se ha incrementado tras la edición de las inscripciones del conuentus Pacensis de J. D'Encarnaçao. Entre estas inscripciones, muchas de las cuales pueden datarse entre los siglos 11 y III d.C. ${ }^{170}$, figuran tres que contienen invocaciones similares a las que conocemos para Ataecina pero dirigidas al popular dios

tes Dea sancta Fortuna Conseruatrix (Bretaña: hacia el año 222 d.C.: R. G. Collingwood y R. P. Wright, Roman Inscriptions of Britain, Oxford $1965(=\mathrm{R} / \mathrm{B})$, num. 968: M.-Th. RaepsaetCharlier, op cit., en nota 160, p. 275, num. 282); deus sunctus Apollo Pacifer (CIL VI $37=$ ILS 3223 de Roma); deus san(ctus) [A]pollo (Bretaña; hacia 238-244 d.C.: RIB 583; M. Th. RaepsaetCharlier, p. 275, nùm. 273); deus sanctus Cocidius (Bewcastle. ILS 4721): sanctissima dea Diana (Germania Inferior; hacia 166 169 d.C.: CIL XIII 12036: M.-Th. Raepsaet-Charlier, p. 277. nùm. 264): dea Fortuna sancta (Germania superior; aǹo 248 d.C.: CIL XIII 6552; M.-Th. Raepsaet-Charlier, p. 280, núm. 120); deus sanctus Saturnus (CIL V 5021 = ILS 4905); deus sanctus Serapis $(\mathrm{CIL}$ VII = ILS 4384); deus sanctus Siluanus (CIL VII $830=$ ILS 3548); daeus santus (sic) Siluanus (CIL V 8136 = ILS 3747 b): deus sanctus Sol (ILS 8940, de comienzos del siglo iv d.C.).

iss La más antigua mención datada de la denominación deus procede de Galia Bélgica y se fecha en el año 124 d.C (CIL XIII 4149); cfr.M.-Th. Raepsaet-Charlier, op. cit., en nota 160, p. 241.

tot Leite, Religioes, pp. 174 ss.; IRCP. p. 633, núm. 566; J. M. Garcia, op. cit. en nota 158, p. 305, núm. 56.

is IRCP, p. 633.

ink J. M. García, op. cit. en nota 158, p. 305.

${ }_{100}$ M." L. Albertos, "Los topónimos en -briga en Hispania", Veleia 7,1990, p. 131.

170 IRCP, p. 807. Un reciente testimonio del culto, a añadir a la serie ya conocida, ha sido dado a conocer por H. Gimeno y G. Vargas, "Inscripción inédita dedicada a Endovellico", $F E 42$, 1992, núm. 188. lusitano: dos menciones de deus sanctus Endouellicus $^{171}$ y la variante gráfica deus sanctus Indouellicus ${ }^{172}$

Fuera de estas divinidades de carácter estrictamente indigena, aún otros dos dioses romanos figuran en los textos hispanos bajo la imprecación deus sanchus: se trata de Euentus ${ }^{17}$ y de Siluanus ${ }^{174}$.

De los ejemplos aducidos se puede desprender que, aunque en el caso de Alaecina son denominaciones frecuentes, los epitetos deus/dea sanctus/sancta distan mucho de ser exclusivos de una sola divinidad. Efectivamente, en el área extremeña la ausencia de otras evidencias epigráficas por el momento invita a ver testimonios de Ataecina tras las referencias a una dea sancta con omisión de teónimo, pero no debe olvidarse que en este mismo ámbito suroccidental de Hispania tuvo una cierta difusión el culto de Proserpina que, por interpretatio con Alaeci$n a$, también fue denominada dea sancta; sólo en el registro epigráfico de Elvas, lugar en donde el culto de Proserpina tuvo un importante arraigo, es denominada Proserpina sancta. Proserpina seruatrix y dea Proserpina ${ }^{175}$.

El que Ataecina aparezca asociada a Proserpina en los epigrafes de Mérida y Cárdenas ${ }^{170}$ no es motivo suficiente para ver tras las dedicaciones a Proserpina la evidencia del culto a Ataecina y viceversa, puesto que de los mencionados epigrafes emeritenses se desprende que no llegó a realizarse una completa hypostasis ${ }^{177}$ y que cada una de las dos divinidades mantuvo su propia personalidad.

Con esta prevención creemos que deben descartarse algunos testimonios aducidos por Leite de Vasconcelos ${ }^{178}$ y muy especialmente el texto de Castilblanco de los Arroyos (Sevilla) ${ }^{179}$, en el que únicamente puede leerse Proserpina sancta ${ }^{1 \times 0}$, y no referencia alguna a Ataecina. 531).

17 CIL II 6265 (IRCP 484) y CII. II $137+$ p. XXXIX (= IRCP

i72 CIL II 6269 b (= IRCP 507).

${ }^{17}$ CIL II 2412: deus sanctus Euentus.

174 HAE 2322: AE 1965, 102, de Porcuna (Jaén): sanctus deus Siluanus.

175 Los testimonios son CIL II $143=$ IRCP 570; CIL II $144=$ IRCP 571 (sancta); CIL II $145=$ IRCP 572 (seruatrix); EE 8, 9 = IRCP 573 (dea) y EE 8, $10=$ IRCP 574.

176 CIL. II 462 y 46 I respectivamente.

17 M. ${ }^{*}$ P. Garcia-Bellido, "Las religiones orientales en la Peninsula Ibérica. Testimonios numismáticos Im. AEA 64. 1991, p. 71 .

176 Leite, Religioes, pp. 154 ss., a propósito de CIL II 143. 144. 145,1044 y EE 8, 358.

17\% CIL 111044

190 Cfr $r$ con el mismo sentido critico Blázquez, Religiones 1962. p. 144; J. González, "Miscelánea epigráfica andaluza», $A E A 55$, 1982, p. 161. 
Con mayor motivo no creemos que puedan adscribirse al culto de Alaecina dos textos de Alcalá del Rio (Sevilla) publicados hace una década ${ }^{|x|}$ en los que se invoca respectivamente a Proserpin [a] y a una Sancta Dea. Un primer elemento en contra de la adscripción es la identidad de los dedicantes, de onomástica oriental; uno de ellos es un seruus Caesaris. Tenemos que convenir con J. D’Encarnaçao que la omisión del teónimo en el segundo de los epigrafes induce a pensar que en ambos casos nos hallamos ante evidencias del culto de Proserpi$n a, \sin$ que el uso de los epitetos Sancta Dea en este caso permita inferir relación alguna con Atae$\operatorname{cina}^{1 \times 2}$.

Quizá haya llegado el momento de eliminar de los repertorios de Ataecina el grupo de inscripciones del suroeste peninsular en donde sólo se invoca a una dea sancta, sin especificar a cuál de ellas se alude, habida cuenta de la frecuencia de la terminología y de la imprecisión de las invocaciones. Salvo que en el futuro aparezcan evidencias contundentes sobre la presencia de su culto en alguno de estos enclaves, proponemos eliminar del registro de Ataecina las siguientes referencias:

1. Dea sancta. Mérida (Badajoz) ${ }^{1 \times 3}$.

2. Dea sancta. Mérida (Badajoz) ${ }^{1 \times 4}$.

3. Dea sancia. Mértola (id., Evora) ${ }^{1 \times 5}$.

|xi J. González, op. cit. en nota 180, pp. 160-161, núm. 13 (AF 1982, 503) y pp. 161-162, núm. 14 (AE 1982, 504). La idea de la identificación de Ataecina en estos textos ha sido mantenida por el autor en J. González, op. cit. en nota 158. pp. 273.

1\%2 J. D'Encarnaçao, op. cit. en nota 65, p. 309

iki HAE 2681, a partir de la edición de 1965 de la Guia de Mérida; L. Garcia Iglesias, op. cit. en nota 158, p. 69, nota 31. suponiéndola una dedicación a Ataecina; M. Almagro Basch, Guia de Mérida, Madrid 1981, p. 40, lám. XVII, que la considera dedicada a Cibeles: id., 150.Jahre DAl 1829-1979, Maguncia 1981 , pág. $160=\mathrm{AE} 1983,486$, con una ligera corrección onomástica; V. Soria Sánchez, «Nuevos descubrimientos de arqueología extremeǹa", REstExtr. 39.3, 1983, p. 510.

ixs J. M." Alvarez Martinez, "Notas de epigrafia extremeña», Boletin del Museo de Zaragoza 4, 1985, pp. 169 ss., fig. $2=$ HEp 2, 34 .

ixs J. Pulido Valente, J, C. Almeida Oliveira y M. Pereira, $F E$ 1,1982 , p. 3, núm. 1; IRCP 95, que no duda en la identificación con Ataecina y fecha el texto a mediados del siglo $\|$ d.C. $=\mathrm{AE}$ 1982, 456; id., op. cit. en nota 65 , p. 309, reafirmándose en su idea de la identificación de los epitetos con Ataecina; id., op. cit. en nota 56, p. 102; J. M." Blázquez, «Nuevos teónimos hispanos. Addenda et corrigenda $\mathrm{V}$ ", en Cuadernos de Prehistoria y Arqueol. Univ. Autón. 13-14 (Hom. Gratiniano Nieto, vol. II), 1986-87, p. 141, también vinculándolo a Ataecina $(=i d$., Religiones en la España Antigua, Madrid 1991, p. 139); R. López Melero, op. cit. en nota 26, p. 111 , núm. 14; J. M. Garcia, op. cit. en nota 158, p. 304 , núm. 53.
4. Dea sancta. Quintos (Beja, Beja) ${ }^{1 \times t}$.

5. Dea sancta. Vila Verde de Ficalho (Serpa, Beja) ${ }^{1 \times 7}$.

6. Daea sancta. Castro de S. Lourenço, en Vila Châ (Esposende, Braga) ${ }^{1 \times x}$

7. D(ea) s(ancta). "Heredade da Defesinha», en Ouguela (Campo Maior, Portalegre) ${ }^{1 \times 4}$.

8. Dea. Tejada de Tiétar (Cáceres). A pesar de tan pobre evidencia documental este fragmento ha sido inexplicablemente asociado en los últimos años a Ataecina ${ }^{100}$.

Los mismos problemas de atribución presenta un texto fragmentario de Ibahernando (Cáceres) ${ }^{|4|}$, editado a comienzos de siglo, en cuya primera linea Fidel Fita ${ }^{192}$ transcribió S(aluti) s(acrum); a la vista

ton CIL II 101; ILER 741; IRCP, p. 357, núm. 288, con el resto de la bibliografia, que sugiere la identificación con Ataecina únicamente a partir de los epitetos; la edición de este oscuro texto grabado sobre el borde de un vaso de piedra depende del manuserito de Cenáculo y de las observaciones de Pérez Bayer; dado que no se puede confirmar la similitud del lugar de hallazgo con el otro texto procedente de Quintos, no se puede garantizar la dedicacion a Ataecina como ocurre con las dos inscripciones de Herguijuela: cfr. además Blázquez, Religiones 1962. p. 142; R. López Melero, op. cit en nota 26, p. 111, núm. 13; J. M. Garcia, op. cit. en nota 158, p. 304 , núm. 54 (= HEp 4 , 988).

187 La primera lectura de esta inscripción (M. M. Alves y A. M. Monge, "Inscriçao votiva de Vila Verde de Ficalho, Serpa", $F E 18,1986$, núm. $84=\mathrm{AE} 1986,278$ y HEp 1.661 ) incluia un desarrollo sanct(a)e pia(e) Seueru/s/ en 1.2-3; tal desarrollo, como bien han sugerido los editores de L'Année Epigraphique. podria corregirse en la forma sanct(a)e Fla(uius) Seueru/s] o similar. lo que elimina el anómalo epiteto Pia, que no está atestiguado en otros textos; $c f r$. además la edición de M." M. Alves, "Para um repertório das inscriçoes romanas do território portugués (1986)", Euphrosyne 17. 1989, p. 374, núm. 38 y J. M. Garcia. op. cit. en nota 158, p. 306, núm. 57 a, que sigue a los primeros editores. El ara presenta en su parte superior cuatro orificios que bien pudieran servir para colocar un exvoto y puede datarse, según sus editores, en el primer cuarto del siglo 11 d.C.

Ixx M. Boaventura, "Ara votiva a Dafa», Lucerna 6, 1965. pp. 270-273: A. Tranoy, op. cit. en nota 116, p. 274; L. A. Dos Santos, A. Tranoy, y P. Le Roux, op. cit. en nota 101, p. $190=$ AE 1983, 559; A.U. Stylow, «Inscripciones latinas del sur de la provincia de Córdoban, Gerión 1, 1983, p. 301, nota 72.

Ixy A. M. Dias Diogo, «Ara votiva de Ouguela, Campo Maior (conv. Pacensis)", FE 8, 1984, núm. 32, pp. 8-10 = AE 1984. 475; J. D'Encarnaçao, op. cit. en nota 56, p. 106; J. M. Garcia, op. cit. en nota 158, p. 306, núm. 57. Adscribir a Ataecina esta inscripción no deja de ser una hipótesis caprichosa, pues bajo la cantidad de siglas que encierra puede ampararse cualquier tipo de invocación; ni siquiera existe seguridad para entender la expresión d(ea) s(ancta) y mucho menos para pensar en una u otra divinidad.

(⿻丷木 V. Soria Sánchez, "Descubrimientos arqueológicos en Extremadura", REstExtr. 31.2, 1975, p. 284; CPIL Cáceres 725.

(v) $\mathrm{F}$. Fita, «Nuevas lápidas romanas de Ibahernando», $B R A H$ 45, 1904, p. 450, núm. 2; CPIL Cáceres 290.

192 Probablemente la inspección del texto fuera realizada por Sanguino Michel, correspondiente de la Real Academia de la Historia, y que a lo largo de 1904 suministró a ésta un buen número de noticias arqueológicas sobre el sur cacereño. 


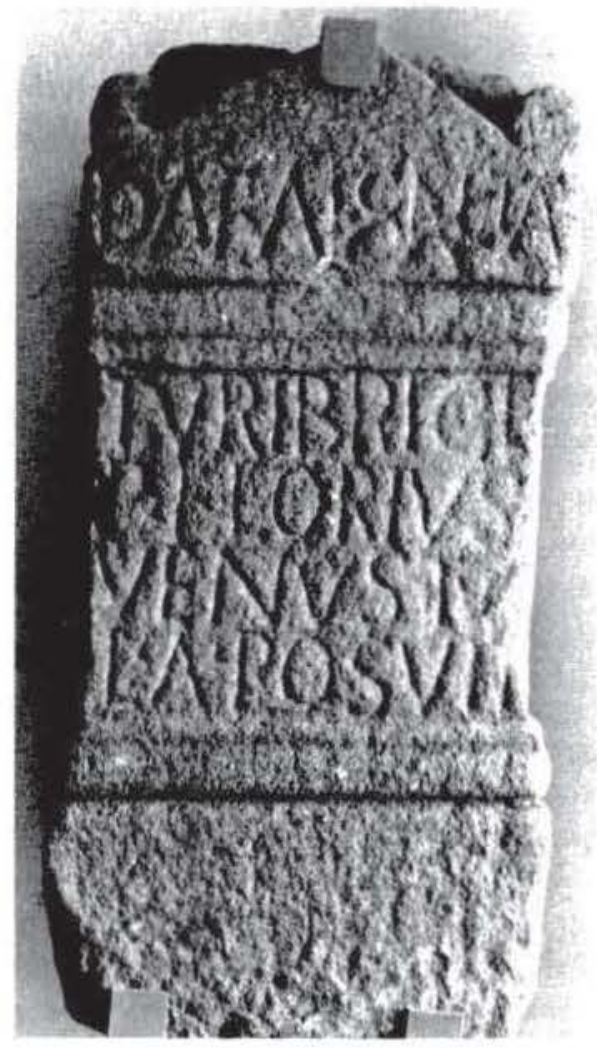

Iigura 53. Inserpenon dedieada a traecina en flergujuela (Cáceres). Museo de Caceres

de las evidencias regionales parece aconsejable restituir s(anctae) s(acrum), maxime teniendo en cuenta que en estas comarcas cacereñas las invocaciones a Salus no suclen abreviarse. Ahora bien, dado que de Santa Ana, cerca de Ibahernando, procede una de las evidencias cultuales de Ataecina, no seria descartable ver tras este epigrafe un nuevo testimonio de esta divinidad, aunque una elemental prudencia aconseje descartarlo de momento.

Sin embargo, quedaria adscrita al culto una inscripción de Herguijuela en la que sólo puede leerse [D(ea) ? / sancta, debido a que del mismo paraje, la "Dehesa El Palacio», procede un testimonio fehaciente del culto (infra núm. 14 y fig. 53 ) y que parece una sencilla omisión del teónimo por la cercania al santuario.

Para concluir con el grupo de inscripciones que invocan a una dea sancta quisiéramos traer a colación un epigrafe procedente también del suroeste peninsular y que puede ser objeto de distintas interpretaciones. Nos referimos a una de las dos inscripciones que conocemos como procedentes de S. Clemente (conc. Loulé, dist. Faro) ${ }^{19}$. En la primera linea

19) CIL II $5136+$ p. 1028; ILER 340/479; IRCP, pp. 104-105. nủm. 58, con el resto de la bibliografia. del texto figuran las abreviaturas $D(\ldots) . S(\ldots) . S(\ldots)$, bajo las que se esconde la divinidad a la que se in. voca y que tradicionalmente se han entendido como dreor stancto) S(iluano) o D(ianae) S(iluestri). A la vista de la relativa proximidad a otros testimonios de dedicaciones a una déa saneta y considerando la extensión del culto de Proserpina en el suroeste. sugerimos a modo de hipotesis entender en el texto una dedicacion del tipo d(eac) s(anclae) s(acrum). debe considerarse además que sólo en un culto arraigado. extendido y bien conocido entre la poblacion o en las proximidades del centro de su devocion se recurria a una abreviación tan extrema de un teónimo.

Una inscripción de Herguijucla dedicada a Ataecina (infra num. 14) contiene la grafia anomala daea (fig. 53): el ejemplo se repite en un texto de Castro de S. Lourenço, en Vila Châ (conc. Esposende, dist. Braga) ${ }^{104}$, equivocamente atribuido tambien a la misma divinidad. Aunque no es habitual, la sustitu. cion de $A E$ pro $E^{14}$ se encuentra con cierta frecuencia en epigrafes votivos, sin que merezca otra consideracion que la estrictamente gráfica, pues afecta a zonas con fuerte impronta romana ${ }^{19 n}$.

\subsection{DEA DOMINA DEA DOMINA SANCTA EN HISPANIA}

Dea y domina son los términos empleados con más frecuencia para referirse a Ataecina en los diferentes textos. Sólo en las inscripciones de Santa Lucia del Trampal aparecen asociados y en ese orden preciso, como demuestra la inscripción núm. 7 del conjunto, en donde el segundo de los sustantivos no aparece abreviado. Fuera del grupo de inscripciones de Alcuéscar, Ataecina sólo es denominada domina en las dedicaciones de La Bienvenida, MedeIlin, Salvatierra de Santiago y Saelices (Cuenca) ${ }^{147}$ (núms. 16-19).

El hecho de que Araecina sea invocada como dea domina sancta resuelve ciertas dudas en la lectura de algunos epigrafes del ảmbito regional de Alcuéscar. como ahora veremos y, al mismo tiempo, representa una tentadora sugerencia para desarrollar grupos de abreviaturas de dudosa interpretación en otros epigrafes.

\footnotetext{
1w4 Vid. nota 188
}

ivs Cfr. ILS pp. 807 ss

106 Cfr. por ejemplo IL.S 3747 b; II.S 9087 ; CIL. VI $2242=$ ILS 4437; un buen numero de ejemplos pueden verse en A.U. Stylow, op. cit en nota 188, p, 300, nota 66.

19? Cfr. las reservas sobre la procedencia expresadas en nota 257. 
Los epigrafes núms. 3, 4. 5 y 6 de Santa Lucia del Trampal atestiguan la costumbre de dirigirse a Alaecina bajo la invocación $d(---) d(--) s(--)$, cuyo desarrollo en la forma d(ea) d(omina) s(ancta) ilumina la inscripción núm. 7 del mismo conjunto. Si analizamos el registro epigráfico de Alcuéscar y Montánchez previo al descubrimiento de Santa Lucia del Trampal, veremos que se conocian ya dos inscripciones votivas que, curiosamente, emplean las mismas abreviaturas iniciales aunque seguidas del nombre de Mercurio y Bellona, respectivamente.

La primera de estas inscripciones, si atendemos al relato de $C$. Callejo sobre el hallazgo ${ }^{19 x}$, procede del Valle de la Zarza, unos cinco kilométros al suroeste de la ermita de Santa Lucia, junto a la carretera que une Cáceres y Mérida (básicamente la antigua "via de la Plata»), casi en el límite entre las provincias de Cáceres y Badajoz ${ }^{199}$, y bastante más lejos de Alcuéscar (unos $9 \mathrm{~km}$ en linea recta) que lo que afirma Callejo; para el erudito cacereño el texto de la inscripción dice: D.D.S. / MERCV / RIO. L.I. / MANIBV / .L.A.P., que él desarrolla en la forma D(ii) D(eabusque) S(acrum) (sic) Mercurio..., corregido a $D$ (eis) d(eabus) s(acrum) Mercurio... por los editores de L'Année Epigraphique.

Para justificar el desarrollo d(ii) d(eabusque) s(acrum) (sic) en su edición del texto, Callejo alega que «la referencia a los dioses y diosas es frecuente en la provincia»" [de Cáceres] ${ }^{200}$. Sin embargo, esta frecuencia, hasta donde conocemos y excluyendo los testimonios de Liber/Libera, sólo incluye cuatro testimonios con un minimo de garantias, pese a tratarse en algunos casos de lecturas muy dudosas que habria que confirmar: deabus debus... ${ }^{201}$, dibu(s) et de(a)bu(s)... ${ }^{202}$, deabus et diuus (sic ??) ${ }^{203}$ y d(is) $e(t) d$ (eabus) s(acrum)... ${ }^{204}$.

Iv* C. Callejo, "Nuevo repertorio epigráfico de la provincia de Cáceres”, $A E A 43,1970$, pp. 137-139, núm. 5, fig. 5= AE 1971. 150; CPIL Cáceres, p. 319, núm. 752; M. Salinas de Frias, La organización tribal de los Vettones, Salamanca 1986, pp. 89 y 90.

$19939^{\circ} 7^{\prime} \mathrm{N}-6^{\circ} 16^{\prime} \mathrm{W}$. Mapa Topográfico Nacional E. 1:50.000, Hoja núm. 752 (Mirandilla).

200 C. Callejo, op. cit. en nota 198, p. 139.

201 HAE 2587 (de J. M." Blázquez, Caparra II, Excav. Arq. Esp. 54, Madrid 1966); R. Etienne y F. Mayet, "Du nouveau sur Caparra-Capera», REA 73, 1971, p. $386=\mathrm{AE} 1971,156 ; \mathrm{CPIL}$ Cáceres 746 .

202 Plasencia. M." L. Albertos, «Nuevas divinidades de la antigua Hispania", Zephyrus 3, 1952, p. $54=$ HAE 399; CPIL Cáceres 382 .

${ }^{203}$ Valdeobispo. A. Sayans, Artes y pueblos primitivos de la Alta Extremadura, Plasencia 1957, pp. 216 ss.; A. Sánchez $\mathrm{Pa}-$ redes, «16 inscripciones latinas inéditas de la Vettonia», en diario Extremadura 22 de enero de 1964, p. 3, citado por CPIL Cáceres 751.

204 Plasenzuela. C. Callejo, «Cédulas epigráficas del campo norbense", Zephyrus 18, 1967, pp. 106-107, núm. 16, lám. XII; CPIL Cáceres 396.
La restitución del contenido de las dos últimas lineas del texto no dejaria ser un ejercicio especulativo a la vista de la irregularidad de los trazos y del posible retallado que parece ponerse de manifiesto en la cuarta linea de la foto publicada por Callejo. Sin embargo, a la vista del registro epigráfico del vecino templo de Santa Lucia, y con las evidencias para el orden de los términos y desarrollo de abreviaturas que proporciona, no cabe duda de que las tres primeras lineas de este antiguo texto de Alcuéscar deben decir:

\section{$D(e o) d(o m i n o) s(a n c t o)$ Mercu- rio ...}

La segunda de las inscripciones a las que hemos aludido fue editada originalmente como procedente de Montánchez y hallada en la llamada «Alqueria de la Quebrada» ${ }^{205}$; salvo que existiera un topónimo similar en las proximidades, en término de Montánchez sólo se conoce un lugar que responda al topónimo de «La Quebrada», y está situado a unos dos $\mathrm{km}$ al sureste de la localidad, al pie del piфo Montánchez, de 994 metros de altura, que es el techo de todos estos contornos. En la lápida puede leerse lo siguiente:

D D S
BELLO
NAE
L. P. S
POSV
IT. L. A.

Tanto el anónimo editor inicial (muy posiblemente Fita) como Hübner supieron ver en la cuarta línea las iniciales de los tria nomina del dedicante, pero las propuestas de desarrollo para las abreviaturas iniciales no coinciden: $d$ (is) d(eabus) s(acrum) (BRAH) y d(onum) $d(e) s(u o)$ ? (Hübner, seguido por Salas).

A la vista de los textos de Santa Lucía del Trampal, nos atreveriamos a proponer el siguiente desarrollo para el texto:

205 Anónimo [F. Fita ?], «Epigrafia romana de Montánchez. Noticias", BRAH 38,1901, p. 498 , sobre información del " $\mathrm{Sr}$. Lozanon $=\mathrm{AE}$ 1902, $3=\mathrm{EE}$ 9, 98, que atribuye la edición a Fita; CPIL Cáceres 337; J. Salas, «Epigrafes a Ma-Bellona», Norba 1, 1980, p. 183, núm. 10 


\section{D(eae) diminae) stanctae)}

Bello-

nae

$L$ (ucius) $P(-\ldots) S(-\cdots)$

posu-

it I(ihens) a(nimo)

\section{L..3: L(ucius) P(ontius ??) S(euterus ??)}

Si para el desarrollo de las abreviaturas iniciales no parecen existir dudas, más hipotética y puramente conjetural es la restitución del nombre del dedicante. Un personaje que invoca a Ataecina en una de las inscripciones de Santa Lucia del Trampal (c fr. supra num. 8) porta este nombre y el cognomen Seuerus es muy frecuente en el ámbito comarcal y en el propio conjunto de Santa Lucia. Los parajes de "Alqueria de la Quebrada" y "Santa Lucia» están ubicados en las dos sierras que flanquean el fértil valle en que se ubica Arroyomolinos de Montánchez y separados entre si por una distancia de unos seis $\mathrm{km}$; de ahi que no nos atrevamos a confirmar esta tentadora identificación.

En el área de Alcuéscar-Montánchez parece que alcanzó una cierta popularidad la forma deus dominus/dea domina para invocar a diferentes divinidades y no sólo a Ataecina. Hemos visto que también los cultos de Mercurio y de Bellona se vieron afectados por esta práctica, $\mathrm{y}$ aún disponemos de otros dos testimonios sobre la misma en el propio enclave de Montánchez, aunque en este caso con omisión de sanctus/sancta que si figuraba en las inscripciones ya citadas.

El primero de los textos está grabado sobre un ara que se encontró empotrada en una casa de la localidad de Montánchez, sin que se pueda precisar el lugar del término en que apareció. El texto dice ${ }^{2060}$ :

$D($ eo $) d($ omino) Merc-
urio $C$ (aius) P-
otius
Maxi-
mus
l(ibens) a(nimo) u(otum) s(oluit)

El segundo figura sobre un ara que se conserva empotrada en el castillo de Montánchez, con los

20 A. González Cordero et alii, op. cit. en nota 4, pp. 298 301, núm. 12, lám. $11=$ HEp 1,$173 ; \mathrm{J}$. Salas y A. González Cordero, op. cit. en nota 125, núm. 7, pp. 184-186, que transcriben do (mino) Mer/c/urio; corregida en su forma actual por Stylow a partir de calco de J. V. Madruga $=$ Add. HEp 3, 129. mismos problemas de localización que la precedente. El texto dice ${ }^{21}$ ?

\author{
De(a)e d- \\ omi- \\ nae $\mathrm{Sa}$ - \\ luti \\ a(nimo) I(ihens) u(otum) \\ $\operatorname{pos}($ uit)
}

A falta de una autopsia definitiva del texto, parece que en la lectura editada falta el nombre del dedicante, posiblemente situado tras la fórmula dedicatoria. En cualquier caso, los cuatro textos propuestos sirven para demostrar cuán popular era esta peculiar invocación ${ }^{20 x}$ tanto para la propia Ataecina como para otras divinidades romanas y orientales en los alrededores de Alcuéscar y Montánchez.

Las invocaciones del tipo deus dominus/dea domina - o en el orden inverso de los términos- no faltan en el mundo romano ${ }^{2 m}$ y tampoco en Hispania. Quizá el conjunto de testimonios más interesante sea el situado en el concelho de Santo Tirso (dist. Porto). De aqui proceden, entre otras, tres inscripciones votivas que emplean este esquema de dedicación sin respetar el mismo orden en todos los textos.

El primero y mejor conservado de los textos está dedicado a un Deus Domenus Cusus Neneoecus ${ }^{210}$ según todos los editores. Pero la foto publicada por Moreira no deja lugar a dudas sobre la existencia de una $\mathrm{M}$ en la cuarta línea, con lo que el nombre de la divinidad debe leerse Nemeoecus.

La segunda inscripción está dedicada a un Dom(inus) Deus N[--]eoec [-- ] $]^{211}$ que todos los editores leen $N$ [en]eoec [us] pero que, por paralelo con la anterior, debe ser N[em]eoec[us].

207 V. Soria, "Descubrimientos arqueológicos en Extremaduran, XVII Congr. Nac. Arq. Logroño 1983, Zaragoza 1985. p. $488=$ HEp 1. 175; Caballero y Rosco, Extremadura Arqueológica 1, 1988, p. 240 la consideran una dedicación a Ataecina, pero no existen pruebas de esta hypostasis.

${ }^{20 *} \mathrm{D}$ (eus) d(ominus) s(anctus) Mercurius. d(eae) d(omina) s(ancta) Bellona, d(eus) d(ominus) Mercurius, dea domina Salus.

${ }_{200}$ Cfr. por ejemplo Deus Dominus Apollo Vergulesis: CIL. V1 $2798=32570=$ ILS 4057 , de Roma.

2ii CIL II $2375=5552+$ A. Moreira, eInscriçoes romanas do concelho de Santo Tirson, Santo Tirso 2, 1992, pp. 22-23, nủm. 6. con el resto de la bibliografia.

211 C. M. Faya Satarem, «Duas inscriçoes romanas inéditas do concelho de Santo Tirson, en $O$ concelho de Santo Tirso. Boletim cultural II.3, 1953, p. $397=$ HAE 514 y AE 1957, 315: revisada por A. Moreira, op, cit, en nota $210, \mathrm{pp} .21$ ss., núm. 5 : Dom(inus) Deus/N/en/eoec/us]/Seueru/s]//S/aturni-/ni [f(ilius) ex] vo-/to posu- /it / - - /. Contra la opinión tradicional, no es el mismo monumento que CIL. $\| 2375=5552+$ p. 891 . 
En la tercera de las inscripciones de Santo Tirso, procedente de S. Martinho do Campo, se ven tres letras en su tercera línea, tradicionalmente leidas como $D(-\cdots) D(\cdots) A(\cdots)$ e hipotéticamente desarrolladas como d(ea) d(omina) A(ugusta) 21?. Aunque el testimonio es excesivamente septentrional para relacionarlo con el culto de Ataecina, cabia la posibilidad de que tales abreviaturas debieran leerse en la forma d(ea) d(omina) A(taecina); sin embargo, las fotos publicadas no garantizan siquiera estas letras, pues da la impresión de que la supuesta $\mathrm{A}$ puede ser una $\mathrm{N}$ con el brazo derecho casi perdido en el canto del fuste; quizá habria que revisar de nuevo el texto, pues no es descartable que en las dos lineas inferiores de la cara frontal deba leerse $d$ (eae) $d$ (ominae) N/abiae, lo que añadiría un nuevo registro al conjunto de testimonios de esta divinidad.

Los dos últimos textos a considerar en este rápido repaso a algunos epigrafes peninsulares emparentados con los de Ataecina nos lleva a dos inscripciones del norte de Portugal procedentes de Giela (feg. y conc. Arcos de Valdevez, dist. de Viana do Castelo). Los dos textos, hallados en un mismo lugar y conservados en el Museo del Seminario Pio XII de Braga, están dedicados a una divinidad de nombre desconocido que en uno de los textos se identifica como $D(--) S(--) K(--) G(--) L_{(--)}$ $L a(--)^{213}$ y en el otro como Do(--) $S a(--) L a(--)$ La(--- $)^{214}$. Del contenido del segundo texto se puede inferir que la dedicación comienza con la expresión do(minus /a) sa(nctus/a), como bien sugieren los editores del texto, aunque no sea posible determinar si estamos ante una dedicación a algún tipo de Lares o a otra divinidad; A. Tranoy ha propuesto para ambos textos una cronología de fines del siglo ॥ y comienzos del ill d. C. En cualquier caso, los dos ejemplos sirven para ampliar el repertorio de inscripciones votivas que emplean formularios similares a los de Ataecina y nos enseñan a ser cautos a la hora de identificar con la divinidad lusitana cualquier grupo de abreviaturas por muy similares que

212 M. Cardozo, Catálogo do Museu de Arqueologia da Sociedade Martins Sarmento I. Secçao lapidar e de escultura, Guimarães 1935, p. 24; Blázquez, Religiones 1962, p. 219; ILER 704; edición y buena fotografia en A. Moreira, "Inscriçoes romanas do concelho de Santo Tirson, Santo Tirso 2, 1992, p. 2425 , núm. 8 , foto 8 , con el resto de la bibliografia. El texto no es CIL II 779 como alli se afirma.

${ }^{213}$ A. Tranoy, op. cit. en nota 116, p. 272; J. Dos Santos, A. Tranoy y $P$. Le Roux, op. cit. en nota 101, p. 193, núm. 16, fig. 21 y $22=\mathrm{AE} 1983,564 ; \mathrm{A}$. Tranoy, op, cit. en nota 104, p. 447. núm. 5 , fig. $5=\mathrm{AE} 1986,385$.

214 A. Tranoy, op. cit. en nota 116, p. 272; J. Dos Santos et alii, op. cit. en nota 101, p. 194, fig. 18-20 = AE 1983, 565; A. Tranoy, op. cit. en nota 104, p. 448 , núm. 6 , fig. 6 y $7=\mathrm{AE}$ 1986, 385 . parezcan, salvo que existan evidencias razonables para justificarlo.

El epiteto Dominus/Domina se encuentra con cierta frecuencia en muchos epigrafes hispanos antepuesto al nombre de la correspondiente divinidad: [D]omin/us M] ars ${ }^{215}$, Cosus Dominus 216, Dea Medica $^{217}$, Domina Daeua ${ }^{21 x}$, Domina Fons ${ }^{214}$, Dominae Nymphae ${ }^{220}$, Dominus Fatus ${ }^{221}$, Iupiter Domimus $(2 \text { testimonios) })^{222}$, Mars Dominus ${ }^{223}$, Diana Domina ${ }^{224}$, etc., además de los repetidos testimonios dedicados a Isis en sus importantes centros de culto de la Bética; sin embargo, faltan las referencias anónimas que si conocemos en otros lugares del Imperio ${ }^{225}$, y a las que habria que sumar ahora una de las inscripciones de Alcuéscar (núm. 12).

\subsection{AlgunOS TESTIMONIOS EXCLUIDOS DEL CULTO A ATAECINA}

1. Ibahernando (Cáceres). Parece difícil de aceptar el testimonio de un ara conocida desde 1900 , que contiene la dedicación realizada por un tal $\mathrm{Vi}$ riatu [s] a una divinidad que se ha querido identificar con Ataecina ${ }^{226}$. El texto editado en Ephemeris Epigraphica decía:

\section{VIRIATV \\ A. A. L. D. SVO P.C.}

215 Villanueva de Córdoba: A. U. Stylow, «Beiträge zur lateinischen Epigraphik im Norden der Provinz Córdoba, II: Baedro. III: Mellarian, en MDAI(M) 28, 1987, pp. 265 ss.. núm. 29, Taf. $350=$ HEp 1. 305 y AE 1986, 362 .

216 Negreira (Coruña): CIRG-I, 22 = HEp 4, 333.

217 HEp 4, 1002.

21x Igabrum (Cabra, Córdoba): A. U. Stylow, op. cit. en nota 188, pp. 295-303, núm. 9,fig. $13-15=\mathrm{AF} 1983,541$; comentarios adicionales en J. M." Blázquez, «Recientes aportaciones a las religiones prerromanas de Hispania II», Gerion 10, 1992. p. 202.

214 AE 1975, 497; J. González, op. cit. en nota 34, núm. 362, de Italica.

220 CIL II 1164; J. González, op. cit. en n. 34, núm. I, de Utrera.

221 CIL II 1276, de Utrera.

222 CIL II 4442 (RIT 919 de Tarragona) y EE 8, 202 (RIT 93 I de Bañeras, Tarragona).

${ }^{223}$ CIL II 3618 de Játiva (Valencia).

224 CIL II $6338 \mathrm{~mm}+$ HEp 1, 338 de Almonacid del Marquesado (Cuenca).

225 G. Lugli, Diz. Epigr. 2, 1956, recogiendo entre otrosel valioso testimonio de CIL VI $809=$ XIV 74 (Ostia): aram fecit Dominae; $c f r$. A. U. Stylow, op. cit. en nota 188, p. 300 , notas 64 y 65 .

226 La primera noticia de este texto figura en una anotación marginal del legajo 9-7848-21 (Antigüedades. Cáceres) de la Real Academia de la Historia; se trata de un escrito de la Comisión 
Desde Hübner se han resuelto las abreviaturas de 1.2 entendiendo el siguiente desarrollo: A(taecinae) A(ugustae) l(ibens) d(e)...; tal desarrollo podría, en todo caso, modificarse en la forma A(taecinae) a(nimo) l(ibens) $d(e)$, como habia propuesto también Hübner a modo de alternativa, que eliminaria la inexplicable conversión de Ataecina en divinidad augustal; sin embargo, no deja de ser aventurado suponer que bajo la primera letra de esta linea deba entenderse la presencia de Ataecina, toda vez que faltan todos sus epitetos y que no es la única divinidad atestiguada en el solar cacereño con esa inicial.

2. Castro de Rocha (Padrón, Coruña) ${ }^{227}$. Como supone G. Pereira, puede ser una falsa lectura del teónimo, sin que se pueda descartar una interpolación a partir de un texto previamente existente.

3. Troviscoso (conc. Monçao, dist. Viana do Castelo) ${ }^{22 x}$. No existen argumentos epigráficos ni geográficos suficientes para desarrollar Ad(aeginae?) en la primera linea del epigrafe.

4. Ubeda (Jaén) ${ }^{229}$. El carácter funerario del texto plantea ciertas dificultades para ver al mismo tiempo una invocación a Ataecina, máxime delante de la dedicación a los dioses Manes y con la tímida abreviatura At(aecinae). Quizá habría que pensar en otra solución para esta abreviatura.

de Monumentos Histórico-Artisticos de Cáceres en donde se notifica el descubrimiento de la necrópolis romana de "Mezquitan y se indica que este otro monumento figura empotrado en una vivienda de la localidad; como en todos los textos entonces encontrados. la precipitación editorial llevó a darlo a conocer en el Boletin de la Real Academia de la Historia según la transcripción realizada por el alcalde de la localidad; ediciones: E. Hübner, "Inscripciones romanas sepulcrales de Ibahernando", Revista de Extremadura 2, 1900, p. 151; F. Fita, "Inscripciones romanas de Mérida y Nava de Ricomalillo", BRAH 36, 1900, p. 448; F. Fita y C. Fernández Duro, «Noticias", BRAH 36. 1900 , p. $408=$ El 9 , 101; Leite, Religiões, p. 150; J. R. Mélida, Catálogo monumental de España. Provincia de Cáceres, Madrid 1924. p. 177; Blázquez, Religiones 1962, p. 143; IL.ER 742; CPIL. Cáceres 294; R. López Melero, op. cit. en nota 26, p. 109. núm. 7.

227 CIL 11 2539; Angel del Castillo y A. D'Ors, Inscripciones romanas de Galicia. Suplemento al fasciculo l: Provincia de La Coruña, Santiago 1960 [= CEG 14, 1959, pp. 145-164], núm. 26; F. Vázquez Saco y M. Vázquez. Seijas, Inscripciones romanas de Galicia II. Provincia de Lugo, Santiago de Compostela 1954, núm. 69; ILER 897; F. Arias Vilas et alii, op. cit. en nota 48, núm. 18; G. Pereira, Corpus de inscripcións romanas de Galicia I. Provincia de A Coruña, Santiago 1991, núm. 21, con el resto de la bibliografia.

${ }_{22 k}$ F. Rusell, Bol. Com. Prov. Monumentos de Orense 15, 1945, pp. $12-15$; J. M. Garcia, op. cit. en nota 158 , p. 508 , núm. $575=$ HEp 4, 1087.

${ }_{224}$ C. González Román, "Inscripciones romanas inéditas de la provincia de Jaén IV», Florentia lliberritana 2, 1991, pp. 231234, núm. III, lám. III = HEp 4, 497; C. González Román y J. Mangas, op. cit. en nota 112, pp. 401-403, núm. 356.

\subsection{LA LISTA DEFINITIVA DE: TESTIMONIOS EN HISPANIA}

La mayor parte de los testimonios de Ataecina conocidos en Hispania han sido objeto de repetidas ediciones lo que, en casi todos los casos, nos exime de nuevas consideraciones de lectura. Sin embargo, algún texto ha pasado desapercibido hasta el presente y en otros cabria hacer algunas matizaciones, por lo que nos detendremos brevemente en ellos antes de establecer la relación definitiva de los testimonios.

En el apretado repertorio epigráfico de Cáceres publicado por M. Beltrán a mediados de los años 70 apareció el fragmento inferior de un monumento procedente de la «Dehesa Zafrilla» (Malpartida de Cáceres, Cáceres) ${ }^{230}$, cuyo deterioro impidió incluso la oportuna referencia del epigrafe en $L$ 'Année Epigraphique. Conservaba únicamente tres líneas de texto, la primera de ellas prácticamente perdida $y$ unos toscos trazos verticales decorando la parte inferior. Por las dimensiones $(57 \times 45 \times 27 \mathrm{~cm})$ fue catalogada como estela y su texto fue interpretado como parte de una mención funeraria.

De Malpartida de Cáceres conocemos siete inscripciones hasta el presente, de las cuales dos de carácter funerario proceden de la finca «Las Brenิas" ${ }^{231}$, otras dos aparecieron en diferentes lugares del pueblo sin que se pueda precisar su lugar de origen $^{232}$, y otras tres fueron halladas en la citada «Dehesa Zafrilla». En este último lugar, los dos textos identificados hasta la fecha están dedicados a Ataecina (cfr. infra núms. 10 y 11 ) y grabados sobre plaquitas metálicas soldadas a estatuillas de cabritas, por lo que la relectura de la parte conservada en este tercer texto puede hacerse sin demasiado riesgo.

Para reafirmar más el carácter votivo del texto, en la parte inferior aparece un esquematismo antropomorfo consistente en un trazo vertical rematado en un círculo superior con los brazos hacia arriba representados por trazos formando ángulo recto (fig. 54); en las estelas decoradas del suroeste son corrientes imágenes similares pero con los brazos hacia abajo; en este caso, a la luz de los paralelos en grabados pre y protohistóricos, no hay duda de que se trata de un orante ${ }^{233}$ y dispondríamos de la pri-

\footnotetext{
${ }^{230}$ M. Beltrán. op. cit. en nota 124, pp. 58-59, núm. 37.

231 HEp 1. 169 y 170.

232 CIL II 855 = CPIL Cáceres 333; CPIL Cáceres 770.

233 La imagen es sobradamente conocida en representaciones Cfr. F. Ballet y P. Raffaelli, «Les gravures rupestres antropomorphes de Savoie. Evolution de la représentation humaine du Néolithique à l'age du Fer», en Les représentations humaine. du Néolithique à l'age du Fer. Actes du 115e. Congr. National des Sociétés Savantes, Paris 1993, p. 185, con ejemplos de Aussois.
} 


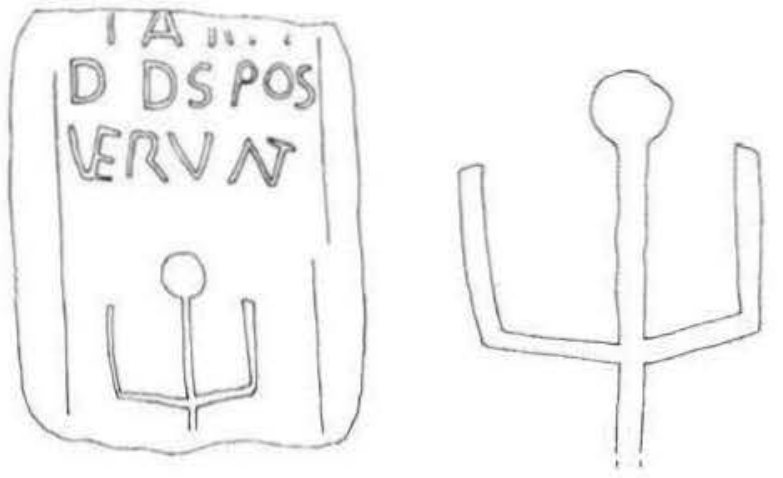

Figura 54.--Inscripción de Malpartida de (áceres y detalle de la representación antropomorfa.

mera representación de este tipo relacionada con el culto de Ataecina y una de las pocas disponibles para la religión prerromana en Hispania. Frente a la interpretación d(onum) d(e) s(uo) posuerunt que hace el primer editor del epigrafe, proponemos la siguiente restitución para la parte conservada del texto:

$$
\begin{aligned}
& {[-1} \\
& +A+++ \\
& \text { d(eae) d(ominae) s(anctae) po- } \\
& \text { suerunt }
\end{aligned}
$$

\section{L.3: Ligaduras VE y NT}

Esta dedicatoria introduce una tercera variante en las invocaciones a Ataecina de Malpartida de Cáceres, ya que tampoco existia uniformidad en las otras dos [de(a) s(ancta) A(taecina) T(urobrigensis) y d(ea) s(ancta) T(urobrigensis) Ad(aecina) respectivamente], pero emparenta el enclave con el conjunto de Santa Lucía de Alcuéscar, en donde esta fórmula está presente en cinco epigrafes.

El hallazgo de tres epigrafes dedicados a Ataecina en la dehesa "Zafrilla" de Malpartida de Cáceres obliga, al mismo tiempo, a plantearse la existencia en el lugar de un santuario de segundo rango o de un centro de culto de tipo familiar dedicado a esta divinidad.

Un segundo epigrafe que conviene revisar procede de Salvatierra de Santiago ${ }^{234}$ que ya Roso de

al pie de los Alpes; A. Beltrán Martinez, "Orantes, fertilidad y antepasados en el arte prehistórico: disgresiones sobre un tema universals, Cullaira 1, 1989, pp. 27 y 29. Agradecemos a Mauro $\mathrm{S}$. Hernández sus indicaciones en este sentido.

${ }^{234}$ M. Roso de Luna, op. cit. en nota 86, p. 123, núm. 10; J. R. Mélida, Catálogo monumental de España. Provincia de Cáceres, Madrid 1924, pp. 196-197, núm. 462; CPIL Cáceres 432.
Luna vio a comienzos de siglo empotrado en un domicilio particular de la localidad. Sólo se conserva la parte izquierda del texto, pero el editor supo reconocer un epigrafe consagrado a Ataecina. El texto editado en 1904 fue el siguiente: DO [ -.- ] / NA [-- ]

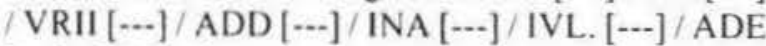
$[\cdots] /$ VS $[--]$.

La primera y segunda lineas parecen contener la corriente invocación como domina que recibe Ataecina, por lo que al final de la primera linea sólo deberian faltar dos letras. Al final de la segunda debe ir, al menos, la inicial del topónimo Turibrigensis, puesto que parece haber un corte asilábico al comienzo de la tercera; en ese caso, aún cabría una interpunción o un espacio de separación, parte de la desinencia del dativo dominae y la mencionada consonante. En la tercera linea Roso dibuja dos astas verticales, la segunda de las cuales debe formar parte de una B. quedando aún espacio para otra letra; si consideramos que el adjetivo debe ir abreviado ya que no continúa en el siguiente renglón, se podría proponer a modo de hipótesis una forma como Turibr(igensi). En la cuarta linea comienza el nombre de la divinidad. que continúa en la quinta; por ello es fảcil restituir las tres letras - AEC - perdidas. En la mencionada quinta linea, que comienza con un nuevo corte asilábico, falta al menos la desinencia del dativo y quedaria espacio para un praenomen del dedicante, aunque el texto puede estar alineado a la izquierda y haberse dejado un pequeño espacio en blanco. En la sexta aparece abreviado, o al menos eso se desprende de la copia de Roso de Luna, el nomen del dedicante, Iulius, al que podría en todo caso seguir alguna de las letras del cognomen, aunque esto último es dificil de establecer por la brevedad de lo conocido; no sobraria un $\operatorname{cog}$ nomen como Adercus, ya conocido en el área cacereña $\mathrm{y}$ el único que se adecua, fuera de ejemplos poco probables como Adelphus o Pylades, al grupo de letra - ADE - que Roso transcribe. Las dos letras de la octava linea más probablemente pertenecen a la desinencia del cognomen que a la fórmula votiva, que se habria perdido. Con las reservas naturales, el texto podria quedar como sigue:

Do[mi]
na[e T-]
uribr(igensi)
Add[aec-]
ina[e -??]
lul(ius) [--?]
Ade[rc]-
us [---]
[---]


Este testimonio amplia el área de dispersión de los testimonios de Ataecina por el sureste cacereño. al tiempo que confirma una fórmula de invocación ya conocida por un epigrafe de Medellin y por tres de Alcuéscar, con uno de los cuales (núm. 10) guarda una extraordinaria similitud.

Tras las consideraciones realizadas aqui y en los apartados precedentes, la relación de testimonios de Alaecina en Hispania, previos al hallazgo de los textos de Alcuéscar, es la siguiente (fig. 55):

1. Ataecina. Talavera de la Reina (Toledo) ${ }^{235}$.

2. Ataecina. Caleruela (Toledo) ${ }^{23 \mathrm{t}}$.

3. $[A t] a(e) c i n a(?)$. Santa Ana (Cáceres) ${ }^{23}$.

4. Dea Ataecina Turibrig(ensis) Proserpina. Mérida (Badajoz) ${ }^{23 x}$. Este testimonio emeritense puede ser una defixio contra un ladrón, como puso de manifiesto A. D'Ors ${ }^{234}$.

23. D Urbina, "Ataecina y Urilouco. Dos divinidades indigenas en Talavera de la Reina”. Minius 2-3, 1993-94. pp. 29-41. de la que ya habian dado noticia J. Mangas y J. Carrobles, al.a ciudad de Talavera de la Reina en época romanan, en tetas de las primeras jornadas de Arqueologia de Talavera de la Reina $y$ sus tierrus. Toledo 1992, p. 102.

24. S. Cortes et alii, "Nuevas inseripciones romanas del Museo de Santa Cruz de Toledom, Museos 3. 1984, p. 75, núm. 31 = Al: 1986, 426: HF.p 1.602): M.- P. González-Conde Puente, «Bassus Turobrigensis y la inscripción de Ataecina en Caleruela (Toledo)". Studia Historica [Salamanca] 6, 1988, p. 131-132 (= AE 1988. 823: HEp 2, 679); G. Alföldy, "Eine Reiter der ala Vettonum». en "Neue und revidierte Militärinschriften aus dem römischen Hispanienn, Römische Heeresgeschichte. Beiträge 1962-1985. Amsterdam 1987, pp. $517-519$ (= AE 1988, 823); comentarios adicionales en J. M.* Blázquez, op. cit. en nota 218. pp. 202 203.

217 La identificación de este testimonio resulta más que problemática a la vista de los rasgos confusos leidos en el texto; se incluye aqui con las naturales reservas siguiendo la transcripción de Roso de I una y Blázquez, annque sólo una autopsia directa permitiria despejar las dudas. Inexplicablemente se vicne atribuyendo esta inscripción a lbahernando, cuando el primer editor (Roso de Luna) advierte expresamente del hallazgo en la «Dehesa Estragana ?" en término de Santa Ana. El lugar de hallazgo, de donde procede un segundo texto. está cerca de la ermita de Santa Maria de la Jara y de la importante necrópolis de "Mezquita", ya en término de Ibahernando. M. Roso de Luna, "Nuevas inscripciones de Ibahernando, Cumbre y Santa Ana", BRAH 42, 1903, p. 235; Blázquez, Religiones 1962, pp. 143 ss.; ILER 739; CPIL Cáceres 448; R. López Melero, op. cit. en nota 26. p. 108 , nủm. 6 .

${ }^{23 x}$ CIL. II $462=$ ILS 4515; Leite, Religiōes, pp. 167 ss.; J. Toutain, Les cultes païens dans l'Empire romain. Première partie: Les provinces latines. Tome III: Les cultes indigènes nutionaux et locaux: Afrique du Nord. Péninsule Iherique, Gaule, Paris 1920, pp. 134 ss.; J. Alvarez Sáenz de Buruaga, «El hallazgo de la lápida de Proserpina de Méridaw, REstExtr. 11, 1955. pp. 325-337; id., «El nuevo hallazgo de la perdida lápida emeritense de Proserpinan, $A E A 30,1957$. pp. 245-251 = AF 1959. 30 , dando a conocer el redescubrimiento del monumento; $A$. D'Ors, «Miscelánea epigráfica», Emerita 28, 1960, p. 329; Blázquez, Religiones 1962, p. 141; M. Almagro Basch, Guia de Mérida. Madrid 1981, p. 66, lám. XXVIII: ILER 736; R. López Melero, op. cit. en nota 26, p. 107 , núm. 1.

239 A. D'Ors, op. cit. en nota 238 , p. 329.
5. D(ea) At(a)e(cina) Proserpina Tu(ribrigensis). Salvatierra de los Barros (Badajoz). Iné$\operatorname{dita}^{2+4}$

6. Dea Ataecina Turohrigac [s]ancta. Mérida

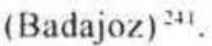

7. D(ea) d(omina) s(ancta). «Dehesa Zafrilla», en Malpartida de Cáceres (fig. 54) ${ }^{2+2}$.

8. D(ea) s(ancta) A(taecina) T(urohrigensis). Cagliari (Cerdeña) ${ }^{2+3}$.

9. D(ea) s(ancta) A(taecina) T(urobrigensis) P(roserpina). Cárdenas (Badajoz) ${ }^{2+4}$.

10. De(a) s(ancta) A(taecina) T(urobrigensis). "Dehesa Zafrilla», en Malpartida de Cáceres ${ }^{245}$. Contra lo asegurado por R. Hurtado ${ }^{2+6}$, no se trata de un ara sino del segundo de los exvotos cuya inscripción aparece grabada en una plaquita de bronce,

2*at Debemos la noticia de su existencia y la lectura de la invocación a la generosidad de José Luis Ramirez Sádaba (univ de (antabria)

4) de Monsalud, op. cit. en nota 120, pp. 541-542 = 1:F: 9. 42: Leite, Religiöes, pp. 147 ss.; J. R. Mélida. Catäloge monumental de la provincia de Badajoz. Madrid 1925-26, p. 201: J. M." de Navascués, Colección de antigüedades que pertenceicron al Sr. Marqués de Monsalud, Madrid 1931. pp. 5 ss.; J. Mallón y T. Marin. Las inscripciones publicadas por el Marqués de Monsulud. Madrid 1951, p. 98, núm. 201: Blảzquez, Religiones 1962, p. 142; R. López Melero, op. cit. en nota 26, p. 107. núm. 2.

24: M. Beltrản Lloris, op. cit. en nota 124, pp. 58-59. nủm. 37.

*4 CIL X 7557: L. Fernandez Fuster, "Ataecina", en IV Congr. Int. de Ciencias Pre y Protohistoricas, Madrid 1954, pp. 971 ss.: Blàzquez, Religionès 1962, p. 144. EI hallazgo debe estar relacionado con la estancia en la isla de una cohorte Lusitanorum. Agradecemos a M.* P. Garcia-Bellido esta información.

24 CIL II 461: Leite, Religiòes, p. 150; Blázquey, Religiones 1962, p. 143; ILER 735: R. López Melero, op. cit. en nota 26. p. 108. nủm. 4 .

* F. Fita, "inscripciones romanas de Cáceres, Ubeda y $\mathrm{Al}$ calá de Henares», BRAH 7, 1885, pp, 45 ss. = CIL 11 5299; P. Paris, Essai sur l'art et l'industric de l'Espagne primitive. Paris 1904, vol. 2, p. 207, fig. 353, con dibujo tomado de E. Cartailhac, p. 301 , fig. 433 (con errores de procedencia; $c f r$, nota 248): Leite, Religiñes, p. 149; L. Vázquez de Parga, «Museo arqueológico Nacional. Adquisiciones en 1940-1945. Exvoto dedicado a Adaegina", en MMAP 8, 1947, p. 79, lám. XIV.2; A. Ferrer. «El exvoto iberorromano de Malpartida de Cáceres dedicado a la deidad Turibrigensi Adaeginaen, $A E A$ 21, núm. 72, 1948, pp. 290 s.; Blázquez, Religiones 1962, p. 142; ILER 744: CPIL Cáceres 139 y $332 ;$ M. Beltrán, Estudios de arqueologia cacereña. Zaragoza 1973, p. 29. fig. 13; R. López Melero, op. cit. en nota 26. p. 110, núm. 11: Los bronce's romanos en España. Madrid 1990. p. 215. núm. 98.

th CPIL Cáceres 139. Tampoco es cierto que apareciera en el camino de Arroyo de la Luz (Cáceres). La tipologia y procedencia exacta de los dos exvotos de Malpartida está confirmada por una carta del Marqués de Castro Fuerte, su primer propietario. a D. Dióscoro Puebla, fechada en Cáceres el 20 de junio de 1885: del contenido de aquella carta recibió puntual información Fidel Fita, quien asi lo recoge en $B R A H 7,1885$, p. 46 y nota 1 . 


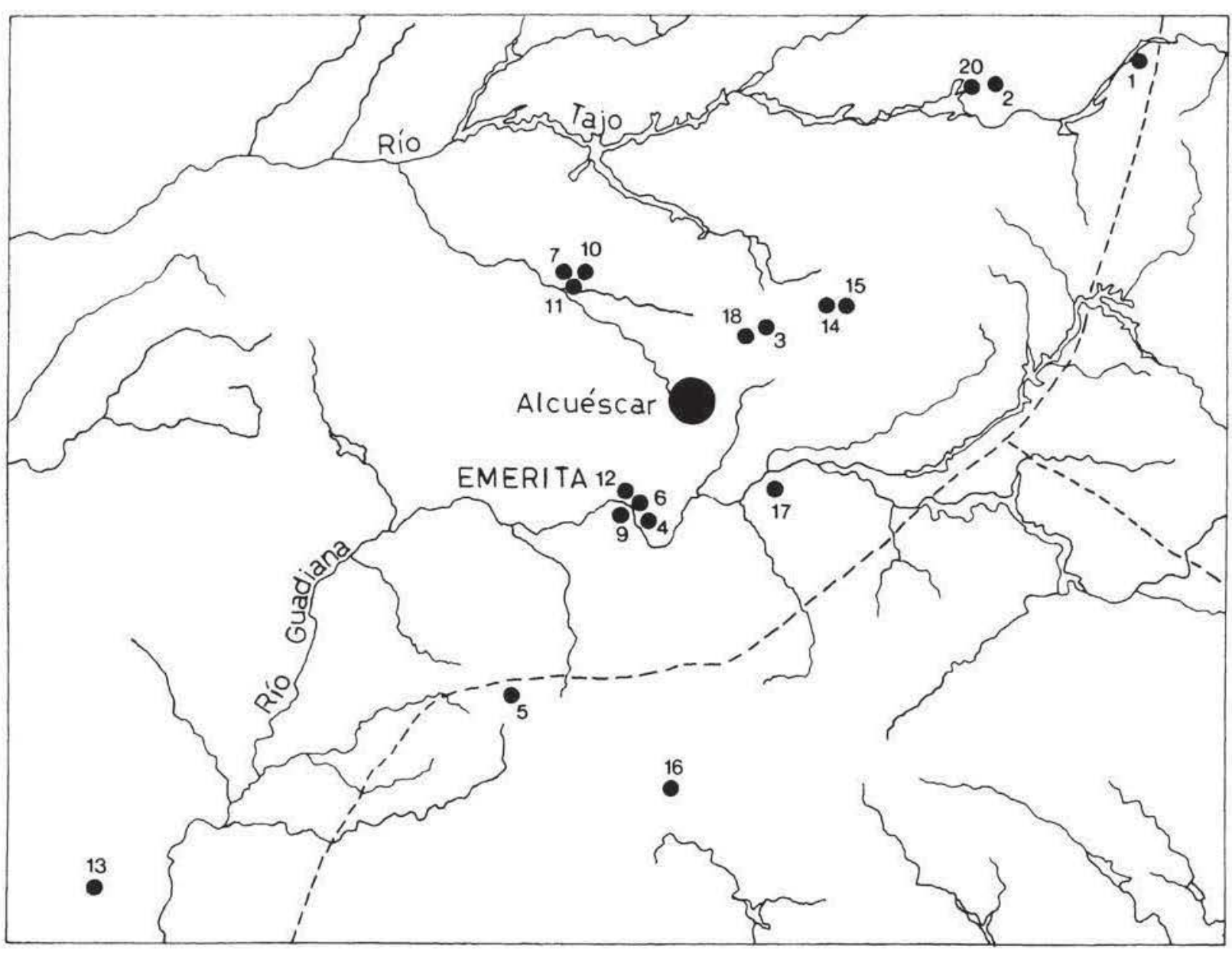

Figura 55.-Distribución de los testimonios del culto de Ataecina en Hispania. La numeración corresponde a la del inventario. Quedan fuera de la ilustración el testimonio de Cagliari y el de Saelices, por las razones expuestas en la nota 257.

adosada a las patas de una cabra, con letras punteadas ${ }^{24}$.

11. D(ea) s(ancta) T(urobrigensis) Ad(aecina). «Dehesa Zafrilla», en Malpartida de Cáceres (Cáceres) ${ }^{24 x}$. Grabada en una placa adosada a las patas de una cabra de bronce.

${ }^{247}$ Este tipo de escritura es corriente en muchos ambientes de tradición indoeuropea en occidente. Se emplea sobre soportes metálicos, tanto para téseras como para seǹalar objetos personales. $C f r$, ejemplos recientes en M. Feugere, Les casques antiques. Visages de la guerre, de Mycènes à l'Antiquité tardive, Paris 1994, p. 50; J. C. Labeaga y J. Untermann, "Las téseras del poblado prerromano de La Custodia, Viana (Navarra)", Trabajos de Arqueologia Navarra 11, 1993-94, p. 46, núm. 1. Baste recordar que incluso una pieza tan significativa como el bronce de Luzaga tenia este tipo de letras punteadas.

${ }^{24 \times} \mathrm{F}$. Fita, "Inscripciones romanas inéditas de Cáceres, Brandomil, Naranco y Lérida", $B R A H 6,1885$, pp. 430 ss. = CIL II 5298 + p. 1031 ; P. Paris, Essai sur l'art et l'industrie de l'Espagne primitive, Paris 1904, vol. 2, p. 207, fig. 353, reproduciendo el dibujo de E. Cartailhac, p. 301, fig. 433, que asegura erróneamente que procede del Alentejo portugués, pese a que ya habia sido dada a conocer por Leite de Vasconcelos
12. Dea sanc(ta) Turib(rigensis). Mérida (Badajoz) $^{249}$.

(AP 5, p. 299, fig. 4) y recogido el texto por Hübner para el supplementum de CIL II; Leite, Religióes. p. 149; F. Fita, «Nuevas inscripciones romana y visigótica de Talaván y Mérida", BRAH 64, 1914, pp. 310 s.; M." P. Corrales y Gallego, «Museo Balaguer", MMAP 3, 1942, pp. 71-72; G. Bonfante, «Some news Latin Inscriptions from Spain", AJA 49, 1945, pp. 196 ss. = AE 1946, 193; F. Russell Cortez, $A E A$ 21, núm. 72, 1948, p. $287=$ AE 1950 , p. 14; A. Ferrer, «El exvoto iberorromano de Malpartida de Cáceres dedicado a la deidad Turibrigensi Adaeginaem, AEA 21, núm. 72, 1948, pp. 288-290; Blázquez, Religiones 1962 , p. 142, fig. 44; ILER 743; CPILCáceres 138 y 331; R. López Melero, op. cit. en nota 26, p. 110 , núm. 10.

${ }^{249} \mathrm{M}$. de Monsalud, "Nuevas inscripciones de Extremadura", BRAH 37, 1902, pp. 323-324 = EE 9, 43; Leite, Religiōes, p. 149; J. R. Mélida, Catálogo monumental de la provincia de Badajoz, Madrid 1925-26, p. 201; J. Mallón y T. Marin, op. cit. en nota 241 , p. 91 s., núm. 186; Blázquez, Religiones 1962, p. 143; ILER 733; R. López Melero, op. cit. en nota 26, p. 108 , núm. 3; G. Gamer, op. cit. en nota 9, p. 197, núm. BA-58, Taf. $85 \mathrm{e}$. 
13. D(ea) s(ancta) Turibrice(nsis). Quintos (Beja, Вeja) ${ }^{250}$.

14. Daea sancta Turibrige(nsis). «Dehesa el Palacion, Herguijuela (Cáceres) (fig. 53) ${ }^{251}$.

15. [D(ea)?] sancta. "Dehesa El Palacio», Herguijuela (Cáceres) ${ }^{252}$.

16. Domina [A]ttaegina [T] urubriga[e]. La Bienvenida (Badajoz) ${ }^{253}$.

17. Domina [T]uribri[g(ensis)] Adaegina. Medellin (Badajoz) ${ }^{254}$.

18. Do[mi]na [T]uribr.igensis) Add[aec]ina. Salvatierra de Santiago (Cáceres) ${ }^{255}$.

$2 \$ 1$ La procedencia del monumento no se puede precisar aunque es probable que fuera hallada en los alrededores de Quintos (cfr. IRCP); CIL II 71; ILER 740; Blázquez, Religiones 1962, p. 143; J. D'Encarnaçao. Diivinidades indigenas sob odominio romano em Portugal, Lisboa 1975, pp. 110 ss.; IRCP 287, con toda la bibliografia anterior: $\mathrm{R}$. Lópe 2 Melero, op. cit. en nota 26, p. 110 , núm. 12; J. M. Garcia, op. cit. en nota 158, p. 305. núm. 55 .

25 La elocuente fotografia editada por Callejo Serrano y la inspección directa que realizamos del texto (22 de marzo de 1995) no permiten albergar dudas de la lectura en 1.1. Sobre el monumento, cfir. M. Roso de Luna, op. cit. en nota 86, p. 131, núm. 34: J. R. Mélida, Catálogo monumental de España. Provincia de Cáceres, Madrid 1924, p. 167, núm. 392: C: Callejo, op cit. en nota 198, pp. 144 ss., núm. 9 (foto); ILIR 737; CPIL. Cáceres 263: M. Beltrán Lloris, op. cit. en nota 105, p. 114; R. López Melero, op. cit. en nota 26, p. 109, nüm. 8; G. Gamer, op. cit. en nota 9 , p. 219 , núm. $\mathrm{CC}-18$.

252 La atribución a Ataecina de este epigrafe es probable, aunque sólo depende del calificativo sancta con que comienza el texto. Es muy probable, como sugirió Callejo Serrano, que en el extremo superior del frontón existiera una abreviatura $D(o m i n a) / D(e a)$ que diera sentido a la dedicación. Sobre el monumento, c fr $r$. M. Roso de Luna, op. cit. en nota 86, p. 130, núm. 31; J. R. Mélida, Catálogo monumental de España. Provincia de Cáceres, Madrid 1924, p. 166, num. 389; C. Callejo, op. cit. en nota 198, pp. 146 ss., num. 10 (foto): CPIL Cáceres 260; M. Beltrán Lloris. op. cit. en nota 105, pp. 113 ss.; J. D’En-carnaçao, op. cit. en nota 65 , p. 309 . que justifica la identificación con Ataecina al proceder del mismo lugar otro texto que menciona expresamente a la Daea (sic) Sancta Turibrige(nsis); R. López Melero, op. cit. en nota 26, p. 109, núm. 9: G. Gamer, op. cit. en nota 9, p. 219, núm. CC -19

253 Esta interesantisima ara de mármol, hallada en el paraje de "Fuente La Vaquera" de la localidad pacense, ha sido repetidamente editada en los últimos años: J. Esteban, op. cit. en nota 26, pp. 21-25; R. López Melero, op. cit. en nota 26, pp. 93 ss. (= HEp 1, 81; AE 1991, 956); J. M." Blázquez, "Nuevos teónimos hispanos. Addenda et corrigenda V', en Cuadernos de Preh. y Arqueol. de la Univ. Autón. de Madrid 13-14 (Hom. Gratiniano Nieto), 1986-87, vol. 2, p. 147, núm. 11 (= AE 1987, 472).

${ }^{254}$ CIL $11605=a d d$. ILS 4515; M. de Monsalud, op. cit. en nota 31 , p. $490=$ EE 9. p. 42 ; Leite, Religioes, p. 369; J. R. Mélida, Catálogo monumental de la provincia de Badajoz, Madrid 1925-1926, p. 369; J. Mallón y T. Marín, op. cit. en nota 241, pp. 9 ss.; Blázquez, Religiones 1962, p. 142; ILER 743; R. López Melero, op. cit. en nota 26, p. 108, núm. 5.

${ }_{255} \mathrm{M}$. Roso de Luna, op. cit. en nota 86, p. 123, núm. 10; CPIL Cáceres 432. Según amable comunicación de Armin U. Stylow, hace unos años en Salvatierra vio un epigrafe dedicado a Ataecina empotrado en una vivienda derrumbada; aunque las condiciones de la observación no permitieron tomar detalles del mismo, no es descartable que se trate del editado en su dia por Roso de Luna.
19. $\langle D>0<$ mina $>$ s(ancta) Tur (obrigensis) A(tae(ina) $^{25 t}$. Saelices (Cuenca) 257 .

20. Noticia del hallazgo de una dedicación a Ataecina en la que sólo se lee el nombre de la divinidad. Despoblado de «Puebla de Naciados», El Gordo (Cáceres) ${ }^{25 x}$.

Estas 20 inscripciones, junto con las 15 evidencias epigráficas de Ataecina en Alcuéscar suman un total de 35 inscripciones con las que podemos hacer a continuación algunas consideraciones globales.

\section{EL NOMBRE DE LA DIVINIDAD}

El buen número de variantes gráficas que presenta el nombre de la divinidad venerada en Alcuéscar y en otros enclaves extremeños ha dado lugar a un largo debate etimológico y epistemológico ${ }^{254}$ básicamente apoyado en los trabajos de D'Arbois, Her-

$25 \mathrm{~h}$ No se puede descartar que en la inscripción la A, que aparentemente es la abreviatura del nombre de la divinidad, pertenezca a la identificación de los dedicantes (Vlenses?. Aulenses? Auilense's?), lo que no crearia conflicto en la invocación por ausencia de teonimo y vendria justificado por ser esta vocal la última letra de una linea.

(II II 5877: ILIER 738 y 1008: M. Almagro Basch, Segobriga II. Inscripciones ibericas, latinas paganas y latinas cristianas. ExcavArqEsp 127, Madrid 1984, p. 80, núm. 14. Este es el único monumento de granito dentro del conjunto epigráfico de Segohriga y. al mismo tiempo, es la única dedicación a Ataecina aparecida fuera del contexto del sureste si exceptuamos el epigrafe de Cerdeña. Tales circunstancias, unidas a la inexistencia de noticias sobre su hallazgo en la ciudad conquense, han hecho suponer a M. Almagro Gorbea que la inscripción no procede de Segobriga, sino de algún lugar más próximo al área extremeña, en contra de lo cual sólo milita la noticia de Fita y Juan de D. de la Rada, que dicen haberla visto entre las procedentes de Segohriga: cfr. M. Almagro Gorbea. «El lucus Dianae con inscripciones rupestres de Segobriga" (en prensa); agradecemos al autor la comunicación verbal de estas impresiones y la consulta de su manuscrito.

${ }_{25 \times} \mathrm{M}$. de la Vega Jimeno, «Aspectos religiosos en Talavera de la Reina y su tierra en época romana», en Actas de las primeras jornadas de Arqueologia de Talavera de la Reina y sus tierras. Toledo 1992, p. 336. Parece tratarse de la parte superior de un ara hoy conservada en Calzada de Oropesa (Toledo).

254 Steuding, "Ataecina", en W. H. Roscher, Ausfürliches Lexikon der griechischen und römischen Mythologie, Leipzig 1884 1890 , vol. 1.1, col. 663 (origen en aidche $=$ nox); H. D'Arbois de Jubainville, "Les Celtes en Espagne», Revue Celtique 14 1893, p. 389 ; Leite, Religioes, pp. 161 ss.; A. Holder, Altceltischer Sprachsschatz, Leipzig 1907, p. 342; C. Hernando Balmori, "Ataecina, Adaegina", Emerita 3, 1935, pp. 214-224; A. Tovar, Estudios sobre las primitivas lenguas hispanas, Buenos Aires 1949 , p. 140; id., "Sustratos hispánicos y la inflexión románica en relación con la infección céltica», en VII Congr. Ling. Rom., Barcelona 1955, p. 396; J. M." Blázquez, Religiones 1962. pp. 145 ss.; id., Diccionario de religiones prerromanas de Hispania, Madrid 1975, pp. 39-42; id.. Primirivas religiones ibéricas II. Religiones prerromanas, Madrid 1983, pp. 286-287; Albertos, Onomástica 1966, p. 38; J. Untermann, «Lusitanisch, Keltiberisch, Keltisch", en Studia Palaeohispanica. Actas del IV Coloquio sobre lenguas y culturas paleohispánicas. Vitoria 1985. Veleia 2-3, 1985-1986 [1987], p. 66; M." P. Garcia y Bellido, op. cit. en nota 177, AEA 64, 1991, p. 72. 


\begin{tabular}{|c|c|}
\hline Invocación & Procedencia \\
\hline Ataecina & Talavera de la Reina (Toledo), núm. 1 \\
\hline Alaecina & Caleruela (Toledo), núm. 2 \\
\hline [At]a(e)cina (?) & Santa Ana (Cáceres), núm. 3 \\
\hline Adecin $[a \mid$ Sancta & Alcuéscar 1 \\
\hline Dea Alaecina Turibrig(ensis) Proserpina & Mérida (Badajoz), núm. 4 \\
\hline D(ea) At(a)e(cina) Proserpina Tu(ribrigensis) & Salvatierra de los Barros (Badajoz), núm. 5 \\
\hline Dea Ataecina Turohrigae /S/ancta & Mérida (Badajoz), núm. 6 \\
\hline$D(e a)$ d(omina) s(ancta) $[--]$ & Alcuéscar 2 \\
\hline D(ea) d(omina) s(ancta) Turibri(gensis) Attegina & Alcuéscar 3 \\
\hline D(ea) d(omina) s(ancta) Turibri(gensis) Adaecina & Alcuéscar 4 \\
\hline$D(e a)$ d(omina) s(ancta) T(uribrigensis) A(taecina) & Alcuéscar 5 \\
\hline D(ea) d(omina) s(ancta) Turibri(g)e(nsis) Adegina & Alcuéscar 6 \\
\hline$D(e a) d(o m i n a)$ s(ancta) & Malpartida de Cáceres (Cáceres), núm. 7 \\
\hline D(ea) dom [i]na Tur(ibrigensis) [--] & Alcuéscar 7 \\
\hline D(ea) d(omina) [T]uri[b]ri(gensis) & Alcuéscar 15 \\
\hline$D(e a)$ s(ancta) A(tuecina) T(urobrigensis) & Cagliari (Cerdeña), núm. 8 \\
\hline$D(e a)$ s(ancta) A(taecina) T(urobrigensis) P(roserpina) & Cárdenas (Badajoz), núm. 9 \\
\hline De(a) s(ancta) A(taecina) T(urobrigensis) & Malpartida de Cáceres (Cáceres), núm. 10 \\
\hline D(ea) s(ancta) T(urobrigensis) Ad(aecina) & Malpartida de Cáceres (Cảceres), núm. 11 \\
\hline Dea sunc(ta) Turib(rigensis) & Mérida (Badajoz), núm. 12 \\
\hline D(ea) s(ancta) Turibrice(nsis) & Quintos (Beja, Beja), núm. 13 \\
\hline Daea sancta Turibrige(nsis) & Herguijuela (Cáceres), núm. 14 \\
\hline Sancta (sic) & Herguijuela (Cáceres), núm. 15 \\
\hline Domina [A] traegina [T]urubriga/e] & La Bienvenida (Badajoz), núm. 16 \\
\hline Domina Turibr(igensis) Attaec [i]na & Alcuéscar 8 \\
\hline Domina Turibri(gensis) [A]degina & Alcuéscar 9 \\
\hline Domina Turibri(gensis) Addaecin(a) & Alcuéscar 10 \\
\hline Domina [T]uribri[g(ensis)] Adaegina & Medellin (Badajoz), núm. 17 \\
\hline Do[mi]na [T]uribr(igensis) Add[aec]ina & Salvatierra de Santiago (Cáceres), núm. 18 \\
\hline$<D>0<$ mina $>$ s(ancta) Tur(obrigensis) A(taecina) & Saelices (Cuenca), núm. 19260 \\
\hline Domina $[--]$ & Alcuéscar 11 \\
\hline Dom(ina) & Alcuéscar 12 \\
\hline Tur(ibrigensis) Ad(aecina) & Alcuéscar 13 \\
\hline$[T]$ uribri(gensis) A[t/d]ecin $[a]$ & Alcuéscar 14 \\
\hline$? ?$ & El Gordo (Cáceres), núm. 20 \\
\hline
\end{tabular}

Figura 56,-Formas de las invocaciones a Ataecina

nando Balmori, Tovar y Blázquez. Una gran parte de las especulaciones sobre el significado del nombre y las funciones de la divinidad se han venido apoyando en la posible relación del nombre de Ataecina con el término irlandés adaig, que significa "noche», cuando hoy parece que la mencionada palabra irlandesa sólo está atestiguada a partir del siglo VIII y, por lo tanto, excede temporalmente la época prerromana y romana ${ }^{261}$. Habrá que esperar,

${ }^{260}$ Sobre las dificultades de establecer el lugar de procedencia del epigrafe, $c f r$. nota 257.

${ }^{261}$ Opinión de J. de $\mathrm{Hoz}$ en M." P. García y Bellido, op. cit. en nota 177 , p. 73. pues, a que filólogos e historiadores de la religión vuelvan a aunar criterios sobre nuevos argumentos para ver resuelto este antiguo debate.

Las vacilaciones gráficas en el nombre de Ataecina deben ser, en su mayor parte, debidas a rasgos de pronunciación y a una transcripción poco rigurosa. Pero sea cual sea el motivo, lo cierto es que hoy disponemos de un elenco de variantes excesivo, especialmente si tenemos en cuenta el reducido número de testimonios para cada una de ellas. El espectro de las denominaciones se amplía aún más con la la introducción de otros elementos nominales en el formulario, como puede verse en la fig. 56 . 
Si consideramos únicamente las variantes del nombre de la divinidad (fig. 57) disponemos de 24 evidencias epigráficas; prescindiendo incluso de los epitetos, el panorama es desolador: ¡15 variantes para designar a la misma divinidad! El muestrario incluye todo tipo de geminaciones, reducciones de diptongos o alternancia de sordas y sonoras. En la restitución de las lagunas de los textos el espacio perdido sugiere a veces la forma a transcribir, pero es imposible con este registro saber cuándo estamos ante sordas o ante sonoras. Bien podria decirse que la única unanimidad de los fieles de Ataecina estribó en la designación de una vocal para abreviar el nombre de la divinidad.

La única forma que encuentra un cierto consenso entre las variantes mostradas en la fig. 57 es Ataecina, que aparece sobre textos de Talavera de la Reina, Caleruela y Mérida, con un total de 4 testimonios.

El panorama expuesto plantea inconvenientes de envergadura para explicar la mayor antigüedad de unas formas u otras, la mayor antigüedad de las referencias con sonidos sordos sobre los sonoros o viceversa, pues la cronologia relativa de los diferentes textos no permite establecer un orden que coincida con la variación de las grafias y, aparentemente, a falta de criterios de datación más precisos, coexisten formas que desde un punto de vista lingüistico podrian considerarse consecutivas.

La explicación de este proceso se debe simplemente a la dificultad de transcripción del nombre de la divinidad en un ambiente con fuerte arraigo del latín como instrumento de comunicación oral, con serias insuficiencias en su escritura. A ello debió sumarse una práctica epigráfíca heterogénea en cada una de las áreas, como hemos puesto de manifiesto al hablar de la tipología de los altares y, cómo no, un desconocimiento real del nombre de la divinidad, conocida secularmente en estos ambientes con fuerte peso del medio indigena.

\begin{tabular}{|c|c|c|}
\hline Nombre & Grafia & Núm. de casos \\
\hline$A(\cdots)$ & $A(\cdots)$ & 5 \\
\hline $\operatorname{Ad}(\cdots)$ & $A d(\ldots)$ & 2 \\
\hline Adaecina & Adaecina & 1 \\
\hline Adaegina & Adaegina & 1 \\
\hline Addaecina & Adduecin (u) & 1 \\
\hline Addae/-Jina & Addlae-/ina & 1 \\
\hline Adecina & Adecina & 1 \\
\hline Adegina & Adegina/[A]degina & 2 \\
\hline Atacina & [At]acina & 1 \\
\hline Ataecina & Ataecina & 4 \\
\hline Ale $(\cdots)$ & $\operatorname{Ate}(\cdots)$ & 1 \\
\hline Attaecina & Antaec [i]na & 1 \\
\hline Attaegina & [A]ttaegina & 1 \\
\hline Attegina & Altegina & 1 \\
\hline Al-Jecina & Al-Jecin $[a]$ & 1 \\
\hline
\end{tabular}

Figura 57.-Variantes atestiguadas del nombre de Ataecina.
El nombre de la divinidad venerada en el conjunto epigráfico de Alcuéscar y en el resto de los epigrafes que ya hemos reseñado debió ser Alaeci$n a$, a la que se le añade un epiteto referido a la localidad en la que debió ser considerada divinidad tutelar y los sustantivos dea o domina (o ambos en el caso de Alcuéscar) al comienzo de las invocaciones. Asi, la forma Dea Alaecina Turobrigensis ${ }^{262}$ podria considerarse que incluye la mayor parte de los elementos comunes a muchas de las dedicaciones ${ }^{20.3}$, aunque no necesariamente en ese orden.

\section{CARACTERISTICAS DEL CULTO}

Ataecina ha recibido una gran atención por parte de los historiadores de la religión ${ }^{264}$, no sólo en razón de la frecuencia de sus testimonios, sino por la interpretatio de que parece ser objeto con Proserpina en algunas regiones del suroeste peninsular. Asociada a este culto de connotaciones infernales ${ }^{2 n s}$, Alacina se viene considerando también una divinidad de carácter infernal ${ }^{260}$ pese a las reticencias expresadas en su dia por Leite de Vasconcelos, que veia en ella un culto agricola ${ }^{267}$, algo que hoy no se considera excluyente. Según Blázquez la asociación con Proserpina vendria por el carácter infernal de Ataecina y no por el carácter agrícola de ambas. En esta asignación de funciones y de espacios algunos trabajos recientes sugieren también para Ataecina

262 Sobre el nombre de la ciudad y las alternancia de las voces Turohriga/Turibriga, cfr. infra.

267 Aunque M. Salinas, op. cit. en nota 198, p. 73 opina que el nombre completo de la divinidad debió ser Déa Sancta Turibrigensis Alaecina, no parece que este orden de elementos sea mayoritario y. de hecho, sólo es visible en cuatro inscrip. ciones.

2nt Steuding, op, cit. en nota 259, col. 663; J. Toutain. op cit. en nota 238, pp. 131-136; G. Fliedner, "Das Weiterleben der Ataecinaw. Theologische Studien und Kritiken 104. 1932. pp. 111-120; S. McKenna, Paganism and pagan survivals in Spain up to the fall of the visigothic Kingdom. Washington 1938, pp. 5 ss. y 25 ss.: L. Fernández Fuster, op, cit. en nota 243, pp. 971 ss.; J. M." Blázquez, Religiones 1962, pp. 141-147; id., Diccionario, op. cit. en nota 259 , pp. $39-42 ;$ id., 1983, op. cit. en nota 259 , pp. $227,242,263,284$ ss., 293 y 307 ss.; J. de Encarnaçao. op. cit. en nota 250 , pp. 110 ss.; R. López Melero, op. cit. en nota 26, pp. 93 ss.

2ns Varro, ling. 5, 68: Hinc Epicharmus Ennii Proserpinam quoque appellat, quod solet esse sub terris. Dicta Proserpina. quod haec ut serpens modo in dexteram modo in sinisteram partem late mouetur. Serpere et proserpere idem dicebant. Cfr. G. Radke, "Proserpina», RE suppl. IX, Stuttgart 1962, col. 12831287.

266 J. Toutain, op. cit. en nota 238, pp. 134 ss.; Blázquez. Religiones 1962, p. 145; J. de Encarnaçao, op. cit. en nota 250 pp. 110 ss.; $i d .$, IRCP, p. 356 , seguidos por gran parte de la historiografia contemporánea.

${ }^{267}$ Leite, Religioes, pp. 161 ss. 
atributos de divinidad lunar ${ }^{2 n x}$; a modo de anécdota, porque seguramente lo hizo sin pensar en el texto de Estrabón ${ }^{264}$, hay que recordar que cuando Roso de Luna dio a conocer una de las inscripciones de Salvatierra de Santiago decorada con un creciente lunar, la contemplación de la pieza le sugirió el siguiente comentario: hermosa piedra coronada por la media luna de Ataecina ${ }^{270}$. En este mismo contexto, G. Fliedner ${ }^{271}$ la llegó a poner en relación con Santa Eulalia, por la veneración que ambas tenian en el ámbito emeritense y supuso que el culto a Santa Eulalia era la superviviencia del culto que ya se habia dispensado a Ataecina ${ }^{272}$.

Divinidad celta, aunque su nombre no se encuentre en otros territorios donde existen celtas ${ }^{273}$, Ataecina seria una de las tantas divinidades prerromanas que mantuvieron su culto fuertemente arraigado durante el Principado, asumiendo connotaciones locales con la adopción de epitetos ${ }^{274}$, y su popularidad vendria apoyada por la frecuente abreviación de su nombre ${ }^{275}$. El lugar central del culto fue Turobriga o Turibriga (vid. infra), como muestran los epitetos que acompañan al nombre de Ataecina, y en esta localidad pudo tener la condición de divinidad tutelar 276 .

La aplicación de criterios restrictivos a la hora de identificar testimonios del culto a Ataecina ha hecho variar también la geografía de esta divinidad. Si hace unos años se suponía que el culto de Ataeci$n a$ se extendia entre los rios Tajo y Guadalquivir, y más especificamente en las riberas del Guadiana, con testimonios en los cuatro conventos juridicos suroccidentales ${ }^{27}$, hoy se puede afirmar que sólo ocasionalmente desborda el Guadiana hacia el sur, al tiempo que han aumentado las evidencias en las riberas del Tajo (fig. 55). La localización en el mapa de las evidencias de Ataecina dibuja hoy un área muy concreta en el área central de Extremadura, que en el triángulo Norba-Turgalium-Emerita alberga 27 de los 35 testimonios $(77,1$ por 100$)$. Tal con-

\footnotetext{
${ }^{26 x}$ M.* P. Garcia-Bellido, op. cit. en nota 177 , p. 73.

${ }^{269}$ Geog. 3, 4 16, aludiendo a una divinidad lunar innominada.

${ }^{270} \mathrm{M}$. Roso de Luna, op. cit. en nota 86 , p. 122, núm. 7.

271 Op. cit. en nota 264 , passim.

272 C fr. en contra S. Mckenna, op. cit. en nota 264, p. 26.

${ }^{273}$ A. Holder, Altceltischer Sprachsschatz, Leipzig 1907. p. 342 ; S. McKenna, op. cit. en nota 264 , p. 6.

${ }^{274}$ J. D'Encarnaçao, «Divinidades indigenas peninsulares: problemas metodológicos do seu estudo», en J. Arce \& J. González (ed.), Estudios sobre la Tabula Siarensis. Anejos de AEA 9. Madrid 1988, p. 264.

275 S. McKenna, op. cit. en nota 264, p. 6.

276 M. Salinas, op. cit. en nota 198, p. 75; J. González, op. cit. en nota 158, p. 273.

277 J. M." Blázquez, op. cit. en nota 259 , p. 286.
}

centración empuja a considerar seriamente la posibilidad de que en esta comarca estuviera situado el centro emisor del culto, el núcleo - no diremos ciudad-que permitió denominar a la divinidad como Ataecina Turibrigensis o Turobrigensis.

Sin embargo, los testimonios epigráficos invitan a pensar en la existencia de varios centros cultuales, más allá de la devoción individual que empujara a cualquiera de los fieles a levantar un ara a Ataecina en su lugar de residencia $\mathrm{y}$, como se ha dicho recientemente, desborda nuestras previsiones de que las divinidades prerromanas tengan un culto exclusivamente local ${ }^{27 x}$. Sobre la base de las evidencias documentales, son tres los lugares en donde podemos situar santuarios de Ataecina:

I. Proximidades de Santa Lucía del Trampal (Alcuéscar, Cáceres). Catorce son los altares dedicados a Ataecina hallados en el templo citado o en sus alrededores, como hemos visto más arriba. Su individualidad formal respecto a otros monumentos de su entorno refuerza la hipótesis de que se trate de un conjunto homogéneo, trasladado hasta aqui desde un solo lugar y no resultado de una requisa heterogénea de material constructivo en la comarca. Refuerza esta idea el altar dedicado por Licinius Rusticus (núm. 21), que omite el teónimo, lo que sólo se entiende en el ámbito de un santuario sobradamente identificado por los fieles y la población del entorno.

2. Dehesa Zafrilla de Malpartida de Cáceres. Conocida por los dos exvotos en forma de cabrita soldados a una placa con inscripción, un tercer documento releido ahora por nosotros (vid. supra apartado 5.4) permite albergar la idea de que en el enclave existiera un centro dedicado a Ataecina.

3. Dehesa El Palacio, de Herguijuela (Cáceres). Proceden de aqui dos arae, una de ellas dedicada a la Daea sancta Turibrige(nsis) (sic) y otra que simplemente invoca sanctae sacrum. La semejanza formal entre los dos monumentos y su idéntica procedencia no deja lugar a dudas sobre la identificación.

Tanto en Mérida como en la vecina Cárdenas se concentran otros cuatro testimonios de Ataecina; Sin embargo, los epígrafes no proceden de un mismo lugar, pues sabemos que uno de ellos fue hallado en el embalse de Proserpina, al que da nombre y los otros proceden del área urbana exceptuando el citado de Cárdenas. Es poco probable pues que en Mé-

${ }^{27 k}$ G. Sopeña, Dioses, ética y ritos. Aproximaciones para una comprensión de la religiosidad entre los pueblos celtibéricos, Zaragoza 1987 , p. 44, nota 76 . 
rida existiera un santuario dedicado a Alaecina, y los epigrafes parecen más el resultado de devociones individuales.

Tal consideración nos lleva a una cuestión más espinosa, la de la existencia o no de una organización alrededor del culto. Casi todos los testimonios de que disponemos parecen abonar la idea de que la elevación de altares a Ataecina fue resultado de iniciativas particulares que concluyeron con la inserción del nombre del devoto en el texto votivo. Sin embargo, dos inscripciones escapan a esta consideración. La más importante de ellas es el texto de Bienvenida en el que, si aceptamos la restitución de una de sus editoras, habria que entender [cul] tiribus suis collectis ma(gistri) f(ecerunt) ${ }^{279}$, que evidencia una intención colectiva y una cierta institucionalización del culto, con las reservas que lo fragmentario del texto impone.

La segunda inscripción a referir aquí es el releido epigrafe de Malpartida de Cáceres, en donde con toda claridad se dice d(eae) d(ominae) s(anctae) posuerunt (vid. supra); es decir, un grupo de fieles impulsaron la colocación del referido altar. En este último caso la referencia a un colectivo tiene más lógica si tenemos en cuenta que alli probablemente existió un centro de culto ${ }^{2 \times 0}$. En este epigrafe aparece, al mismo tiempo, la imagen de un orante en su parte inferior, representado con una serie de trazos esquemáticos pero suficientes; tal imagen evoca contextos gráficos de la Hispania mediterránea y es la única representación de este tipo que conocemos en el marco de las religiones indigenas en la Hispania de tradición indoeuropea.

Una de las características del culto de Ataecina fue el uso de exvotos de bronce probablemente usados en conjunción con altares. De forma fehaciente sólo conocemos dos exvotos de Malpartida de Cáceres, en los que las figuras de cabritas en posición erguida van soldadas a placas con el texto que contiene la dedicación a Ataecina. A partir de estos testimonios podemos inferir que otras figuras similares conservadas en diferentes museos extremeños, tanto en España como en Portugal, son indicios de la existencia del culto, como ya había supuesto en su día Leite de Vasconcelos y como ha seguido defendiendo la mayor parte de la historiografía ${ }^{281}$.

\footnotetext{
${ }^{279}$ R. López Melero, op. cit. en nota 26, p. 95.

200 No es fácil interpretar la dedicación a Ataecina supuestamente procedente de Saelices (Cuenca), en la que se citan a unos Vlenses?, por lo que la excluimos de este comentario.

${ }_{2 \times 1}$ Es un hecho corriente en la Hispania prerromana la elaboración de pequeñas figurillas de bronce, tanto representaciones humanas como de animales, que suelen ir asociadas a prácticas religiosas. Estas imágenes debian servir a un buen número de
}

El hecho más curioso que destaca en la observación de algunas de estas figurillas es la presencia de salientes inferiores o piezas soldadas que, lejos de servir para estabilizar la pieza en una posición exenta, parecen estar destinados a permitir su incrustación en una peana, de cuyas características poco sabiamos hasta el hallazgo de los monumentos de Alcuéscar.

En efecto, en algunas de las aras de Santa Lucia del Trampal no existe un foculus sobre el coronamiento, sino un par de muescas, a veces alargadas, que parecen destinadas a permitir la colocación sobre el monumento de los correspondientes exvotos. Pero ni estos altares conservan huella del bronce que alli debió colocarse, ni las figurillas conservan adherencias del material con el que fueron fijadas a los altares. Sin embargo, llama la atención que los vástagos que permitian tal unión estén rotos en algunos ejemplares, por lo que podriamos imaginar que fueron arrancados de forma violenta probablemente para recuperar la pieza una vez que la dedicación habia perdido su sentido o que se había perdido la memoria del dedicante.

Antes de pormenorizar los hallazgos conviene señalar que de Torrejoncillo, lugar de donde proceden varios de ellos, no existe todavía ningún tipo de evidencia epigráfica, por lo que todas las valoraciones deben hacerse con cautela.

La relación sumaria de los exvotos que con seguridad o de forma bastante probable deben relacionarse con el culto de Ataecina no es hoy demasiado extensa y, excluido el ejemplar de La Aliseda $2 \times 2$ que parece pertenecer a otro ambiente temporal, se reduce a los ejemplares cacereños de Malpartida y Torrejoncillo ${ }^{2 \times 3} \mathrm{y}$ a algunas piezas portuguesas:

cultos, y no sólo al de Ataecina, por lo que quizá habria que evitar generalizaciones y restringir el marco de Ataecina a las figurillas de cabras que hasta ahora tenemos evidenciadas. Por otra parte, un criterio menos selectivo llevaria a tener que defender el culto de Ataecina en áreas geográficas muy extensas. prácticamente en toda Lusitania, algo para lo que hoy carecemos de evidencias. Sobre las implicaciones de estas y otras imágenes animales en Lusitania, $c f r$. A. Garcia y Bellido, «El jarro ritual lusitano de la colección Calzadillan, $A E A$ 30, 1957, núm. 96, pp. 121 ss.; $i d$., «De nuevo sobre el jarro ritual lusitano publicado en AEA 30,1957, pp. 121 ss.", AEA 31, núm. 97-98. 1958, pp. 153 ss.: J. M." Blázquez, «Bronces prerromanos del Museo de Cáceres", $A E A$ 35, núm. 105-106, 1962, pp. 128-131; M. Beltrán Lloris, op, cit. en nota 105, p. 41 .

$2 \times 2$ J. M. "Blázquéz, op. cit. en nota 281, pp. 128-129; M. Beltrán Lloris, op, cit, en nota 124, pp. 108-111; id, op. cit. en nota 105, p. 85; A. Álvarez Rojas y M." C. Garcia-Hoz. op. cit. en nota 155, p. 21.

$2 \times 3$ J. M.* Blázquez, op. cit. en nota 281, pp. 128-131; M. Beltrán Lloris, op. cit. en nota 124, pp. 108-111; id., op, cit. en nota 105, p. 85; A. Álvarez Rojas y M." C. Garcia-Hoz, op. cit. en nota 155, p. 25. 
1. Malpartida de Cáceres (Cáceres, Museo Balaguer, de Vilanova y la Geltrú/Barcelona) ${ }^{2 \times 4}$. Figura de bronce que representa una cabra cuyos cuartos delanteros se apoyan en una placa rectangular que contiene la inscripción; los traseros van soldados a otra pieza cilindrica que se une por detrás a esta placa. El extremo inferior de la placa termina en un resalte, seguramente partido, destinado a insertar en una peana.

2. Malpartida de Cáceres (Museo Arqueológico Nacional, Madrid) ${ }^{2 \times 5}$. Cabrita en posición erguida con las cuatro patas soldadas a dos placas rectangulares, una de ellas con inscripción votiva, que conluyen en una peana dispuesta a ser engarzada en un soporte.

3. Medellin (Badajoz, Museo de Mérida): Dos cabritas dispuestas paralelamente y unidas por las patas mediante dos placas ${ }^{286}$. En algunas arae de Santa Lucía del Trampal se observan en la parte superior dos huecos paralelos que podrian corresponder a la colocación de piezas de este tipo con las patas soldadas.

4. Torrejoncillo (Cáceres, Museo de Cáceres). Cabrita exenta con los cuartos delanteros y traseros agrupados formando dos puntos de apoyo aptos para incrustarse en la cabecera de un ara. Mide $6,3 \times 9,5$ $\mathrm{cm}^{2 \times 7}$.

5. Torrejoncillo (Cáceres, Museo de Cáceres). Cabrita similar a la anterior, con los cuartos delanteros agrupados en un vástago para incrustar en un soporte. Mide $3,7 \times 8,7 \mathrm{~cm}^{288}$.

6. Torrejoncillo (Cáceres, Museo de Cáceres). Cabrita del mismo tipo que las anteriores pero con los extremos de las patas partidos. Cabria la posibilidad de que los hubiera perdido al ser arrancada de un pedestal. Mide $4,5 \times 8,5 \mathrm{~cm}^{284}$.

7. Torrejoncillo (Cáceres, Museo de Cáceres). Cabrita exenta en posición erguida, sin agrupamiento de las patas y con el cuerpo finamente trabajado simulando la pelambrera. Mide $5,7 \times 6,4 \mathrm{~cm}^{290}$.

2ks Cfr. nota 248.
2ks Cfr. nota 245.

286 J. Álvarez Sáenz de Buruaga, «Un exvoto de bronce a Ataecina Proserpina en el Museo de Mérida», en XI Congr.Nac.Arq. Mérida 1968, Zaragoza 1970, pp. 827 ss.; T. Nogales, «Bronces romanos en Augusta Emerita), en Bronces romanos en España, Madrid 1990, p. $109+$ Catálogo, p. 216 , núm. 99.

287 J. M." Blázquez, op. cit. en nota 281 , p. 129 , núm. 2, fig. 2; Bronces romanos en España, Madrid 1990, p. 216 , núm. 100.

28x Ibid., pp. 129-130, núm. 3, fig. 3; Bronces romanos en España, Madrid 1990, p. 216 , núm. 100.

2 Ib9 Ibid., p. 130, núm. 4, fig. 4.

${ }^{290} \mathrm{M}$. Beltrản Lloris, op. cit. en nota 124, pp. 109-110, núm. 1 .
8. Torrejoncillo (Cáceres, Museo de Cáceres). Cabrita en posición de trote con una mayor simplificación de los rasgos. Mide $5,3 \times 6,5 \mathrm{~cm}^{291}$.

9. Torrejoncillo (Cáceres, Museo de Cáceres). Cabeza de una cabrita de mayores proporciones que las anteriores $(3.5 \mathrm{~cm}$ de altura $)$ con una tosca indicación de los rasgos ${ }^{292}$

10. El Museo de Evora guarda exvotos de cabras que Leite de V. relaciona con este culto ${ }^{293}$.

Entre el gran número de exvotos y figurillas prerromanas de bronce conservadas en el Museo Arqueológico Nacional, la mayor parte procedentes de los grandes santuarios ibéricos del área de Sierra Morena, existe un apreciable repertorio de representaciones animales que no están excesivamente lejos desde el punto de vista conceptual de los exvotos de Ataecina cacereños y portugueses. Sin embargo, es difícil encontrar paralelos formales suficientemente elocuentes para relacionar alguna de esas representaciones con el referido culto, máxime cuando muchas de ellas proceden de colecciones antiguas y se ignora su procedencia. Una excepción podria hacerse: la de una representación de una cabrita con los cuernos muy pronunciados que tiene un tratamiento estético muy parecido al de los bronces de Torrejoncillo y que se asemeja más a las figuras animalísticas extremeñas que a las de los santuarios ibéricos, sin que sea posible conocer su procedencia y establecer de forma fehaciente esta relación ${ }^{294}$

La cronologia de los testimonios de culto a Ataecina permite aventurar su vigencia durante los tres primeros siglos de la era, como ponen de manifiesto los epígrafes que la mencionan. Aunque algunos de ellos ofrecen serias dificultades de datación, otros pueden ser fácilmente adscritos al siglo I d.C., como ocurre con el de Quintos ${ }^{295}$; no es fácil considerar contemporáneo el de Medellin (CIL II 605), que Hübner consideraba litteris profundis et vetustis, pero que invoca a una Domina [T]uribri[g(ensis)] Adaegina, con las connotaciones temporales que el término domina pueda imponer. Las cronologías más recientes vendrían dadas, probablemente, por los epígrafes hallados en Alcuéscar, que podrían alcanzar los primeros años del siglo ॥I d.C. (vid. supra).

\footnotetext{
2 Ibid., pp. 109-110, núm. 2

202 Ibid., pp. 109-110, núm. 3.

${ }^{243}$ Leite, Religioes, pp. 169 y 172 y fig. 34-35.

${ }^{204}$ F. Álvarez-Ossorio, Museo Arqueológico Nacional. Catálogo de los exvotos de bronce ibéricos, Madrid 1941, p. 147. lám. CXL, núm. 1829. Antigua colección Vives. Altura: $6 \mathrm{~cm}$.

${ }^{295} \mathrm{CIL}$ II 71. Datación de J. D’Encarnaçao atendiendo al tipo de letra y a la ausencia de cognomen.
} 
No existe un patrón de referencia para definir a los devotos de Ataecina; ya hemos aludido al carácter heterogéneo de los dedicantes de los textos de Santa Lucia. En el resto de los testimonios, aunque la onomástica de los fieles se ha perdido en algunos epigrafes, el espectro coincide básicamente con el de la población de las distintas zonas, sin que exista una mayor presencia de individuos de origen indigena ${ }^{2 \%}$. La razón de fondo debe buscarse en el profundo enraizamiento del culto en fechas avanzadas del Principado y en los procesos de interpretatio con divinidades romanas y orientales que favorecian la generalización del culto. Pero al mismo tiempo, un rápido repaso por la onomástica de los dedicantes y su zona de origen puede hacerse sin dificultad con el apoyo del registro onomástico de cada una de las comarcas. Es decir, en áreas con fuerte presencia de onomástica de origen prerromano, los dedicantes de Ataecina se ajustan a esta definición. mientras que en la proximidad de los grandes centros urbanos como Beja o Mérida la onomástica latina o grequizante es dominante. Lo mismo puede decirse de rasgos propios como la omisión del sustantivo filius en filiaciones o de las anomalias gráficas en los textos. En todos los casos hay una correspondencia precisa con las tradiciones epigráficas de los contornos y no se pueden establecer caracteres comunes que hagan pensar en un colectivo especifico.

Para concluir esta valoración general del culto debemos referirnos a la relación epigráfica entre los cultos de Ataecina y de Proserpina. Sobre el culto de Proserpina en Hispania no disponemos de un repertorio epigráfico abultado; los escasos testimonios conocidos, que siguen faltando en la Tarraconensis ${ }^{297}$, proceden mayoritariamente de Elvas y de su territorio, en donde conocemos cinco epigrafes dedicados a esta divinidad ${ }^{29 x}$; aún en Lusitania disponemos ahora de otra evidencia epigráfica en La

3wo Talavera de la Reina (núm. 1): Flaus Presi (filius ?): Caleruela (núm. 2): Bassus; Santa Ana (núm. 3): T. Norbanus (?) (-) : Mérida (núm. 6): Artemas Claudi Martilini ser(uus); Malpartida de Cáceres (núm. 10. CIL II 5299): Cocceius Modestianus: Malpartida de Cáceres (núm. II. CIL II 5298): Victorin(us) ser(uus) C(...) Séuerae: Mérida (núm. 12): L. luuentius Iulianus: Quintos (núm. 13): L. Axonius; Herguijuela (núm. 14): P. Florius Venustus: Herguijuela (num. 15): Crastena Viralis (f.?); Bienvenida (núm. 16): /Cul/tores (?): Salvatierra de Santiago (núm. 18): Iul(ius) (-?) Ade/rc/us (?): Saclices (?) (nủm. 19): Vlenses?

${ }^{247}$ A. M." Canto, La religión romana en Hispania. Fuentes epigráficas, arqueologicas y numismáticas, Madrid 1982. pp. 9 у 11.

298 CIL II I43 (IRCP 570): Proserpina: CIL II 144(IRCP 571): Proserpina; CIL II 145 (IRCP 572): Proserpina seruatrix; EE 8. 9 (IRCP 573): Dea Proserpina; EE 8, 10 (IRCP 574): Proserp(ina).
Garrovilla (Badajoz) ${ }^{204}$; en la Bética conocemos un epigrafe en Castilblanco (Sevilla) ${ }^{301} \mathrm{y}$ aún otros dos en Alcalá del Rio (Sevilla) ${ }^{13}$. Junto a estos testimonios explicitos hay que consignar aqui aquellos textos en que aparece junto a Ataecina en Mérida, Cárdenas y en un epigrafe inédito de Salvatierra ${ }^{302}$. En algunos de estos textos se la denomina seruatrix, sancta, dea o sancta dea, como en uno de los textos sevillanos.

Aunque el número de evidencias sigue creciendo con respecto a cómputos realizados hace sólo una década, nótese que su área de distribución no rebasa por el norte el Guadiana; justamente lo contrario ocurre con Ataecina, que en contadas ocasiones transgrede hacia el sur esta línea.

De la dispersión de los testimonios de una y otra divinidad se desprende que la zona de contacto de ambos cultos fue, evidentemente, el área emeritense, lo que explicaria los procesos de interpretatio que en la ciudad o al sur de ella pudieran producirse.

Tal observación impide generalizar sobre la interpretatio de Ataecina y Proserpina. La propia evidencia epigráfica muestra que no se ha realizado una auténtica hypostasis y que ambos cultos tienen áreas especificas de desarrollo. Habria que traer a colación ahora los epigrafes que mencionan sólo a una dea sancta y que hemos descartado más arriba como evidencias de Ataecina. Nótese que cinco de ellos proceden de Mérida, Mértola, Beja y Serpa, sobre o al sur de la latitud de Mérida. Si en esta región meridional Proserpina es denominada con los epitetos que ya hemos visto antes, es fácil deducir que estas tácitas alusiones a una dea sancta deben referirse a Proserpina y no a Ataecina.

\section{LA SEDE DEL CULTO Y LA UBICACIÓN DE TUROBRIGA}

\subsection{EL. DEBATE HISTORIOGRÁFICO Y LA REDUCCIÓN DEL NOMBRE}

Turobriga es mencionada por Plinio (3, 14), tras Arucci y antes de Lastigi, entre las ciudades de la Beturia céltica ${ }^{303}$; dado que el pasaje pliniano pre-

${ }^{209}$ Dedicación inédita a Proserpina hecha por Severianus. Noticia de J, L. Ramirez Sádaba, Studia Hisłorica [Salamanca] 10-11, 1992-1993, p. 140, nota 20 y p. 143.

toi CIL. II 1044.

vit AE 1982, 503 y AE 1982, 504

ww2 Agradecemos la noticia de su existencia a D. José Luis Ramírez Sádaba (Univ. Cantabria)

tos N.h. 3. 14: prater haec in Celrica Acinippo. Arunda. Arunci, Turohriga, Lastigi, Salpesa. Saepone, Serippo. 
senta un orden alfabético en la relación de los núcleos, desde E. Albertini se ha querido buscar explicación a la mención de Turobriga fuera de su lugar correspondiente. El propio Albertini sugirió que Arucci Turobriga no fueran dos ciudades sino una, lo que daria sentido al pasaje pliniano y vendria avalado por el hecho de que la turobrigense Baebia Crinita diera muestras de su liberalidad precisamente en la ciudad de Arucci. Tal solución encuentra, como el propio Albertini advirtió, un serio obstáculo en la localización del centro principal del culto de Ataecina, que de esta forma habría de situarse no en la Lusitania sino en la Bética occidental; para resolver el dilema, Albertini optó por suponer la existencia de dos ciudades con el mismo nombre: la primera, Arucci Turobriga en territorio onubense y, la segunda, una Turobriga de Lusitania que sería el centro de culto de Ataecina ${ }^{304}$.

En la misma linea de duplicación de topónimos, desde la obra de Resende en 1593 y con ecos en los trabajos de J. Fragoso de Lima, se ha llegado a suponer la existencia de dos ciudades de nombre Arucci: una cercana a Aroche (Huelva) y otra, de nombre Noua Arucci (!!) en Moura y cercana a Corte de Messangil, de donde procedia la inscripción que mencionaba a un [Tu]rubrige $(\mathrm{n}) \mathrm{sis}^{305}$.

La duplicación del topónimo Arucci fue consecuencia de una lectura interesada del texto CIL II 963. Esta inscripción, hallada en los alrededores de Aroche (Huelva), fue trasladada a la ciudad portuguesa de Moura en el siglo xvi; la restitución que Mommsen ${ }^{30 \%}$ sugirió de este texto dice: [lu]liae Agrippina[e diui Caludi]/Cae[sa]ris Aug(usti) German[ici]/matri Aug(usti) n(ostri)/ciuitas Aruccitana $^{307}$, cuyo único inconveniente es el aparente anacronismo del adjetivo noster en un momento

104 E. Albertini, Les divisions administratives de l'Espagne romaine, Paris 1923, pp. 86 ss.; Cfr. R. Corzo y A. Jiménez, "Organización territorial de la Bética», $A E A$ 53, 1980, p. 45.

wos J. Fragoso de Lima, "Aspectos da romanizaçao no territorio portugés da Bétican, AP 1, 1951, p. 194; seguido recientemente en E. Cerrillo et alii, "Ciudades, territorios y vias de comunicación en la Lusitania meridional españolan, en Lés Villes de Lusitanie romaine. Hierarchies et territoires. Table Ronde... Talence, 8-9 decembre 1988, Paris 1990, p. 57.

${ }^{100}$ Ad CIL II 963.

${ }^{30}$ CIL II 963; J. González, Corpus de Inscripciones latinas de Andalucia, vol. I: Huelva. Sevilla 1989, pp. 28 ss., núm. 2 $=\operatorname{HEp} 3,197$, con casi toda la bibliografia anterior. Deben añadirse las siguientes obras: W. Trilmich, «Ein Kopffragment in Mérida und die Bildnisse der Agrippina Minor aus den hispanischen Provinzen", en Homenaje a Sáenz de Buruaga, Badajoz 1982, p. 120 ; J. D:Encarnaçao, "Uma homenagem a Agripina, mulher de Germânico", Conimbriga 28, 1989, pp. 157-167; id., "Epigrafia romana do Museu Municipal de Moura", en Moura na época romana. Cadernos do Museu Municipal de Moura I, 1990, pp. 70-71, núm. 7; J. Fragoso de Lima, Monografia arqueológica do concelho de Moura, Moura 1988, pp. 70 ss. Lectura $\tan$ antiguo ${ }^{3 n x}$, que Sillières resuelve transcribiendo Aug(ustae) n(ostrae) ${ }^{304}$. En la inscripción se menciona la ciuitas Aruccitana y, además, bastaba leer n(oua) al final de la tercera linea para tener una noua ciuitas Aruccitana en territorio portugués. Todas las lecturas modernas de CIL 11 963, tanto las partidarias de Agrippina Maior como las de Agrippina Minor. son suficientes para desmontar la hipótesis de las dos ciudades de nombre Arucci, como se ha señalado ya en diversas ocasiones ${ }^{310}$.

En la línea de la discusión geográfica, hace una veintena de años L. García Iglesias sugirió un camino intermedio, que armonizaba parte de las tesis ya expuestas y que consistia en identificar Turobriga con Arucci, pero no con el núcleo onubense, sino con el portugués defendido por Fragoso ${ }^{311}$.

En los últimos años ha vuelto a cobrar fuerza en determinados círculos la teoria de Albertini a la luz del paisaje arqueológico onubense: J. González ${ }^{312}$ ha reunido los argumentos para remitir Arucci a los alrededores de Aroche (Huelva), cerca de la localización que sugiere también para Turobriga, armonizando asi sus impresiones con el texto pliniano; sus consideraciones topográficas siguen las explicaciones de tipo arqueológico expuestas en su día por J. M. ${ }^{a}$ Luzón, quien en el «Llano de San Mamés», a unos $2,5 \mathrm{~km}$ al norte de Aroche, encontró el podio de un templo ${ }^{313}$, sugiriendo la identificación de esta Arucci onubense con Turobriga.

seguida en A. M. Canto, "La Beturia céltica. Introducción a su epigrafian, en Celtas y Túrdulos: La Beturia. Cuadernos Emeritenses 9. Mérida 1995, p. 319

tox J. D'Fncarnaçao y J. González ha sugerido desarrollar al final de la tercera linea $A u g(u s t i)$ n(epoti). lo que llevaria la dedicación a Agrippina Maior, mujer de Germánico y madre de Caligula. La hipótesis choca con la sugerencia de Mommsen a favor de Agrippina Minor, seguida por Trillmich y otros autores. y retomada por A. Canto (ad. HEp 3. 197) al rebatir - a nuestro juicio con suficientes argumentos - las hipótesis de González y D.Encarnaçao. Estariamos ante una dedicación a la mujer de Claudio y madre de Nerón, fechable entre los años 54 y 59 d.C.

109 P. Sillières, "Voies romaines et limites des provinces et des cités", en Les Villes de Lusitanie romaine. Hiérarchies el territoires. Table Ronde... Talence. $8-9$ décembre 1988, Paris 1990 , p. 85 , nota 68 .

310 P. Sillières, op. cit. en nota 309, pp. 84 ss. y nota $68 ; \mathrm{J}$ González, op. cit. en nota 307, pp. 24 ss.; J, de Alarçao, «Vestigios romanos do concelho de Moura", en Moura na época romana. Cadernos do Museu Municipal de Moura I. 1990, pp. 32-33.; J. L. Ramirez Sádaba, "La Baeturia céltica y los limites con Lusitania", en Actas del II Congr. de Historia de Andalucia. Córdoba 1991, Historia Antigua, Córdoba 1994, p. 350.

${ }^{314}$ L. Garcia Iglesias, "La Beturia, un problema geográfico de la Hispania Antigua", en $A E A 44,1971$, p. 99; $i d$., "El Guadiana y los limites comunes de Bética y Lusitanian, HAnt 2, 1972 , p. 177.

312 J. González, op. cit. en nota 158, pp. 274 ss.

313 J. M." Luzón, "Antigüedades romanas de la provincia de Huelvan, en Huelva, Prehistoria y Antigüedad, Madrid 1975. pp. 305 ss. 
Tales hipótesis han encontrado eco en los trabajos de A. M." Canto, que opta por identificar las ruinas del "Llano de San Mamés» con Turobriga. contrihuta de Arucci, y sede del culto de Ataeci$n a^{t 14}: y$ en los de J. González, quien es partidario de leer las letras $M T F$ que figuran sobre un tubo de plomo alli encontrado ${ }^{15}$ en la forma m(unicipium) T(urohrigensis) f(ecit) ${ }^{\text {th }}$. Sobre la misma base argumental, la prudencia de que siempre hizo gala M. ${ }^{*}$ L. Albertos (q.e.p.d.) sugiere tener en cuenta como probable esta ubicación, aunque sujeta a las naturales reservas ${ }^{317}$.

Si no ha faltado la polémica al tratar de ubicar Turobriga sin chocar con el texto pliniano, tampoco los argumentos epigráficos han dado mejor resultado. Habida cuenta del epiteto alusivo a este núcleo que suele acompañar al nombre de Ataecina, los hallazgos de evidencias de su culto han sido guia inevitable para situar la ciudad allá donde se producian los descubrimientos. Todas estas hipótesis sobre bases epigráficas responden a intentos de ubicar Turobriga en áreas más septentrionales que las aludidas, casi siempre en la Extremadura española, tratando de afirmar asi el carácter lusitano de la divinidad. Asi se ha buscado Turobriga en Torre de Santa Maria (Cáceres) ${ }^{31 \times}$, Cabeza de Buey (Badajoz) ${ }^{319}$, Cerca de Almorcón (Badajoz) ${ }^{320}$, en las cercanias de Mérida ${ }^{121}$, y cerca de Bienvenida (Badajoz) ${ }^{322}$, lugar este último en el que parecen incidir un buen número de estudios sobre topografia antigua de Extremadura ${ }^{323}$. No encontramos motivos suficientes, ni de indole geográfica ni de tipo epi-

\footnotetext{
HA Op. cit. en nota 307, p. 319.

i1s J. González y A. Pérez, «La romanización de Huelva», en Huelva y su provincia. Sevilla. 1986, p. 262.

ith J. González, op. cit. en nota 158, p. 276.

"1) M. L. Albertos, op. cit. en nota 169, p. 142.

i1x M. de Monsalud. op. cit. en nota 31, p. 487.

119 J. R. Mélida, Catálogo monumental de la provincia de Badajoz, Madrid, 1925-1926, pp. 451 ss.

120 A. Garcia y Bellido, "De nuevo sobre el jarro ritual lusitano publicado en AEA 30,1957 , pp. 121 ss.n, AE.4 31, 1958, p. 155, nota 2 .

121 A. Tovar, Iberische Landeskunde. Zweitwe Teil: Die Völker und die Städte des antiken Hispanien II. Lusitanien, Baden-Baden, 1974 , p. 173.

32 R. López Melero, op. cit. en nota 26, p. 103, seguida por L. Berrocal-Rangel, «La Beturia: definición y caracterización de un territorio prerromanon, en Celtras y Türdulos: La Beturia. Cuadernos Emeritenses 9, Mèrida 1995, p. 158.

323 J. M." Fernández Corrales, El Irazado de las vias romanas en Extremadura, Cáceres 1987, p. 67 y mapa de pp. 114-115: aunque no alude expresamente a ello, la comparación entre la descripción viaria de la p. 67 y el citado mapa, en donde sitúa Turobriga al noroeste de Regina, dejan ver la identificación cerca de Bienvenida. La misma cartografía y con similar ubicación de Turobriga ha vuelto a ser empleada en E. Cerrillo et alii, op. cit. en nota 305 , p. 57 , fig. 3 y p. 69 , fig. 11.
}

gráfico, para entender la propuesta de ubicar en Cancho Roano (Zalamea de la Serena, Badajoz) un culto "dedicado a una diosa antecesora de la Atuecina posterior", como propuso hace unos años J. Maluquer ${ }^{224}$, que considera a Ataecina epervivencia de la gran diosa indigena y funeraria de la época megalitica».

No abundan los Turobrigenses en la epigrafia latina. Sólo cuatro testimonios componen un exiguo panorama en el que la mayor parte de las referencias al topónimo deben buscarse en los epitetos de Ataecina. Las referencias son las siguientes:

1. Aroche (Huelva). De aqui procede la conocida inscripción de Baebia C. f. Crinita, Turobrigensis, sacerdos, que muestra su liberalidad como la construcción de un templum Apollinis et Dianae ${ }^{325}$. y que ha servido de pretexto para situar Turobriga en tierras onubenses.

2. De Caleruela (Toledo) procede un ara cuyo texto dice: Bassus Turobri(gensis), eques alae Vettomum, aram posit Ataecinae uotum soluit m(erito) $|--|^{136}$. La inscripción es de un extraordinario interés puesto que vincula el culto de Ataecina con el núcleo de Turohriga pero no a través de los epitetos de la divinidad, sino por la origo del dedicante.

3. "Corte de Messangil» (Vale de Vargo, conc. de Serpa, dist. de Beja). Hace más de cuarenta años Abel Viana dio a conocer en una nota periodística un texto procedente de este lugar y que, aparentemente, menciona un Turubrigensis ${ }^{327}$. El texto ha perdido la parte izquierda de todas sus lineas, pero es fácil ver una inscripción funeraria de un joven de diecisiete años cuyo nombre plantea ciertos problemas de restitución: la paginación sugiere que hemos perdido el praenomen y el inicio del nomen, para el que no encontramos solución posible si no es admitiendo un error de transcripción por parte de los primeros editores; en cuanto a su cognomen, es fácil restituir Masculus, probablemente precedido de la filiación. El difunto seria, pues, [- --]obaerius [-. . M] asculus [Tu]rubrige(n)sis.

4. "Quinta do Marim» (Quelfes, conc. de Olhao, dist. de Faro). Museo de Moncarapacho. Aunque la inscripción plantea muchos problemas de

124 J. Maluquer y M." E. Aubet. Andalucia y Extremadura, Barcelona, 1981, p. 283

135 CIL 11964 = ILS 5402; ILER 1760. Cfr. la voz Turohricesis (sic) en E. W. Haley, op. cit, en nota 9, p. 62, núm. 214.

in Cfr. supra nota 236.

127 A. Viana, "Arqueologia alentejana", Diario Alentejo 30 de agosto de 1941; edición de J. Fragoso de Lima, "Aspectos da romanizaçao no territorio portugés da Bétican, AP N.S. I, 1951. p. $194=$ HAE 848 


\begin{tabular}{|c|c|}
\hline Epiteto de la divinidad & Procedencia \\
\hline Thurihrigensis ?) & Alcuéscar núm. 5 \\
\hline Turohvigensis :) & Cagliari (Cerdena), num. $x$ \\
\hline Tiurohrigensis ') & (ärdenas (Badajoz). núm. 9 \\
\hline Thurohrigensis ") & $\begin{array}{l}\text { Malpartida de (äceres (Cáceres). } \\
\text { núm. } 10\end{array}$ \\
\hline Trurobrigensis ?) & $\begin{array}{l}\text { Malpartida de Cáceres (Càceres). } \\
\text { nùm. II }\end{array}$ \\
\hline Tu(ribrigensis) & $\begin{array}{l}\text { Salvatierra de los Barros (Badajoz). } \\
\text { núm. } 5\end{array}$ \\
\hline Tur(ihrigensis) & Saclices (Cuenca). núm. $19^{33 \mathrm{~K}}$ \\
\hline Tur(ihrigensis) & Alcuéscar núm. 7 \\
\hline Tur(ibrigensis) & Alcuéscar núm. 13 \\
\hline Turib(rigensis) & Mérida (Badajoz). nùm. 12 \\
\hline Turihr(igensis) & Alcuéscar núm. 8 \\
\hline /T/urithr(igensis) & $\begin{array}{l}\text { Salvatierra de Santiago (Cáceres). } \\
\text { núm. } 18\end{array}$ \\
\hline Turihri(gensis) & Alcuéscar núm. 3 \\
\hline Turihri(gensis) & Alcuéscar núm. 4 \\
\hline Turibri(gensis) & Alcuéscar nủm. 9 \\
\hline Turihri(gensis) & Alcuéscar núm. 10 \\
\hline IT/uribri(gensis) & Alcuéscar núm. 14 \\
\hline /T/uri/h/ri(gensis) & Alcuéscar núm. 15 \\
\hline Turibrig(ensis) & Mérida (Badajoz), núm. 4 \\
\hline [T]urihri/g(ensis)] & Medellin (Badajoz), núm. 17 \\
\hline Turihrice(nsis) & Quintos (Beja. Beja). núm. 13 \\
\hline Turihrige(nsis) & $\begin{array}{l}\text { "Dehesa El Palacion (Herguijuela, } \\
\text { (áceres). núm. If }\end{array}$ \\
\hline Turihri(g)e(nsas) (sic) & Alcuéscar nùm. 6 \\
\hline Turohrigae & Mérida (Badajoz), núm. 6 \\
\hline |T/urufirigalel & La Bienvenida (Badajoz), núm. 16 \\
\hline
\end{tabular}

\begin{tabular}{|l|l|}
\hline \multicolumn{1}{|c|}{ Origo } & \multicolumn{1}{c|}{ Procedencia } \\
\hline Turohrigensis & Aroche (Huelva) \\
Turobri(gensis) & Caleruela (Toledo) \\
[Tu/rubrige(n)sis. & Vale de Vargo (Serpa, Beja) \\
Turubri/gensis] & Quelfes (Olhao, Faro) \\
\hline
\end{tabular}

Figura 58.- Referencias a Turobriga/Turibriga en las dedicaciones a Ataecina y en la origo de otros personajes.

restitución, se debe descartar que la referencia topográfica que incluye forme parte de una dedicación a Ataecina. Por el contrario, parece una mención de origo en la forma Turubri[gensis] ${ }^{329}$.

Esta relación no incluye el enigmático topónimo que figura sobre una tésera procedente del castro de Las Merchanas (Lumbrales, Salalamanca), cuyo texto dice: tes(s)era Caurie(n)sis magistratu Turi[---] ${ }^{330}$;

${ }^{32 x}$ Sobre las dificultades de establecer el lugar de procedencia del epigrafe, cfr. nota 257.

320 J. Fernandes-Mascarenhas, Fornos de cerâmica e outros vestigios romanos do Algarve, Lourenço Marques 1974, pp. 22 ss.; lectura mejorada en IRCP, p. 81, núm. 37.

${ }^{330}$ A. Tovar, «El Bronce de Luzaga y las téseras de hospitalidad latinas y celtibéricas», Emerita 16,1948, p. 82, núm. 8; id., 1949, op. cit. en nota 259, p. 173; id., «Notas epigráfi-

\begin{tabular}{|l|r|}
\hline \multicolumn{1}{|c|}{ Nombre } & Casos \\
\hline T(...) & 5 \\
Tu(...) & 1 \\
Turt -..) & 3 \\
Turibriga & 14 \\
Turohriga & 3 \\
Turuhriga & 3 \\
\hline
\end{tabular}

Figura 59.-Formas del topónimo.

en el documento se viene aceptando la referencia a Caurium (Coria, Cáceres), pero es dificil entender que el magistrado anónimo lo sea de Turibriga habida cuenta del lugar del hallazgo. Curchin ha llegado a sospechar si Turi [---] no es, en realidad, más que parte del nombre del magistrado que suscribe el pacto correspondiente, como habia insinuado Tovar en 1948. El documento, probablemente pre-flavio a juzgar por la referencia a un magistratus si aceptamos la argumentación de Haley, debe aludir a un núcleo ubicado cerca de su lugar de hallazgo.

Con los precedentes ya considerados, disponemos de dos tipos de referencias para conocer el nombre del antiguo enclave que fue sede del culto de Ataecina ${ }^{331}$; de una parte, los epítetos de la divinidad y, de otra, las referencias de origo. Los primeros aluden a Turibriga/Turobriga en 20 ocasiones, exceptuando otras 5 en que su nombre sólo se abrevia con una letra; las segundas, como hemos visto, sólo suman 4 hallazgos. A primera vista llama la atención la falta de uniformidad en el conjunto de los testimonios (fig. 58).

Las opciones que tenemos para el nombre del enclave que es sede del culto son tres: Turobriga, Turibriga y Turubriga. En la fig. 59 se recogen también las referencias abreviadas del topónimo o de los adjetivos que de él derivan. Pese a la disparidad gráfica, parece mayoritaria la acepción Turibriga, en gran parte inducida por la preeminencia de esta

cas sobre objetos del Museo Arqueológico Nacionaln, RABM 61,1955 , p. 578 (= HAE 1051); J. Maluquer, Carta arqueologica de España. Salamanca, Salamanca 1956, pp. 74 ss. $\quad(=$ HAE 1309): ILER 5858; L. A. Curchin, The creation of a romanized elite in Spain, Diss. Otawa 1981, p. 243, num. 507; id., The Local Magistrates of Roman Spain. Toronto 1990, p. 170. núm. 325; E. W. Haley, op. cit. en nota 9, p. 199, núm. 167. nota 314 .

${ }^{331}$ No ha tenido ningún eco la tesis de Leite de Vasconcelos de suponer que el nombre de la ciudad derivase de un radical -ltur que hubiera perdido la vocal inicial. Desde los primitivos trabajos de Tovar esta suposición parece descartada por los filólogos; cfr. A. Tovar, Emerita 16, 1948 (op. cit. en nota 329), p. 82 ; id., 1949, op. cit. en nota 259, pp. 173 ss.; M. Lejeune, Celtiberica, Salamanca 1955, p. 80. 
forma en el conjunto de Santa Lucia del Trampal. Por ello, salvo argumentos evidentes en contra, en las inscripciones procedentes de este enclave hemos optado por la restitución Turibrigensis.

El nombre de Turibriga pertenece a un nutrido grupo de topónimos en -briga, integrado por al menos 89 testimonios según el recuento realizado por $M{ }^{a}{ }^{a} \mathrm{~L}$. Albertos ${ }^{332}$, que constituye un claro elemento céltico $^{333}$ no siempre antiguo ni relacionado con poblaciones prerromanas (Iuliobriga, Caesarobriga, etc.).

Los estudios de J. Untermann y M. ${ }^{a}$ L. Albertos han puesto de manifiesto que el reparto geográfico de este grupo de topónimos en -briga coincide con el área de hallazgos de toponimia y onomástica indoeuropea ${ }^{334}$, con especial incidencia en la mitad norte de Portugal, sur de Galicia y curso del Tajo. El conjunto de estos topónimos en -briga es extremadamente heterogéneo $\mathrm{y}$, con frecuencia, no es posible encontrar una forma indigena anterior de la que puedan derivar; es el caso de Iuliobriga. Caesarobriga, Brutobriga o Augustobriga, cuyos radicales son evidentemente latinos y deben considerarse topónimos formados en el momento de llevarse a cabo la promoción juridica del núcleo urbano; algo parecido sucede en Conimbriga, en donde no conocemos un término indigena previo.

Sin embargo, estas dificultades no siempre existen. Nótese que algunos de estos topónimos están formados a partir de nombres personales latinos o epítetos imperiales a los que se añade el término -briga; por lo mismo cabe imaginar que existan otros formados a partir de nombres indigenas ${ }^{334}$ bis: Una ciudad de nombre Dessobriga, tradicionalmente ubicada en la divisoria de Burgos y Palencia ${ }^{335}$, podria tener alguna relación con el antropónimo Desical Dessica, del que todos los ejemplos proceden de Lara de los Infantes (Burgos) ${ }^{336}$; Tongobriga, un empla-

132 M." L. Albertos, op, cit. en nota 169, Veleia 7, 1990, pp. $131-146$.

i3 F. Villar, Los indoeuropeos y los origenes de Europa, Madrid 1991, p. 457.

${ }^{34}$ J. Untermann. Sprachräume und Sprachbewegungen in vorrömischen Hispanien, Wiesbaden 1961, mapas 3 y 19: M. L. Albertos, op. cit. en nota 169, p. 145, mapa.

$33+$ bis $\mathrm{Al}$ respecto, cfr. J. de $\mathrm{Hoz}$, "Castellum Aviliobris. Los celtas del extremo occidente continental», en Indogermanica el Caucasica, Berlin 1994, p. 353.

33 It. Ant. 449, 4; E. Saavedra, Discursos leidos ante la Real Academia de la Historia en la recepción publica de D. Eduardo Saavedra el dia 28 de diciembre de 1862, Madrid 1914, $2^{a}$ ed.. p. 95; C. Sánchez Albornoz, El Reino de Asturias I. De Virovesca a Suessatio. Oviedo 1972, pp. 145 ss.; J. M. Roldán, Itineraria Hispana. Fuentes antiguas para el estudio de las vias romanas en la Peninsula Ibérica, Valladolid 1973, p. 234; M." L. Albertos, op. cit. en nota 169, p. 136

336 Sobre el antropónimo, cfr. Albertos, Tarraconense, p. 105; ead., "Nuevos antropónimos hispánicos», Emerita 40.2, 1972. zamiento en territorio de Vettones, conocido gracias a una inscripción de Brozas (Cáceres) que menciona a los uicani Tongobri [g/enses ${ }^{337}$ podria ponerse en relación con el antropónimo Tongius/Tongius, que es frecuente en ese ámbito regional; más dificultades habría para relacionar un topónimo como Lacobriga, tradicionalmente identificado con la ciudad de Lagos, con un nombre como Lacon, pese a que los tres únicos testimonios conocidos proceden del centro/sur de Portugal ${ }^{336}$ y uno de ellos de un punto tan meridional como Moncarapacho (Olhao, Faro) ${ }^{339}$. No es descartable, pues, que la forma Turibrigal Turohiga tenga su origen en un nombre personal.

\subsection{TURIBRIGA/TUROBRIGA EN SU MARCO REGIONAL. EL LUCUS FERONIAE Y EL LIMITE MERIDIONAL DE LOS VETTONES}

Al valorar el conjunto epigráfico de Santa Lucia del Trampal hemos sugerido la posibilidad de que todos los monumentos hubieran sido acarreados desde un mismo núcleo que tuvo a Ataecina como divinidad tutelar y que este paraje estuviera próximo al templo de Santa Lucía, opinión ya expuesta en varias ocasiones ${ }^{340}$. La dificultad estriba en saber si estamos ante el centro principal, el Turibrigensis, o ante otro lugar de culto secundario. La resolución de este conflicto pasa por la observación de la fig. 55, con el reflejo cartográfico de los hallazgos de Ataecina. Puede comprobarse que, salvo las evidencias ubicadas junto al Tajo en el limite entre Toledo y Cáceres y los escasos testimonios al sur del Guadiana, casi todos los altares de Ataecina se encuentran en un área muy reducida cuyo perímetro prácticamente puede tener a Santa Lucía del Trampal como epicentro.

p. 287; Abascal, Nombres, p. 343. Los ejemplos, todos ellos de Lara de los Infantes, son los siguientes: Ancoema Desica Segif. (J. A. Abásolo, op. cit. en nota $111=$ ERLara, núm. 59); Coemea Desica Aploni f. (ERLara 183); Coemea Dessica Visadiaquini f. ? (CIL II 2866 + ERLara 158); /D/essic/a] (AE 1983, 600).

${ }^{37}$ CIL II $743=$ ILER $670+$ CPILCáceres 97. de Brozas: L. A. Curchin, "Vici and pagi in roman Spain», REA 87.3-4, 1985, p. 330, núm. 6; P. Le Roux, "Vicus et castellum en Lusitanie sous I'Empire», Studia Historica [Salamanca] 10-11, 19921993, p. 153, núm. 5; A. Aguilar y P. Guichard, Villas romaines d'Estrémadure. Doña Maria, La Sevillana et leur environnement, Madrid 1993, p. 44. Nótese, sin embargo, la existencia de una dedicación al Genius Tongobrigensium (CIL II 5564, de Freixo, conc. de Marco de Caneveses, dist, de Porto), hallada al norte del Duero.

${ }^{33}$ CIL 11761 de Alcántara; CIL II 12 de Moncarapacho; HEp 3. 492.2, de Cárquere.

$33^{\circ} \mathrm{CIL} 1112+$ IRCP 47.

wo L. Caballero et alii, Extremadura arqueoligica 2, op. cit. en nota 2, p. 510; M." P. Garcia y Bellido, op. cit. en nota 177. pp. 70 ss. 
A la vista de estos datos sugerimos identificar ese centro de culto aún desconocido, pero de cuyas evidencias epigráficas disponemos, con la Turibriga que tuvo a Ataecina por divinidad tutelar. El único inconveniente, y no pequeño aunque soluble, de esta hipótesis viene dado por la probabilidad de que el área de Alcuéscar perteneciera históricamente al territorium de Emerita.

Si hacemos caso a Agenio Urbico, la pertica emeritense se extendia en ambas márgenes del Anas y su superficie era apreciable tanto hacia el norte como hacia el sur. Los limites septentrionales de este territorium emeritense suelen situarse muy cerca de la linea que hoy separa las provincias de Cáceres y Badajoz, que coincide aproximadamente con la divisoria de vertientes definida por la cacereña Sierra de San Pedro y su continuación oriental en la Sierra de Montánche $z^{341}$; según este planteamiento, el área en que se ubica la iglesia de Santa Lucía del Trampal forma parte del territorium emeritense $^{342}$.

En este espacio los veteranos ocuparon en un primer momento los extremos más alejados del casco urbano y del curso del rio ${ }^{343} \mathrm{y}$, también según Agenio Urbico, en el ager emeritense habia un lucus consagrado a Feronia cuya extensión alcanzaba los 1.000 iugera $^{344}$. M. ${ }^{\text {a }}$ P. García y Bellido ha sugerido en varios trabajos recientes la identificación de este lucus Feroniae con uno de los silua publica que existian al norte de la pertica, posición geográfica que encaja bien con la ubicación del templo de Santa Lucia del Trampal; en tal caso, seria factible suponer que Ataecina fue objeto de una nueva interpretatio y que el santuario ubicado en las cercanías de Santa Lucía del Trampal fuera el centro cultual de ese lucus Feroniae que mencionan las fuen-

341 J. L. Ramirez Sádaba, "La demografia del territorium emeritense (excepto el casco urbano) según la documentación epigráfica", Studia Historica [Salamanca] 10-11, 1992-1993, p. 132; A. Alonso et alii, «Tres ejemplos de poblamiento rural romano en torno a ciudades de la via de la Plata: Augusta Emerita, Norba Caesarina y Capara", Studia Historica [Salamanca] 10-11. 1992-1993, p. 73.

${ }^{342}$ A. Alonso et alii, op. cit. en nota 341 , p. 78.

${ }^{343} \mathrm{Ag}$. Urb., 44 (Thulin) = Front., de contr. agr. pp. 51 ss. (Lachmann); Sobre la atribución de la obra, $c f r$. los argumentos en C. Lachmann, Gromatici veteres, Berlin 1848 , p. 83 , que adjudica el texto a Frontino. Sobre esta cuestión, $c f r$. P. López Paz, La economia politica de los romanos, vol. I. I: La ciudad romana ideal. El territorio, Santiago de Compostela 1994. pp. xxi ss.; sobre la pertica emeritense y la interpretación del pasaje, $c f r$. en ủltimo término, con la bibliografia anterior, E. Ariño y J. M." Gurt, "Catastros romanos en el entorno de Augusta Emerita. Fuentes literarias y documentación arqueológican, Studia Historica [Salamanca] 10-11, 1992-1993, pp. $58 \mathrm{ss}$.

344 Ag. Urb., 37 (Thulin): «...ad lucum Feroniae Augustinorum iugera $M . »$. tes ${ }^{345}$. Los argumentos expuestos parecen sobradamente convincentes, máxime observando el paisaje actual del área y su riqueza natural, y sólo encuentran obstáculo en la hipotética existencia de Turibriga en si misma como ciudad. Un problema que tiene solución histórica.

Pese a las repetidas evidencias sobre el nombre del núcleo en que Ataecina fue divinidad tutelar, no conocemos una sola de su condición de centro urbano. Más aún, la importancia del santuario no puede aducirse como argumento para justificar tal condición cuando un centro de culto como el de Endovelico en Terena, con mayor trascendencia epigráfica, carece de ella. La imagen que podemos formarnos de Turibriga - 0 Turobriga en una acepción más generalizada a partir del texto pliniano- es la de un enclave, quizá sólo un espacio acotado con algunas viviendas en su interior, que servía para depositar los exvotos y colocar las arae dedicadas a Ataecina. La imagen es probablemente la de un temenos como ha supuesto M. ${ }^{a} \mathrm{P}$. García y Bellido ${ }^{346}$.

Turibriga seria, de esta manera, no una ciudad, ni siquiera un núcleo de cierta entidad del que se habrian hecho eco con mayor frecuencia los autores clásicos, sino un pequeño uicus $\mathrm{o}$, si se quiere por la falta de evidencias urbanas, un pagus ubicado dentro del territorium emeritense y administrativamente vinculado a él, identificable físicamente con un paraje cercano al templo de Santa Lucía de Alcuéscar y uno de los tantos puntos oscuros del texto pliniano sobre la Beturia ${ }^{347}$, que continúa siendo un problema geográfico de primera magnitud en la historia de la Hispania romana ${ }^{348}$.

345 M. P. Garcia-Bellido, op. cit. en nota 177, pp. 69 ss. y algunos trabajos inéditos más recientes que amablemente ha puesto a nuestra disposición. $\mathrm{Cfr}$. los comentarios al respecto de J. M. ${ }^{a}$ Blázquez, op. cit. en nota 218, pp. 202-203.

346 Op. cit. en nota 177, p. 70.

${ }^{347}$ No es un caso único en la descripción geográfica del suroeste peninsular. $C f r$. al respecto B. Galsterer-Kröll, "Untersuchungen zu den Beinamen der Städte des Imperium Romanum", Ep. St. 9, Bonn 1972, pp. 99-145; ead., B. Galsterer-Kröll, «Zu den spanischen Städtelisten des Plinius», $A E A 48,1975$, pp. $120-$ 128 , que demuestra que el título Iulia alude a privilegios concedidos por César y Augusto; B.D. Hoyos, «Pliny the Elder's Titled Baetican Towns: Obscurities, Errors and Origins", en Historia 28,1979 , pp. $439-471$; A. Capalvo Liesa, «El léxico pliniano sobre Hispania: etnonimia y designación de asentamientos urbanos», Caesaraugusta 63, 1986, pp. 49-67; M. Mayer, "Plinio el Viejo y las ciudades de la Bética. Aproximación a un estado actual del problema», en J. González (ed.), Estudios sobre Urso. Colonia Iulia Genetiva, Sevilla 1989, pp. 303-333.

${ }^{34 k}$ Gran parte de la bibliografia que ha enjuiciado los límites de la provincia bética aborda este espacio occidental, cercano al trifinium provincial, que sigue siendo objeto de polémica. Un elenco bibliográfico, no exhaustivo, puede ser el siguiente: $A$. Prieto, "Sobre los límites del conventus Cordubensis", HAnt 2, 1972, pp. 125-133; N. Marín-A. Prieto, «En torno a un nuevo 
Existe un cierto consenso, apoyado en confusas informaciones literarias de nuestras fuentes antiguas, a la hora de aceptar la extensión de los Vettones por amplias zonas del sureste cacereño ${ }^{349}$. Aunque autores como Estrabón y Plinio ${ }^{350}$ se limiten a decir que entre el Tajo y el Guadiana habitaban, entre otros, muchos grupos de vettones y pese la parca información de Ptolomeo, da la impresión de que esa presencia vettona en estas tierras del mediodia cacereño fue algo más que un puro episodio.

Desde hace unos años, $\mathrm{y}$ con las evidencias gráficas proporcionadas por M. ${ }^{a}$ P. González-Conde, parece fácil admitir que el límite entre Carpetanos y Vettones, es decir, el limite oriental de estos últimos, cruzaba de norte a sur la provincia de Toledo

planteamiento de los limites de la provincia romana de la Bética", HAnt 4, 1974, pp. 77 ss.; J. Francisco Martin, "Cuestiones en torno al limite occidental de la Bética", en Actas del I Congreso de Historia de Andalucia. Córdoba 1976, vol. 1. Fuentes y metodologia. Andalucia en la Antigüedad, Córdoba 1978, pp. 179-185; E. Corzo-A. Jiménez, "Organización territorial de la Bética", $A E A$ 53, 1980, pp. 21-47; P. Sillières, "Centuriation et voie romaine au sud de Mérida: Contribution a la delimitation de la Bétique et de la Lusitanie", en $M C V$ 18, 1982, pp. 437 ss.; A. U. Stylow, "Ordenación territorial romana en el valle de Los Pedroches (conventus Cordubensis)", en XVII Congr. Nac. Arq. Logroño 1983, Zaragoza 1985, pp. 657-666; A. U. Stylow, Solia, op, cit. en nota 73, pp. 235-278; A. U. Stylow, Baedro-MeIlaria, op. cit. en nota 215 , pp. 57-127; J. M. Fernández Corrales, "El territorio de Augusta Emerita y los limites entre la Bética y Lusitania", XIX Congr. Nac. Arq. Castellón 1987, Zaragoza 1989, pp. 889-898; M." L. Cortijo Cerezo, "La politica territorial julio-claudia y flavia en la Bétican, $M H A \quad 11-12,1990-$ 1991, pp. 249-293; N. Marin et alii, «La ordenación del territorio en la Bastetania durante el Alto Imperio", en C. González Román (ed.), La Bética en su problemática histórica, Granada 1991, pp. 153-169; A. U. Stylow, «El municipium Flavium V(-.-) de Azuaga (Badajoz) y la municipalización de la Baeturia Turdulorum", Studia Historica [Salamanca] 9, 1991, pp. 11-27; $\mathrm{M}$ * L. Cortijo Cerezo, «Sobre la delimitación de la Bética como provincia", en In memoriam J. Cabrera Moreno, Granada 1992. pp. 51-68; J. L. Ramirez Sádaba, «La Baeturia céltica y los limites con Lusitania", Actas del II Congreso de Historia de Andalucia. Córdoba 1991. Historia Antigua, Córdoba 1994, pp. $345-353$.

${ }^{349}$ La bibliografía sobre los Vettones, siendo importante en número, no lo es comparada con la atención que han recibido otras etnias hispanas. Sin citar por no ser exhaustivos los fundamentales estudios arqueológicos de J. Cabré, J. Maluquer o F. Fernández, así como trabajos de indole general que abordan la región y sus habitantes, $c f r$. A. Schulten y $\mathrm{R}$. Grosse, $R E$ VIII.2, 1958, 1873 ss.; A. Tovar, op. cit. en nota 321 , pp. 202 ss.; J. M. Roldán, "Fuentes antiguas para el estudio de los Vettones», $\mathrm{Ze}$ phyrus 19-20, 1968-1969, pp. 73-106; R. Martin Valls, Protohistoria y romanización de los Vettones, Valladolid 1974; M." L. Albertos Firmat, "Vettones y Lusitanos en los ejércitos imperiales", en Estudios dedicados a Carlos Callejo Serrano, Cáceres 1979, pp. 31-51; M. Salinas, op. cit. en nota 198; J. A. Redondo Rodríguez, «Algunas consideraciones acerca de la romanización de los Vettones en el sureste cacereño", Norba-Historia 5, 1984, pp. 69-80; M." P. González-Conde, «Elementos para una delimitación entre Vettones y Carpetanos en la provincia de Toledo", Lucentum 5, 1986, pp. 87-93.

350. Strabo, Geog. 3, 1, 6; Plin., N.h. 4, 112. señalado por la presencia o ausencia de los Ilamados verracos. Si sabemos que tales manifestaciones escultóricas son caracteristicas de esta etnia, también es verdad que no lo son en exclusiva, pues los hallazgos se extienden a zonas más occidentales y septentrionales, alcanzando el norte de Portugal. Sin embargo, hasta el presente sólo el hallazgo de un ejemplar en Totanes ${ }^{351}$ - la excepción que confirma la regla - trasgrede por el este una línea que pasaria cerca de Talavera de la Reina dejando a su izquierda los verracos documentados (el área vettona) y a su derecha un territorio carente de ellos (el área carpetana) ${ }^{352}$.

Si por el oriente disponemos de argumentos tan sólidos, la cuestión se diluye cuando analizamos el limite meridional, que entra en conflicto con el objeto de nuestro estudio sobre los epígrafes de Alcuéscar. A partir de la información de las fuentes se viene aceptando que el límite meridional de los Vettones alcanzaría casi el curso del Guadiana, llegando a sugerirse en alguna ocasión como referencia la Sierra de Montánchez ${ }^{353}$. Dentro de este espacio quedarian englobados, en consecuencia, muchos de los conocidos emplazamientos indigenas y de tradición indigena del sur cacereño, incluyendo por supuesto los enclaves que hasta el momento han proporcionado esculturas de verracos: Cáceres, Torremocha y Botija, con seis ejemplares en este último lugar ${ }^{354}$. Botija, o más exactamente el yacimiento arqueológico de Villasviejas del Tamuja dentro de su término, constituye una referencia inexcusable en este relato debido a que, pese a su presencia en un territorio que aparentemente se puede identificar como vettón, parece apartarse de este patrón en el análisis numismático, como ha demostrado M. ${ }^{2}$ P. García y Bellido ${ }^{355}$, que considera celtíbero este núcleo.

Pese a las ambigüedades en la descripción regional de Plinio y otros autores de comienzos del Principado, un autor como Prudencio, nacido a mediados del siglo iv pero que publica su obra hacia el

351 G. López Monteagudo, Esculturas zoomorfas celtas de la Peninsula Ibérica, Madrid 1989, p. 105.

352 M." P. González-Conde, op. cit. en nota 349 , p. 91 y fig. 1 .

${ }^{353}$ J. J. Sayas y R. López Melero, "Vettones», en J. M." Solana (ed.), Las entidades étnicas de la Meseta norte de Hispania en época prerromana, Anejos de Hispania Antiqua, Valladolid 1991 , p. 79

${ }_{354}$ G. López Monteagudo, op. cit. en nota 351, pp. 82 ss.

355 M." P. Garcia-Bellido, "Célticos y Túrdulos en la Beturia según los documentos monetales", en Celtas y Turdulos: La Beturia. Cuadernos Emeritenses 9, Mérida 1995, p. 284, con la bibliografia sobre el enclave y sus monedas, que por innecesaria reiteración omitimos aqui. 
año 405 d.C., se refiere a Mérida como clara colonia Vettoniae ${ }^{356}$, retomando asi una calificación étnica que habia sugerido ya una fuente cesariana ${ }^{357}$. A partir de estas dos evidencias se viene aceptando la fundación de Emerita en territorio vettón ${ }^{35 x}$.

Sin embargo, sólo ahora que podemos sugerir una ubicación probable para Turibriga o Turobriga disponemos también de una base argumental sólida para confirmar las suposiciones del bellum ciuile o de Prudencio. Para ello traeremos nuevamente a colación un elocuente epigrafe hallado en Caleruela (Toledo), también tierra de Vettones, al que ya hemos hecho antes referencia y que textualmente dice: Bassus Turobri(gensis), eques alae Vettonum, aram posit Ataecinae; uotum soluit m(erito) [--- $]^{359}$.

$\mathrm{El}$ ala de Vettones a la que pertenece Bassus probablemente fue formada en época julio-claudia y trasladada en seguida a Britannia, donde aparece atestiguada a mediados del siglo । d. C. en Aquae Sulis (Bath); se traslada a finales de siglo a Brecon Gaer (sur de Gales) y desde finales del siglo II está en Vinouia (Binchester), al sur del muro de Adriano, en donde se mantiene durante el siglo $\mathrm{II}^{360}$.

La cronología del epigrafe de Bassus no es fácil de establecer ${ }^{301}$, sobre todo porque posee rasgos

\footnotetext{
356 Prudencio, Perist. 3, 186.

ss) Bell. Ciu. 1, 38, 1.

15x J. M. Roldán, op. cit. en nota 349 , p. 105; A. M. “ Canto, "Colonia lulia Augusta Emerita. Consideraciones en torno a su fundación y territorion, Gerión 7, 1989, p. 167.

${ }^{159}$ Cfr. supra nota 236. Curiosamente, de la misma localidad toledana procede un epigrafe dedicado a lupiter Solutorius, del que conocemos un buen número de evidencias en ámbito cacereño; aparentemente no sólo la unidad étnica, sino la unidad religiosa de estas tierras del medio Tajo parece confirmada. Cfr. J. Mangas et alii, "Nuevas inscripciones de la provincia de Toledon HAnt 16, 1992, p. 257, núm. 11; reinterpretada por $\mathrm{S}$. U. Stylow en la crónica de HEp 4, 881 .

${ }^{360}$ Sobre el ala Hispanorum Vettonum, más tarde c(iuium) R(omanorum), cfr. C. Cichorius, "Ala», RE 1.1, 1958, col. 1269; J. M. Roldán, Hispania y el ejército romano, Salamanca 1974, pp. 61,134 y $136 \mathrm{ss} . ;$ M.* L. Albertos, op. cit. en nota 349 , pp. 33 ss., núm. 8 y 9; P. A. Holder, Studies in the auxilia of the Roman Army from Augustus to Trajan. BAR Int. Ser. 70, Oxford 1980, pp. 150 y 280, núm. 541-542; P. Le Roux, L'armée romaine et l'organisation des provinces ibériques d'Auguste d̀ l'invasion de 409, París 1982, pp. 193, 276, 336 y núm. 81; M." P. González-Conde, op. cit. en nota 236, p. 132. Los testimonios de soldados del Ala Vettonum son sólo tres hasta la fecha: 1. L. Vitellius Mantaif. Tancinus, ciues Hisp(anus) Cau-rie(n)sis, eq(ues) alae Vettonum c(iuium) R(omanorum), de Aquae Sulis (Bath, Gales) (CIL VII $52=$ ILS $2517 /$ RIB 159); 2. Can-d [idi -.-Jni fili Hisp. Vetto (RIB 403); 3. Bassus Turobri(gensis) eques alae Vettonum, de Caleruela ( $c f r$. supra nota 236). Las evidencias epigráficas de la unidad son además un diploma del año 103 d.C. hallado en .Malpas, entre Chester y Shrewsbury, que incluye al ala Hispanorum Vettonum c.R. (ILS 2001) y un cursus anónimo de un praef. eq. alae Vetton. hallado en Segermes (CIL VIII 23068 = ILS 9012).

${ }_{361}$ Cfr. la discusión en G. Alfoldy, op. cit. en nota 236, pp. 518-519.
}

paleográficos muy irregulares, comunes a las officinae que trabajan el granito en el oriente cacereño y en las zonas toledanas próximas, que se pueden encontrar a los largo de los dos primeros siglos del Principado. Tampoco la cronología de la unidad puede servirnos de auxilio en esta tarea, ya que se forma en la primera mitad del siglo । d. C. y es evidente que el texto puede ser posterior. Sin embargo, hay que destacar que Bassus no ostenta los tria nomina propios de un auxiliar que retorna a su patria, sino el sencillo nombre personal de un indigena que carece todavia de los privilegios de la ciudadania; por otra parte, en el epigrafe se señala con claridad la condición de eques y no la de uet(eranus). Bastarian estos argumentos para suponer que la dedicación se hace en el momento del enrolamiento en la unidad y no en la fecha de su licencia. Es muy poco probable que unidades como el ala Vettonum siguieran recibiendo contingentes desde su lugar de origen décadas después de haber abandonado la Peninsula con destino a los diferentes frentes; por el contrario, el testimonio onomástico de los veteranos de los auxilia parece sugerir una incorporación paulatina a las unidades de contingentes humanos enrolados en las zonas de destino. En otras palabras, no parece factible suponer que Bassus fuera enrolado en una leva posterior al traslado a Britania de su unidad, y más probable es que pertenezca al contingente inicial de la misma. Esta argumentación permitiria datar el epígrafe a más tardar en época de Claudio, lo que nos aseguraría una de las más tempranas evidencias del culto de Ataecina.

Lo más probable es que Bassus fuera reclutado en su ciudad de origen (Turobriga) para una unidad recién formada, el ala Hispanorum Vettonum, integrada por contingentes demográficos uniformes. Según eso, Turobriga sería por descontado ciudad vettona y su integración como un enclave no privilegiado en el norte del territorium emeritense - según vimos más arriba - nos permitiria dar la razón a Prudencio y suponer que la deductio emeritense ${ }^{362}$ se hizo, al menos parcialmente, sobre territorio vettón.

${ }^{362}$ La fundación de Mérida ha sido objeto de múltiples estudios en los últimos veinticinco años. Una buena muestra de los principales argumentos puede encontrarse en L. Garcia Iglesias, «Notas sobre el panorama económico colonial de Augusta Emerita", Revista de la Universidad de Madrid 79, 1971, pp. 97111 ; J. Álvarez Sáenz de Buruaga, "La fundación de Mérida", en Augusta Emerita, Madrid 1976, pp. 19-32; R. Wiegels, "Zum Territorium der augusteiche Kolonie Emeritan, en $M D A I(M) 17$, 1976, pp. 258 ss.; R. Corzo, "In finibus Emeritensium», en $\mathrm{Au}$ gusta Emerita, Madrid 1976, pp. 222 ss.; R. Etienne y F. Mayet, "La dénomination antique de Mérida», Lucerna. Home- 
Más aún, la argumentación expuesta sugiere identificar a Bassus como uno de los muchos indigenas residentes en áreas de ciudades privilegiadas y en contacto con ciudadanos romanos que verían en el alistamiento en los auxilia una posibilidad de promoción y de integración en el tejido social que las

nagem a D. de Pinho Brandão, Porto 1984, pp. 159 ss.; J. M: Álvarez Martinez, El puente y el urhanismo de Augusta Emerita. Madrid 1981; A. Canto, "Colonia Iulia Augusta Emerita. Consideraciones en torno a su fundación y territoriom, Gerión 7. 1989. pp. 149 ss; J. M. Fernández Corrales, "El territorio de Augusta Emerita y los limites entre la Bética y Lusitania». XIX Congr. Nac. Arq. Castellón 1987, Zaragoza 1989, pp. 889-898; A. Canto, "Las tres fundaciones de Augusta Emerita", en W. Trillmich y P. Zanker (eds.). Stadtbild und Ideologie. Die Monumentalisierung hispanischer Städte zwischen Republik und deductiones coloniales habian generado. En ese contexto, su dedicación a Ataecina sería una invocación protectora a la diosa tutelar de su ciudad de origen, y divinidad vettona por excelencia ${ }^{363}$, ante las nuevas perspectivas que su nuevo rango le ofrecia.

Kaiserzeit. Madrid 1987, München. Bayerische Akademie der Wissenschaften, 1990, pp. 289-296: F. Mayet, «Mérida: capitale économiquen, en Les Villes de Lusitanie romaine. Hiérarchies et territoires. Table Ronde... Talence, 8-9 décembre 1988, Paris 1990, pp. 207-212. Una relación bibliográfica exhaustiva hasta 1992 puede verse en A. Velázquez, Repertorio de hibliografia arqueológica emeritense. Cuadernos emeritenses 6, Mèrida 1992.

tot J. J. Sayas y R. López Melero, op. cit. en nota 353 , p. 110. 